UNIVERSIDADE DE SÃO PAULO

ESCOLA POLITÉCNICA

LABORATÓRIO DE ENGENHARIA BIOMÉDICA

VITOR MARTINS CHAUD

MODELAGEM DO SISTEMA NEUROMUSCULAR HUMANO PARA ESTUDO DE CONTRAÇÕES ISOMÉTRICAS

SÃO PAULO 
VITOR MARTINS CHAUD

\section{MODELAGEM DO SISTEMA NEUROMUSCULAR HUMANO PARA ESTUDO DE CONTRAÇÕES ISOMÉTRICAS}

Dissertação apresentada à Escola Politécnica da Universidade de São Paulo para a obtenção do título de Mestre em Engenharia Elétrica.

SÃO PAULO 
VITOR MARTINS CHAUD

\title{
MODELAGEM DO SISTEMA NEUROMUSCULAR HUMANO PARA ESTUDO DE CONTRAÇÕES ISOMÉTRICAS
}

\author{
Dissertação apresentada à Escola Politécnica da \\ Universidade de São Paulo para a obtenção do título \\ de Mestre em Engenharia Elétrica. \\ Área de Concentração: Engenharia Biomédica \\ Orientador: Prof. Dr. André Fabio Kohn
}

SÃO PAULO

2013 
FICHA CATALOGRÁFICA

Chaud, Vitor Martins

Modelagem do sistema neuromuscular humano para estudo de contrações isométricas / V.M. Chaud. -- São Paulo, 2013. $130 \mathrm{p}$.

Dissertação (Mestrado) - Escola Politécnica da Universidade de São Paulo. Departamento de Engenharia de Telecomunicações e Controle.

1. Neurociências (Sistemas computacionais) 2. Neurônios motores 3. Matemática (Modelagem) 4. Sistemas dinâmicos I. Universidade de São Paulo. Escola Politécnica. Departamento de Engenharia de Telecomunicações e Controle II. t. 


\section{DEDICATÓRIA}

Aos meus pais, pelo apoio incondicional.

À minha irmã, Isabela, por sempre trazer graça à minha vida. 


\section{AGRADECIMENTOS}

Ao professor André Kohn e a todas as outras pessoas que, de uma forma ou de outra, contribuíram para o desenvolvimento deste trabalho.

Ao Conselho Nacional de Desenvolvimento Científico e Tecnológico (CNPq) pela concessão da bolsa de mestrado (processo 132776/2011-1). 


\section{RESUMO}

A precisão de uma ação motora depende de vários fatores, como: 1) grau de variabilidade da força gerada por cada músculo envolvido, 2) velocidade de geração da força, 3) coordenação das ativações dos músculos. A geração e o controle da força muscular possuem mecanismos que ainda precisam ser mais bem estabelecidos, tanto para o aprimoramento das teorias de controle motor, quanto para o desenvolvimento de técnicas que permitam a prevenção ou a compensação de certas deficiências. A perda de desempenho motor pode ser decorrente de doenças que afetam o sistema neuromuscular ou de alterações associadas ao envelhecimento. Sabe-se, por exemplo, que idosos podem possuir maior variabilidade e menor velocidade de desenvolvimento da força, quando comparados com jovens. Uma das formas de se entender os mecanismos responsáveis pelos fenômenos observados em experimentos neurofisiológicos, em indivíduos saudáveis, em pacientes ou em idosos, é por meio de uma representação adequada de tais mecanismos em modelos matemáticos. Tais modelos podem, pela escolha de um conjunto de parâmetros e de sinais de entrada, ser simulados, explorando-se toda gama de cenários plausíveis para a geração de um determinado fenômeno, tendo como referência os dados obtidos experimentalmente.

Resumidamente, o presente trabalho trata do estudo do sistema neuromuscular por modelagem matemática e simulação computacional, com particular interesse nos músculos do tríceps sural e no primeiro interósseo dorsal (um músculo intrínseco da mão), sendo estes músculos amplamente utilizados em estudos experimentais e de modelagem. Maior enfoque é dado em contrações isométricas (i.e., ângulo articular mantido fixo), avaliando-se a organização do núcleo motor, em termos anatômicos e fisiológicos, recebendo como entrada a atividade sináptica das vias pré-motoneuronais, e estudando como diferentes arranjos das propriedades neurais podem resultar em características encontradas experimentalmente para a força muscular.

Inicialmente foi feita uma ampla expansão de um simulador existente (ReMoto), tanto em aspectos de modelagem quanto de interface. Em seguida, este modelo expandido foi empregado para um estudo da influência do grau de rigidez muscular nas respostas reflexas do tornozelo. Posteriormente, um novo modelo de pool de motoneurônios, com ampla representação de características biofísicas, foi desenvolvido e, por fim, este modelo foi utilizado, em conjunto com modelos de tratos descendentes e da geração de força muscular, para representar a geração de forças isométricas em jovens e idosos. 


\section{ABSTRACT}

The precision of a motor action depends on several factors such as: 1) the level of force variability of each involved muscle, 2) the rate of force development, 3) the coordination of the activations of the muscles involved. Several mechanisms underlying the force generation in a muscle and its control by the nervous system remain to be fully comprehended. An appropriate description of these mechanisms would allow an improvement in motor control theories and could contribute to the development of techniques for the prevention or compensation of some disabilities. Losses in motor performance may be caused by diseases affecting the neuromuscular system or due to aging processes. For instance, old adults may exhibit higher force variability and lower velocity of force development than young adults. Proper representations of such mechanisms in mathematical models constitute a promising way to test hypotheses raised by neurophysiological experiments to explain an observed phenomenon. These models can be used to investigate aspects of health/disease or young/old subjects and, by varying their parameter sets, it is possible to explore a broad range of plausible scenarios under which the experimentally observed phenomena are replicated.

This project deals with the study of the neuromuscular system by mathematical modeling and computer simulations, applied to the triceps surae and the first dorsal interosseus (two of the most experimentally and theoretically studied muscles). The principal focus is on isometric contractions (i.e., fixed joint angle) and the study of the organization of the motor nucleus (anatomical and physiological aspects) receiving inputs from premotoneuronal pathways. The study analyzes how different patterns of organization result in experimentally observed aspects of muscle force.

Initially, an existing simulator of the neuromuscular system (ReMoto) was broadly extended to include new models and a friendly interface. The extended model was used to investigate the influence of muscle stiffness on the reflex responses in the ankle joint. Next, a new motoneuron pool mathematical model was developed based on known biophysics. Finally, this model was integrated with models of pre-motoneuronal neurons estabilishing synapses with motoneurons and of muscle force generation in order to represent isometric force generation in young and old adults. 


\section{LISTA DE ILUSTRAÇÕES}

Figura 1-1 - (A) Músculos extensores do tornozelo. Modificado de (GRAY, 1989). (B) primeiro interósseo dorsal (FDI) (HUDSON et al., 2009)............................................3

Figura 1-2 - Sistema nervoso central e vias motoras descendentes. Figura modificada de (KANDEL; SCHWARTZ; JESSELL, 2000).

Figura 1-3 - Acima e à esquerda: estrutura morfológica de um MN alfa. Abaixo: diferentes músculos inervados pelos seus respectivos núcleos (pools) de MNs. Figura modificada de (KANDEL; SCHWARTZ; JESSELL, 2000).

Figura 1-4 - Seção transversal de um segmento da medula espinhal ilustrando sua divisão em setores (à esquerda) e alguns neurônios representativos (à direita). Figura modificada de (BURKE, 2003).

Figura 1-5 - Músculo esquelético nos níveis macroscópico (A), de uma fibra (B), de uma miofibrila (C) e de filamentos proteicos (D). Figura modificada de (KANDEL; SCHWARTZ; JESSELL, 2000).

Figura 1-6 - Variação da tensão muscular com a taxa de disparos de uma MU. Figura modificada de (KANDEL; SCHWARTZ; JESSELL, 2000).

Figura 1-7 - A) Exemplo de recrutamento das MUs em que ocorre um perfil do tipo onion skin (DE LUCA; HOSTAGE, 2010). A linha preta mostra a força desenvolvida pelo músculo e as linhas coloridas mostram as taxas médias de disparos de cada MU recrutada. B) Exemplo de recrutamento das MUs em que não ocorre um perfil do tipo onion skin (MORITZ et al., 2005). Em ambos os experimentos o músculo aferido foi o FDI. Embora os eixos das abscissas não sejam iguais nas duas figuras é possível compará-las, pois, até o instante $8 \mathrm{~s}$ na Figura $\mathrm{A}$, a força aumenta progressivamente com tempo. Os protocolos experimentais, porém, são diferentes, o que provavelmente causa os diferentes padrões de recrutamento.

Figura 1-8 - Ilustração do fuso neuromuscular, evidenciando suas fibras musculares intrafusais, suas eferências motoras e suas aferências sensoriais.

Figura 1-9 - Ilustração do órgão tendinoso de Golgi, evidenciando seus elementos constitutivos.

Figura 1-10. Diagrama esquemático do simulador (ELIAS et al., 2011). Esta figura mostra somente dois dos quatro núcleos motores, um para o $\mathrm{m}$. sóleo (SOL) e o outro para o m. tibial anterior (TA). Os comandos descendentes, responsáveis pela extensão e flexão do tornozelo, ativam a população de MNs e neurônios espinhais: células de Renshaw (RC), interneurônios inibitórios la (laln) e interneurônios 
inibitórios lb (Ibln). Valores entre parêntesis mostram o número padrão de cada elemento da rede. Aferentes la e lb vêm dos nervos tibial (PTN) e fibular (CPN), que podem ser eletricamente estimulados separadamente.

Figura 2-1 - Exemplo de página para a seleção de um cenário de demonstração no ReMoto.

Figura 2-2 - Exemplo de página para a escolha de modelo, parametrização e modulação das vias descendentes no ReMoto.

Figura 2-3 - Exemplo de gráficos criados para proporcionar a visualização de parâmetros estruturais no ReMoto. Distribuição espacial dos diferentes tipos de MUs na seção transversal do músculo, considerando todos os tipos de MUs (A), apenas MUs tipo S (B), apenas MUs tipo FR (C) e apenas MUs tipo FF (D). .23

Figura 2-4 - Página criada no ReMoto para a exibição instantânea do progresso da simulação.

Figura 2-5 - Página da nova interface do ReMoto para a visualização de resultados de simulação.

Figura 2-6 - Exemplo de página do ReMoto para análise de resultados

Figura 2-7 - Visualização da distribuição dos limiares de recrutamento dos MNs por estimulação elétrica do nervo. A) Ilustração das vias aferentes e eferentes ativadas pela estimulação do nervo. B) Distribuição do limiar de recrutamento empregada originalmente no ReMoto (ordem inversa de recrutamento). C) Distribuição aleatória uniforme. D) Distribuição aleatória Gaussiana.

Figura 2-8 - Curvas de recrutamento. a) Exemplo de curva de recrutamento obtida experimentalmente (FLOETER; KOHN, 1997). b) Curva de recrutamento obtida com a parametrização original do ReMoto. c) Curva de recrutamento obtida pelo ajuste dos limiares somáticos dos MNs para disparo de PAs. d) Curva de recrutamento obtida utilizando uma distribuição aleatória uniforme dos limiares de recrutamento por estimulação elétrica.

Figura 2-9. Diagrama UML mostrando as classes utilizadas para representação dos modelos de proprioceptores na estrutura do simulador ReMoto.

Figura 2-10. Esquema do modelo de MS. Figura reproduzida de (MILEUSNIC et al., 2006).

Figura 2-11. Modelo da fibra intrafusal. Todas as fibras intrafusais (bag 1, bag 2 e chain) possuem uma região polar e uma sensorial (equatorial). Figura reproduzida de (MILEUSNIC et al., 2006). 
Figura 3-1. Diagrama de blocos representando o modelo neuromuscular. a) Visão simplificada do modelo. O pool de MNs contendo $n_{M N}$ MNs recebe entradas de $n_{D T}$ axônios descendentes e $n_{l a}$ aferentes. O complexo (ou unidade) músculo-tendão é excitado pela atividade dos $\mathrm{MNs}$ e é restrito mecanicamente pela dinâmica da articulação. b) $O$ modelo de unidade músculo-tendão compreende um tendão em série com um músculo penado. PE representa a rigidez e a viscosidade e CE é responsável pela geração da força ativa. MS provê a atividade aferente la devida à dinâmica muscular.

Figura 3-2. Exemplo de simulação no qual a articulação do tornozelo é rotacionada de $8^{\circ}$ (dorsiflexão), estirando o músculo SOL. Decurso temporal do EMG (a), dos instantes de disparos dos MNs (b), dos instantes de disparos dos aferentes la (c), do comprimento do fascículo muscular (d), da força muscular (e), e do ângulo da articulação (f)

Figura 3-3. Variação das propriedades do músculo e do tendão como função do nível de ativação, quando a MTU é estirada pela dorsiflexão do tornozelo. a) Comprimento do fascículo muscular antes do estiramento. b) Amplitude do estiramento muscular. c) Velocidade de estiramento muscular. d) rigidez dinâmica do músculo e do tendão durante o estiramento.

Figura 3-4. Variação da amplitude do reflexo H com a força muscular basal. O reflexo resultante foi normalizado pela onda $\mathrm{M}$ máxima. A força muscular foi normalizada pela máxima força que o músculo pode produzir com a articulação na posição neutra.

Figura 3-5. Variação do SLR e da resposta aferente la com a força muscular basal. O SLR foi normalizado pela onda M máxima. A força muscular foi normalizada pela máxima força que o músculo pode produzir com a articulação na posição neutra.....45

Figura 3-6. Variação do SLR como função da ativação fusimotora por MNs gama estáticos e dinâmicos (a) e como função do valor máximo para a condutância entre os aferentes la e os MNs alfa (b).

Figura 4-1 - Esquema do modelo motoneuronal de dois compartimentos ilustrando os tipos de correntes presentes em cada compartimento. Figura retirada de (KURIAN; CROOK; JUNG, 2011).

Figura 4-2 - Circuito elétrico que representa o modelo de motoneurônio. $C_{m s}$ e $C_{m d}$ são as capacitâncias específicas, enquanto Vs e Vd são os potenciais de membrana dos compartimentos somático e dendrítico, respectivamente; $\boldsymbol{g} \boldsymbol{c}$ é a condutância de acoplamento entre os dois compartimentos; $\boldsymbol{g} \boldsymbol{L}$ é a condutância de fuga do compartimento; $\boldsymbol{g} \boldsymbol{x}$ e $\boldsymbol{E} \boldsymbol{x}$ representam a condutância e o potencial de reversão (Nernst) associados à corrente iônica $x$, em que $x$ é substituído por $\mathrm{Na}$ : sódio; $\mathrm{Kdr}$ : potássio; CaN: cálcio tipo N; KCa: potássio dependente de cálcio; NaP: sódio 
persistente; CaP: cálcio persistente. O sinal do potencial de reversão de cada corrente iônica é representado pela polarização da bateria, com referência ao meio extracelular. Por exemplo, o potencial de reversão do $\mathrm{Na}$ possui sinal positivo, enquanto que o do $\mathrm{K}$ possui sinal negativo.

Figura 4-3 - Variáveis de estado (variáveis de ativação e de inativação; e concentração de cálcio) associadas ao compartimento somático com um voltageclamp triangular lento sobre este compartimento. As linhas tracejadas indicam o valor do potencial de reversão para a corrente iônica associada a cada variável de ativação ou inativação.

Figura 4-4 - Constantes de tempo associadas às condutâncias ativas no compartimento somático com um voltage-clamp triangular lento sobre este compartimento. As linhas tracejadas indicam o valor do potencial de reversão para a corrente iônica associada a cada variável de ativação ou inativação.

Figura 4-5 - Variáveis de estado (variáveis de ativação e de inativação; e concentração de cálcio) associadas ao compartimento dendrítico com um voltageclamp triangular sobre o mesmo compartimento. As linhas tracejadas indicam o valor do potencial de reversão para a corrente iônica associada a cada variável de ativação ou inativação.

Figura 4-6 - Constantes de tempo associadas às condutâncias ativas no compartimento dendrítico com um voltage-clamp triangular lento sobre o mesmo compartimento. As linhas tracejadas indicam o valor do potencial de reversão para a corrente iônica associada a cada variável de ativação ou inativação. .65

Figura 4-7 - Atenuação do potencial elétrico no compartimento dendrítico para um voltage-clamp senoidal no compartimento somático. 69

Figura 4-8. Simulações para determinar as correntes de reobase e os potenciais limiares (thresholds) para os MNs do pool.

Figura 4-9. Decurso temporal da AHP em resposta a um pulso de corrente de duração 1 ms e amplitude de $150 \mathrm{nA} / \mathrm{cm}^{2}$. A - Motoneurônio sem correntes persistentes dendríticas (cenário base). B - Motoneurônio com correntes persistentes dendríticas (cenário com nível intermediário de excitabilidade).

Figura 4-10. Características de disparo do pool de motoneurônios, no cenário base, em resposta a current-clamps triangulares. A: Correntes injetadas no compartimento somático. B: Taxas de disparos. C: Potencial somático. D: Curvas FI (corrente injetada versus taxa de disparos). E: Potencial dendrítico. F: Derivada da taxa de disparos com relação à corrente injetada (ganhos das curvas FI). Nas figuras da coluna da direita, marcadores com forma triangular representam a fase ascendente da corrente 
injetada, enquanto que marcadores com forma circular representam a fase descendente.

Figura 4-11. Características de disparo do pool de motoneurônios, no cenário de excitabilidade intermediária, em resposta a current-clamps triangulares. A: Correntes injetadas no compartimento somático. B: Taxas de disparos. C: Potencial somático. D: Curvas FI (corrente injetada versus taxa de disparos). E: Potencial dendrítico. F: Derivada da taxa de disparos com relação à corrente injetada (ganhos das curvas Fl). Nas figuras da coluna da direita, marcadores com forma triangular representam a fase ascendente da corrente injetada, enquanto que marcadores com forma circular representam a fase descendente.

Figura 4-12. Características de disparo do pool de motoneurônios, no cenário alta excitabilidade, em resposta a current-clamps triangulares. A: Correntes injetadas no compartimento somático. B: Taxas de disparos. C: Potencial somático. D: Curvas FI (corrente injetada versus taxa de disparos). E: Potencial dendrítico. F: Derivada da taxa de disparos com relação à corrente injetada (ganhos das curvas FI). Nas figuras da coluna da direita, marcadores com forma triangular representam a fase ascendente da corrente injetada, enquanto que marcadores com forma circular representam a fase descendente. .75

Figura 5-1. A) Exemplo representativo do desempenho de jovens e idosos na manutenção de forças a 5, 20, 35 e 50\% da MVC (GALGANSKI; FUGLEVAND; ENOKA, 1993). B) Variabilidade da força (medida pelo coeficiente de variação - CV) durante a tarefa ilustrada na figura A, para jovens e idosos (GALGANSKI; FUGLEVAND; ENOKA, 1993).

Figura 5-2. Esquema do modelo sistema neuromuscular. A atividade do neurônio pré-motoneuronal (PMN i) é modulada pelo sinal de entrada. Tais neurônios fazem sinapses excitatórias com os MNs, dependendo do grau de conectividade estipulado. $\mathrm{O}$ trem de disparos de um $M N$ j é entrada para um gerador de força $(F \mathrm{j})$ e um gerador de MUAPs (E j). A soma das saídas dos geradores de força resulta na força total do músculo, enquanto que a soma das saídas dos gerados de MUAPs resulta no EMG do músculo.

Figura 5-3 - Relação entre o tempo de contração e a amplitude de abalo de unidades motoras em: (A) gastrocnêmico de gato (BURKE; TSAIRIS, 1974); (B) músculo tenar da mão de humano (THOMAS et al., 1990); (C) modelo de (FUGLEVAND; WINTER A.; PATLA, 1993).

Figura 5-4 - A) Distribuição das amplitudes de abalos. B) Distribuição de tempos de contração no músculo tenar (na mão) de humano. Modificado de (Chan, Doherty et al. 2001). 
Figura 5-5 - Ilustração da geração de potenciais excitatórios pós-sinápticos no compartimento somático (C) e dendrítico (B) dos $\mathrm{MNs}$, devidos à atividade dos neurônios PMNs (A). Nesta simulação foram utilizados apenas 3 PMNs para efeito ilustrativo. 100

Figura 5-6 - A) Exemplo de simulações para geração de vários níveis de força em jovens. B) Força média gerada em função da frequência média de disparos dos neurônios PMNs. Os dados foram ajustados a uma sigmoide resultando em $\mathrm{R}^{2}=0.999$. Sigmoide: Mean Force $=1.21 /(0.0124+\exp (-0.1217 *$ Input Frequency $))$. 101

Figura 5-7 - Frequência instantânea de disparos dos MNs do pool (caso jovem) para diferentes níveis de força alvo: A) $2,5 \%$, B) $10 \%$, C) $30 \%$, D) $60 \%$, E) $80 \%$, F) $90 \%$, G) $100 \%$. 102

Figura 5-8 - Variabilidade da força gerada pelo modelo de jovem. A) Desvio padrão da força em função da força média. B) Coeficiente de variação da força em função da força média. As barras indicam desvio padrão dentre os valores obtidos das dez repetições para cada nível de força. 103

Figura 5-9 - A) Variabilidade dos instantes entre disparos e B) da frequência instantânea de disparos de todos os MNs do pool, para diferentes níveis de força. 104

Figura 5-10 - Desvio padrão da frequência instantânea de disparos dos MNs em função do nível de força exercido. 104

Figura 5-11 - Na coluna da esquerda são mostradas as forças médias exercidas por cada $M U(A)$, os desvios-padrão $(C)$ e os coeficientes de variação $(E)$, para cada nível de força. Os gráficos da coluna da direita mostram uma ampliação da região de interesse dos gráficos à esquerda. A força média e seu desvio-padrão são dados em \% da MVC, enquanto que o CV é dado em \%. 105

Figura 5-12 - A) Exemplo de simulações para geração de vários níveis de força em idosos. B) Força média gerada em função da frequência média de disparos dos neurônios PMNs. Os dados foram ajustados a uma sigmoide resultando em $\mathrm{R}^{2}=0.988$. Sigmoide: Mean Force $=4.53 /(0.045+\exp (-0.084 *$ Input Frequency) $) .. . \ldots \ldots \ldots \ldots \ldots . . . . . .106$

Figura 5-13 - Frequência instantânea de disparos dos MNs do pool (caso idoso) para diferentes níveis de força alvo: A) $3 \%$, B) $20 \%$, C) $40 \%$, D) $60 \%$, E) $70 \%$, F) $85 \%$, G) $100 \%$.

Figura 5-14 - Variabilidade da força gerada pelo modelo de idoso. A) Desvio padrão da força em função da força média. B) Coeficiente de variação da força em função da força média. As barras indicam desvio padrão dentre os valores obtidos das dez repetições para cada nível de força. 108 
Figura 5-15 - Comparação da variabilidade da força em jovens (em vermelho) e idosos (em azul), com a força resultante normalizada (A) ou em valores absolutos (B). As barras indicam desvio padrão dentre os valores obtidos das dez repetições para cada nível de força. 109

Assim como no caso de jovens, é possível observar (Figura 5-12 B) que a relação entrada/saída do sistema neuromuscular de idosos modelado pode ser bem ajustado por uma função sigmoidal $\left(R^{2}=0.988\right)$. Este ajuste, porém, é um pouco menos próximo dos dados do que no caso do modelo de jovens, embora ainda possua um alto coeficiente de determinação. 


\section{LISTA DE TABELAS}

Tabela 1-1. Objetivos associados ao estudo do sistema neuromuscular por modelagem matemática.

Tabela 3-1. Parâmetros utilizados no modelo.

Tabela 4-1. Comparativo dos parâmetros associados às características passivas dos MNs. $\boldsymbol{R} \boldsymbol{n}$ é a resistência de entrada no soma, $\boldsymbol{\tau m}$ é a constante de tempo da membrana, $\boldsymbol{p}$ é a relação entre a área do compartimento somático $(\boldsymbol{A} \boldsymbol{s})$ e a área total, $\boldsymbol{D}$ é a distância com relação ao centro do soma em que se divide o $\mathrm{MN}$ em dois compartimentos.

Tabela 4-2. Parâmetros associados às características passivas do modelo de MN. Notar que $\boldsymbol{r n}, \boldsymbol{g L s}, \boldsymbol{g L d}, \boldsymbol{g c}, \boldsymbol{C m \boldsymbol { d }}, \boldsymbol{e} \mathbf{C m} \boldsymbol{s}$ são grandezas normalizados pela área de seu respectivo compartimento.

Tabela 4-3. Parâmetros associados às características ativas do compartimento somático do modelo de $\mathrm{MN}$. $\boldsymbol{g} \boldsymbol{x}$ é a máxima condutância, $\boldsymbol{E} \boldsymbol{x}$ é o potencial de reversão, $\boldsymbol{\theta} \boldsymbol{x} \boldsymbol{w}$ é o potencial de meia ativação/inativação, $\boldsymbol{k} \boldsymbol{x} \boldsymbol{w}$ é a sensibilidade de ativação/inativação e $\boldsymbol{\tau} \boldsymbol{x} \boldsymbol{w}$ é a constante de tempo de ativação/inativação associados ao canal iônico $x$ e à variável de ativação/inativação $w$. Notar que as condutâncias máximas para cada tipo de canal iônico são normalizadas pela área do compartimento somático. 60

Tabela 4-4. Parâmetros associados às características ativas do compartimento dendrítico do modelo de $M N$. $\boldsymbol{g} \boldsymbol{x}$ é a máxima condutância, $\boldsymbol{E} \boldsymbol{x}$ é o potencial de reversão, $\boldsymbol{\theta} \boldsymbol{x} \boldsymbol{w}$ é o potencial de meia ativação/inativação, $\boldsymbol{k} \boldsymbol{x} \boldsymbol{w}$ é a sensibilidade de ativação/inativação e $\boldsymbol{\tau} \boldsymbol{x} \boldsymbol{w}$ é a constante de tempo de ativação/inativação associados ao canal iônico $x$ e à variável de ativação/inativação $w$. Notar que as condutâncias máximas para cada tipo de canal iônico são normalizadas pela área do compartimento dendrítico.

Tabela 4-5. Parâmetros associados à dinâmica de cálcio

Tabela 4-6. Valores calculados de grandezas associadas às características passivas do modelo de motoneurônio. .68 
Tabela 4-7. Valores de atenuação e defasagem do potencial elétrico medido no compartimento dendrítico para um voltage-clamp senoidal $(250 \mathrm{~Hz})$ no compartimento somático.

Tabela 4-8. Medidas de corrente de reobase e de potencial limiar (threshold) para os MNs, assim como mostrado na Figura 4-8. $\Delta \boldsymbol{i}$ é a incerteza na medida da reobase e $\Delta v$ é a incerteza na medida do limiar. . .70

Tabela 4-9. Métricas resultantes para a AHP para as condições de dendritos passivos e ativos .71

Tabela 5-1. Alterações do sistema neuromuscular com envelhecimento 85

Tabela 5-2. Parâmetros adotados para o modelo de sistema neuromuscular de jovens e de idosos. .98 


\section{LISTA DE ABREVIATURAS E SIGLAS}

\begin{tabular}{|c|c|}
\hline ACo & Acetilcolina \\
\hline AHP & pós-hiperpolarização (after-hyperpolarization) \\
\hline $\mathbf{A P}$ & Potencial de ação (Action Potential) \\
\hline ATP & Trifosfato de Adenosina (Adenosine Triphosphate) \\
\hline a.u. & unidades arbitrárias (arbitrary units) \\
\hline CNS & Sistema Nervoso Central (Central Nervous System) \\
\hline CPN & Nervo Peroneal Comum (Common Peroneal Nerve) \\
\hline DDVA & Atenuação da voltagem dependente da direção (Direction-dependent Voltage Attenuation) \\
\hline DT & Tratos Descendente (Descending Tract) \\
\hline EMG & Eletromiograma \\
\hline EPSP & Potencial escitatório pós-sináptico (Excitatory Postsynaptic Potential) \\
\hline FDI & Primeiro Interósseo Dorsal (First Dorsal Interosseus) \\
\hline GTO & Órgão Tendinoso de Golgi (Golgi Tendon Organ) \\
\hline IFR & Frequência de Disparos Instantânea (Instantaneous Firing Rate) \\
\hline IN & Interneurônio (Interneurons) \\
\hline ISI & Intervalo entre disparos (Interspike Interval) \\
\hline LG & Grastrocnêmio Lateral (Lateral Grastrocnemius) \\
\hline МCP & Metacarpofalangeal (Metacarpophalangeal) \\
\hline MN & Motoneurônio (Motoneuron) \\
\hline MU & Unidade Motora (Motor Unit) \\
\hline MUAP & Potencial de ação de unidade motora (Motor Unit Potential) \\
\hline MG & Grastrocnêmio Medial (Medial Gastrocnemius) \\
\hline MS & Fuso Neuromuscular (Muscle Spindle) \\
\hline MTU & Unidade músculo-tendão (Musculotendon Unit) \\
\hline MVC & Contração Voluntária Máxima (Maximum Voluntary Contraction) \\
\hline PC & Corrente Persistente (Persistent Current) \\
\hline PMN & Neurônio Pré-Motoneuronal (Premotoneuronal Neuron) \\
\hline PTN & Nervo Tibial (Posterior Tibial Nerve) \\
\hline $\mathbf{R C}$ & Células de Renshaw (Renshaw Cell) \\
\hline SOL & Sóleo (Soleus) \\
\hline
\end{tabular}




\section{SUMÁRIO}

RESUMO

. i

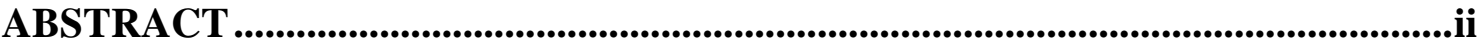

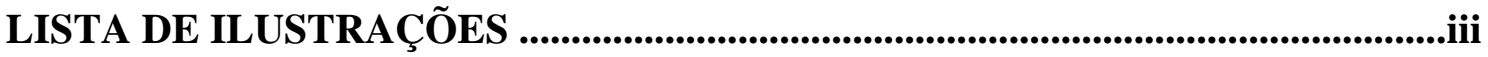

LISTA DE TABELAS .......................................................................................................

LISTA DE ABREVIATURAS E SIGLAS ...........................................................

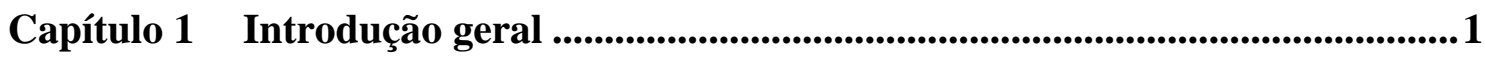

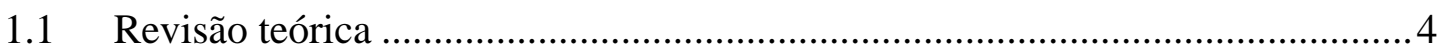

1.1.1 Anatomia e fisiologia do sistema neuromuscular................................. 4

1.1.1.1 Sistema Nervoso Central ............................................................. 4

1.1.1.2 Músculo e Unidades Motoras ............................................................. 8

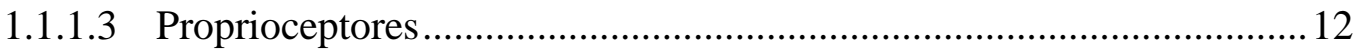

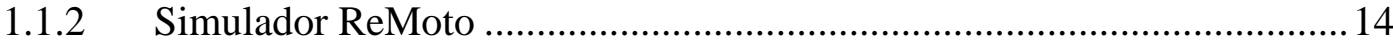

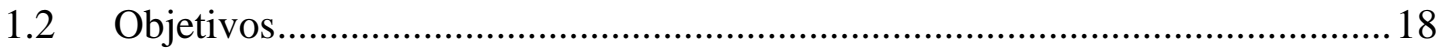

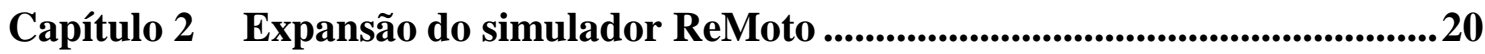

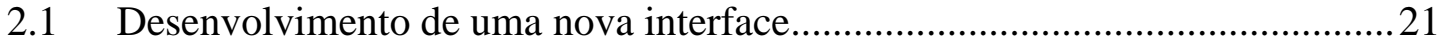

2.2 Implementação de ferramentas para análise ...............................................26

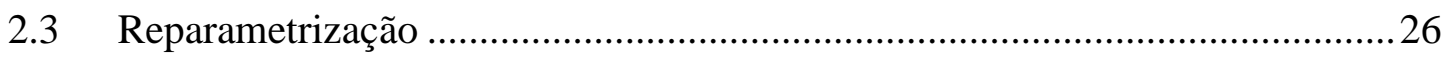

2.4 Implementação e integração do modelo de fuso neuromuscular.......................29

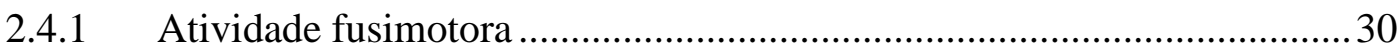

2.4.2 Mecânica das regiões sensorial e polar...................................................... 31

2.4.3 Contribuição da fibra intrafusal para a taxa de disparo aferente ............... 32

Capítulo 3 Alterações de reflexos com o nível de força exercida ...........................34

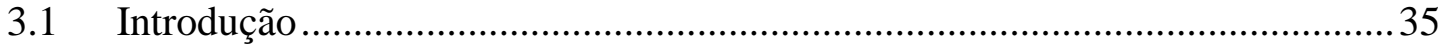

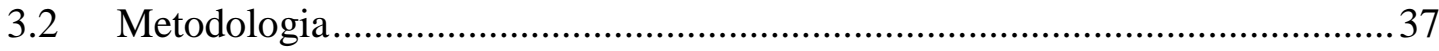

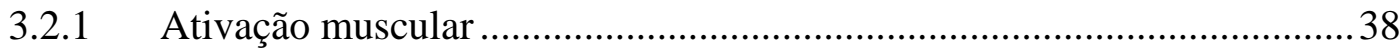


3.2.2 Dinâmica de contração muscular............................................................. 38

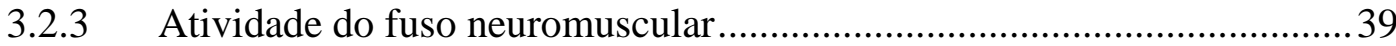

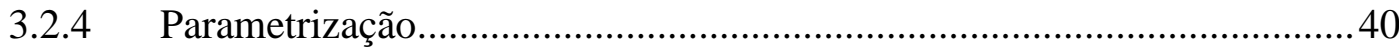

3.2.5 Protocolos de simulação ................................................................... 41

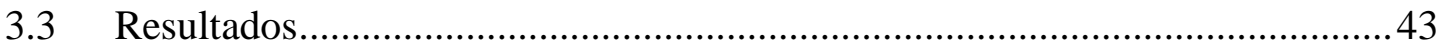

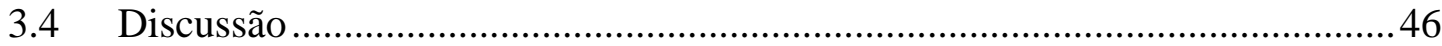

Capítulo 4 Modelo de pool de motoneurônios .....................................................................50

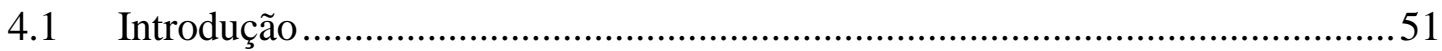

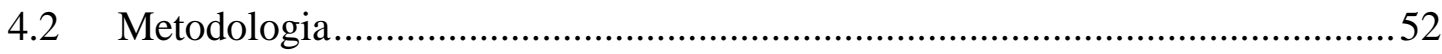

4.2.1 Estrutura do modelo de motoneurônio ......................................................52

4.2.2 Parametrização das propriedades passivas ..............................................57

4.2.3 Parametrização das propriedades ativas ..................................................60

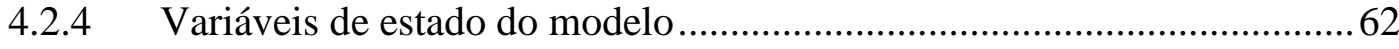

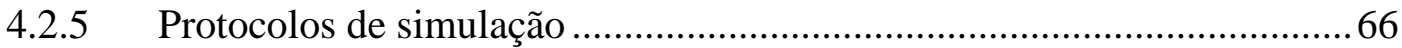

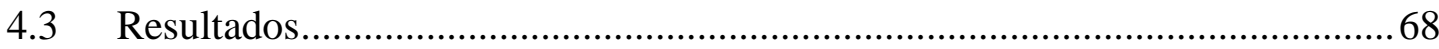

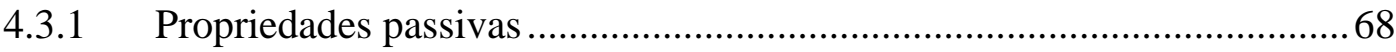

Atenuação do potencial dependente da direção ..................................................69

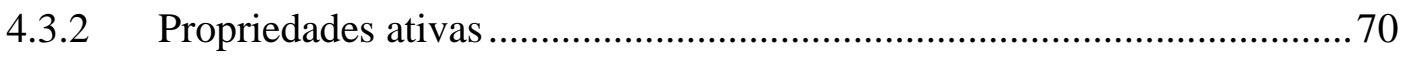

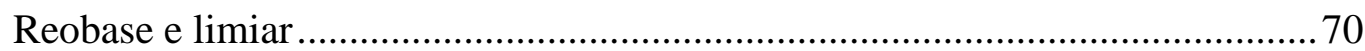

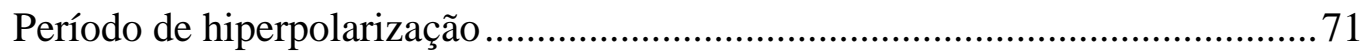

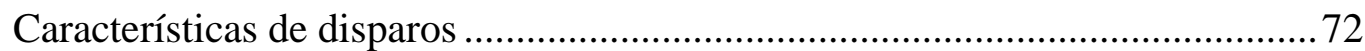

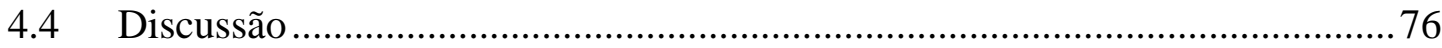

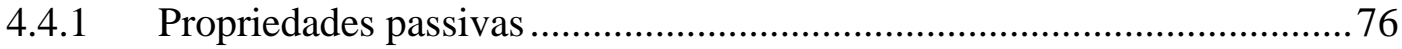

4.4.2 Atenuação do potencial dependente da direção........................................76

4.4.3 Efeitos de ressonância e de amplificação ................................................. 77

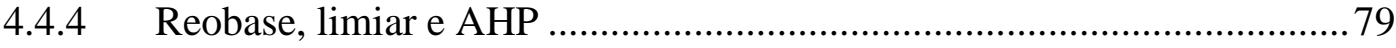

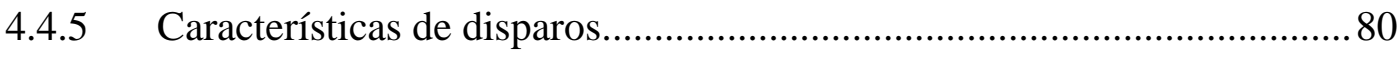


Capítulo 5 Geração e variabilidade de forças isométricas em jovens e idosos ....83

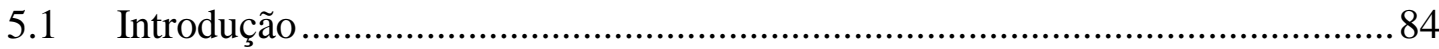

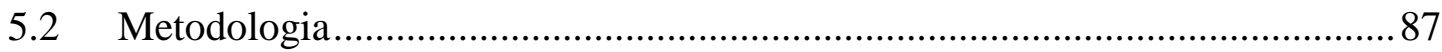

5.2.1 Modelo das vias pré-motoneuronais ..................................................... 88

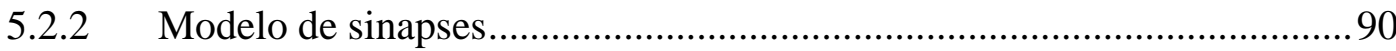

5.2.3 Modelo de abalo da unidade motora......................................................... 95

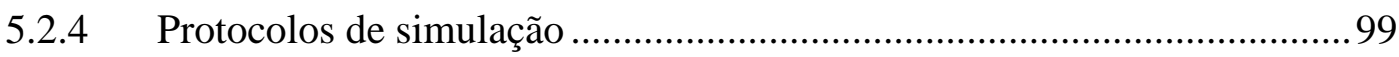

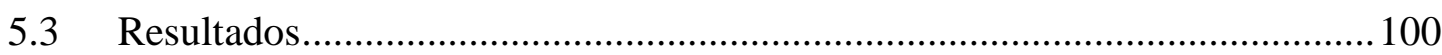

5.3.1 Geração de força em jovens.................................................................. 101

5.3.2 Variabilidade da força em jovens ...................................................... 103

5.3.3 Geração de força em idosos................................................................ 106

5.3.4 Variabilidade da força em idosos ......................................................... 108

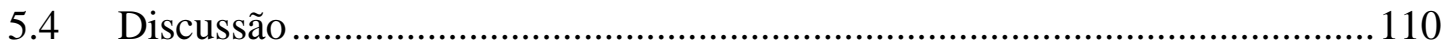

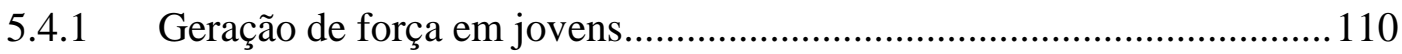

5.4.2 Características de disparos do pool de MNs em jovens ........................ 110

5.4.3 Variabilidade da força em jovens .................................................... 112

5.4.4 Geração de força em idosos............................................................ 114

5.4.5 Características de disparos do pool de MNs em idosos......................... 115

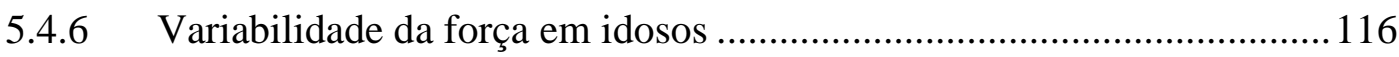

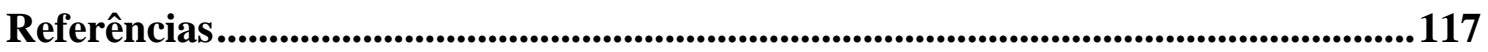

Apêndice 1 Cálculo dos parâmetros passivos ................................................................128

Apêndice 2 Reparametrização das propriedades passivas .................................129

Apêndice 3 Faixa de recrutamento em jovens e idosos ..........................................130 


\section{Capítulo 1 Introdução geral}


única forma de um ser humano atuar voluntariamente no ambiente ao seu redor é
pela contração de seus músculos (ROTHWELL, 1994) ${ }^{1}$. Certos grupos musculares
são ainda responsáveis pela manutenção da respiração (e.g., diafragma e músculos intercostais), da circulação sanguínea (e.g., coração), dentre outras ações autônomas.

O tecido muscular é inervado por células neurais, chamadas motoneurônios (MNs). Similarmente aos MNs, as fibras musculares são excitáveis, ou seja, quando um potencial de ação (AP) do MN atinge seu terminal sináptico sobre a fibra muscular, ocorre liberação de acetilcolina (ACo) na junção neuromuscular, acarretando uma onda de despolarização na fibra muscular (MUAPs), a qual se contrai (i.e., gera um abalo ou twitch). A eficácia desta comunicação neuromuscular é muito alta, de forma que, um MN e o conjunto de fibras musculares que ele inerva constituem uma unidade funcional, chamada unidade motora (MU). Assim, um AP no MN vai gerar abalos em praticamente todas as fibras musculares por ele inervadas.

Grandezas observadas macroscopicamente, como a força gerada por certo músculo, são resultantes de um conjunto de eventos que ocorrem em escalas menores. Neste caso, para se entender os fenômenos envolvidos na geração de força em diversas situações, é necessário entender os mecanismos neurais e musculares que a geram. Há várias abordagens para investigar o sistema neuromuscular, como: caracterizações anatômicas e físiológicas; experimentos neurofisiológicos, biomecânicos e comportamentais; estudos comparativos entre humanos e animais, entre jovens e idosos, e entre indivíduos saudáveis e doentes. Tais abordagens geram grande quantidade de dados, os quais precisam ser tratados e interpretados à luz das teorias existentes. A neurociência computacional pode atuar como ponte entre a abordagem experimental e a puramente teórica, servindo em parte como ferramenta para testar ou criar teorias, confrontando dados simulados com experimentais, e em parte contribuindo para uma visão crítica dos dados experimentais, sugerindo falhas e/ou novas abordagens.

Nesta dissertação, são apresentados estudos do sistema neuromuscular por modelagem matemática, com particular interesse nos músculos associados com o controle da articulação do tornozelo (Figura 1-1 a) e em um músculo intrínseco da mão (Figura 1-1 b). A articulação do tornozelo tem papel fundamental na marcha e na manutenção da postura ereta, o que justifica as inúmeras pesquisas com o fim de estudá-la. Já o primeiro interósseo dorsal (FDI) é um músculo intrínseco da mão que possui, além de sua funcionalidade motora, características

\footnotetext{
${ }^{1}$ Esta visão, porém, está sendo modificada com o desenvolvimento de interfaces cérebro-máquina.
} 
interessantes do ponto de vista experimental. Além de possibilitar fácil acesso para medidas eletrofisiológicas, ele é o único músculo responsável pela abdução da segunda articulação metacarpofalangeal (MCP), facilitando a inferência de sua força a partir do torque articular medido. Mais detalhes sobre estas articulações serão discutidos adiante. Nos trabalhos aqui descritos, maior enfoque é dado em contrações isométricas (i.e., ângulo articular mantido fixo), avaliando-se a organização, em termos anatômicos e fisiológicos, do núcleo motor recebendo como entrada a atividade sináptica das vias pré-motoneuronais, e estudando como diferentes arranjos das propriedades neurais podem resultar em características encontradas experimentalmente para a força muscular.

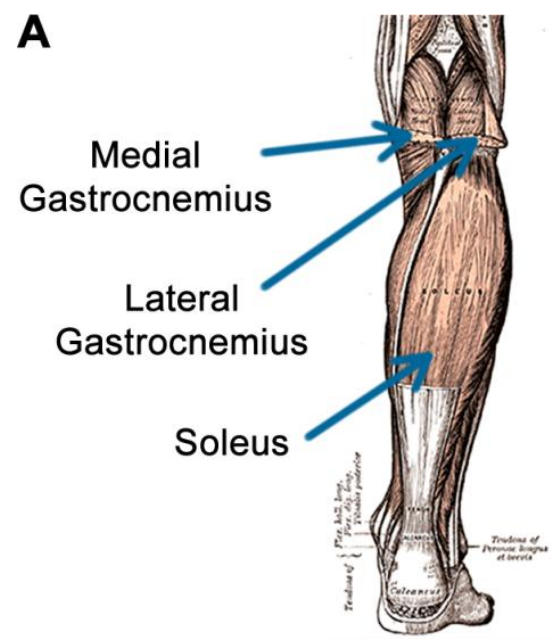

B

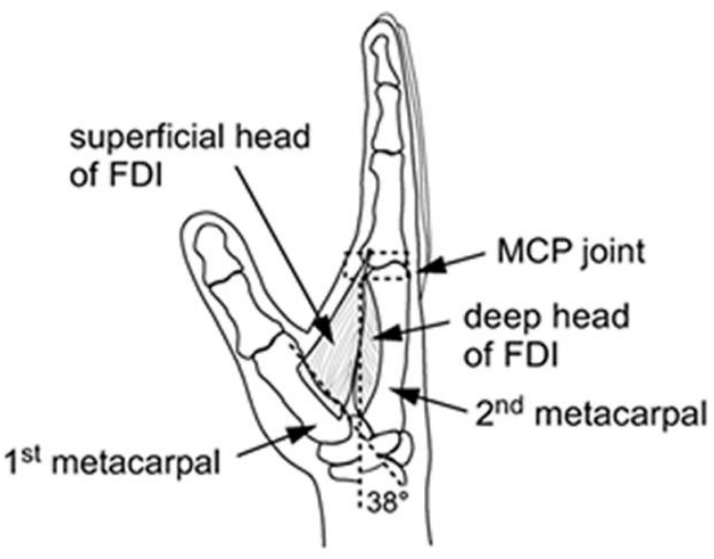

Figura 1-1 - (A) Músculos extensores do tornozelo. Modificado de (GRAY, 1989). (B) primeiro interósseo dorsal (FDI) (HUDSON et al., 2009).

Neste documento é feita a descrição dos trabalhos resultantes do projeto de mestrado e são discutidas possíveis aplicações e extensões dos mesmos. Inicialmente é feita uma breve revisão da literatura e são elucidados os principais objetivos. Em seguida, são apresentados, na forma de capítulos, os trabalhos desenvolvidos durante o projeto. 


\subsection{Revisão teórica}

Este trabalho se enquadra principalmente na área conhecida como neurociência computacional. Esta área inclui a produção de modelos matemáticos em diferentes escalas a fim de estudar sistemas neurais de humanos ou de animais. Para exemplificar, do ponto de vista estrutural, tais modelos podem compreender desde canais iônicos em neurônios individuais, até redes completas contendo milhares de neurônios. Funcionalmente, podem descrever a dinâmica de abertura/fechamento de canais iônicos na membrana neural, de potenciais elétricos entre os meios intra e extracelular e de disparos de APs em redes neuronais. Além da investigação de aspectos puramente neurais, estes modelos têm sido associados a modelos que expressam as dinâmicas de ativação e contração musculares com o intuito de explorar conceitualmente o sistema neuromuscular (COFER et al., 2010; DIDERIKSEN; ENOKA; FARINA, 2011; HIDLER; RYMER, 1999).

A seguir (na seção 1.1.1) é feita uma breve revisão de conceitos básicos associados ao controle do movimento. Esta seção, porém, apenas destaca alguns pontos de interesse. Para uma revisão mais abrangente o leitor é convidado a consultar, por exemplo, (ENOKA, 2008; KANDEL et al., 2013; ROTHWELL, 1994). Na seção 1.1.2 é feita uma revisão do simulador ReMoto e de seus aspectos de modelagem (CISI; KOHN, 2008).

\subsubsection{Anatomia e fisiologia do sistema neuromuscular}

\subsubsection{Sistema Nervoso Central}

O sistema nervoso central (CNS) é constituído por redes neuronais que integram e regulam grande parte das funções do organismo. É responsável, por exemplo, pela coordenação de movimentos voluntários (Figura 1-2), modulados por um influxo de informações sensoriais (vias aferentes). O CNS pode ser dividido em encéfalo, onde ocorre um alto nível de integração sensorial e atividades conscientes, e medula espinhal que recebe tanto vias neuronais descendentes do encéfalo, quanto vias aferentes do sistema periférico. $\mathrm{Na}$ medula espinhal ocorre grande parte das atividades motoras reflexas e seus circuitos neurais estão intimamente associados com a execução de movimentos, voluntários ou não.

Há vários tratos descendentes (DTs) que podem incidir sobre um determinado grupo de MNs espinhais. Particularmente, conexões monossinápticas oriundas do trato córtico- 
espinhal são importantes para o controle direto de certos grupos musculares, como é o caso, por exemplo, de músculos das mãos (LEMON, 2008). Já as conexões indiretas incluem, por exemplo, aquelas vindas do trato vestíbulo-espinhal, as quais são importantes para a manutenção da postura e para a reabilitação após acidentes do sistema nervoso (BAKER, 2011).

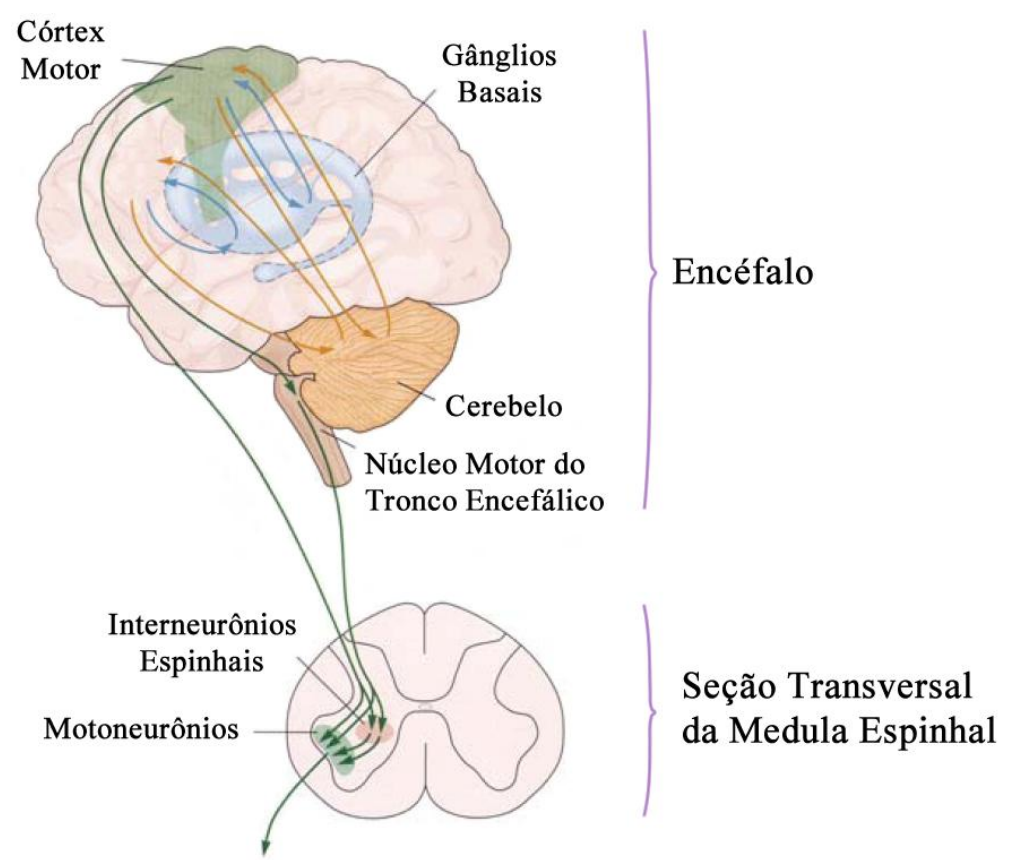

Figura 1-2 - Sistema nervoso central e vias motoras descendentes. Figura modificada de (KANDEL; SCHWARTZ; JESSELL, 2000).

Os MNs podem ser divididos em alfa e gama, sendo os MNs alfa diretamente responsáveis pela geração de força muscular e os MNs gama responsáveis pela ativação de fibras intrafusais. Um MN alfa e todas as fibras musculares por ele inervadas formam uma unidade motora (MU). A MU representa a menor porção do músculo que o sistema nervoso pode controlar (ECCLES; SHERRINGTON, 1930). Sinais de toda parte do sistema nervoso relacionados com o movimento convergem para as MUs, dando a estas o distinto papel de "via final comum" ("final common pathway") para produção e controle do movimento (SHERRINGTON, 1925). A coleção de neurônios motores alfa que inervam um determinado músculo é chamada de Núcleo Motor (ou pool de MNs). O pool de MNs de um dado músculo é agrupado em núcleos arranjados em uma coluna percorrendo vários segmentos da medula espinhal (Figura 1-3). Um pool de MNs típico contém cerca de centenas de MNs. Geralmente, pools de MNs de músculos maiores contêm mais neurônios que os de músculos menores. O músculo Sóleo (SOL) (Figura 1-1a), por exemplo, contém cerca de 900 MNs, enquanto que o 
FDI (Figura 1-1b) contém cerca de 180 MNs. A relação entre a quantidade de fibras musculares e a quantidade de MNs em um músculo é chamada de número de inervação.

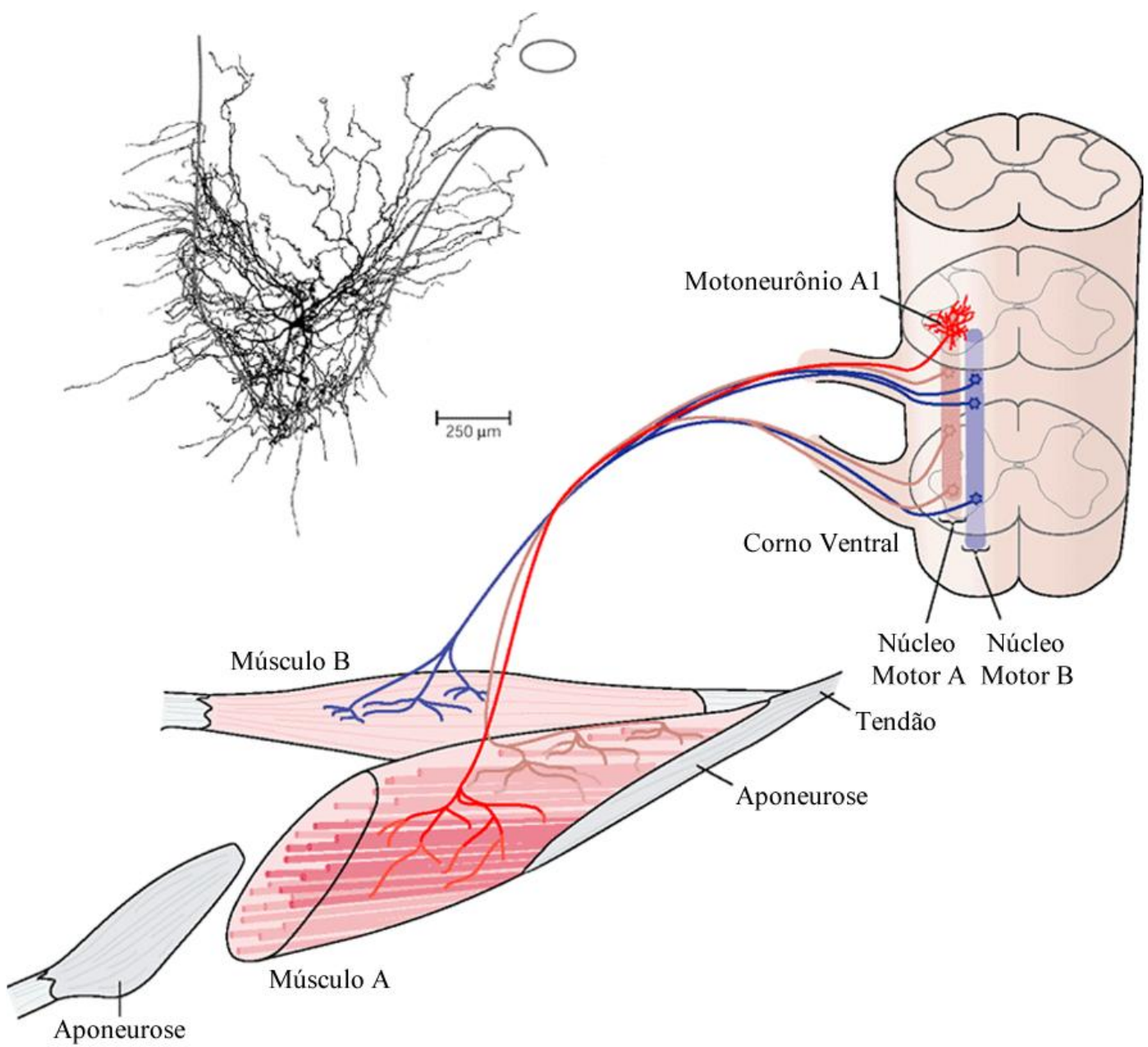

Figura 1-3 - Acima e à esquerda: estrutura morfológica de um MN alfa. Abaixo: diferentes músculos inervados pelos seus respectivos núcleos (pools) de MNs. Figura modificada de (KANDEL; SCHWARTZ; JESSELL, 2000).

Durante uma contração voluntária, cada fibra muscular gera uma força contráctil que se transmite aos tendões, bem como uma atividade elétrica que se propaga por todo comprimento do músculo. Um eletrodo posicionado sobre o músculo pode captar a atividade elétrica das fibras musculares na sua proximidade, sendo este sinal chamado de eletromiograma (EMG).

A geração de APs no MN é determinada pelo balanço entre as propriedades intrínsecas dos MNs e pela entrada sináptica recebida por eles (HECKMAN; ENOKA, 2012). Cada MN gera APs como decorrência da entrada sináptica oriunda de várias fontes, como aferências sensoriais, interneurônios locais e vias superiores. Um único MN recebe de 50.000 a 140.000 
contatos sinápticos, que, quando ativados, liberam neurotransmissores, levando à abertura de canais iônicos na membrana neuronal, ou diretamente (em receptores ionotrópicos) ou indiretamente (em receptores metabotrópicos). A distinção entre receptores ionotrópicos e metabotrópicos é que entradas ionotrópicas resultam na abertura imediata de canais iônicos, enquanto que entradas metabotrópicas ativam uma cascata de eventos intracelulares, os quais alteram a resposta do MN a entradas ionotrópicas subsequentes (HECKMAN; GORASSINI; BENNETT, 2005; HECKMAN et al., 2008).

Dentre as propriedades intrínsecas dos MNs, destaca-se a AHP (do inglês, afterhyperpolarization), que é um período, após o disparo de um AP, em que o potencial de membrana neuronal é mais negativo que seu valor de repouso. O período de AHP é considerado um importante mecanismo intrínseco do MN para a determinação de suas taxas mínimas e máximas de disparos (KERNELL, 1965).

Os interneurônios (INs), neste contexto, referem-se ao conjunto de neurônios cujos corpos celulares estão localizados na medula espinhal (exceto os MNs) e que participam do controle neural associado ao movimento, realizando comunicação entre as vias aferentes, eferentes e os tratos descendentes (Figura 1-4). A célula de Renshaw, por exemplo, participa da chamada inibição recorrente, na qual MNs ativados acabam gerando inibições (via célula de Renshaw) sobre outros MNs.

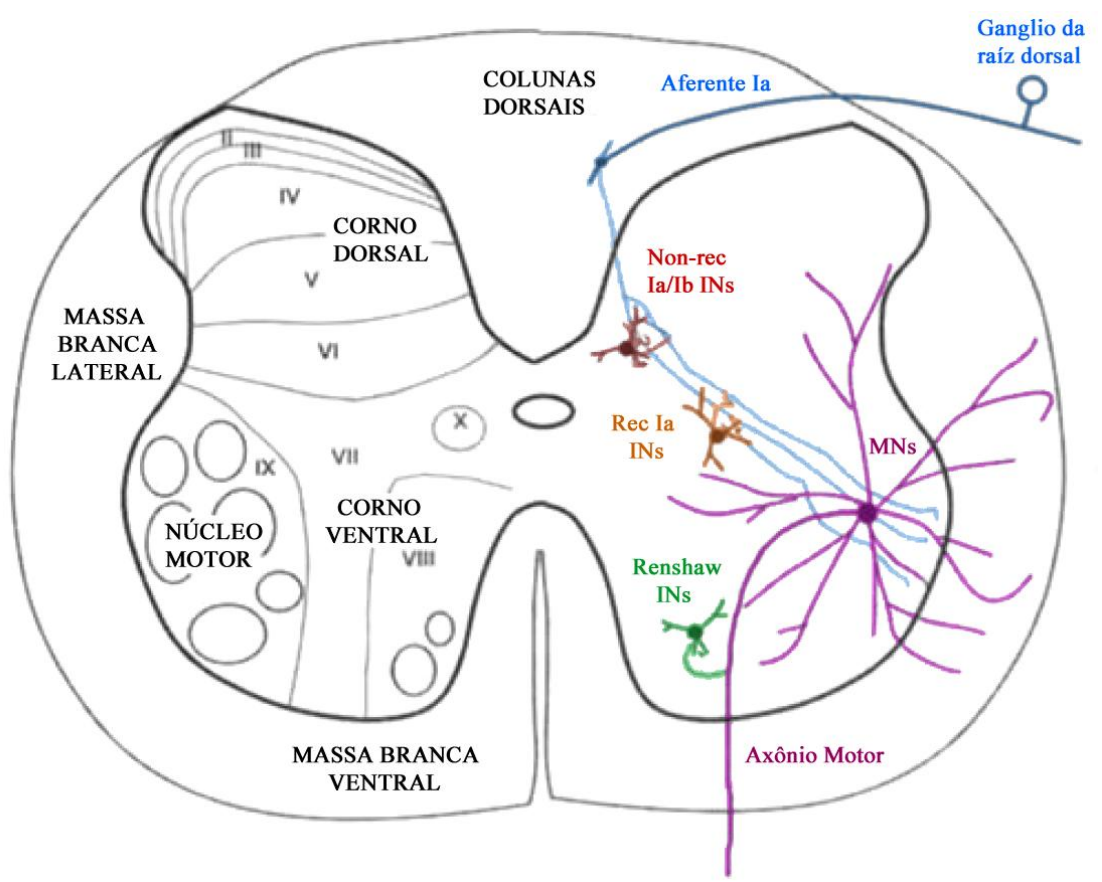

Figura 1-4 - Seção transversal de um segmento da medula espinhal ilustrando sua divisão em setores (à esquerda) e alguns neurônios representativos (à direita). Figura modificada de (BURKE, 2003). 


\subsubsection{Músculo e Unidades Motoras}

Os músculos são divididos em esqueléticos (ou estriados), lisos e cardíacos, diferenciando-se nas organizações celulares e nas propriedades contrácteis. Este trabalho trata apenas de músculos esqueléticos, os quais serão referidos doravante apenas como músculos. Suas principais funções são: produção de movimento; estabilização da articulação e manutenção da postura; e produção de calor. Os músculos possuem quatro propriedades que garantem o cumprimento destas funções:

- Excitabilidade elétrica: produção de potenciais de ação que se propagam pelas fibras, de forma semelhante à que ocorre com os neurônios.

- Contratilidade: capacidade do músculo se contrair em resposta a um estímulo elétrico.

- Extensibilidade: capacidade do músculo se estirar (acima de seu comprimento de repouso), mantendo sua contratilidade.

- Elasticidade: capacidade do tecido muscular de retornar ao seu comprimento de repouso após um estiramento ou uma contração.

A Figura 1-5 ilustra um músculo em quatro níveis diferentes: macroscópico (Figura 1-5 A), fibra muscular (Figura 1-5 B), miofibrila (Figura 1-5C) e de filamentos proteicos (Figura $1-5 \mathrm{D})$.

A

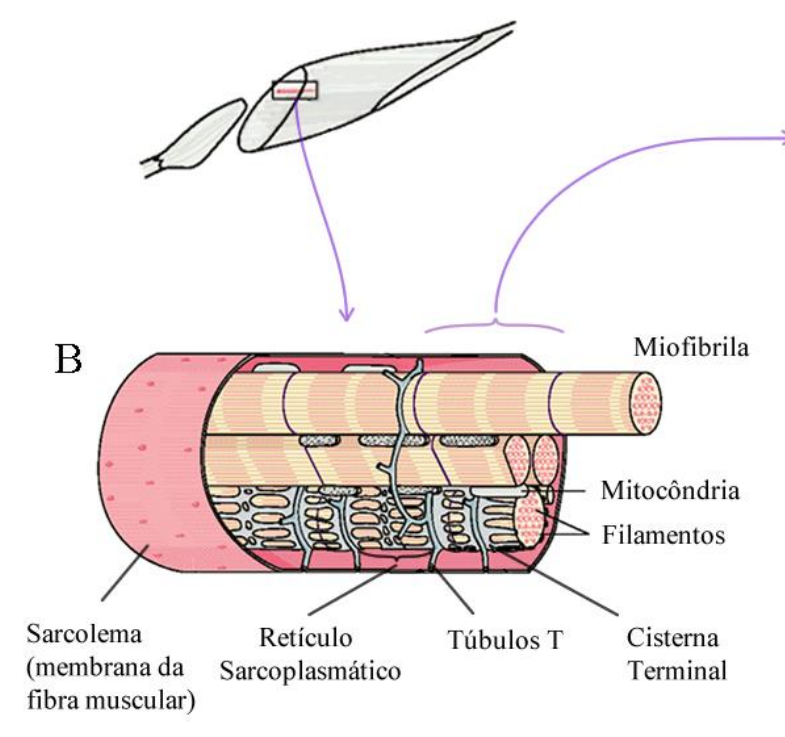

$\mathrm{C}$

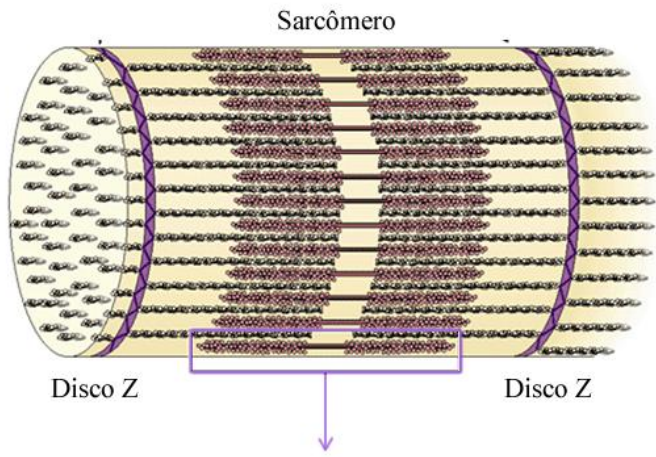

Filamento Fino (F-actina)

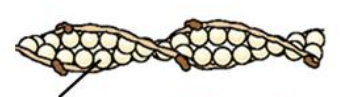

Actina

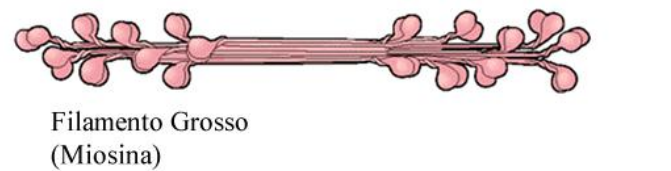

Figura 1-5 - Músculo esquelético nos níveis macroscópico (A), de uma fibra (B), de uma miofibrila (C) e de filamentos proteicos (D). Figura modificada de (KANDEL; SCHWARTZ; JESSELL, 2000). 
As fibras musculares são frágeis individualmente, mas em conjunto com tecido conjuntivo, formam um músculo bastante resistente. Membranas de tecido conjuntivo delimitam estruturas intramusculares como os fascículos, os quais contêm fibras, que por sua vez contêm miofibrilas. Cada miofibrila é formada por unidades contráteis chamadas sarcômeros, os quais são constituídos de filamentos proteicos grossos (miosina) e finos (actina).

O acoplamento excitação-contração muscular é dependente de energia (trifosfato de adenosina - ATP) e de íons de cálcio e pode ser resumido pelas seguintes etapas (BEAR; CONNORS; PARADISO, 2001):

- Excitação

- PA no MN alfa;

○ Liberação de ACo na junção neuromuscular;

- Abertura dos canais dos receptores nicotínicos e despolarização do sarcolema;

- Abertura de canais de sódio dependentes de voltagem, geração de PAs na fibra muscular e propagação dos mesmos pelos túbulos T;

- Liberação de $\mathrm{Ca}^{2+}$ no retículo sarcoplasmático.

- Contração

○ Ligação do $\mathrm{Ca}^{2+}$ à troponina.

○ Exposição dos sítios de ligação na actina.

- Conexão das cabeças de miosina na actina.

○ Rotação das cabeças de miosina.

- Desconexão das cabeças de miosina à custa de ATP.

- O ciclo prossegue enquanto houver $\mathrm{Ca}^{2+}$ e ATP.

- Relaxamento

- Sarcolema e túbulos T retornam aos seus potenciais de repouso.

- Bombeamento, dependente de ATP, de $\mathrm{Ca}^{2+}$ de volta para o retículo sarcoplasmático.

- Troponina encobre os sítios de ligação na actina. 
A contração muscular resulta das atividades individuais e combinadas das MUs. Desta forma, a geração de força em um determinado músculo pode ser controlada pela taxa de disparos da MU (Figura 1-6) e pela quantidade de unidades motoras, pertencentes ao núcleo motor deste músculo, que estejam ativadas.

Em gatos, as MUs são diferenciadas de acordo com suas características morfológicas e fisiológicas em: S (slow), FR (fast-resistant) e FF (fast-fatigable). Já em humanos, a divisão funcional em tipos distintos de MUs ainda é tema de debate (ENOKA et al., 2011; FUGLEVAND, 2011). Além disto, sabe-se que normalmente existe uma ordem de recrutamento das MUs, na qual, em condições normais, são primeiramente recrutadas MUs menores (do tipo $\mathrm{S}$ ), seguidas pelas do tipo FR e, finalmente, pelas do tipo FF, seguindo uma ordem crescente de tamanho. Este fenômeno é chamado de "princípio do tamanho" (HENNEMAN, 1957). Este recrutamento, porém, pode ser alterado, por exemplo, quando a excitação das MUs se dá por estimulação elétrica.

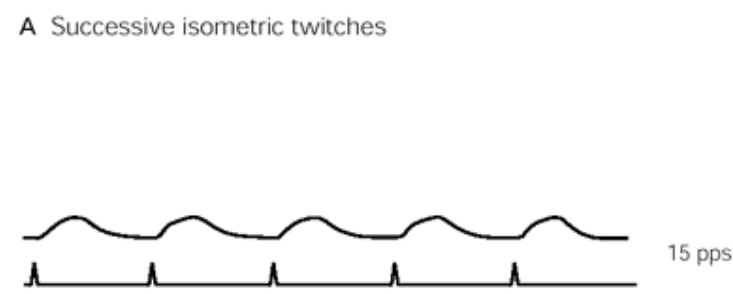

B Summation of successive isometric twitch contractions

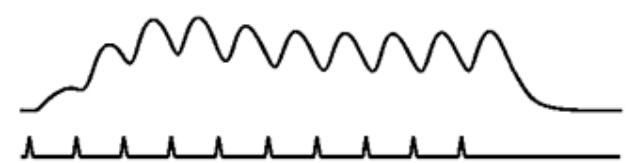

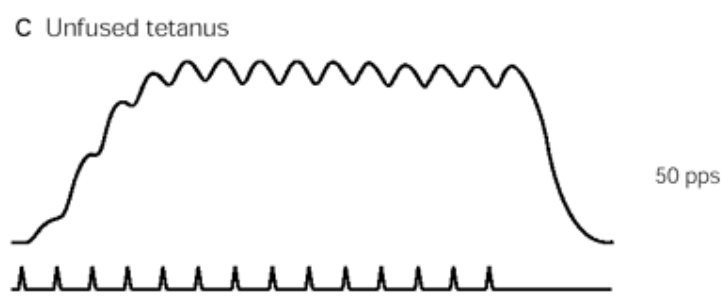

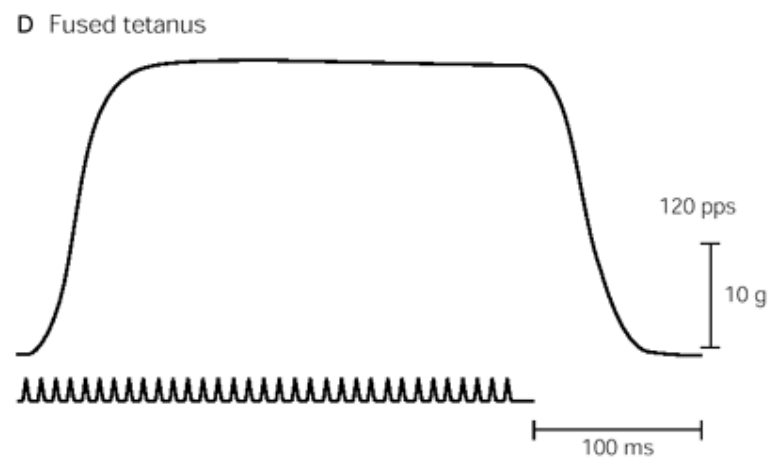

Figura 1-6 - Variação da tensão muscular com a taxa de disparos de uma MU. Figura modificada de (KANDEL; SCHWARTZ; JESSELL, 2000). 
A organização do recrutamento das MUs e da modulação das taxas de disparos das MUs constitui um aspecto muito importante para a geração e o controle da força. Não há consenso atualmente sobre como é esta organização. Alguns pesquisadores defendem que as MUs recrutadas primeiramente com um aumento gradual da força sempre terão taxas de disparos mais elevadas que MUs recrutadas posteriormente (Figura 1-7a). Este perfil de organização é chamado “onion skin” (DE LUCA; HOSTAGE, 2010). Contrastantemente, outros trabalhos recentes mostram perfis de recrutamento diferentes do "onion skin", nos quais MUs recrutadas posteriormente possuem taxas de disparos superiores às daquelas recrutadas anteriormente (BARRY et al., 2007; MORITZ et al., 2005) (Figura 1-7b).

A

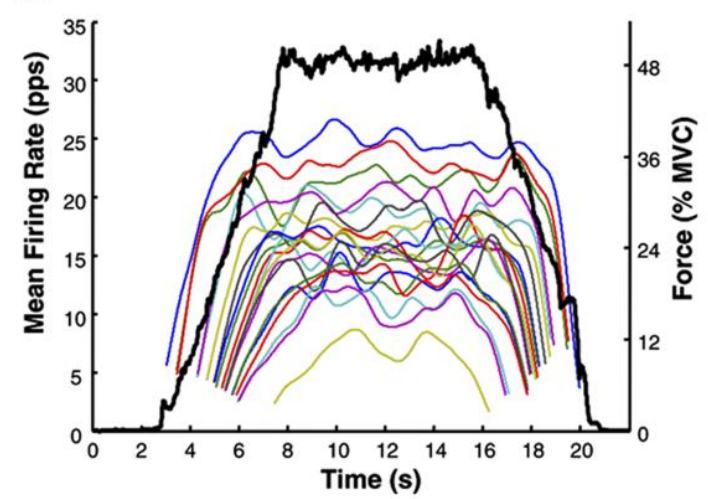

B

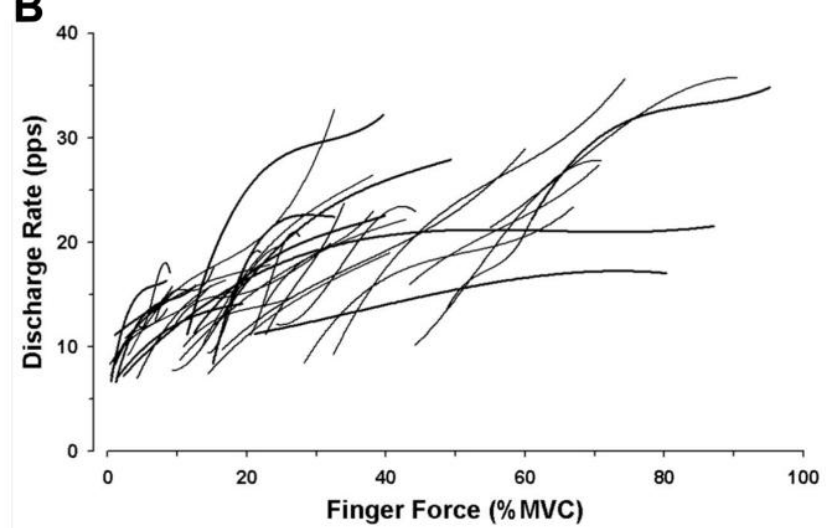

Figura 1-7 - A) Exemplo de recrutamento das MUs em que ocorre um perfil do tipo onion skin (DE LUCA; HOSTAGE, 2010). A linha preta mostra a força desenvolvida pelo músculo e as linhas coloridas mostram as taxas médias de disparos de cada MU recrutada. B) Exemplo de recrutamento das MUs em que não ocorre um perfil do tipo onion skin (MORITZ et al., 2005). Em ambos os experimentos o músculo aferido foi o FDI. Embora os eixos das abscissas não sejam iguais nas duas figuras é possível compará-las, pois, até o instante $8 \mathrm{~s}$ na Figura A, a força aumenta progressivamente com tempo. Os protocolos experimentais, porém, são diferentes, o que provavelmente causa os diferentes padrões de recrutamento. 


\subsubsection{Proprioceptores}

Há vários tipos de entradas sinápticas sobre os MNs que são importantes para o controle da força. A maioria destas entradas é altamente espalhada pelo pool de MNs, embora algumas possam ser predominantes sobre $\mathrm{MNs}$ associados com um tipo particular de fibra (HECKMAN; ENOKA, 2004). Várias projeções para os MNs no nível espinhal tem origem de fibras sensoriais. As mais importantes, durante a contração muscular, são as do tipo Ia (com efeito excitatório) e as do tipo Ib (com efeito inibitório) (HECKMAN; ENOKA, 2004). A distribuição e as características das entradas sinápticas são, de forma geral, pouco conhecidas. Uma exceção é o aferente Ia, oriundo do fuso neuromuscular (MS), os quais realizam conexões monossinápticas com praticamente todo pool de MNs.

O MS (Figura 1-8) é um sensor localizado em paralelo com as fibras musculares e cuja atividade está correlacionada com o comprimento e a velocidade de estiramento do músculo. Seus sinais de saída são conduzidos pelos aferentes Ia e II até o corno dorsal da medula espinhal, onde estabelecem conexões com outros neurônios. O MS é normalmente constituído por três tipos de fibras musculares especializadas (bag1, bag2 e chain), as quais conferem a este sensor uma grande complexidade e habilidade em fornecer informação sensorial sob uma ampla gama de estados. O ganho deste sensor pode ser ajustado pela atividade de MNs gama $\left(\gamma_{\mathrm{s}}\right.$ e $\left.\gamma_{\mathrm{d}}\right)$ e as suas respostas aferentes (Ia e II) são consequência do estiramento das fibras intrafusais, o qual está diretamente associado com o estiramento das fibras musculares extrafusais em paralelo.

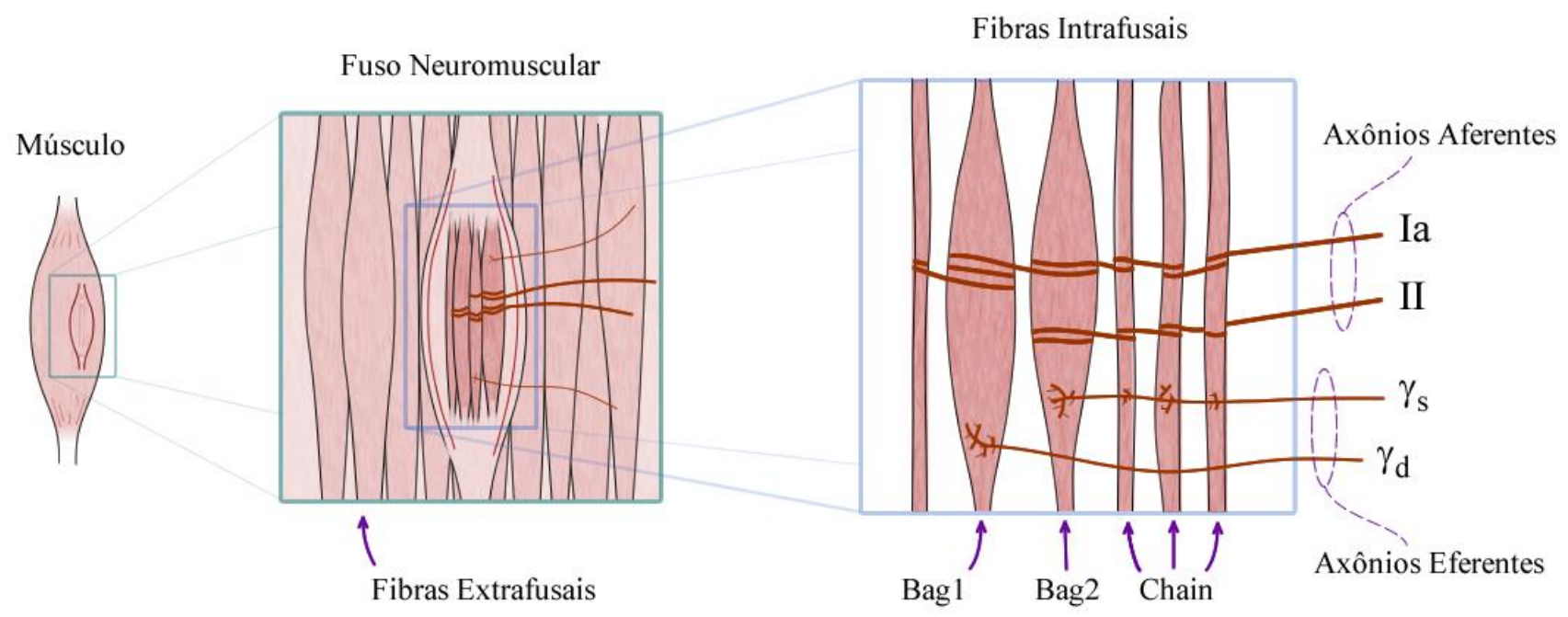

Figura 1-8 - Ilustração do fuso neuromuscular, evidenciando suas fibras musculares intrafusais, suas eferências motoras e suas aferências sensoriais. 
O órgão tendinoso de Golgi (GTO) representa outro sensor neuromuscular, este, porém, localizado entre filamentos tendinosos, ou seja, em série com as fibras musculares e cuja atividade está correlacionada com a tensão à qual tais fibras estão submetidas. Seu sinal de saída é conduzido pelo neurônio Ib até o corno dorsal da medula espinhal, onde estabelece conexões com INs medulares.

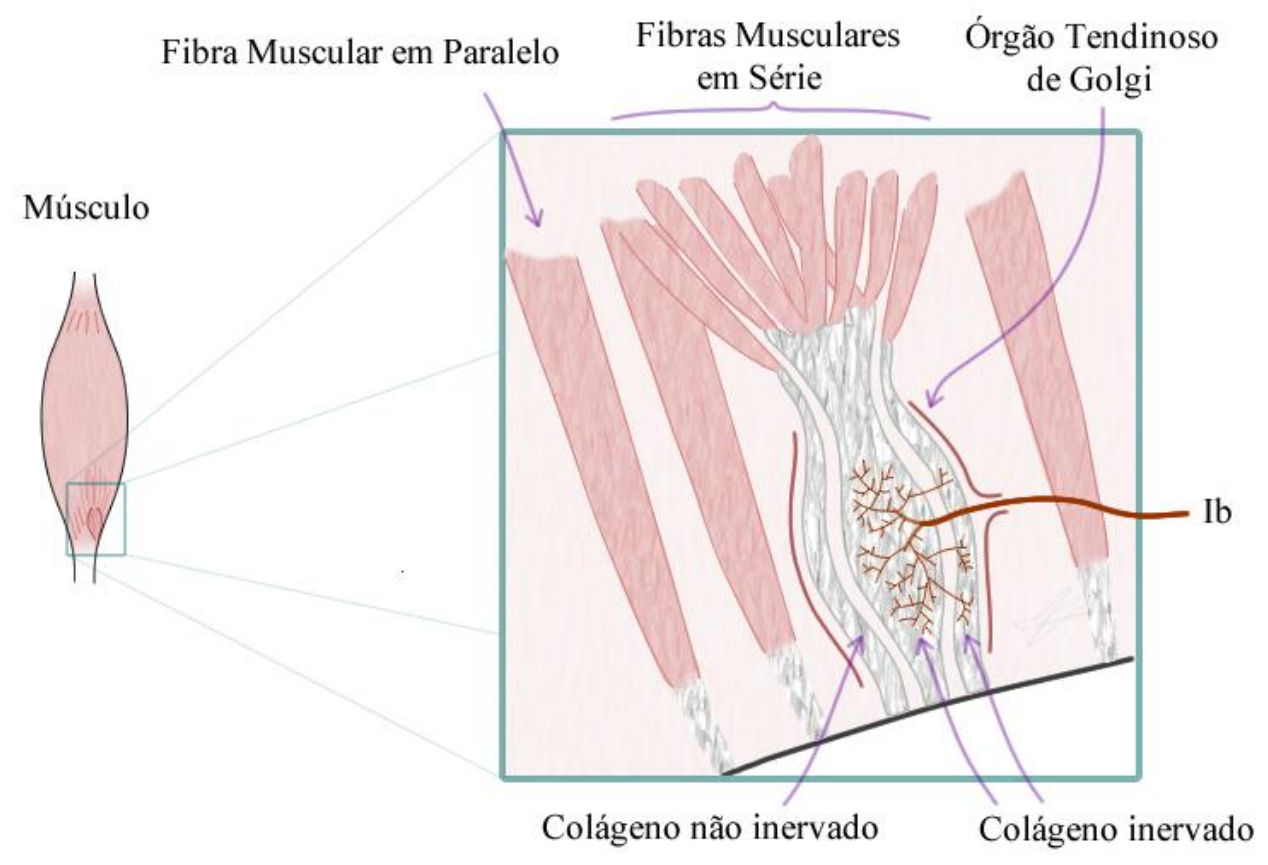

Figura 1-9 - Ilustração do órgão tendinoso de Golgi, evidenciando seus elementos constitutivos.

A excitação dos aferentes sensoriais Ib é causada pela deformação das fibras de colágeno, resultante da deformação das fibras musculares associadas (Figura 1-9). Desta forma, o GTO realiza uma amostragem da tensão presente em um determinado músculo. 


\subsubsection{Simulador ReMoto}

Um projeto recentemente desenvolvido no Laboratório de Engenharia Biomédica da Universidade de São Paulo (LEB USP) teve como objetivo desenvolver um ambiente de simulação de acesso livre para estudar as redes neuronais medulares e os músculos da perna por elas inervados (CISI; KOHN, 2008). Este simulador (chamado ReMoto) está em constante desenvolvimento e sua intenção é atingir um grande público por meio de seu fácil acesso e interface gráfica amigável. Ele foi desenvolvido como uma aplicação web e pode ser usado em qualquer navegador de internet (browser) disponível nos diferentes sistemas operacionais, incluindo dispositivos móveis.

O ReMoto permite se estudar diferentes níveis de organização do sistema neuromuscular, partindo dos canais iônicos neuronais até o controle da força muscular. Esta ligação entre os níveis elementares e mais complexos de comportamento muscular incluem dinâmicas de canais iônicos, sinapses, neurônios, conjunto de neurônios, condução nervosa, conjunto de fibras musculares e músculos, que integrados formam o sistema neuromuscular. Tal simulador multiescala é baseado na descrição matemática dos componentes individuais e suas interações, resultando em força muscular e EMG em um nível macroscópico. Uma característica adicional é a possibilidade de se simular a estimulação dos nervos, como feito em neurofisiologia clínica, para analisar as respostas nervosa e muscular, reflexos $\mathrm{H}$ e inibições recíproca e recorrente na medula espinhal (PIERROT-DESEILLIGNY; BURKE, 2005).

Nesta seção, a estrutura geral do ReMoto será brevemente apresentada focando nas suas características e apontando suas potenciais aplicações em simulação multiescala do sistema neuromuscular. A primeira fase de desenvolvimento do simulador foi focada na modelagem matemática de cada elemento com base em dados biofísicos e fisiológicos. Recentemente, um forte esforço conjunto entre o autor do presente trabalho e o bolsista de doutorado Leonardo A. Elias foi feito para melhorar a interface com o usuário, que era um grande gargalo na versão original (ver Capítulo 2).

Uma completa descrição do simulador pode ser encontrada no trabalho que descreve sua primeira versão (CISI; KOHN, 2008). Brevemente, o simulador tem uma modelagem detalhada de quatro núcleos motores que comandam os músculos responsáveis pela extensão (sóleo - SOL, gastrocnêmio medial - GM e gastrocnêmio lateral - GL) e flexão (tibial anterior - TA) do tornozelo. Cada núcleo tem um conjunto de MNs e interneurônios (INs) 
espinhais que medeiam inibição recorrente (células de Renshaw - RC), inibição recíproca (INs inibitórios Ia que recebem entradas dos músculos antagonistas) e inibição Ib. Os aferentes Ia e Ib estão presentes no ReMoto para possibilitar estudos de reflexos medulares (e.g., reflexo H) gerado pela estimulação elétrica aplicada aos nervos (nervo tibial - PTN, para o SOL, GM e GL; nervo fibular - CPN, para o TA). A quantidade de neurônios espinhais e axônios aferentes foram baseados em estimativas da literatura experimental para humanos e gatos. O conjunto de MNs comanda as unidades musculares, que geram tanto atividade elétrica (MUAPs) quanto mecânica (abalos, ou twitches, musculares). Cada músculo tem como saída o EMG, calculado como a soma de todos os MUAPs que ocorrem aleatoriamente no tempo, e a força, que é calculada como a soma de todos os twitches. A Figura 1-10 mostra um exemplo da estrutura da rede para dois núcleos motores (SOL e TA) e as vias que medeiam a excitação monossináptica Ia, inibição Ib, inibição recorrente e recíproca.

Cada modelo de MNs de diferentes tipos (i.e., tipos S, FR e FF) é representado por dois compartimentos cilíndricos representando o soma e a árvore dendrítica. O compartimento somático possui canais de $\mathrm{Na}^{+}$e rápido de $\mathrm{K}^{+}$, responsáveis pela gênese do potencial de ação, e um canal lento de $\mathrm{K}^{+}$que gera a AHP. O compartimento dendrítico é modelado como uma estrutura passiva contendo condutâncias sinápticas excitatórias e inibitórias. Os INs são modelados como um único compartimento contendo os mesmos canais iônicos presentes no soma dos MNs. O comportamento dinâmico de cada canal iônico é uma simplificação do formalismo proposto em (HODGKIN; HUXLEY, 1952) que foi usado no sentido de diminuir a complexidade computacional do sistema e acelerar as simulações (DESTEXHE, 1997). Os valores de parâmetros foram escolhidos para que os modelos individuais de neurônios apresentassem comportamentos similares aos apresentados pelas mesmas células de gatos (e.g., ganho da relação f-I). Esses neurônios recebem contatos sinápticos que foram modelados segundo um modelo cinético (DESTEXHE; MAINEN; SEJNOWSKI, 1994) cuja amplitude dos potenciais pós-sinápticos pode aumentar ou diminuir após ativações repetitivas, representando a facilitação e a depressão sináptica, respectivamente. Após o disparo de um AP no MN, há um atraso dependente da velocidade de condução axonal (que tem uma distribuição aleatória ao longo da população) até o mesmo atingir a placa motora. De forma similar, há um atraso de transmissão sináptica dos comandos descendentes e das fibras aferentes para os neurônios espinhais. 


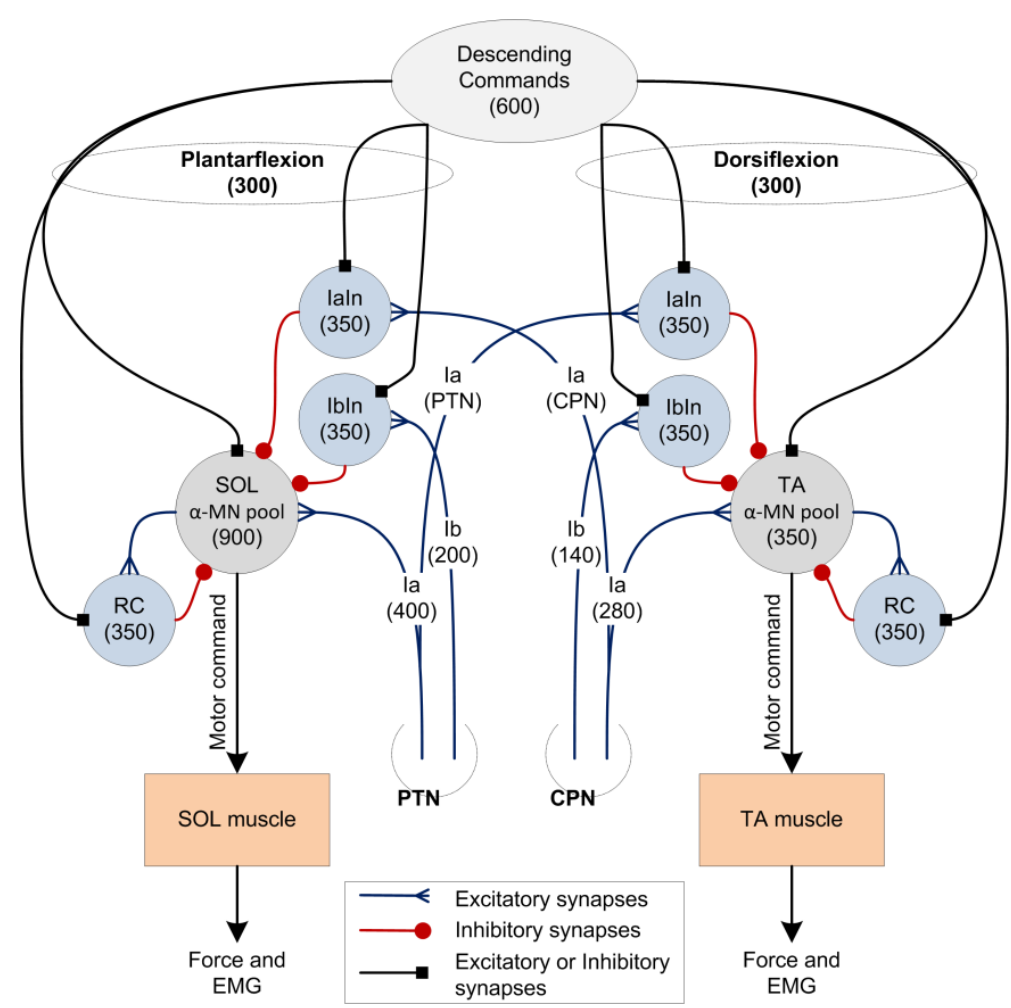

Figura 1-10. Diagrama esquemático do simulador (ELIAS et al., 2011). Esta figura mostra somente dois dos quatro núcleos motores, um para o m. sóleo (SOL) e o outro para o m. tibial anterior (TA). Os comandos descendentes, responsáveis pela extensão e flexão do tornozelo, ativam a população de MNs e neurônios espinhais: células de Renshaw (RC), interneurônios inibitórios Ia (IaIn) e interneurônios inibitórios Ib (IbIn). Valores entre parêntesis mostram o número padrão de cada elemento da rede. Aferentes Ia e Ib vêm dos nervos tibial (PTN) e fibular (CPN), que podem ser eletricamente estimulados separadamente.

Os MUAPs são modelados por funções de Hermite-Rodriguez (LO CONTE; MERLETTI; SANDRI, 1994), que somados geram o EMG. Um filtro passa-faixa e ruído branco são aplicados ao sinal para reproduzir no simulador o que ocorre na aquisição de um EMG real. Já o twitch é modelado como a resposta impulsiva de um sistema criticamente amortecido (FUGLEVAND; WINTER A.; PATLA, 1993).

Dois nervos que suprem o tríceps sural (TS), constituído por SOL, GM e GL, e o TA, podem ser eletricamente estimulados (breves pulsos de corrente), como é frequentemente feito em neurofisiologia clínica, para se obter ondas $\mathrm{M}$ e reflexos $\mathrm{H}$, que são úteis para se estudar a medula espinhal humana de forma não invasiva, tanto em indivíduos sãos quanto em patologias (Pierrot-Deseilligny and Burke 2005). Exemplos de aplicação derivados das ondas M e reflexos $\mathrm{H}$ são os estudos sobre a mudança da excitabilidade dos MNs, depressão sináptica e inibição recíproca que ocorrem em diferentes desordens neurológicas (Elbasiouny, Moroz et al. 2010). As propriedades dos MNs e a depressão sináptica podem ser alteradas no ReMoto simplesmente mudando os valores dos parâmetros que aparecem em cada página web relacionada ao modelo em questão. A técnica de se estimar o nível de inibição recíproca 
(como feito de forma não invasiva em humanos) é possível de ser replicada no simulador, por exemplo: um reflexo H no m. SOL é gerado pela estimulação do nervo PTN, porém, este é condicionado por um estímulo elétrico quase síncrono (pequeno atraso em relação ao estímulo do PTN) aplicado no nervo CPN, que excita os interneurônios inibitórios que, por sua vez, inibem os MNs do SOL (e.g., veja (Pierrot-Deseilligny and Burke 2005)). O nível de inibição recíproca é dado pela relação entre as amplitudes dos reflexos $\mathrm{H}$ condicionados e os não condicionados, ou seja, aqueles obtidos sem o estímulo no CPN.

Além do exposto acima, é possível se estimular intracelularmente os neurônios espinhais com diferentes formas de onda (degrau, rampa, pulso, senóides e sinais aleatórios) com o intuito de se estudar o comportamento dinâmico individual de cada célula. Por fim, a população de MNs pode ser ativada por comandos descendentes cujos trens de disparo de potenciais de ação são modelados como processos pontuais estocásticos, cujas intensidades podem ser moduladas para gerar um dado comportamento motor dinâmico (e.g., mimetizando ativações cíclicas compatíveis com locomoção). 


\subsection{Objetivos}

Este trabalho possui escopo bastante amplo, mas pode ter seus objetivos divididos em três linhas gerais:

- Estudo e desenvolvimento (aperfeiçoamento e expansões) do simulador ReMoto (CISI; KOHN, 2008). Esta linha do objetivo é descrita no Capítulo 2.

- Estudo do sistema neuromuscular por meio de simulações e modelos matemáticos (Capítulo 3, Capítulo 4 e Capítulo 5).

- Estudo por simulação de fatores ligados ao envelhecimento do sistema neuromuscular (Capítulo 5).

O primeiro objetivo consiste no entendimento dos aspectos tanto neurofisiológicos envolvidos no ReMoto, quanto das ferramentas computacionais utilizadas para o seu desenvolvimento. Os aspectos neurofisiológicos estão sumarizados na seção 1.1.1 e descritos em (CISI; KOHN, 2008). Já as ferramentas computacionais incluem: linguagem de programação $\mathrm{Java}^{\mathrm{TM}}$ (Oracle); ambiente de desenvolvimento Eclipse, servidor Apache Tomcat, banco de dados Hyper-SQL, framework Struts e JFreeChart para a geração de gráficos. Estes estudos estão descritos no Capítulo 2.

O estudo do sistema neuromuscular por modelagem matemática envolve muitos aspectos, mas no presente trabalho, pretende-se abordar os tópicos mostrados na Tabela 1-1.

Por fim, pretende-se avaliar como alguns, dos aspectos envolvidos com o envelhecimento do sistema neuromuscular, podem influenciar na geração e na variabilidade da força. Exemplos de parâmetros ou características a serem tratados incluem: número de MNs, número de neurônios que fazem sinapses com os MNs, alteração do limiar e da faixa de recrutamento dos MNs, variabilidade dos ISIs e das frequências de disparos dos MNs, sempre que possível comparando com dados experimentais. Estes estudos estão descritos no Capítulo 5. 
Tabela 1-1. Objetivos associados ao estudo do sistema neuromuscular por modelagem matemática.

\begin{tabular}{|c|c|}
\hline Tópico de estudo & Capítulo que descreve o estudo \\
\hline $\begin{array}{l}\text { Integração do modelo de fuso neuromuscular } \\
\text { (MILEUSNIC et al., 2006) com o modelo de (CISI; } \\
\text { KOHN, 2008) para proporcionar a realimentação pelo } \\
\text { aferente Ia. }\end{array}$ & \multirow{5}{*}{ Capítulo 3: Reflexos de estiramento } \\
\hline $\begin{array}{l}\text { Simulações envolvendo os músculos do tornozelo e } \\
\text { utilizando o ReMoto. }\end{array}$ & \\
\hline Simulação do reflexo de estiramento. & \\
\hline $\begin{array}{l}\text { Estudo da influência das propriedades do músculo e do } \\
\text { tendão (e.g., grau de rigidez) sobre a realimentação Ia e } \\
\text { o reflexo de estiramento. }\end{array}$ & \\
\hline $\begin{array}{l}\text { Efeito da atividade fusimotora sobre o reflexo de } \\
\text { estiramento. }\end{array}$ & \\
\hline Desenvolvimento de um modelo de motoneurônio. & \multirow[b]{2}{*}{$\begin{array}{l}\text { Capítulo 4: Modelo de pool de } \\
\text { motoneurônios }\end{array}$} \\
\hline $\begin{array}{l}\text { Desenvolvimento de um modelo de pool de MNs com } \\
\text { uma representação adequada das diferentes } \\
\text { características anatômicas e fisiológicas entre os } \\
\text { diferentes MNs. }\end{array}$ & \\
\hline $\begin{array}{l}\text { Representação da atividade neuronal por processos } \\
\text { pontuais. }\end{array}$ & \multirow{4}{*}{$\begin{array}{l}\text { Capítulo 5: Geração de forças } \\
\text { isométricas em jovens e idosos }\end{array}$} \\
\hline $\begin{array}{l}\text { Desenvolvimento de um modelo de geração de força em } \\
\text { contrações isométricas. }\end{array}$ & \\
\hline $\begin{array}{l}\text { Avaliar a influência da organização do pool de MNs } \\
\text { sobre a força gerada por um músculo. Por exemplo, } \\
\text { verificar sob quais condições ocorre ou não um } \\
\text { recrutamento do tipo onion-skin (DE LUCA; } \\
\text { HOSTAGE, 2010). }\end{array}$ & \\
\hline $\begin{array}{l}\text { Simulações envolvendo variabilidade de força durante } \\
\text { contrações isométricas. }\end{array}$ & \\
\hline
\end{tabular}


Capítulo 2 Expansão do simulador ReMoto 
uito foi feito para o entendimento e melhoria do simulador ReMoto. Um dos gargalos na utilização do simulador era sua interface complexa e pouco amigável. Então, numa etapa inicial, foi feita uma reformulação completa da interface do simulador através da criação de novas páginas (JSPs) e de rotinas em Java para a manipulação dos dados. Esta etapa de reformulação da interface do ReMoto foi acompanhada de um ganho progressivo de conhecimento da intrincada estrutura do simulador, ou seja, como os modelos são implementados e interligados, além dos códigos necessários para comunicação com banco de dados e comunicação dos Servlets (tecnologia Java para requisição e resposta de conteúdo web).

\subsection{Desenvolvimento de uma nova interface}

A Figura 2-1 ilustra uma página da nova versão do ReMoto para a seleção de um cenário de simulação. Sendo selecionado um cenário, os parâmetros do modelo são automaticamente ajustados para representar tal situação.

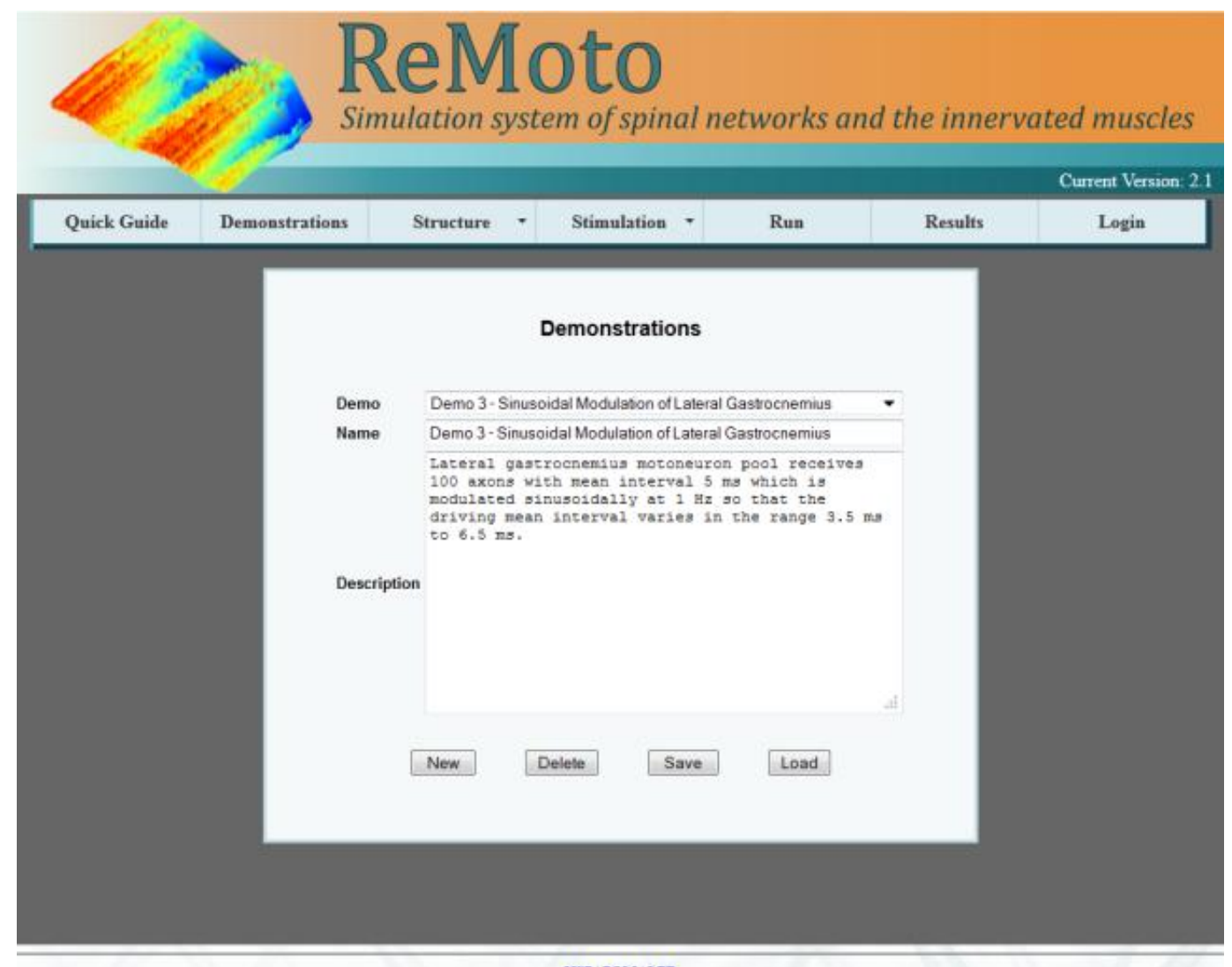

USP | ROLI III

Cogyrighe 22011 Byomedical Eagineering Laboratory. All nighta reserved

Figura 2-1 - Exemplo de página para a seleção de um cenário de demonstração no ReMoto. 
Na Figura 2-2 é mostrado como pode ser feita, nesta nova versão, a configuração dos tratos descendentes. Gráficos auxiliares mostram para o usuário o perfil da distribuição estatística escolhida para os ISIs e a modulação da intensidade do processo pontual.

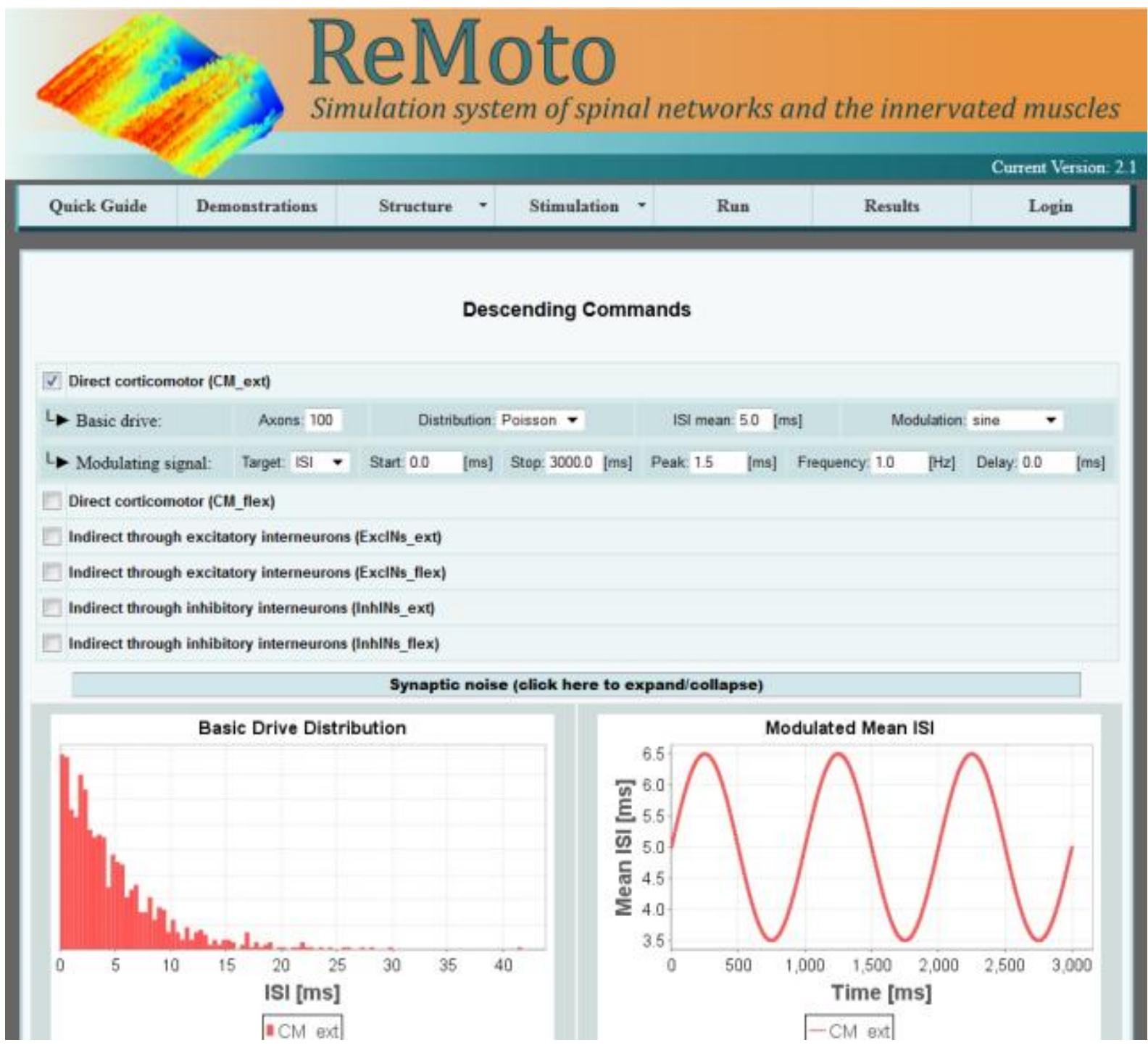

Figura 2-2 - Exemplo de página para a escolha de modelo, parametrização e modulação das vias descendentes no ReMoto. 
Como o ReMoto trata de uma complexa integração entre modelos e uma grande quantidade de parâmetros, a visualização destes parâmetros como ilustra a Figura 2-3 torna-se essencial para a compreensão do cenário empregado na simulação em sua totalidade. Neste exemplo é mostrada a distribuição espacial dos diferentes tipos de MUs na seção transversal do músculo. Este tipo de visualização automática dos parâmetros não era possível na versão original do ReMoto.

A

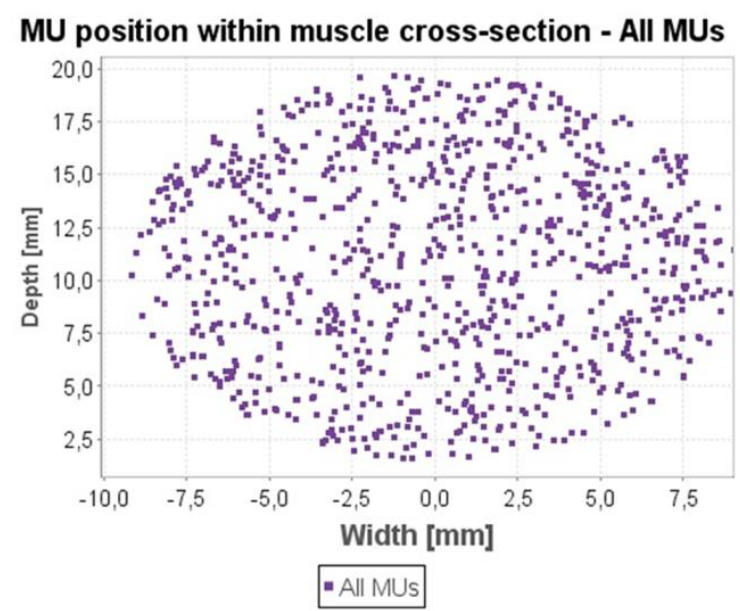

C

MU position within muscle cross-section - All MUs

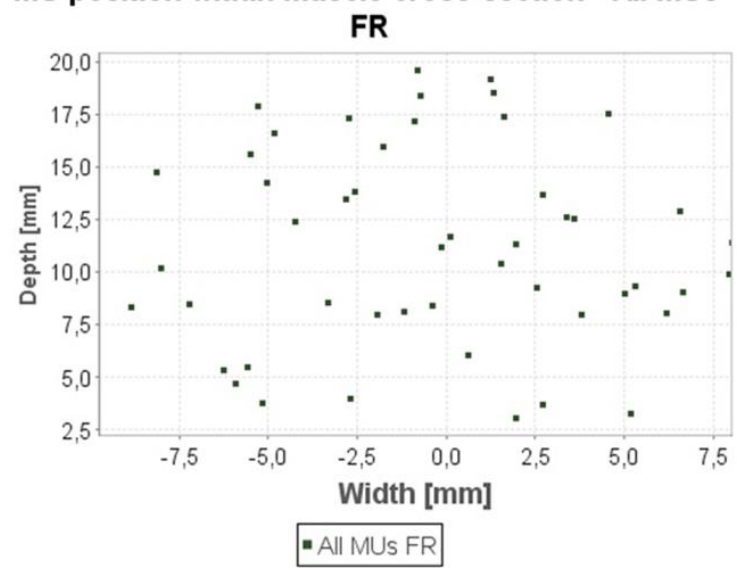

B

MU position within muscle cross-section - All MUs S

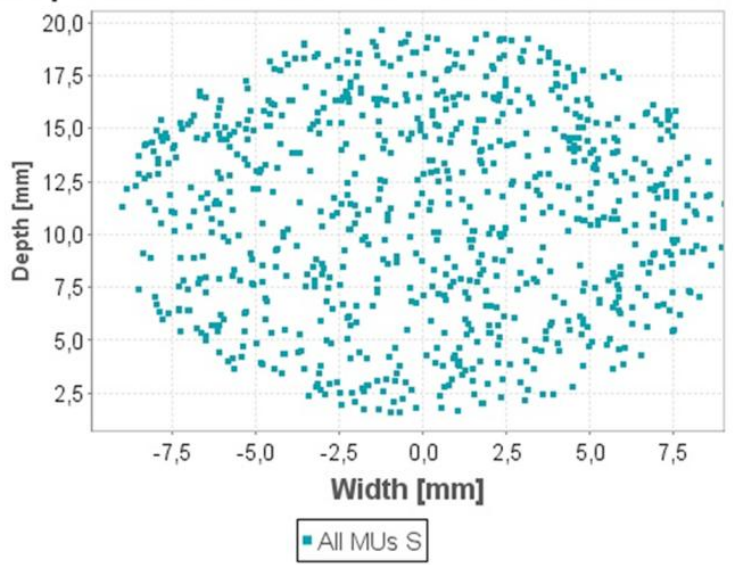

D

MU position within muscle cross-section - All MUs

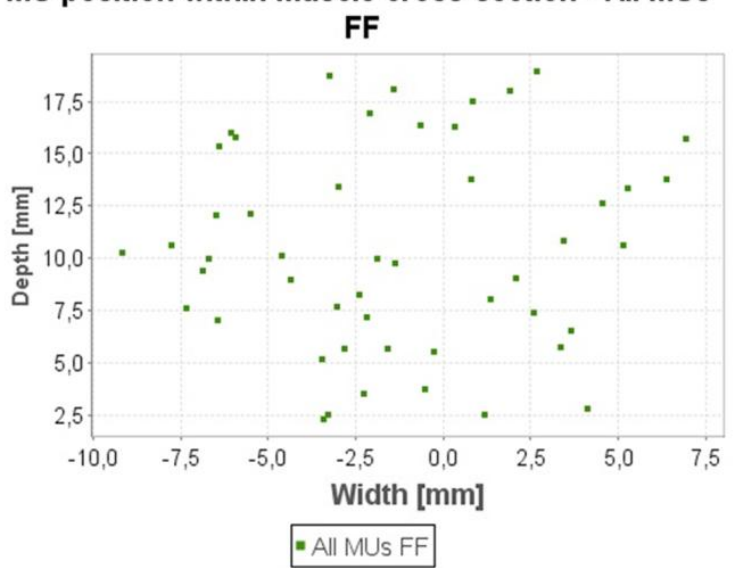

Figura 2-3 - Exemplo de gráficos criados para proporcionar a visualização de parâmetros estruturais no ReMoto. Distribuição espacial dos diferentes tipos de MUs na seção transversal do músculo, considerando todos os tipos de MUs (A), apenas MUs tipo S (B), apenas MUs tipo FR (C) e apenas MUs tipo FF (D). 
A fim de facilitar o acompanhamento do progresso da simulação sendo realizada foi implementada uma interface, utilizando tecnologia Applet, para mostrar dinamicamente ao usuário a porcentagem de conclusão da simulação (Figura 2-4). Quando a simulação é encerrada, o usuário é redirecionado automaticamente para a página de resultados.

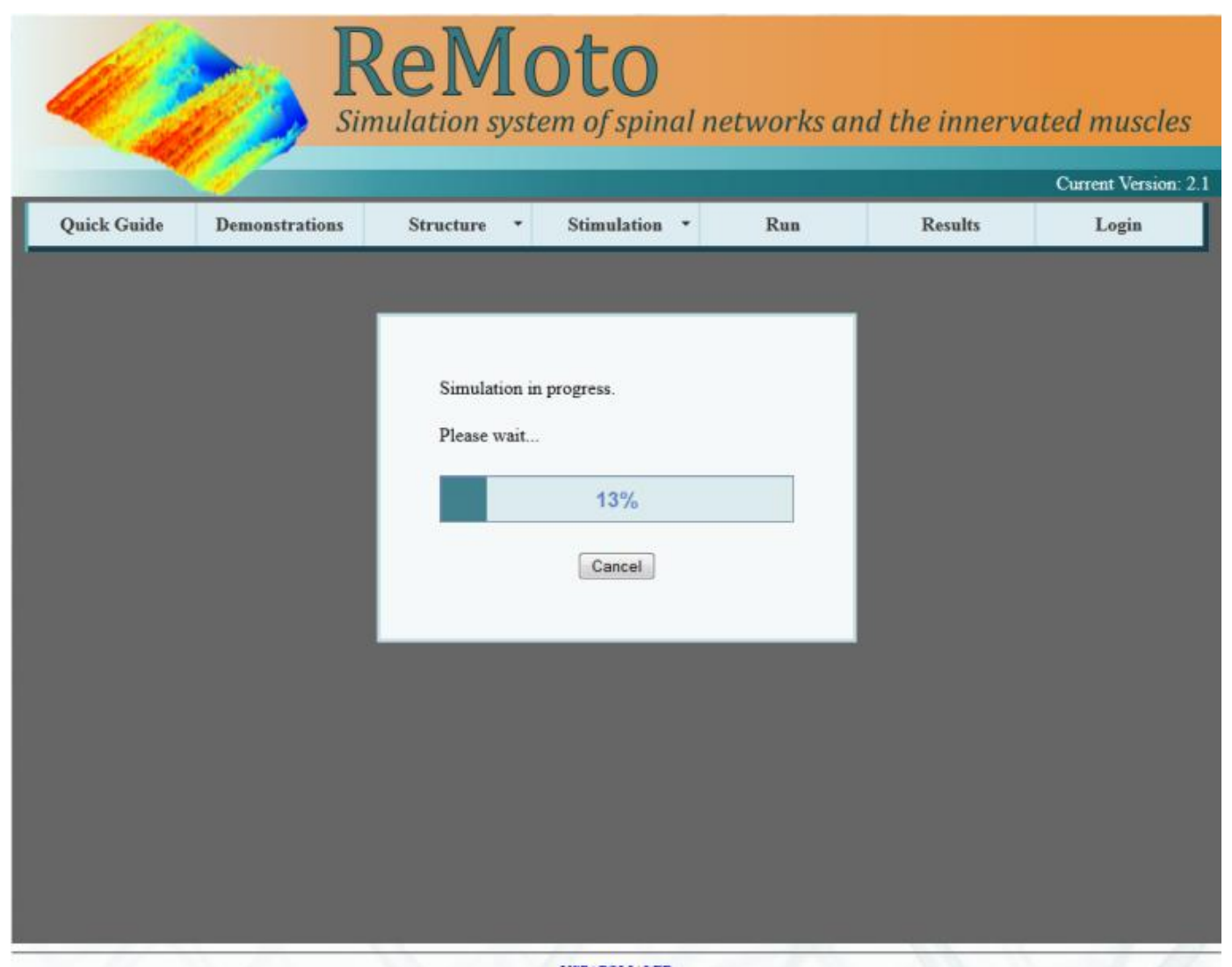

USP I POLI ILE

Copyright $\odot 2011$ Biomedical Engineering Laboratory. All rights reserved.

Figura 2-4 - Página criada no ReMoto para a exibição instantânea do progresso da simulação. 
A Figura 2-5 mostra a nova interface para a visualização dos resultados simulados no ReMoto. O usuário pode selecionar, de forma hierárquica, a grandeza que pretende visualizar e clicar em "Refresh" para ver o gráfico, em "Generate in new window” para que o gráfico seja mostrado numa outra página, em "View as interactive graphic" para visualizar um gráfico interativo no qual pode, por exemplo, dar zoom, e em "Export Data" para visualizar os dados em um arquivo de texto, possibilitando um futuro processamento dos dados.

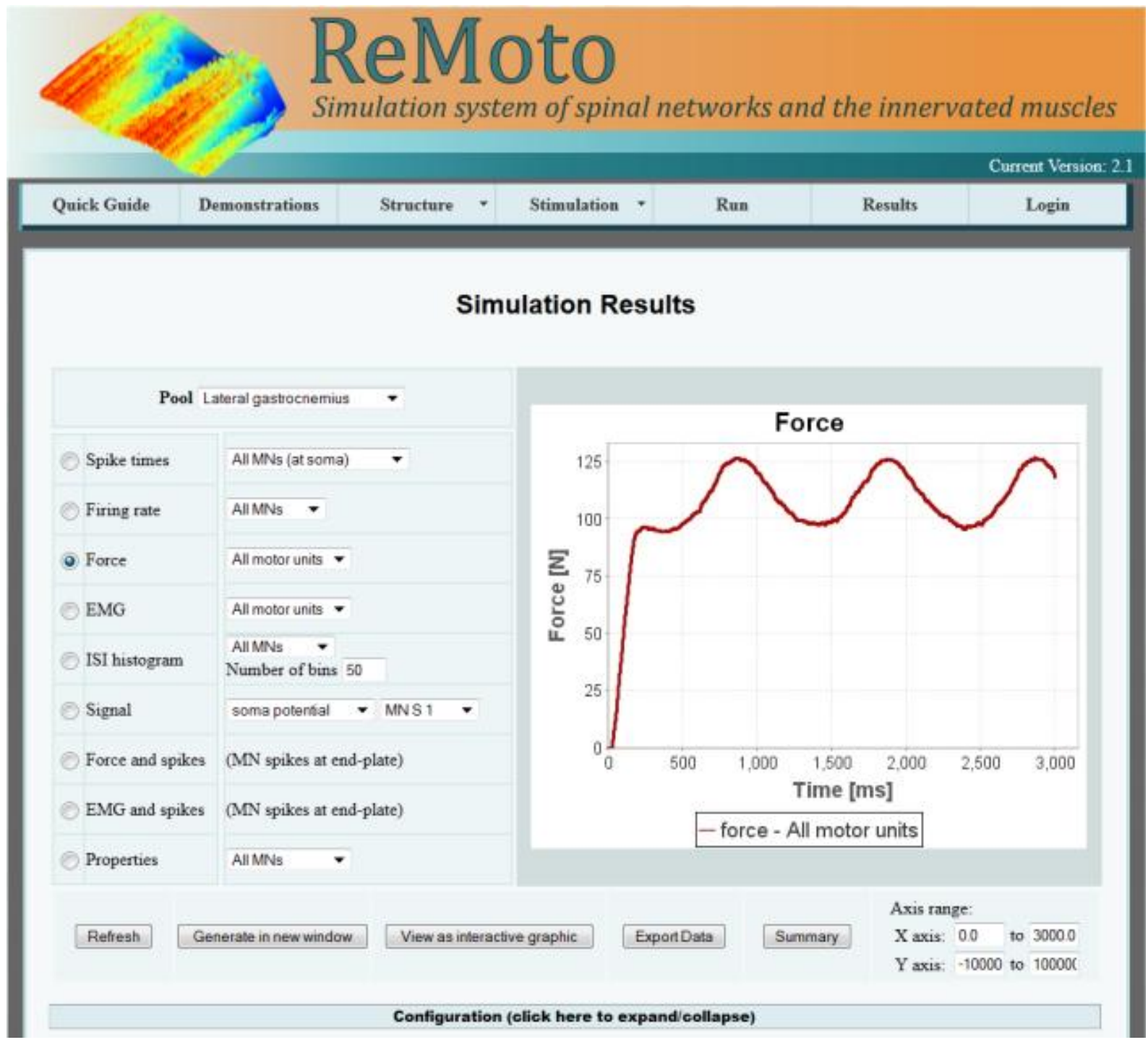

Figura 2-5 - Página da nova interface do ReMoto para a visualização de resultados de simulação. 


\subsection{Implementação de ferramentas para análise}

Foram implementadas novas interfaces (Figura 2-6) e rotinas para a análise dos resultados no próprio ReMoto, como: determinação do valor máximo, mínimo e médio de um sinal; cálculo da variância, desvio padrão e coeficiente de variação; e transformada de Fourier por FFT. Estas rotinas, porém, estão em uma nova versão do ReMoto que ainda não foi disponibilizada ao público.

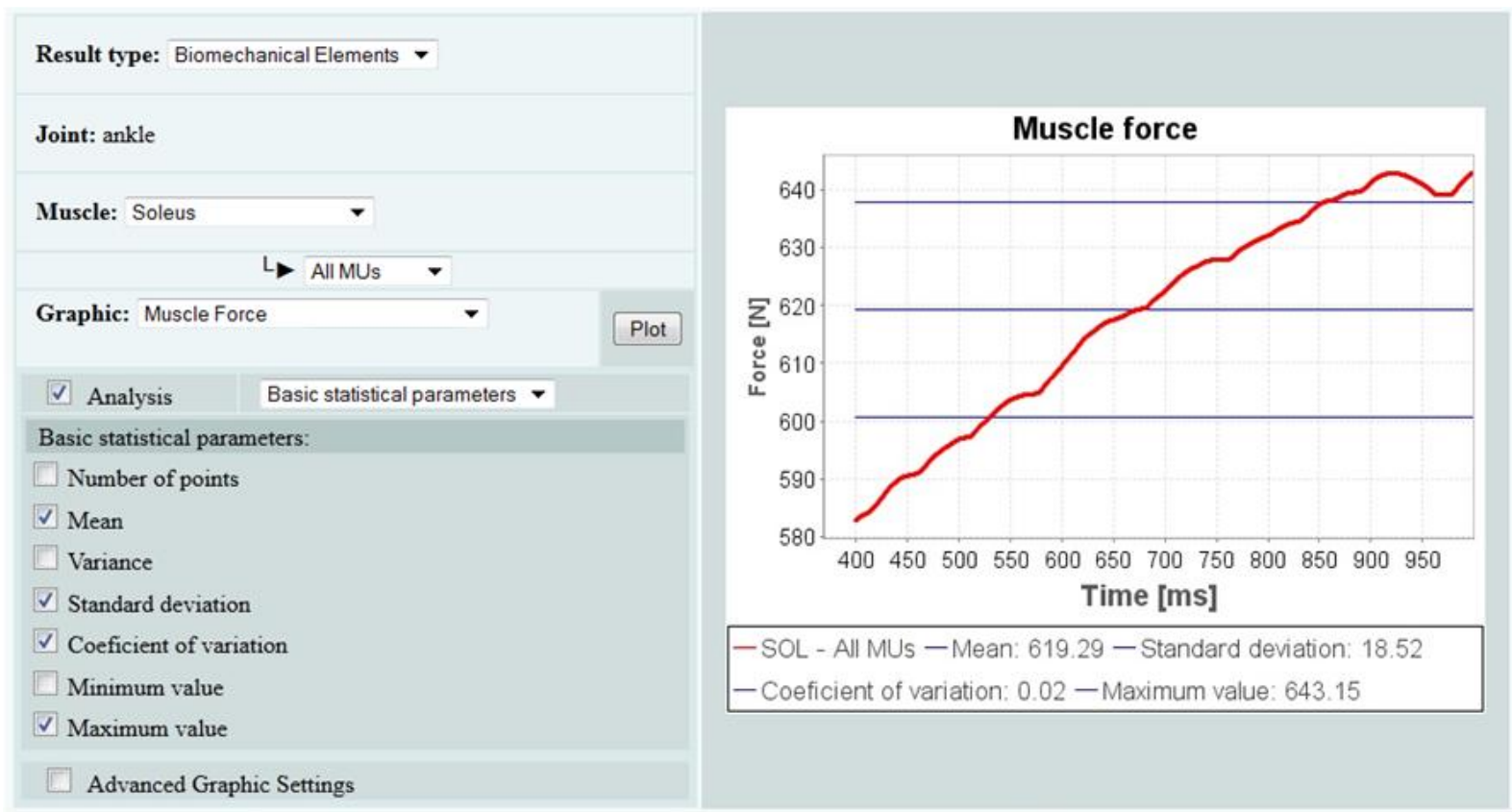

Figura 2-6 - Exemplo de página do ReMoto para análise de resultados.

\subsection{Reparametrização}

Foram feitos vários ajustes de parâmetros e extensões do simulador pela inclusão se novos modelos. Alguns destes ajustes são listados a seguir:

- Limiares do compartimento somático dos MNs

- Aleatorização dos limiares de recrutamento dos axônios dos MNs

- Amplitudes dos abalos foram modificadas para representar a gama de 100 vezes encontrada experimentalmente

- Tempos de contração, os quais possuem correlação com as amplitudes de abalos.

- Amplitude dos MUAPs para se manterem proporcionais às amplitudes dos abalos

- Velocidades de condução axonal de MNs e fibras aferentes 
A Figura 2-7 ilustra a criação de diferentes formas de parametrização do limiar de recrutamento dos MNs por estimulação elétrica do nervo. Isto foi feito, pois a forma pela qual estes limiares se distribuem entre a população de MNs ainda é tema de debate (BERGQUIST; CLAIR; COLLINS, 2011). O perfil de recrutamento originalmente presente no ReMoto está mostrado na Figura 2-7B e está de acordo com os dados experimentais em que se estimulava os axônios de gatos diretamente com os eletrodos (Figura 2-7A). Porém, estudos recentes (BERGQUIST; CLAIR; COLLINS, 2011) defendem que, quando a estimulação é transcutânea, a ordem de recrutamento é aleatória.

A

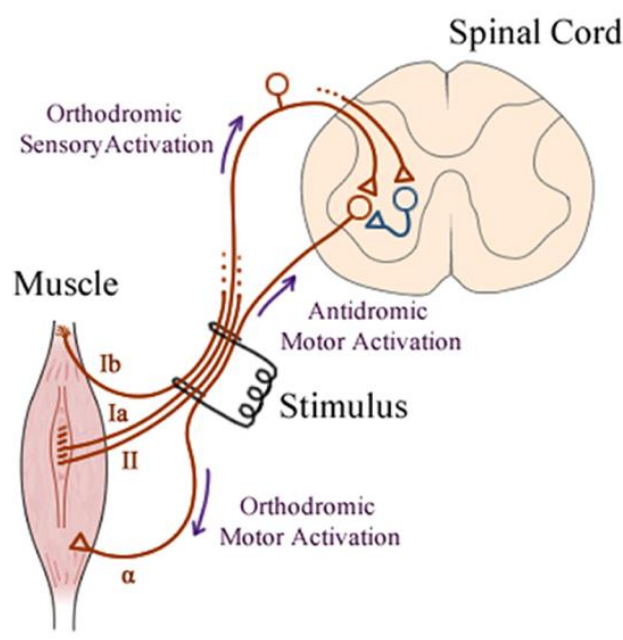

C

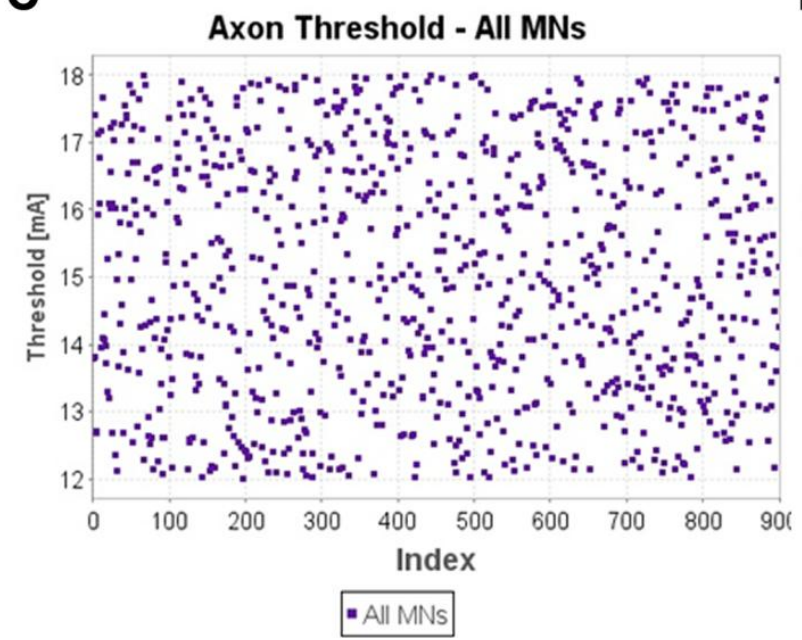

B

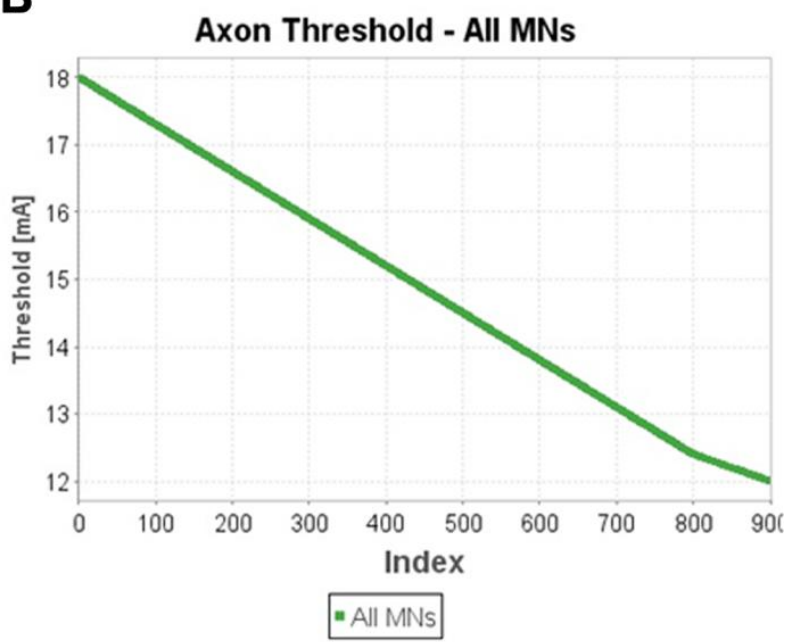

D

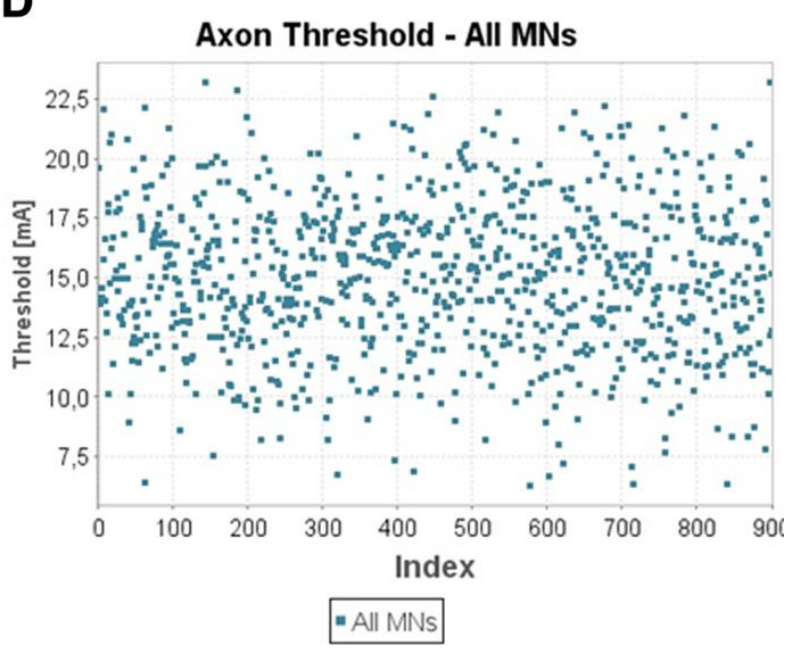

Figura 2-7 - Visualização da distribuição dos limiares de recrutamento dos MNs por estimulação elétrica do nervo. A) Ilustração das vias aferentes e eferentes ativadas pela estimulação do nervo. B) Distribuição do limiar de recrutamento empregada originalmente no ReMoto (ordem inversa de recrutamento). C) Distribuição aleatória uniforme. D) Distribuição aleatória Gaussiana. 
A fim de avaliar o efeito de diferentes tipos de recrutamento (Figura 2-7) foi feito o levantamento de "curvas de recrutamento", em que se mede a amplitude da onda M e do reflexo $\mathrm{H}$ resultantes da estimulação elétrica transcutânea. A Figura 2-8 mostra uma comparação entre as curvas de recrutamento obtidas. Em Figura 2-8a é mostrada uma curva típica obtida experimentalmente (FLOETER; KOHN, 1997). A Figura 2-8b mostra a curva obtida com a parametrização original do ReMoto. A Figura 2-8c mostra a curva obtida após os limiares de recrutamento do compartimento somático dos MNs terem sido ajustados para melhor corresponder com dados experimentais. A Figura 2-8d mostra a curva obtida com uma distribuição aleatória uniforme dos limiares de recrutamento por estimulação elétrica. Como pode ser notado a relação entre a máxima amplitude do reflexo $\mathrm{H}$ e a máxima amplitude da onda $\mathrm{M}$ se aproxima mais da média experimental (Figura 2-8a) quando se utiliza um padrão aleatório de recrutamento (Figura 2-8d).

A

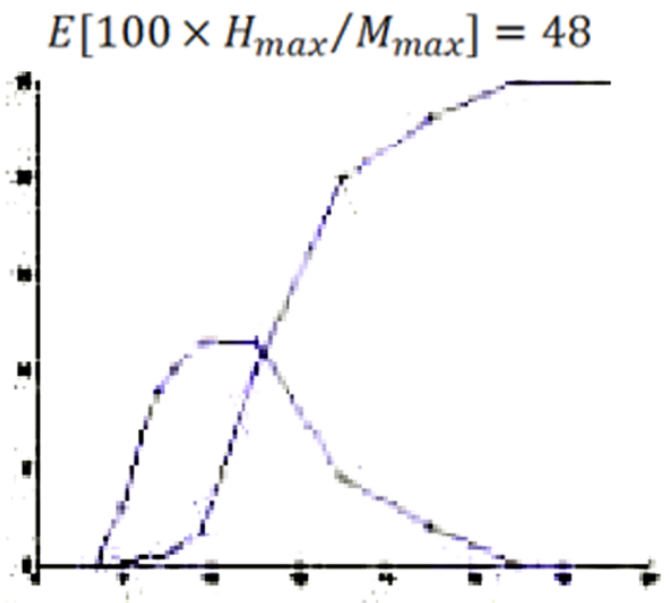

C

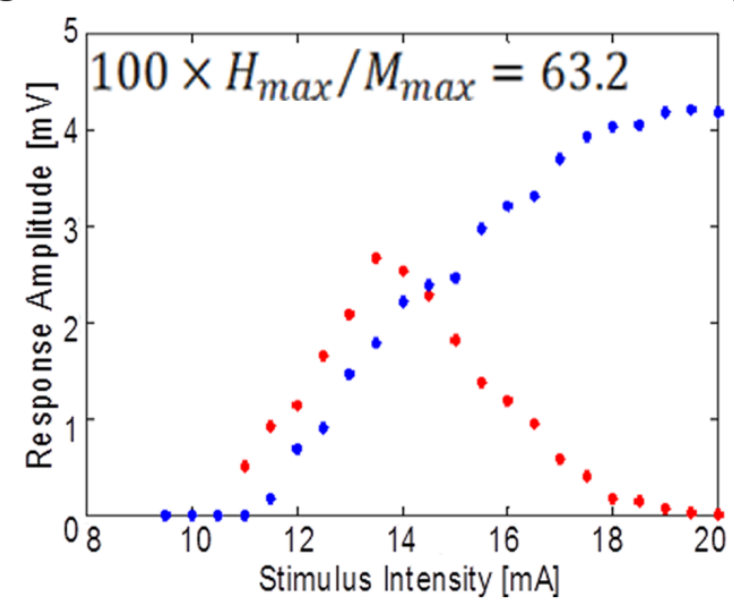

B

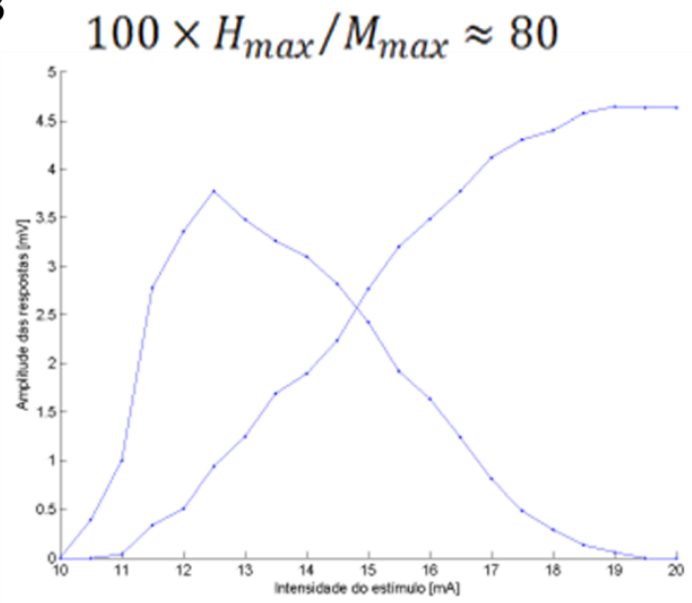

D

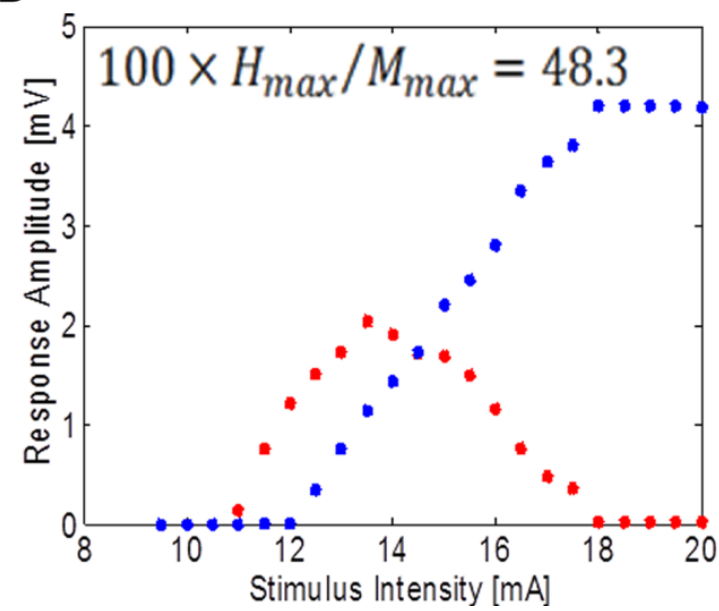

Figura 2-8 - Curvas de recrutamento. a) Exemplo de curva de recrutamento obtida experimentalmente (FLOETER; KOHN, 1997). b) Curva de recrutamento obtida com a parametrização original do ReMoto. c) Curva de recrutamento obtida pelo ajuste dos limiares somáticos dos MNs para disparo de PAs. d) Curva de recrutamento obtida utilizando uma distribuição aleatória uniforme dos limiares de recrutamento por estimulação elétrica. 


\subsection{Implementação e integração do modelo de fuso neuromuscular}

O modelo matemático de MS descrito nesta seção foi codificado em linguagem de programação Java ${ }^{\mathrm{TM}}$ e integrado na estrutura do simulador neuromuscular ReMoto. A Figura 2-9 mostra o diagrama UML (Unified Modeling Language) associado aos proprioceptores musculares e a relação dos mesmos com os demais elementos do simulador. Para a integração das equações diferenciais ordinárias associadas aos modelos foi utilizado o método de RungeKutta de quarta ordem com passo de integração (T) fixo. Resultados envolvendo este modelo estão presentes no trabalho descrito no Capítulo 3 deste documento.

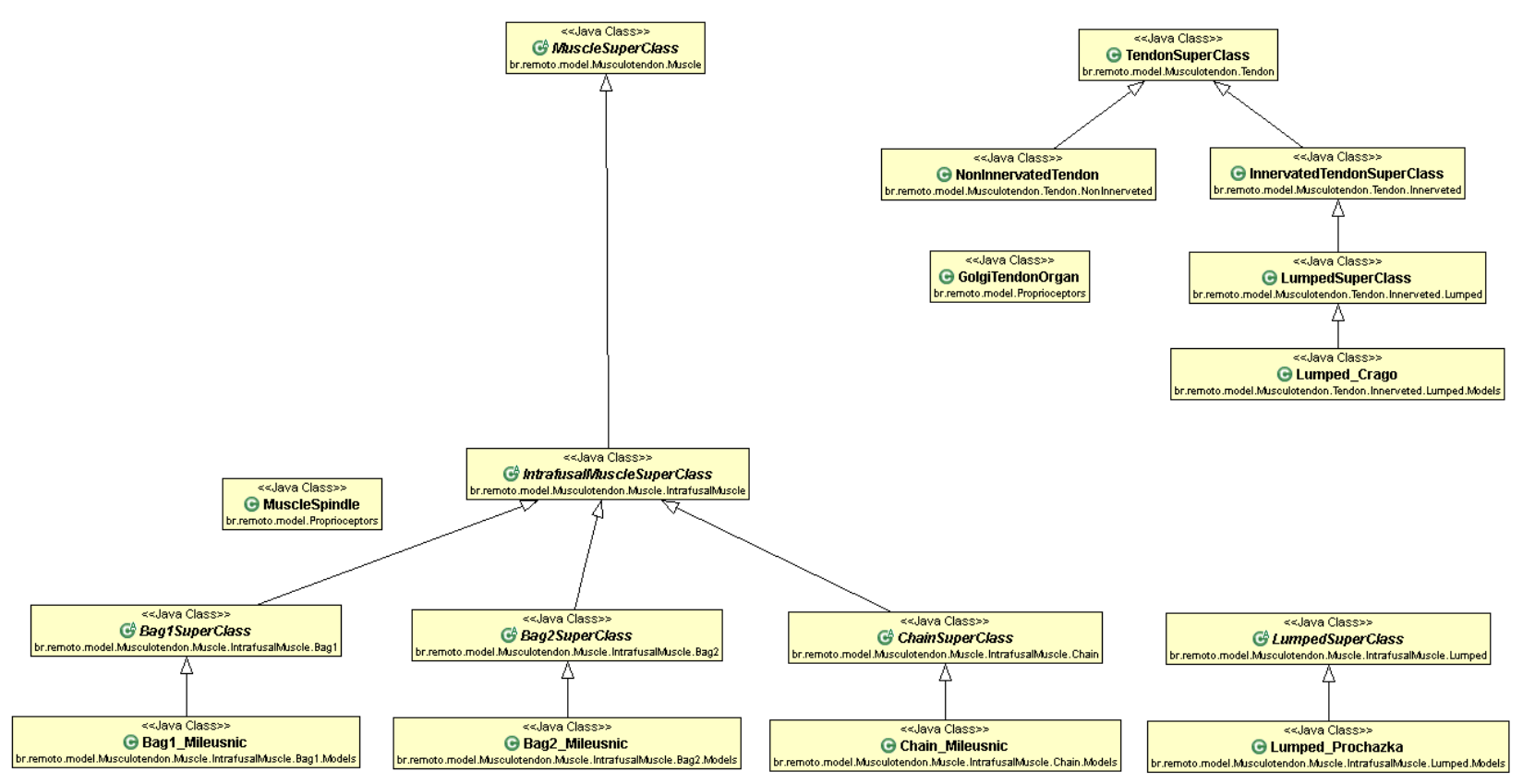

Figura 2-9. Diagrama UML mostrando as classes utilizadas para representação dos modelos de proprioceptores na estrutura do simulador ReMoto.

O modelo de MS (MILEUSNIC et al., 2006) pode ser ilustrado pelo diagrama de blocos da figura seguinte. É constituído por três entradas (comprimento do fascículo L, eferência gama dinâmica $\gamma_{\mathrm{d}} \mathrm{e}$ eferência gama estática $\gamma_{\mathrm{s}}$ ) e duas saídas (aferência primária Ia e aferência secundária II). De forma resumida, as saídas (atividade aferente) dependem da atividade mecânica das fibras intrafusais, a qual deforma os terminais dos neurônios aferentes e os faz disparar PAs. As saídas, então, são dadas como frequência de disparo de PAs no neurônio sensorial em questão (Ia ou II). 


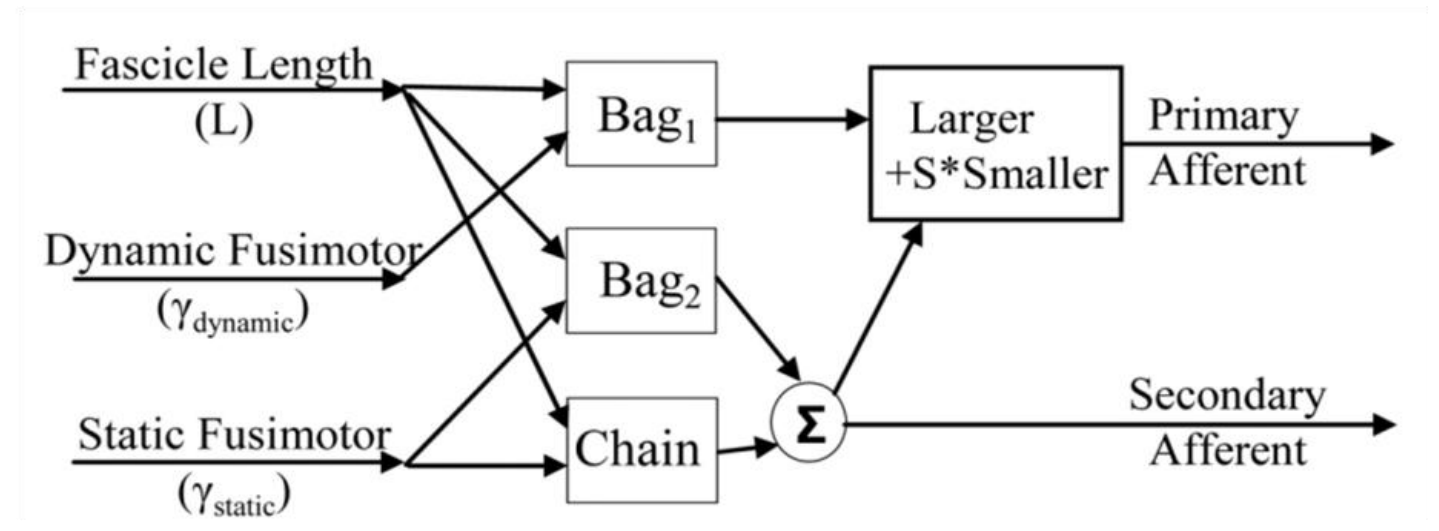

Figura 2-10. Esquema do modelo de MS. Figura reproduzida de (MILEUSNIC et al., 2006).

\subsubsection{Atividade fusimotora}

A fim de representar as propriedades mecânicas das fibras intrafusais e, particularmente, sua ativação pelos neurônios motores gama, as três equações seguintes são utilizadas. A Equação (1) é utilizada somente para a fibra bag1, a Equação (2) para a bag2 e a Equação (3) para a chain.

$$
\begin{gathered}
\frac{d f_{\text {dyn }}}{d t}=\frac{\frac{\gamma_{d y n}^{P}}{\gamma_{\text {dyn }}^{P}+\text { freq }}+f_{\text {bag } 1}}{\tau}+f_{\text {dyn }} \\
\frac{d f_{\text {static }}}{d t}=\frac{\frac{\gamma_{\text {static }}^{P}}{\gamma_{\text {static }}^{P}+\text { freq } q_{\text {bag } 2}^{P}}+f_{\text {static }}}{\tau} \\
f_{\text {static }}=\frac{\gamma_{\text {static }}^{P}}{\gamma_{\text {static }}^{P}+\text { freq } q_{\text {chain }}^{P}}
\end{gathered}
$$




\subsubsection{Mecânica das regiões sensorial e polar}

Os modelos de fibras intrafusais possuem as mesmas estruturas (Figura 2-11), diferenciando-se apenas pelos seus parâmetros. Cada fibra é dividida em uma região polar e em uma região sensorial (equatorial). A região polar é modelada como uma mola com constante $\mathrm{K}^{\mathrm{PR}}$ em paralelo com um elemento contrátil, o qual é constituído de um gerador de força $(\Gamma)$ e um elemento de amortecimento $(\beta)$. M representa a massa da fibra intrafusal e é importante para que haja estabilidade computacional no modelo em questão (MILEUSNIC et al., 2006). Já a parte sensorial consiste simplesmente em uma mola em série com a região polar, como pode ser observado na figura.

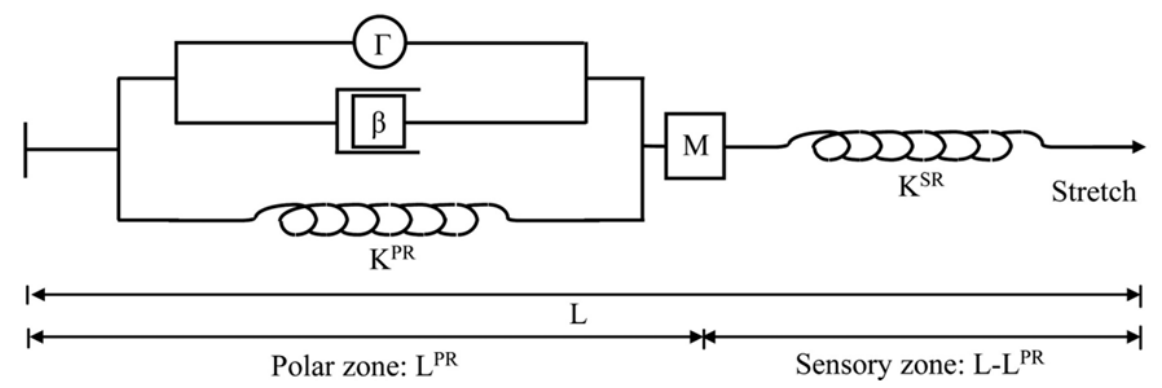

Figura 2-11. Modelo da fibra intrafusal. Todas as fibras intrafusais (bag 1, bag 2 e chain) possuem uma região polar e uma sensorial (equatorial). Figura reproduzida de (MILEUSNIC et al., 2006).

Este esquema resulta na Equação (4) e na Equação (5) para as tensões nas regiões polar e sensorial, respectivamente, de cada fibra:

$$
\begin{gathered}
T=M \times \ddot{L}^{P R}+\beta \times C \times\left(L^{P R}-R\right) \times \operatorname{sign}\left(\dot{L}^{P R}\right) \times \operatorname{abs}\left(\dot{L}^{P R}\right)^{a}+ \\
K^{P R} \times\left(L^{P R}-L_{0}^{P R}\right)+\Gamma
\end{gathered}
$$

, em que $\quad \beta=\beta_{0}+\beta_{1} \times f_{\text {dyn }}+\beta_{2} \times f_{\text {static }}$ e $\Gamma=\Gamma_{1} \times f_{\text {dyn }}+\Gamma_{2} \times f_{\text {static }}$

$$
T=K^{S R} \times\left[\left(L-L^{P R}\right)-L_{0}^{S R}\right]
$$




\subsubsection{Contribuição da fibra intrafusal para a taxa de disparo aferente}

Como as regiões polar e sensorial estão em série, suas tensões são iguais. Portanto, igualando a Equação (4) e a Equação (5), chega-se à equação diferencial (Equação (6)) que representa a tensão numa fibra intrafusal em função das entradas do sistema:

$$
\begin{gathered}
\ddot{T}=\frac{K^{S R}}{M} \times\left[C \times \beta \times \operatorname{sign}\left(\dot{L}-\frac{\dot{T}}{K^{S R}}\right) \times a b s\left(\dot{L}-\frac{\dot{T}}{K^{S R}}\right)^{a} \times\left(L-L_{0}^{S R}-\frac{T}{K^{S R}}-R\right)\right. \\
\left.+K^{S R} \times\left(L-L_{0}^{S R}-\frac{T}{K^{S R}}-L_{0}^{P R}\right)+M \times \ddot{L}+\Gamma-T\right]
\end{gathered}
$$

Tendo em mãos a tensão exercida em cada fibra, calcula-se através das seguintes equações, a contribuição de cada fibra para a atividade aferente.

$$
\text { Afferent_potential } \text { primary }=G \times\left[\frac{T}{K^{S R}}-\left(L_{N}^{S R}-L_{0}^{S R}\right)\right]
$$

Afferent_potential secondary $_{\text {_t }}$

$$
=G \times\left\{\begin{array}{c}
\mathrm{X} \times \frac{\mathrm{L}_{\text {secondary }}}{\mathrm{L}_{0}^{\mathrm{SR}}}\left[\frac{\mathrm{T}}{\mathrm{K}^{\mathrm{SR}}}-\left(\mathrm{L}_{\mathrm{N}}^{\mathrm{SR}}-\mathrm{L}_{0}^{\mathrm{SR}}\right)\right]+ \\
+(1-\mathrm{X}) \times \frac{\mathrm{L}_{\text {secondary }}}{\mathrm{L}_{0}^{\mathrm{PR}}} \times\left(\mathrm{L}-\frac{\mathrm{T}}{\mathrm{K}^{\mathrm{SR}}}-\mathrm{L}_{0}^{\mathrm{SR}}-\mathrm{L}_{\mathrm{N}}^{\mathrm{SR}}\right)
\end{array}\right\}
$$

Tendo resolvido a Equação (7) para todas as fibras intrafusais, somam-se os valores resultantes para bag2 e chain. Assim, é comparada a contribuição da fibra bag1 com a soma das contribuições das fibras bag2 e chain. Então, basta utilizar a seguinte equação para calcular a resposta aferente primária.

$$
\text { Ia }=S \times \text { Smaller }+ \text { Larger }
$$

, em que Smaller and Larger são os resultados citados anteriormente e S é uma constante. 
A Equação (8) é calculada somente para bag2 e chain. Assim, a atividade aferente secundária é obtida por:

$$
\begin{aligned}
& I I=\text { Afferent_potential } \\
& \quad+\text { Affecondary }(\text { bag } 2) \\
& \quad
\end{aligned}
$$

Além disto, os atrasos $t_{I a}$ e $t_{I I}$ são adicionados com o intuito de considerar o atraso total na condução do sinal pelos neurônios Ia e II, respectivamente. 
Capítulo 3 Alterações de reflexos com o nível de força exercida 
$\mathrm{U}$

m modelo matemático biologicamente realista do sistema neuromuscular do SOL foi utilizado para estudar as influências das propriedades mecânicas da unidade músculo-tendão (MTU) sobre a realimentação proprioceptiva e sobre o reflexo de curta latência. O modelo é constituído por: i) comandos descendentes estocásticos sobre um núcleo de MNs; ii) um modelo muscular do tipo Hill; iii) um modelo do fuso neuromuscular com seus aferentes Ia estabelecendo uma via de realimentação com os MNs. Reflexos H e de estiramento foram simulados, considerando suas possíveis dependências com as propriedades mecânicas da MTU o com o nível de ativação muscular. Os principais resultados mostraram uma relação intrínseca entre a resposta Ia ao estiramento muscular e a rigidez relativa entre o músculo e o tendão. Adicionalmente, a ativação fusimotora e o ganho sináptico entre os aferentes Ia e os MNs foram capazes de modular o reflexo de curta latência (SLR), indicando que estes mecanismos podem ajudar a manter os reflexos funcionalmente ativos durante diferentes tarefas. Estes resultados preliminares estão de acordo com dados experimentais e ajudam esclarecer a intrincada relação existente entre a mecânica muscular e a atividade neural.

\subsection{Introdução}

Sinais de realimentação de receptores nos músculos e nos tendões modulam a atividade do núcleo de MNs, provendo importantes informações para o controle motor. Várias vias de realimentação, operando em diferentes níveis do sistema nervoso, proveem o sistema neuromuscular com a habilidade de manter seu desempenho em diversas situações, sem necessariamente depender de um comando direto do cérebro. A fonte mais estudada desta realimentação proprioceptiva é o MS, cuja saída está correlacionada com o comprimento muscular e suas derivadas temporais (WINDHORST, 2007). Os disparos de PAs oriundos do MS viajam por axônios aferentes e ativam o núcleo de MNs, que inervam o músculo homônimo, diretamente ou indiretamente passando por INs espinhais. A via monossináptica entre Ias e MNs do músculo homônimo contribui fortemente com um aumento abrupto da ativação muscular em resposta a uma estimulação elétrica do nervo contendo estes neurônios (reflexo $\mathrm{H}$ ) ou em resposta a um estiramento muscular, gerando o SLR.

Quando um estiramento é imposto à MTU, este estiramento é apenas parcialmente sentido pelo músculo, pois o tendão em série também possui certa complacência, reduzindo o 
movimento das fibras musculares (RACK et al., 1983). A distribuição dos estiramentos entre o músculo e o tendão depende a rigidez relativa entre estes elementos. Tem sido sugerido que com o aumento do nível de força muscular (ou equivalentemente o aumento do nível de ativação muscular) sua rigidez aumenta mais do que aquela do tendão, causando um declínio progressivo da amplitude e da velocidade de estiramento muscular para um mesmo estímulo externo aplicado. Assim, na ausência de mecanismos para compensar estes efeitos, um aumento da ativação de fibras extrafusais iria diminuir a responsividade dos MSs e dos reflexos (CRONIN et al., 2008, 2009). Candidatos para esta compensação poderiam ser os ganhos estático e dinâmico do MS controlados pelas ativações fusimotoras e a inibição présináptica dos aferentes Ia.

O SLR contribui para o aumento da força e a regulação da rigidez muscular (ALLUM; MAURITZ, 1984). Assim, uma melhor compreensão de seus mecanismos é necessária para melhor entender seu papel no controle motor. Neste estudo, simulações computacionais foram empregadas para avaliar como a rigidez relativa entre o músculo e o tendão pode afetar a atividade Ia e, consequentemente, o SLR. A fim de melhor diferenciar entre a influência da excitabilidade do núcleo de MNs e da dinâmica muscular na atividade reflexa, simulações do reflexo $\mathrm{H}$ também foram realizadas. Além disto, uma análise de sensibilidade foi feita para investigar se a atividade fusimotora e/ou a inibição pré-sináptica dos aferentes Ia poderia modular as respostas reflexas. 


\subsection{Metodologia}

Neste estudo, somente parte dos modelos presentes no ReMoto (CISI; KOHN, 2008) foi utilizada. Além disto, modelos de outros componentes foram implementados permitindo investigações envolvendo propriedades mecânicas musculares e atividade proprioceptiva (Figura 3-1). Ao invés de um "gerador de twitches" representando a força em uma MU, como é feito no ReMoto, um modelo do tipo Hill foi utilizado para representar a mecânica muscular, formando com um modelo de tendão, a MTU.

a
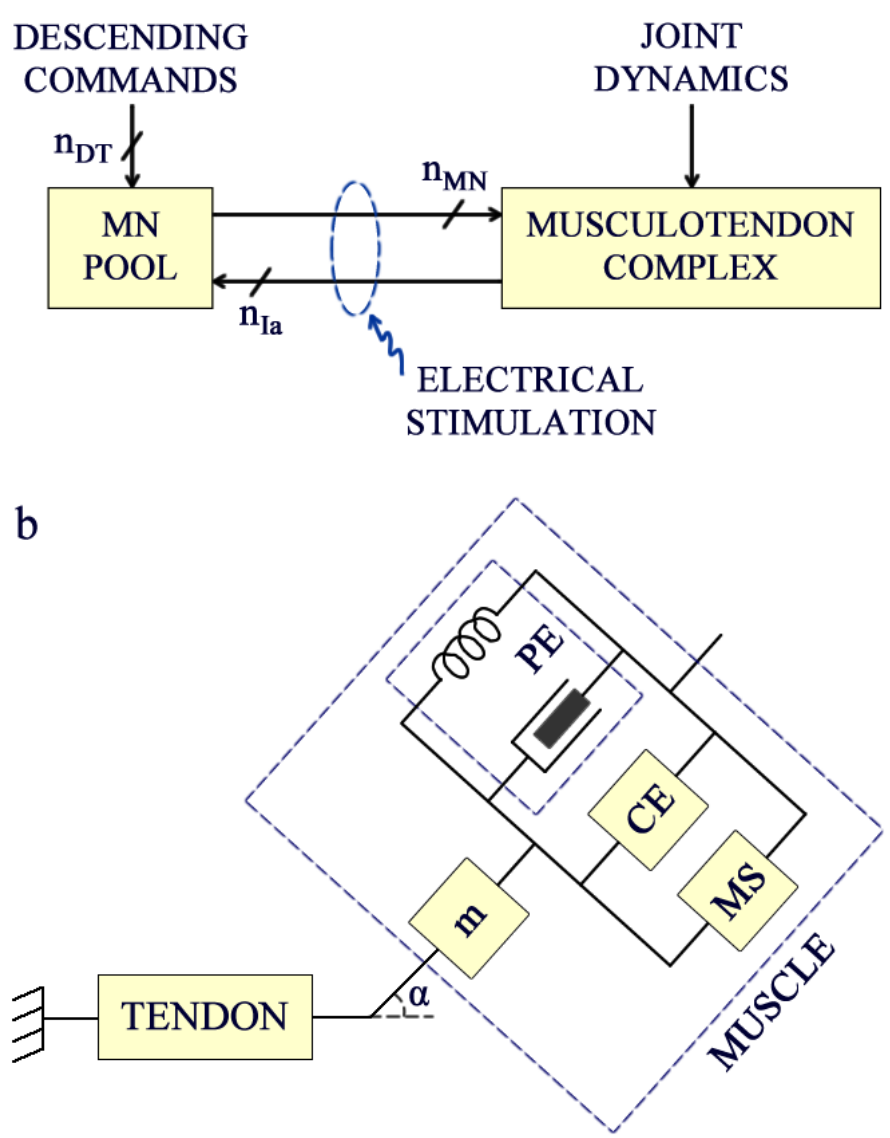

Figura 3-1. Diagrama de blocos representando o modelo neuromuscular. a) Visão simplificada do modelo. O pool de MNs contendo $n_{M N}$ MNs recebe entradas de $n_{D T}$ axônios descendentes e $n_{I a}$ aferentes. $O$ complexo (ou unidade) músculo-tendão é excitado pela atividade dos MNs e é restrito mecanicamente pela dinâmica da articulação. b) 0 modelo de unidade músculo-tendão compreende um tendão em série com um músculo penado. PE representa a rigidez e a viscosidade e $\mathrm{CE}$ é responsável pela geração da força ativa. MS provê a atividade aferente Ia devida à dinâmica muscular. 


\subsubsection{Ativação muscular}

Um sistema de segunda ordem criticamente amortecido em série com uma função não linear (sigmoidal) representou a ativação devida a cada MU. A ativação muscular total (a) foi a soma da ativação de todas MUs seguida de uma normalização. As amplitudes de twitch e as velocidades de contração foram ajustadas para cada MU, a fim de corresponder com dados experimentais. Somente MUs do tipo S foram consideradas, sendo estas as que constituem em grande maioria o SOL.

\subsubsection{Dinâmica de contração muscular}

Quatro elementos mecânicos foram responsáveis pela resposta da MTU à ativação e a mudanças de comprimento (Figura 3-1b). O tendão foi modelado como um elemento em série com o músculo e com uma curva tensão-estiramento obtida seguindo a metodologia de Zajac (ZAJAC, 1989) e implementação como em (THELEN, 2003). As fibras musculares foram englobadas em uma representação consistindo em um elemento ativo e dois elementos passivos. Um elemento contrátil baseado em (BROWN; SCOTT; LOEB, 1996) gerou a força ativa como mostra a Equação (11).

$$
F_{c}=a \cdot f_{l} \cdot f_{v}
$$

em que $a$ é o nível de ativação muscular, $f l$ é representa a relação força-comprimento e $f v$ representa a relação força-velocidade.

Elementos passivos baseados em (DE VLUGT et al., 2011) representaram a elasticidade e a viscosidade dos tecidos envolvendo as fibras musculares. Estas forças passivas são exponencialmente dependentes do comprimento da fibra muscular $L_{M}$. A cinemática inversa do ângulo da articulação para o comprimento da MTU ( $\left.L_{M T}\right)$ foi baseado em um ajuste polinomial (Equação (12)) sobre os dados de (ARNOLD et al., 2010).

$$
L_{M T}=a_{1} \times A A^{4}-a_{2} \times A A^{3}-a_{3} \times A A^{2}+a_{4} \times A A+a_{5}
$$




\subsubsection{Atividade do fuso neuromuscular}

O modelo descrito na seção 2.4 desta monografia foi implementado para predizer a frequência de disparos média do aferente Ia $\left(I a_{M S}\right)$ em resposta ao comprimento muscular, à velocidade de estiramento e à atividade fusimotora. Entradas fusimotoras estática e dinâmica modulam a sensibilidade do MS a mudanças no comprimento e/ou na velocidade de estiramento. Foi suposto que esta atividade fusimotora não influencia diretamente a dinâmica de contração muscular. A atividade aferente, como descrita na Equação (13), modula a intensidade de processos estocásticos pontuais (ISIs com distribuição gama) representando os disparos de cada aferente Ia.

$$
I a_{i}=I a_{M S}-R T_{i}+I F R_{i}
$$

em que $\mathrm{Ia}_{\mathrm{i}}$ é a atividade aferente, $\mathrm{RT}_{\mathrm{i}}$ é o limiar de recrutamento e $I F R_{i}$ é a frequencia de disparos inicial do i-ésimo aferente Ia; $I a_{M S}$ é a saída do modelo de MS. RT $\mathrm{T}_{\mathrm{i}}$ varia linearmente entre os aferentes Ia e $I F R_{i}$ é um número aleatório com distribuição Gaussiana (média = 5, desvio padrão $=2.5$ ). 


\subsubsection{Parametrização}

Parâmetros para o núcleo de MNs e para o EMG podem ser encontrados em (CISI; KOHN, 2008). Em geral, os parâmetros do modelo de MS foram os mesmo de (MILEUSNIC et al., 2006) e os parâmetros para a MTU foram os mesmos de (DE VLUGT et al., 2011). Entretanto, algumas modificações de parâmetros estão listadas na Tabela 3-1.

Tabela 3-1. Parâmetros utilizados no modelo.

\begin{tabular}{|c|c|c|c|}
\hline Símbolo & Descrição & Valor & Unidade \\
\hline$n_{M N}$ & Número de MNs & 800 & --- \\
\hline$n_{I a}$ & Número de aferentes Ia & 400 & --- \\
\hline$n_{D T}$ & Número de DTs & 100 & --- \\
\hline$\gamma_{D y n}$ & Valor nominal do gama dinâmico & 30 & $\mathrm{~Hz}$ \\
\hline$\gamma_{\text {Static }}$ & Valor nominal do gama estático & 30 & $\mathrm{~Hz}$ \\
\hline$F_{0}$ & Força máxima isométrica do músculo & 2.839 & $\mathrm{~N}$ \\
\hline$R T_{i}$ & Liminar de recrutamento do aferente Ia & $0-60$ & $\mathrm{~Hz}$ \\
\hline$a_{1}$ & Coeficiente da Equação (12) & $9,11 * 10^{-11}$ & $\mathrm{~m}$ \\
\hline$a_{2}$ & Coeficiente da Equação (12) & $-3,15^{*} 10^{-8}$ & $\mathrm{~m} / \mathrm{grau}$ \\
\hline$a_{3}$ & Coeficiente da Equação (12) & $-2,24 * 10^{-6}$ & $\mathrm{~m} / \mathrm{grau}^{2}$ \\
\hline$a_{4}$ & Coeficiente da Equação (12) & $7,22 * 10^{-4}$ & $\mathrm{~m} / \mathrm{grau}^{3}$ \\
\hline$a_{5}$ & Coeficiente da Equação (12) & 0.323 & $\mathrm{~m} / \mathrm{grau}^{4}$ \\
\hline$L_{0}$ & Comprimento ótimo do fascículo muscular & 0,049 & $\mathrm{~m}$ \\
\hline$G_{b a g 1}$ & $\begin{array}{l}\text { Termo relacionando o estiramento da região } \\
\text { sensorial do MS com a atividade aferente na } \\
\text { fibra bag1 }\end{array}$ & 6.666 & $\mathrm{~Hz} / \mathrm{L}_{0}$ \\
\hline$G_{\text {bag } 2 / \text { Chain }}$ & Idem a $G_{b a g l}$ para as fibras bag2 e chain & 3.333 & $\mathrm{~Hz} / \mathrm{L}_{0}$ \\
\hline
\end{tabular}




\subsubsection{Protocolos de simulação}

Os cenários e as análises empregados neste estudo são descritos a seguir.

- Rigidez do músculo e do tendão: para avaliar a rigidez, o modelo de MTU foi simulado para diferentes níveis basais de ativação. Foi simulada uma dorsiflexão ( $8^{\circ}$ de amplitude a $250 \%$ s) como ilustra a Figura 3-2. A rigidez do músculo e a do tendão foram medidas e comparadas, assim com o comprimento do fascículo muscular antes do estiramento, a amplitude de estiramento muscular e a velocidade de estiramento muscular.
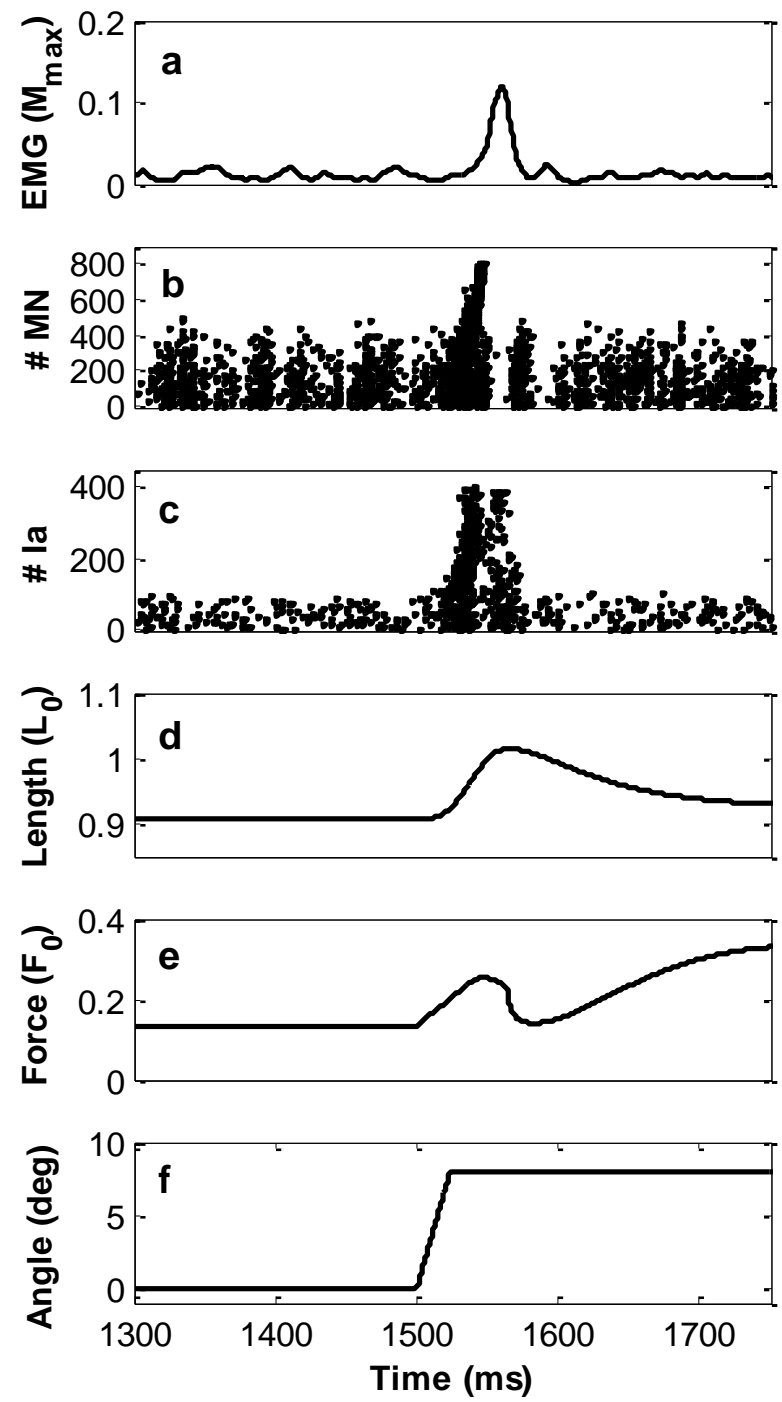

Figura 3-2. Exemplo de simulação no qual a articulação do tornozelo é rotacionada de $8^{\circ}$ (dorsiflexão), estirando o músculo SOL. Decurso temporal do EMG (a), dos instantes de disparos dos MNs (b), dos instantes de disparos dos aferentes Ia (c), do comprimento do fascículo muscular (d), da força muscular (e), e do ângulo da articulação (f). 
- Reflexo H: a medição do reflexo H é importante para diferenciar entre o efeito da excitabilidade do pool de MNs e os efeitos da MTU e da dinâmica do MS na resposta reflexa. Foi simulada uma estimulação de $10 \mathrm{~mA}$ no nervo PTN, gerando o reflexo H. A fim de quantificar a resposta reflexa, o sinal de EMG foi reamostrado a $2 \mathrm{kHz}$, filtrado (Butterworth de $1^{a}$ ordem passa-baixas com $40 \mathrm{~Hz}$ de frequência de corte), e normalizado pela amplitude da onda $\mathrm{M}$ máxima $\left(\mathrm{M}_{\max }\right)$.

- Reflexo de estiramento: foi simulada uma dorsiflexão ( $8^{\circ}$ de amplitude a $250^{\circ}$ s) como ilustrada na Figura 3-2f, resultando em uma resposta na força muscular Figura 3-2e, e em um estiramento do SOL Figura 3-2d. Este estiramento levou a um aumento da atividade Ia Figura 3-2c e, consequentemente da atividade do pool de MNs (Figura 3-2b), causando um SLR no EMG Figura 3-2a. O sinal de EMG foi reamostrado a 2 $\mathrm{kHz}$, filtrado, e normalizado por $\mathbf{M}_{\max }$.

- Efeito da ativação fusimotora e da condutância sináptica máxima: para avaliar a sensibilidade do SLR com respeito à ativação fusimotora, os níveis de ativação estática e dinâmica foram variados entre 0 e $90 \mathrm{~Hz}$. Adicionalmente, gIa-MN_max foi variado de 300 a 1200 nS. Em termos simplistas, a variação de ga-MN_max está relacionada ao efeito de inibição pré-sináptica sobre os aferentes Ia. O SLR foi medido como descrito anteriormente. 


\subsection{Resultados}

O comprimento do fascículo muscular antes do estiramento diminuiu monotonicamente com a ativação muscular (Figura 3-3a), enquanto que a variação do comprimento e a velocidade muscular durante o estiramento primeiro aumentam e depois diminuem (Figura 3-3b e Figura 3-3c). Conforme o nível de ativação aumentou, o grau de rigidez do músculo e do tendão variou como mostra a Figura 3-3d. Esta relação determinou o estiramento relativo nestes elementos em uma dada força basal. A redução do comprimento do fascículo antes do estiramento com o aumento da ativação causou um aumento do comprimento do tendão antes do estiramento e, consequentemente, um aumento na sua rigidez. Em cerca de 30 a $40 \%$ da ativação máxima, a rigidez do tendão atingiu seu valor máximo e ficou aproximadamente invariável para maiores níveis de ativação. As regiões ascendentes em Figura 3-3b e Figura 3-3c foram coincidentes com um aumento relativo da rigidez do tendão comparando com a rigidez do músculo. Consistentemente, a amplitude e a velocidade de estiramento diminuíram com a ativação na região em que a rigidez muscular aumentou mais que a rigidez do tendão.
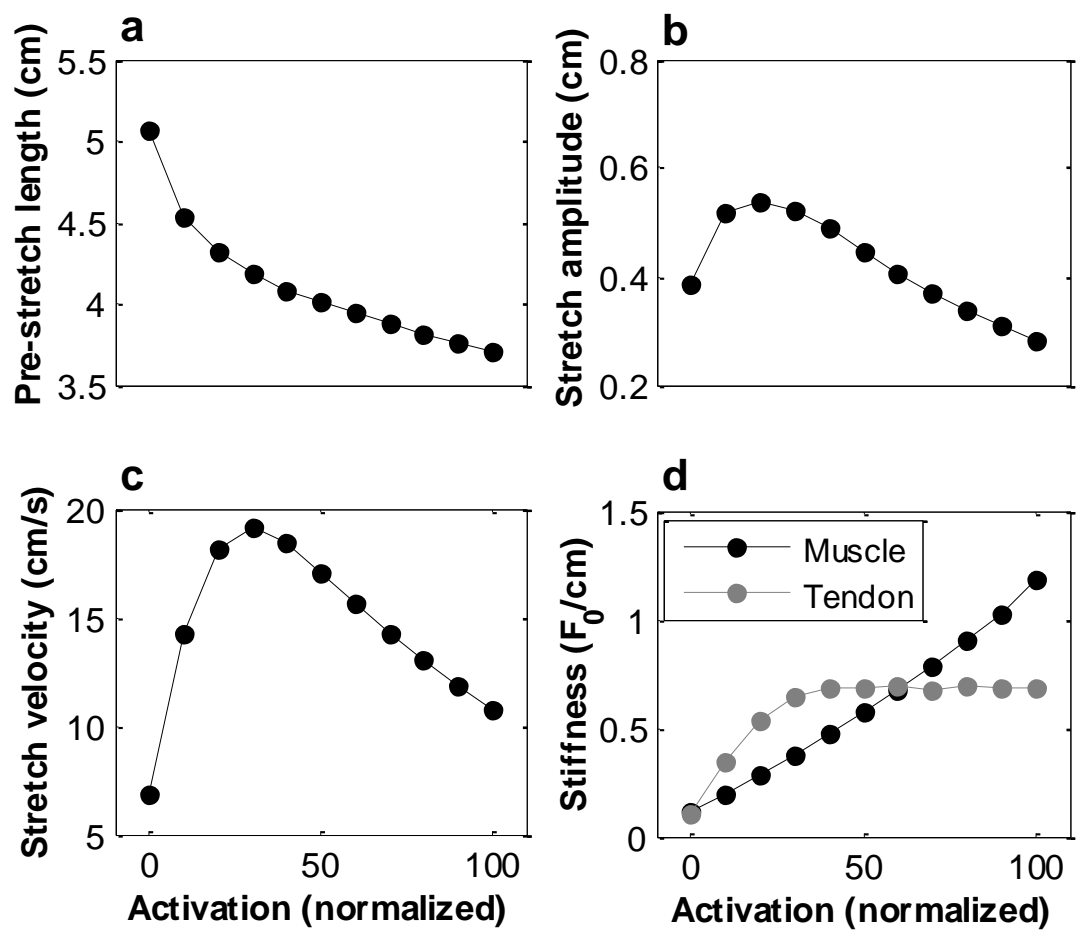

Figura 3-3. Variação das propriedades do músculo e do tendão como função do nível de ativação, quando a MTU é estirada pela dorsiflexão do tornozelo. a) Comprimento do fascículo muscular antes do estiramento. b) Amplitude do estiramento muscular. c) Velocidade de estiramento muscular. d) rigidez dinâmica do músculo e do tendão durante o estiramento. 
A variação do reflexo $\mathrm{H}$ com a força muscular é mostrada na Figura 3-4. A força máxima $\left(\mathrm{F}_{\max }\right)$ que o músculo pode gerar com o tornozelo na posição neutra foi $0.7 \mathrm{~F}_{0}$. A amplitude do reflexo $\mathrm{H}$ correspondente ao menor nível de força simulada (adotada como referência) foi $0.19 \mathrm{M}_{\max }$. Deste ponto até cerca de $30 \%$ de $\mathrm{F}_{\max }$, a amplitude continuou aproximadamente constante. Um aumento de cerca de $37 \%$ na amplitude do reflexo foi observado de 30 a $50 \% \mathrm{~F}_{\max }$ e, para maiores níveis de contração, a amplitude declinou progressivamente até $15 \%$ abaixo do valor de referência $\left(\mathrm{em}_{\mathrm{max}}\right.$ ). Uma curva quadrática foi ajustada, levando a um coeficiente de determinação $\left(R^{2}\right)$ de 0.57 .

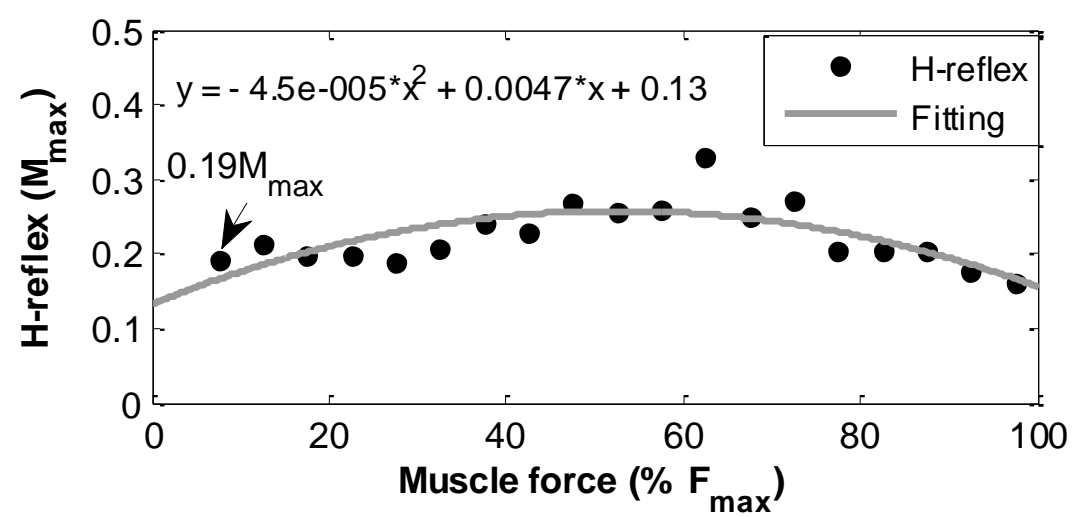

Figura 3-4. Variação da amplitude do reflexo $\mathrm{H}$ com a força muscular basal. $\mathrm{O}$ reflexo resultante foi normalizado pela onda M máxima. A força muscular foi normalizada pela máxima força que o músculo pode produzir com a articulação na posição neutra.

De forma semelhante ao reflexo H, o SLR aumenta e depois diminuiu com o nível basal de força muscular. A Figura 3-5 mostra a relação entre a amplitude do SLR e a força muscular (Figura 3-5a) e entre a resposta aferente Ia e a força muscular (Figura 3-5b). Houve um aumento no SLR da condição de repouso até aproximadamente $20 \%$ de $\mathrm{F}_{\max }$. Para valores superiores de contração a amplitude do reflexo diminuiu progressivamente. O ajuste destes dados por uma quadrática resultou em $\mathrm{R}^{2}=0.58$. Uma relação semelhante foi observada para as respostas do aferente Ia. Houve uma região ascendente seguida por uma região descendente, com um pico em $\sim 23 \%$. Em níveis de contração superiores a $85 \%$ de $\mathrm{F}_{\max }$, a resposta Ia foi significativamente diminuída, e o reflexo não pôde ser distinguido no sinal de EMG. 

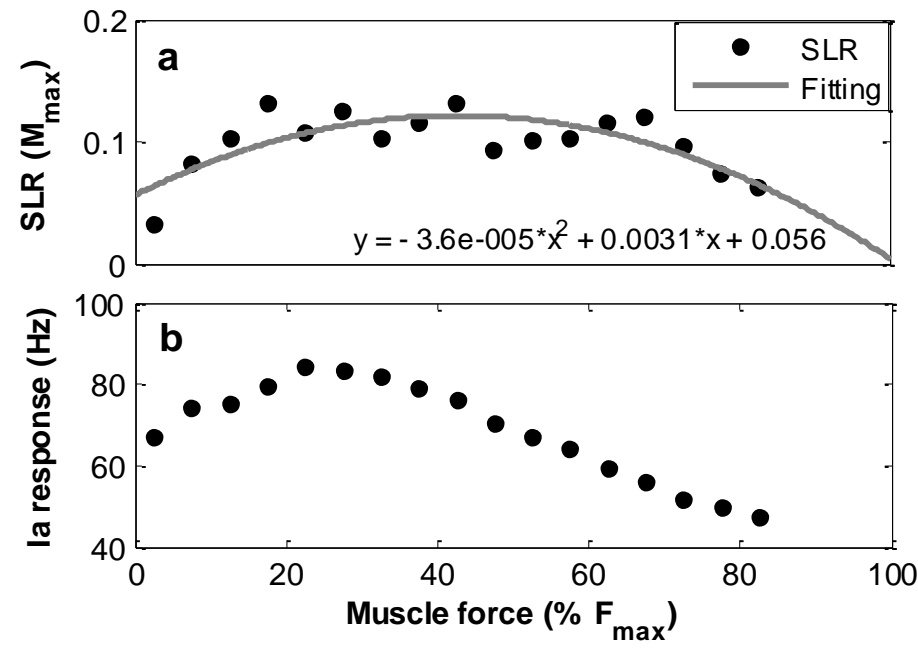

Figura 3-5. Variação do SLR e da resposta aferente Ia com a força muscular basal. O SLR foi normalizado pela onda M máxima. A força muscular foi normalizada pela máxima força que o músculo pode produzir com a articulação na posição neutra.

A Figura 3-6 mostra a sensibilidade do SLR com respeito à ativação fusimotora e a $\mathrm{g}_{\text {Ia- }}$ MN_max para um nível fixo de contração muscular $\left(\sim 20 \%\right.$ de $\left.\mathrm{F}_{\max }\right)$. O SLR aumentou com a ativação fusimotora dinâmica até $45 \mathrm{~Hz}$ e continuou aproximadamente no mesmo nível para maiores níveis de ativação fusimotora, porém com um aumento em sua variabilidade (Figura 3-6a). Um efeito similar foi observado pela variação de g ga-MN_max (Figura 3-6b). Por outro lado, o SLR não mostrou uma alteração expressiva com a ativação fusimotoras estática (Figura 3-6a).
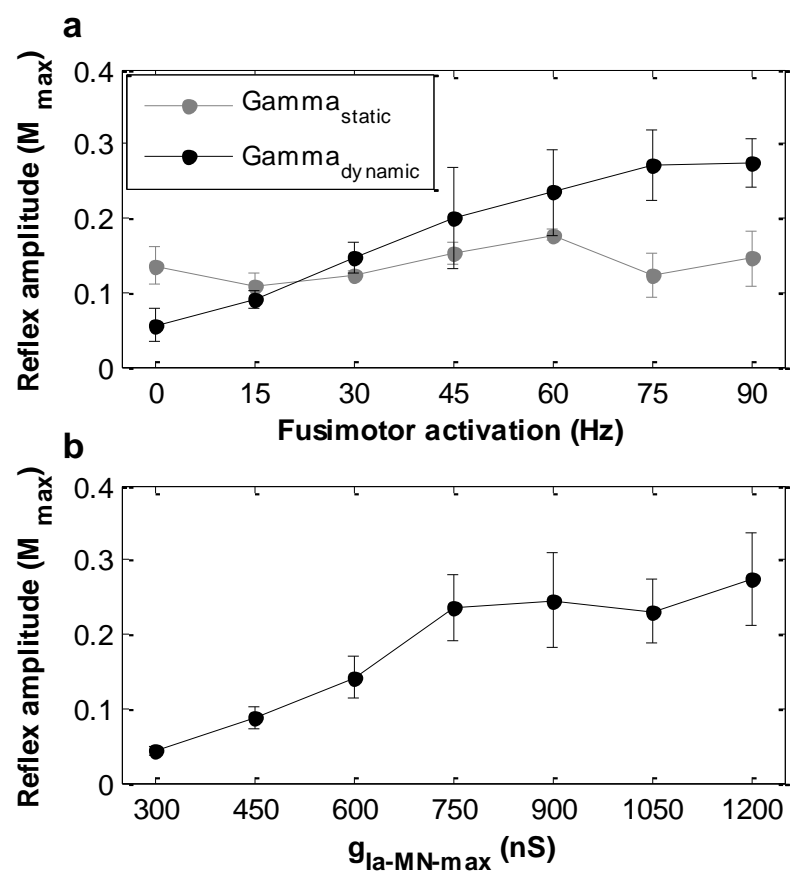

Figura 3-6. Variação do SLR como função da ativação fusimotora por MNs gama estáticos e dinâmicos (a) e como função do valor máximo para a condutância entre os aferentes Ia e os MNs alfa (b). 


\subsection{Discussão}

Neste estudo, o comportamento de parâmetros observados experimentalmente, como o reflexo $\mathrm{H}$ e o SLR, foi avaliado pelo uso de modelos matemáticos, os quais incluíram a representação de neurônios individuais, assim como a ativação muscular e sua dinâmica de contração. Foi possível inferir os efeitos de parâmetros mecânicos na atividade neural e viceversa, levando a interpretações importantes com relação ao acoplamento entre elementos neurais e mecânicos. Esta é a primeira vez em que um modelo de larga escala, levando em consideração o comportamento de neurônios individuais, proprioceptores, e dinâmica muscular, foi empregado para investigar estas questões.

Os resultados para a dinâmica muscular estão de acordo com os dados experimentais. Por exemplo, quando o músculo é ativado com o tornozelo mantido a $0^{\circ}$, o comprimento da fibra muscular se mantém abaixo do comprimento ótimo Figura 3-3a, i.e., o SOL está na região ascendente de sua curva força-comprimento (MAGANARIS, 2001). Adicionalmente, o comprimento do fascículo antes do estiramento, a amplitude e a velocidade de estiramento (Figura 3-3a, b, c) diminuíram em certa faixa da ativação muscular basal, de acordo com (CRONIN et al., 2008, 2009). Entretanto, nas simulações, houve uma região ascendente nas curvas para a amplitude e a velocidade de estiramento (Figura 3-3b, c), devida à escolha de parâmetros adotada para a MTU, o que resultou em um aumento maior da rigidez do tendão do que na do músculo entre 0 e $30 \%$ de ativação. Além disto, o aumento na rigidez do tendão com o nível de ativação foi muito semelhante ao levantado experimentalmente (PROSKE; MORGAN, 1987). A mudança da rigidez relativa entre o músculo e o tendão com o nível de ativação (ou força) é uma importante característica (RACK et al., 1983) e parece ter sido bem capturada pelo modelo de MTU.

Para ganhar uma visão do papel da excitabilidade do pool de MNs na atividade reflexa, o reflexo $\mathrm{H}$ foi simulado pela estimulação do nervo PTN, o que elimina a dinâmica do MS na geração do reflexo. Entretanto, em experimentos com humanos ainda há considerações metodológicas sobre o quanto o reflexo $\mathrm{H}$ realmente representa a excitabilidade do pool de MNs (KNIKOU, 2008). Por exemplo, uma estimulação de baixa intensidade tende a recrutar somente aferentes Ia, os quais possuem axônios com maiores diâmetros, enquanto que estimulações com alta intensidade tendem a recrutar outros aferentes, como Ib e cutâneo, os quais poderiam afetar a atividade sináptica liquida sobre o pool de MNs (BUTLER; YUE; DARLING, 1993). No cenário simulado, foi utilizado um estímulo de baixa intensidade a fim 
de recrutar somente aferentes Ia (e não MNs) e evitar a saturação da via reflexa. A amplitude do reflexo H (mostrada na Figura 3-4) exibiu um comportamento similar aos resultados experimentais. Por exemplo, alguns experimentos mostraram que o reflexo $\mathrm{H}$ aumenta até 40 a 60\% MVC (medido como torque do tornozelo) no SOL humano durante contrações isométricas (BUTLER; YUE; DARLING, 1993; OYA; CRESSWELL, 2008). Ainda, outro estudo mostrou certa constância no reflexo H do SOL em níveis inferiores a $10 \%$ do MVC (RUEGG; KRAUER; DREWS, 1990).

Além dos fatores influenciando o reflexo H, o SLR é também afetado pela dinâmica do MS, a qual por sua vez depende do comportamento muscular e da ativação fusimotora. Como a rigidez do músculo é dependente de sua força (ou ativação) basal (RACK et al., 1983), tem sido sugerido que a resposta do aferente Ia a um estiramento muscular também seria dependente do nível de contração. Isto seria principalmente devido à dependência do MS com a velocidade de estiramento, a qual por sua vez varia com o nível de ativação (CRONIN et al., 2008, 2009). Isto é evidenciado pela comparação do gráfico inferior da Figura 3-5 com a Figura 3-3a e a Figura 3-3b. A resposta do aferente Ia como função da força muscular teve uma região ascendente e outra descendente semelhante ao comportamento da amplitude e velocidade de estiramento muscular (como função do nível de ativação). Esta modulação da resposta aferente Ia pela ativação muscular basal corrobora a hipótese levantada em (CRONIN et al., 2008) para explicar a modulação do SLR. Entretanto, este não é o único mecanismo pelo qual o SLR pode ser modulado.

Alguns estudos mostraram um aumento do SLR no SOL com o nível de torque basal até cerca de 50\% (GOTTLIEB; AGARWAL; JAEGER, 1981; TOFT et al., 1991). Porém, os resultados simulados mostraram um aumento do SLR até somente $20 \%$ de $\mathrm{F}_{\max }$. Esta diferença é em parte explicada pelo fato de, para o cenário escolhido, a excitabilidade do pool de MNs agiu como um fator limitante para o SLR (veja adiante). Adicionalmente, a comparação entre os resultados simulados apresentados aqui para o reflexo H e o SLR em diferentes níveis de contração muscular com dados experimentais não é direta, pois os últimos geralmente se referem ao torque da articulação e não à força muscular. Como a força muscular não é necessariamente relacionada linearmente com o torque para toda a faixa de movimento, esta comparação deve ser feita com cautela.

No que diz respeito à excitabilidade do pool de MNs, as simulações indicaram que o período refratário dos MNs é um fator limitante para qualquer tipo de reflexo. Com o aumento da excitabilidade do pool de MNs, mais MNs estarão em seu período refratário absoluto ou 
relativo em um dado instante, os impedindo de participar na geração do reflexo. Outro fator limitante é o número finito de MNs no pool, o que causa um decréscimo no número de MNs inativos (porém prontos para responder e participar do reflexo) com o aumento da excitabilidade do pool. Estes resultados são muito semelhantes aos apresentados em (CAPADAY; STEIN, 1987). Estes efeitos de saturação foram totalmente responsáveis pela diminuição do reflexo H vista na Figura 3-4 e parcialmente responsáveis pela diminuição do SLR mostrada na Figura 3-5a, pois o SLR é também influenciado pela variação da resposta aferente Ia mostrada na Figura 3-5b.

No cenário escolhido para a simulação do SLR, a atividade fusimotora e g ga-MN_max foram mantidos constantes pros diferentes níveis de força. Este provavelmente não é o caso para várias condições do comportamento humano. Entretanto, o principal objetivo deste estudo não era reproduzir a forma exata da curva força muscular vs SLR, mas avaliar como esta relação poderia ser alterada pelas características mecânicas da MTU e por fatores moduladores como ativação fusimotora e $\mathrm{g}_{\text {Ia-MN_max }}$, sendo este último fator relacionado com a inibição pré-sináptica dos aferentes Ia. Os resultados mostrados na Figura 3-6 evidenciam o efeito modulatório que a ativação fusimotora e ga-MN_max podem exercer no SLR. Entretanto, o SLR mostrou-se insensível à ativação fusimotora estática, o que indica que a velocidade de estiramento é possivelmente mais relevante do que a amplitude de estiramento na modulação do SLR. Tem sido proposto que uma diminuição da inibição pré-sináptica pode contrabalancear a redução das respostas aferentes conforme a força muscular aumenta (CRONIN et al., 2009). Como pode ser inferido da Figura 3-6b, é plausível que, um aumento dos potenciais pós-sinápticos (pela diminuição da inibição pré-sináptica) resulte em um deslocamento do SLR para maiores níveis. Portanto, a modulação da inibição pré-sináptica pode de fato representar um mecanismo para manter os reflexos funcionalmente ativos, mesmo em altos níveis de contração, contrabalanceando a diminuição vista na Figura 3-5A. O mesmo vale para a ativação fusimotora dinâmica, embora se espere que esta ativação alcance seu nível máximo em cerca de $25 \%$ da $\mathrm{F}_{\max }$ (CRONIN et al., 2008).

Vale notar que neste estudo preliminar não foi dada muita atenção para as taxas de disparos dos MNs, as quais estão intimamente relacionadas com a excitabilidade do pool de MNs e poderiam estar fora da faixa normal para a fisiologia humana. Aparentemente, para o cenário escolhido, a excitabilidade dos MNs estava alta em níveis intermediários de força, causando uma saturação prematura dos reflexos evocados (Figura 3-4 e Figura 3-5a). Assim, a fim de melhorar as simulações, permitindo comparações mais diretas com dados 
experimentais, o nível de excitação do pool de MNs deveria ser mais bem controlado e um modelo adicional da mecânica articular deveria ser incorporado. Entretanto, neste estudo, somente levantamentos qualitativos e comparativos eram intencionados, o que possibilitou avaliar importantes mecanismos e suas influências na realimentação e na geração de reflexos. 
Capítulo 4 Modelo de pool de motoneurônios 


\subsection{Introdução}

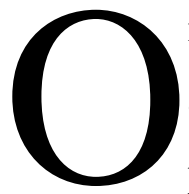

modelo de pool de MNs mais empregado em trabalhos científicos recentes é aquele descrito em (FUGLEVAND; WINTER A.; PATLA, 1993). Este modelo, porém, não incorpora as características biofísicas dos MNs e apenas atribui o recrutamento e as taxas de disparos com as quais os MNs do pool disparam APs. Existem também modelos mais complexos de MNs, que representam a morfologia neuronal pela concatenação de vários compartimentos (BUI et al., 2006; ELBASIOUNY et al., 2005). Todavia, estes modelos são complexos demais para possibilitar uma representação da população de MNs em um pool. O nível de detalhe, presente neste tipo de modelo, requer a uma série de parâmetros que muitas vezes não são viáveis de se determinar experimentalmente. Uma abordagem intermediária é a representação do neurônio por modelos de dois compartimentos, nos quais um compartimento representa as características mais associadas à geração de APs (soma e segmento inicial) e outro representa as características mais associadas à arborização dendrítica e a transmissão e processamento dos potenciais póssinápticos para o soma (PINSKY; RINZEL, 1994). Alguns modelos de dois compartimentos foram desenvolvidos para reproduzir as características de MNs (BOOTH; RINZEL; KIEHN, 1997; CISI; KOHN, 2008; ELIAS; KOHN, 2013; KURIAN; CROOK; JUNG，2011; NEGRO; FARINA, 2011; WILLIAMS; BAKER, 2009a, 2009b). Entretanto, por serem mais simples que os modelos morfológicos, estes modelos (para a parametrização geralmente adotada) não apresentam adequadamente características de acoplamento entre os compartimentos, como a atenuação de voltagem dependente da direção (DDVA). Em MNs reais, um potencial elétrico aplicado ao soma do $\mathrm{MN}$ é mais facilmente transmitido para os dendritos do que no sentido contrário (KIM; MAJOR; JONES, 2009). A parametrização utilizada nos trabalhos citados resulta no efeito oposto ao mencionado, ou seja, o potencial elétrico é mais facilmente transmitido do dendrito para o soma, do que do soma para o dendrito. Com isto, a contribuição dos EPSPs dendríticos para a geração de AP fica mal representada, tanto para o $\mathrm{MN}$ individual quanto no que diz respeito à atividade da população de MNs. Kim e Jones (2009) propuseram uma metodologia que permite a um modelo de dois compartimentos uma representação mais realista do DDVA e que pode conferir ao modelo características mais próximas ao encontrado fisiologicamente. No trabalho descrito neste capítulo, a metodologia de Kim e Jones (2009) foi aplicada e complementada pela 
representação de condutâncias iônicas presentes nos MNs a fim de criar um modelo que represente adequadamente o comportamento do MN individual e do pool de MNs.

\subsection{Metodologia}

\subsubsection{Estrutura do modelo de motoneurônio}

A estrutura do modelo de $\mathrm{MN}$ utilizada neste trabalho é semelhante àquelas apresentadas em (BOOTH; RINZEL; KIEHN, 1997; KURIAN; CROOK; JUNG, 2011; WILLIAMS; BAKER, 2009a). A cinética dos canais iônicos representados segue o formalismo do modelo de Hodgkin-Huxley (HODGKIN; HUXLEY, 1952). A corrente iônica associada a cada tipo de canal representado segue

$$
I_{\text {ion }}=g_{\text {ion }} m^{y} h^{z}\left(V-E_{\text {ion }}\right)
$$

em que

$\mathrm{V}$ é o potencial de membrana $(\mathrm{em} \mathrm{mV})$.

m é a variável de ativação.

h é a variável de inativação.

y e $\mathrm{z}$ são números inteiros (pequenos) que representam a influência do processo de ativação/inativação na condutância.

$g_{i o n}$ é a condutância máxima para este tipo de canal iônico $\left(\mathrm{em} \mathrm{mS} / \mathrm{cm}^{2}\right)$.

$E_{i o n}$ é o potencial de reversão para o íon correspondente (também chamado de potencial de Nernst ou de equilíbrio).

A cinética de ativação/inativação das condutâncias iônicas é governada por equações da forma

$$
\frac{d w}{d t}=\frac{w_{\infty}(V)-w}{\tau_{w}(V)}
$$

em que

$w$ é a variável de ativação ou inativação.

$w_{\infty}(V)$ é a função de ativação/inativação em regime estacionário.

$\tau_{w}(V)$ é a constante de tempo do processo de ativação/inativação. 
A função de ativação/inativação em regime estacionário é dada por

$$
w_{\infty}(V)=\frac{1}{1+e^{\frac{\left(V-\theta_{w}\right)}{k_{w}}}}
$$

em que

$\theta_{w}$ é o potencial de meia ativação ou inativação (em $\left.\mathrm{mV}\right)$.

$k_{w}$ é a sensibilidade da ativação ou inativação (em $\mathrm{mV}$ ).

A constante de tempo $\tau_{w}(V)$, em geral, possui um valor fixo. Porém as constantes de tempo associadas à inativação do canal de $\mathrm{Na}^{+}$e à ativação de $\mathrm{K}^{+}$rápido do compartimento somático são funções do potencial de membrana somático $V_{S}$ (Equações (17) e (18)).

$$
\begin{gathered}
\tau_{N a_{h}}\left(V_{S}\right)=\frac{120}{e^{\left(\frac{V_{S}+50}{15}\right)}+e^{-\left(\frac{V_{S}+50}{16}\right)}} \\
\tau_{K d r_{n}}\left(V_{S}\right)=\frac{28}{e^{\left(\frac{V_{S}+40}{40}\right)}+e^{-\left(\frac{V_{S}+40}{50}\right)}}
\end{gathered}
$$

O balanço de corrente entre a membrana neuronal é representado, então, por uma equação como

$$
C_{m} \frac{d V}{d t}=-\sum_{i o n} I_{i o n}-g_{L}\left(V-E_{L}\right)-I_{s y n}+I_{a p p}
$$

em que

$C_{m}$ é a capacitância específica da membrana $\left(\mathrm{em} \mu \mathrm{F} / \mathrm{cm}^{2}\right)$.

$I_{\text {syn }}$ é a corrente sináptica, se presente $\left(\mathrm{em} \mu A / \mathrm{cm}^{2}\right)$.

$I_{a p p}$ é a corrente injetada (em $\left.\mu A / \mathrm{cm}^{2}\right)$.

O modelo de Hodgkin-Huxley original apresenta apenas condutâncias dependentes de voltagem. Porém, há vários outros tipos de canais iônicos que dependentes de outros fatores além do potencial de membrana, incluindo canais que cuja ativação depende da sua ligação com certas moléculas. A concentração intracelular do íon $\mathrm{Ca}^{2+}$ é um destes fatores que 
influenciam a ativação de certos canais e uma modelagem simples desta concentração supõe que a concentração aumenta em decorrência do influxo de íons de $\mathrm{Ca}^{2+}$ por canais de cálcio e que um processo de bombeamento linear pela membrana plasmática remove tais íons da célula. A quantidade total de cálcio numa célula ou em um compartimento celular é composta por cálcio livre e por cálcio ligado. Assim, a dinâmica da concentração de cálcio $\left[\mathrm{Ca}^{2+}\right]$ (em $\mu M)$ é representada por

$$
\frac{d}{d t}\left[C a^{2+}\right]=\lambda\left(-\alpha I_{C a}-r_{C a}\left[C a^{2+}\right]\right)
$$

em que

$\lambda$ é a porcentagem de cálcio livre.

$\alpha$ é um fator que converte a corrente iônica, $I_{C a}$, para uma taxa de variação da concentração de cálcio.

$r_{C a}$ é a taxa de remoção devida à bomba de cálcio.

Neste trabalho emprega-se um modelo fenomenológico de MN constituído por dois compartimentos: um representando o soma e a região proximal da árvore dendrítica e outro representando a região distal da árvore dendrítica (BOOTH; RINZEL; KIEHN, 1997; KURIAN; CROOK; JUNG, 2011; WILLIAMS; BAKER, 2009a). Esta estrutura está ilustrada na Figura 4-1.

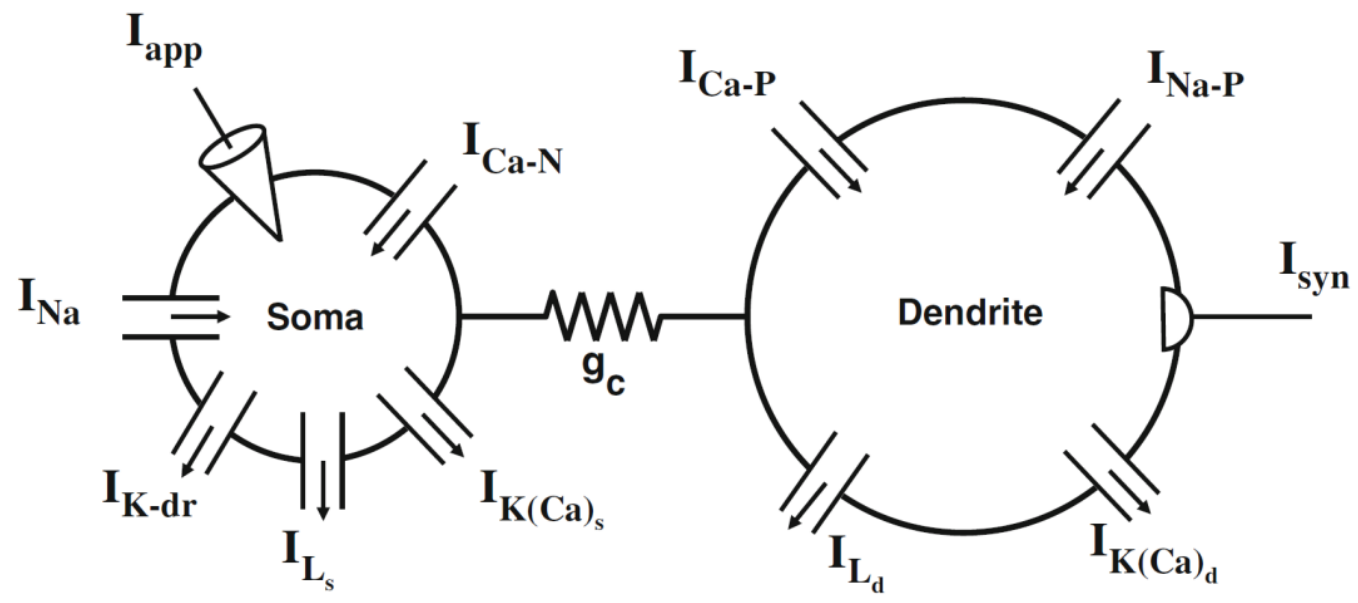

Figura 4-1 - Esquema do modelo motoneuronal de dois compartimentos ilustrando os tipos de correntes presentes em cada compartimento. Figura retirada de (KURIAN; CROOK; JUNG, 2011). 
A Figura 4-2 mostra um diagrama de circuito elétrico que representa o modelo. A convenção adotada é a de que uma corrente é positiva quando está saindo da célula.

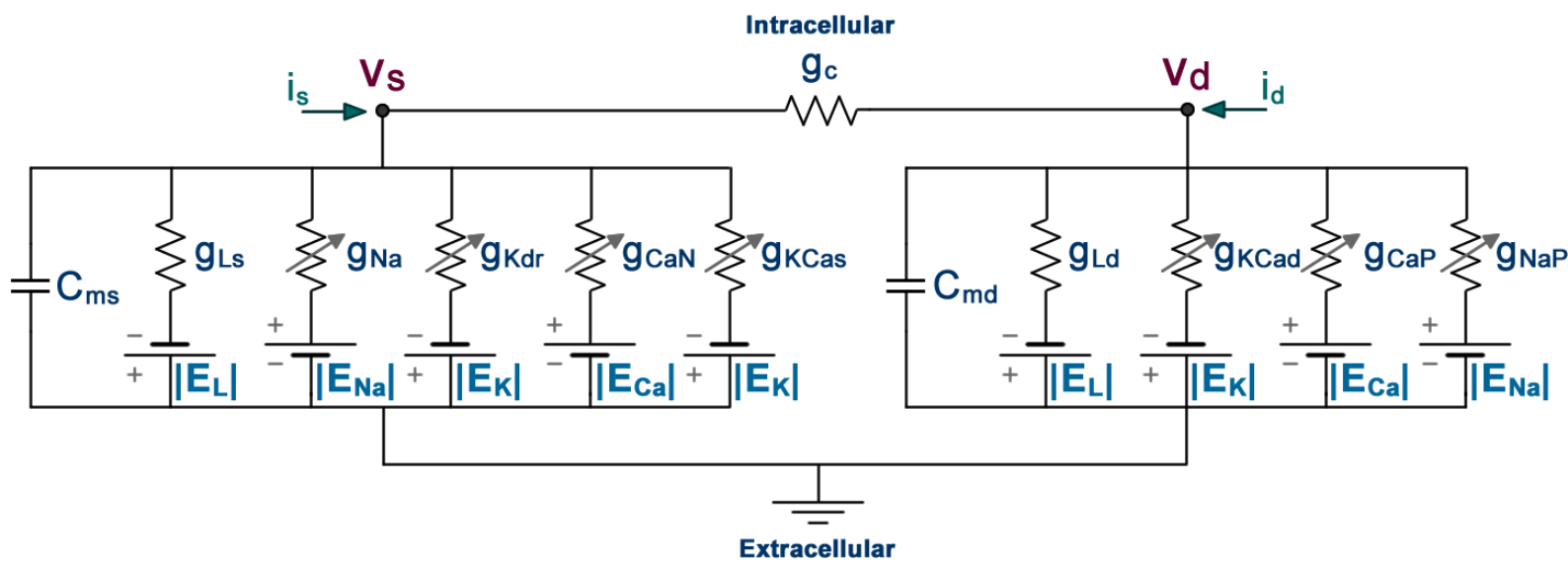

Figura 4-2 - Circuito elétrico que representa o modelo de motoneurônio. $C_{m s}$ e $C_{m d}$ são as capacitâncias específicas, enquanto $V_{s}$ e $V_{d}$ são os potenciais de membrana dos compartimentos somático e dendrítico, respectivamente; $g_{c}$ é a condutância de acoplamento entre os dois compartimentos; $g_{L}$ é a condutância de fuga do compartimento; $g_{x}$ e $E_{x}$ representam a condutância e o potencial de reversão (Nernst) associados à corrente iônica $\mathrm{x}$, em que $\mathrm{x}$ é substituído por Na: sódio; Kdr: potássio; CaN: cálcio tipo N; KCa: potássio dependente de cálcio; NaP: sódio persistente; $\mathrm{CaP}$ : cálcio persistente. $O$ sinal do potencial de reversão de cada corrente iônica é representado pela polarização da bateria, com referência ao meio extracelular. Por exemplo, o potencial de reversão do Na possui sinal positivo, enquanto que o do K possui sinal negativo.

A seguir, são descritas as equações que regem cada correte iônica presente no modelo, assim como o balanço destas correntes nos dois compartimentos. O balanço de corrente no compartimento somático é dado por

$$
C_{m s} \frac{d V_{s}}{d t}=-I_{N a}-I_{K d r}-I_{C a N}-I_{K C a S}-I_{L S}+\frac{g_{c}}{p}\left(V_{d}-V_{s}\right)+I_{s}(t)
$$

em que

$V_{S}$ é o potencial de membrana no soma.

$I_{N a}$ é uma corrente de sódio (rápida).

$I_{K d r}$ é uma corrente de potássio (delayed-rectifier).

$I_{\text {CaN }}$ é uma corrente de cálcio do tipo $\mathrm{N}$.

$I_{K C a S}$ é uma corrente de potássio dependente da concentração intracelular de cálcio.

$I_{L S}$ é uma corrente de fuga no soma.

$I_{S}$ representa uma corrente injetada no soma ( $I_{a p p}$ na Figura 4-1).

$g_{c}$ é a condutância de acoplamento entre os dois compartimentos.

$p$ é a porcentagem da área somática em relação à área total do MN. 
No compartimento dendrítico tem-se

$$
C_{m d} \frac{d V_{d}}{d t}=-I_{K C a d}-I_{C a P}-I_{N a P}-I_{L d}+\frac{g_{c}}{1-p}\left(V_{s}-V_{d}\right)+I_{d}(t)
$$

em que

$V_{d}$ é o potencial de membrana no dendrito.

$I_{K C a d}$ é uma corrente de potássio dependente da concentração intracelular de cálcio.

$I_{C a P}$ é uma corrente de cálcio persistente.

$I_{N a P}$ é uma corrente de sódio persistente.

$I_{L d}$ é uma corrente de fuga no dendrito.

$g_{c}$ é a condutância de acoplamento entre os dois compartimentos.

$p$ é a porcentagem da área somática em relação à área total do $\mathrm{MN}$.

As correntes são definidas pelas seguintes equações.

$$
\begin{gathered}
I_{N a}=g_{N a} m_{\infty(N a)}^{3}\left(V_{S}\right) h_{N a}\left(V_{S}-E_{N a}\right) \\
I_{K d r}=g_{K d r} n^{4}\left(V_{s}-E_{K}\right) \\
I_{C a N}=g_{C a N} m_{C a N}^{2} h_{C a N}\left(V_{S}-E_{C a}\right) \\
I_{K C a s}=g_{K C a s} \frac{\left[C a^{2+}\right]}{\left[C a^{2+}\right]+S_{C a}}\left(V_{s}-E_{K}\right) \\
I_{K C a d}=g_{K C a d} \frac{\left[C a^{2+}\right]}{\left[C a^{2+}\right]+S_{C a}}\left(V_{d}-E_{K}\right) \\
I_{C a P}=g_{C a P} m_{C a P}\left(V_{d}-E_{C a}\right) \\
I_{N a P}=g_{N a P} m_{N a P} h_{N a P}\left(V_{d}-E_{N a}\right) \\
I_{L s}=g_{L s}\left(V_{s}-E_{L}\right) \\
I_{L d}=g_{L d}\left(V_{d}-E_{L}\right)
\end{gathered}
$$


Como já explicitado em alguns casos, neste modelo, as condutâncias e as capacitâncias são divididas pela área do respectivo compartimento. As condutâncias são expressas em $\mathrm{mS} / \mathrm{cm}^{2}$, as capacitâncias em $u F / \mathrm{cm}^{2}$ e toda corrente possui unidade de $\mu A / \mathrm{cm}^{2}$, enquanto que o potencial de membrana é dado em $m V$. Não há, neste modelo, difusão dos íons de $\mathrm{Ca}^{2+}$ entre os compartimentos. A concentração de cálcio no soma é afetada por $I_{C a N}$, enquanto que a concentração de cálcio nos dendritos é afetada por $I_{C a P}$, assim como em (KURIAN; CROOK; JUNG, 2011).

\subsubsection{Parametrização das propriedades passivas}

O modelo de MN descrito na seção anterior possui grandezas que são "normalizadas" pela área do compartimento em questão. Sabe-se, porém, que os MNs que constituem um determinado pool possuem tamanhos variados e estas diferenças morfológicas contribuem para que haja uma dispersão das características fisiológicas dos MNs de um determinado pool. Desta forma, a parametrização das propriedades passivas (i.e., propriedades que não dependem do potencial de membrana) no modelo de MN deve servir tanto para conferir a MNs individuais características anatômicas que influenciam a sua atividade quanto para que seja representada a dispersão das características anatômicas e fisiológicas de um determinado pool de MNs.

Enquanto modelos multi-compartimentais podem representar de forma mais próxima da realidade as características do neurônio, os modelos de dois compartimentos têm sido amplamente empregados por serem passíveis de análise matemática e por muitas vezes serem suficientes para representar um fenômeno de interesse. Até recentemente, os modelos de dois compartimentos tinham seus parâmetros designados fenomenologicamente, ou seja, de forma a reproduzir certo comportamento desejado, e não necessariamente possuíam um correlato físico (PINSKY; RINZEL, 1994). Porém, os trabalhos recentes de Kim e Jones (KIM; JONES, 2011, 2012; KIM; MAJOR; JONES, 2009) propiciam uma metodologia para parametrizar as propriedades passivas do modelo de dois compartimentos, a partir de dados eletrotônicos reais, permitindo reproduzir, de forma comparável a modelos morfologicamente realistas, certas características dos MNs. Em especial, é analisada, nestes trabalhos, a representação da DDVA, ou seja, qual o decaimento do potencial elétrico transmitido de um compartimento para o outro. Os autores mostraram que esta característica exerce um 
importante papel no efeito dos potenciais-platô (KIM; JONES, 2011), de retro-propagação de APs e na biestabilidade dos MNs (KIM; JONES, 2012), vistos por modelagem e simulação. A metodologia de Kim e Jones emprega cinco parâmetros eletrotônicos:

- $r_{n}$ : resistência de entrada somática normalizada pela área do soma.

- $\tau_{m}$ : constante de tempo da membrana.

- $V A_{S D}^{D C}$ : atenuação do potencial de membrana do soma pros dendritos (em regime estacionário).

- $\quad V A_{D S}^{D C}$ : atenuação do potencial de membrana dos dendritos pro soma (em regime estacionário).

- $V A_{D S}^{A C}$ : atenuação do potencial de membrana dos dendritos pro soma (a $250 \mathrm{~Hz}$ ).

Com isto, determina-se os parâmetros passivos do modelo: $g_{L s}, g_{L d}, g_{c}, C_{m d}$ e $C_{m s}$ (ver Apêndice 1). No presente trabalho, a metodologia proposta em (KIM; JONES, 2012) é utilizada para a parametrização das propriedades passivas dos MNs. São adotadas as seguintes suposições:

- A distância $D$ entre o soma e o ponto da árvore dendrítica onde se realizam as medidas de DDVA é fixada em $300 \mu m$.

- O fator $p$ é também fixo em um valor de 1,68.

- Apesar de ter sido mostrado em (KIM; MAJOR; JONES, 2009) que as DDVAs variam com a resistência de entrada, não são fornecidas funções que permitam ajustar estes dados. Desta forma, supõe-se que as variações das DDVAs com a resistência de entrada sejam aproximadamente proporcionais, mantendo o nível de assimetria do modelo. Assim, neste trabalho, as DDVAs constantes e especificadas pelos seguintes valores:

○ $V A_{S D}^{D C}=0,89$

○ $V A_{D S}^{D C}=0,26$

○ $V A_{S D}^{A C}=0,49$

- A resistência de entrada e a constante de tempo da membrana são baseadas em (ZENGEL et al., 1985). Além disto, supõe-se que os MNs com maiores valores de resistência de entrada possuem maiores valores de constante de tempo, dada a correlação mostrada em (ZENGEL et al., 1985) entre estas grandezas. 
- A fim de simplificar a atribuição dos parâmetros, foram adotados valores fixos para as capacitâncias de membrana, não tendo sido utilizado então o parâmetro $V A_{D S}^{A C}$ da metodologia de Kim e Jones. Porém, tais capacitâncias possuem uma assimetria soma-dendrito similar à empregada em (KIM; JONES, 2012).

A Tabela 4-1 resume os dados discutidos e indica suas referências.

Tabela 4-1. Comparativo dos parâmetros associados às características passivas dos MNs. $R_{n}$ é a resistência de entrada no soma, $\tau_{m}$ é a constante de tempo da membrana, $p$ é a relação entre a área do compartimento somático $\left(A_{s}\right)$ e a área total, $D$ é a distância com relação ao centro do soma em que se divide o MN em dois compartimentos.

\begin{tabular}{|c|c|c|c|}
\hline (ZENGEL et al., 1985) & $\begin{array}{c}\text { (FLESHMAN; SEGEV; BURKE, } \\
\text { 1988; SEGEV; FLESHMAN; } \\
\text { BURKE, 1990) }\end{array}$ & $\begin{array}{c}\text { (KIM; JONES, } \\
\text { 2012) }\end{array}$ & Parâmetros adotados \\
\hline $\begin{array}{l}R_{n}=0,4 a 4,0 \mathrm{M} \Omega \\
\tau_{m} \\
=4,0 a 14,0 \mathrm{~ms} \\
I_{r h}=2 a 38 \mathrm{nA}\end{array}$ & $\begin{array}{l}R_{n}=0,7 \text { a } 4,2 \mathrm{M} \Omega \\
\tau_{m}=7,1 \text { a } 13,0 \mathrm{~ms} \\
\text { Área total } \\
=414.900 \text { a } 726.600 \mathrm{\mu m}^{2}\end{array}$ & $\begin{array}{l}p=0,168 \\
D=300 \mu m\end{array}$ & $\begin{array}{l}p=0,168 \\
D=300 \mu \mathrm{m} \\
R_{n}=0,4 \mathrm{a} 4,0 \mathrm{M} \Omega \\
\text { Área total } \\
=400.000 \text { a } 700.000 \mathrm{\mu m}^{2} \\
A_{s}=p * \text { Área total } \\
=67.200 \text { a } 117.600 \mathrm{\mu m}^{2}\end{array}$ \\
\hline
\end{tabular}

A Tabela 4-2 mostra os parâmetros passivos resultantes da metodologia adotada. São mostrados os valores para o menor e para o maior MN. A distribuição dos parâmetros para os MNs intermediários foi feita de forma linear.

Tabela 4-2. Parâmetros associados às características passivas do modelo de MN. Notar que $r_{n}, g_{L s}, g_{L d}, g_{c}, C_{m d}, e C_{m s}$ são grandezas normalizados pela área de seu respectivo compartimento.

\begin{tabular}{|c|c|c|c|}
\hline Parâmetro & Símbolo (unidade) & Menor MN & Maior MN \\
\hline Área do compartimento somático & $A_{s}\left(\mathrm{~cm}^{2}\right)$ & $0,672 \cdot 10^{-3}$ & $1,176.10^{-3}$ \\
\hline Área do compartimento dendrítico & $A_{d}\left(\mathrm{~cm}^{2}\right)$ & $3,3 \cdot 10^{-3}$ & $5,8 \cdot 10^{-3}$ \\
\hline Resistência de entrada do soma & $R_{n}(M \Omega)$ & 4,0 & 0,4 \\
\hline $\begin{array}{l}\text { Resistência de entrada do } \\
\text { compartimento somático }\end{array}$ & $r_{n}\left(k \Omega . \mathrm{cm}^{2}\right)$ & 2,69 & 0,47 \\
\hline $\begin{array}{l}\text { Condutância específica (de fuga) do } \\
\text { compartimento somático }\end{array}$ & $g_{L S}\left(\mathrm{mS} / \mathrm{cm}^{2}\right)$ & 0,358 & 2,05 \\
\hline $\begin{array}{l}\text { Condutância específica (de fuga) do } \\
\text { compartimento dendrítico }\end{array}$ & $g_{L d}\left(m S / \mathrm{cm}^{2}\right)$ & 0,0031 & 0,018 \\
\hline $\begin{array}{l}\text { Condutância de acoplamento entre os } \\
\text { compartimentos }\end{array}$ & $g_{c}\left(\mathrm{mS} / \mathrm{cm}^{2}\right)$ & 0,0211 & 0,121 \\
\hline $\begin{array}{l}\text { Capacitância de membrana do } \\
\text { compartimento somático }\end{array}$ & $C_{m s}\left(\mu F / \mathrm{cm}^{2}\right)$ & 5,0 & 5,0 \\
\hline $\begin{array}{l}\text { Capacitância de membrana do } \\
\text { compartimento dendrítico }\end{array}$ & $C_{m d}\left(\mu F / \mathrm{cm}^{2}\right)$ & 0,05 & 0,05 \\
\hline
\end{tabular}




\subsubsection{Parametrização das propriedades ativas}

Os parâmetros associados às propriedades ativas (dependentes de voltagem) do MN foram em grande parte baseados em trabalhos anteriores (BOOTH; RINZEL; KIEHN, 1997; KURIAN; CROOK; JUNG, 2011). Porém, certas modificações importantes foram realizadas a fim de melhor representar os dados experimentais. A Tabela 4-3 mostra os valores adotados para os parâmetros associados a cada corrente iônica presente no compartimento somático. Como pode ser observado, não há uma dispersão destes parâmetros para os diferentes MN do pool, exceto o parâmetro $\tau_{\mathrm{CaN}_{h}}$, o qual resulta em diferentes características da AHP para os MNs (ver seção 4.3.2).

Tabela 4-3. Parâmetros associados às características ativas do compartimento somático do modelo de MN. $g_{x}$ é a máxima condutância, $E_{x}$ é o potencial de reversão, $\theta_{x_{w}}$ é o potencial de meia ativação/inativação, $\boldsymbol{k}_{x_{w}}$ é a sensibilidade de ativação/inativação e $\tau_{x_{w}}$ é a constante de tempo de ativação/inativação associados ao canal iônico $x$ e à variável de ativação/inativação $w$. Notar que as condutâncias máximas para cada tipo de canal iônico são normalizadas pela área do compartimento somático.

\begin{tabular}{|c|c|c|c|}
\hline Corrente iônica & Parâmetro & Menor MN & Maior MN \\
\hline \multirow{7}{*}{$\begin{array}{l}\text { Sódio rápida } \\
\text { (Na) }\end{array}$} & $g_{N a}\left(m S / c^{2}\right)$ & 120 & 120 \\
\hline & $E_{N a}(m V)$ & 55 & 55 \\
\hline & $\theta_{N a_{m}}(m V)$ & -35 & -35 \\
\hline & $\theta_{N a_{h}}(m V)$ & -55 & -55 \\
\hline & $k_{N a_{m}}(m V)$ & $-7,8$ & $-7,8$ \\
\hline & $k_{N a_{h}}(m V)$ & 7 & 7 \\
\hline & $\tau_{N a_{h}}(m s)$ & Eq. (17) & Eq. (17) \\
\hline \multirow{5}{*}{$\begin{array}{c}\text { Potássio delayed-rectifier } \\
\text { (Kdr) }\end{array}$} & $g_{K d r}\left(m S / c^{2}\right)$ & 100 & 100 \\
\hline & $E_{K d r}(m V)$ & -80 & -80 \\
\hline & $\theta_{K d r_{n}}(m V)$ & -28 & -28 \\
\hline & $k_{K d r_{n}}(m V)$ & -15 & -15 \\
\hline & $\tau_{N a_{h}}(m s)$ & Eq. (18) & Eq. (18) \\
\hline \multirow{8}{*}{$\begin{array}{l}\text { Cálcio tipo-N } \\
\quad(\mathrm{CaN})\end{array}$} & $g_{\text {CaN }}\left(\mathrm{mS} / \mathrm{cm}^{2}\right)$ & 10 & 10 \\
\hline & $E_{K d r}(m V)$ & 80 & 80 \\
\hline & $\theta_{\mathrm{CaN}_{m}}(\mathrm{mV})$ & -30 & -30 \\
\hline & $\theta_{\operatorname{CaN}_{h}}(m V)$ & -45 & -45 \\
\hline & $k_{\mathrm{CaN}_{m}}(\mathrm{mV})$ & -5 & -5 \\
\hline & $k_{\mathrm{CaN}_{h}}(\mathrm{mV})$ & 5 & 5 \\
\hline & $\tau_{\mathrm{CaN}_{m}}(\mathrm{~ms})$ & 16 & 16 \\
\hline & $\tau_{\mathrm{CaN}_{h}}(m s)$ & 160 & 10 \\
\hline \multirow{2}{*}{$\begin{array}{l}\text { Potássio dependente de cálcio } \\
\text { (KCaS) }\end{array}$} & $g_{K C a S}\left(m S / \mathrm{cm}^{2}\right)$ & 10 & 10 \\
\hline & $E_{K C a S}(m V)$ & -80 & -80 \\
\hline
\end{tabular}


A Tabela 4-4 mostra os valores adotados para os parâmetros associados a cada corrente iônica presente no compartimento dendrítico. Como pode ser observado, não há uma dispersão destes parâmetros para os diferentes $\mathrm{MN}$ do pool, exceto o parâmetro $\tau_{N a P_{h}}$, o qual resulta em diferentes tempos de decaimento da corrente de NaP para os MNs (ver Figura 4-5 e Figura 4-6).

Tabela 4-4. Parâmetros associados às características ativas do compartimento dendrítico do modelo de MN. $g_{x}$ é a máxima condutância, $E_{x}$ é o potencial de reversão, $\theta_{x_{w}}$ é o potencial de meia ativação/inativação, $\boldsymbol{k}_{x_{w}}$ é a sensibilidade de ativação/inativação e $\tau_{x_{w}}$ é a constante de tempo de ativação/inativação associados ao canal iônico $x$ e à variável de ativação/inativação $w$. Notar que as condutâncias máximas para cada tipo de canal iônico são normalizadas pela área do compartimento dendrítico.

\begin{tabular}{|c|c|c|c|}
\hline Corrente iônica & Parâmetro & Menor MN & Maior MN \\
\hline \multirow{4}{*}{$\begin{array}{c}\text { Cálcio persistente } \\
\text { (CaP) }\end{array}$} & $g_{C a P}\left(\mathrm{mS} / \mathrm{cm}^{2}\right)$ & 0,06 & 0,06 \\
\cline { 2 - 4 } & $E_{C a}(\mathrm{mV})$ & 80 & 80 \\
\cline { 2 - 4 } & $\theta_{C a P_{m}}(\mathrm{mV})$ & -25 & -25 \\
\cline { 2 - 4 } & $k_{C a P_{m}}(\mathrm{mV})$ & -7 & -7 \\
\cline { 2 - 4 } & $\tau_{C a P_{m}}(\mathrm{~ms})$ & 50 & 50 \\
\hline \multirow{5}{*}{$\begin{array}{c}\text { Sódio persistente } \\
\text { (NaP) }\end{array}$} & $g_{N a P}\left(\mathrm{mS} / \mathrm{cm}^{2}\right)$ & 0,01 & 0,01 \\
\cline { 2 - 4 } & $E_{N a P}(\mathrm{mV})$ & 55 & 55 \\
\cline { 2 - 4 } & $\theta_{N a P_{m}}(\mathrm{mV})$ & -35 & -35 \\
\cline { 2 - 4 } & $\theta_{N a P_{h}}(\mathrm{mV})$ & -45 & -45 \\
\cline { 2 - 4 } & $k_{N a P_{m}}(\mathrm{mV})$ & -3 & -3 \\
\cline { 2 - 4 } & $k_{N a P_{h}}(\mathrm{mV})$ & 6 & 6 \\
\cline { 2 - 4 } & $\tau_{N a P_{m}}(\mathrm{~ms})$ & 5 & 2000 \\
\cline { 2 - 4 } & $\tau_{N a P_{h}}(\mathrm{~ms})$ & 20000 & 0.8 \\
\hline \multirow{5}{*}{$\begin{array}{c}\text { Potássio dependente de cálcio } \\
\text { (KCaD) }\end{array}$} & $g_{K C a D}\left(\mathrm{mS} / \mathrm{cm}^{2}\right)$ & 0.8 & -80 \\
\cline { 2 - 4 } & $E_{K C a D}(\mathrm{mV})$ & -80 & 5 \\
\hline
\end{tabular}

Por fim, a Tabela 4-5 mostra os parâmetros adotados para a dinâmica de cálcio, iguais aos de (BOOTH; RINZEL; KIEHN, 1997; KURIAN; CROOK; JUNG, 2011).

Tabela 4-5. Parâmetros associados à dinâmica de cálcio

\begin{tabular}{|l|c|c|}
\hline \multicolumn{1}{|c|}{ Parâmetro } & $\begin{array}{c}\text { Símbolo } \\
\text { (unidade) }\end{array}$ & Valor \\
\hline Porcentagem de cálcio livre & $\lambda$ & 0,01 \\
\hline $\begin{array}{l}\text { Fator que converte a corrente iônica } \boldsymbol{I}_{\boldsymbol{C a}} \text { para uma taxa } \\
\text { de variação da concentração de cálcio }\end{array}$ & $\alpha\left(\frac{\mathrm{mol}}{\mathrm{C} \cdot \mathrm{cm}}\right)$ & 0,009 \\
\hline Taxa de remoção devida à bomba de cálcio & $r_{C a}\left(\mathrm{~ms}^{-1}\right)$ & 2 \\
\hline Meia saturação da concentração de cálcio & $S_{C a}(\mu M)$ & 0,2 \\
\hline
\end{tabular}




\subsubsection{Variáveis de estado do modelo}

As figuras a seguir ilustram o comportamento modelado para as variáveis de estado associadas a cada MN do pool (Figura 4-3 e Figura 4-5), e suas constantes de tempo (Figura 4-4 e Figura 4-6), conforme se varia o potencial do compartimento.
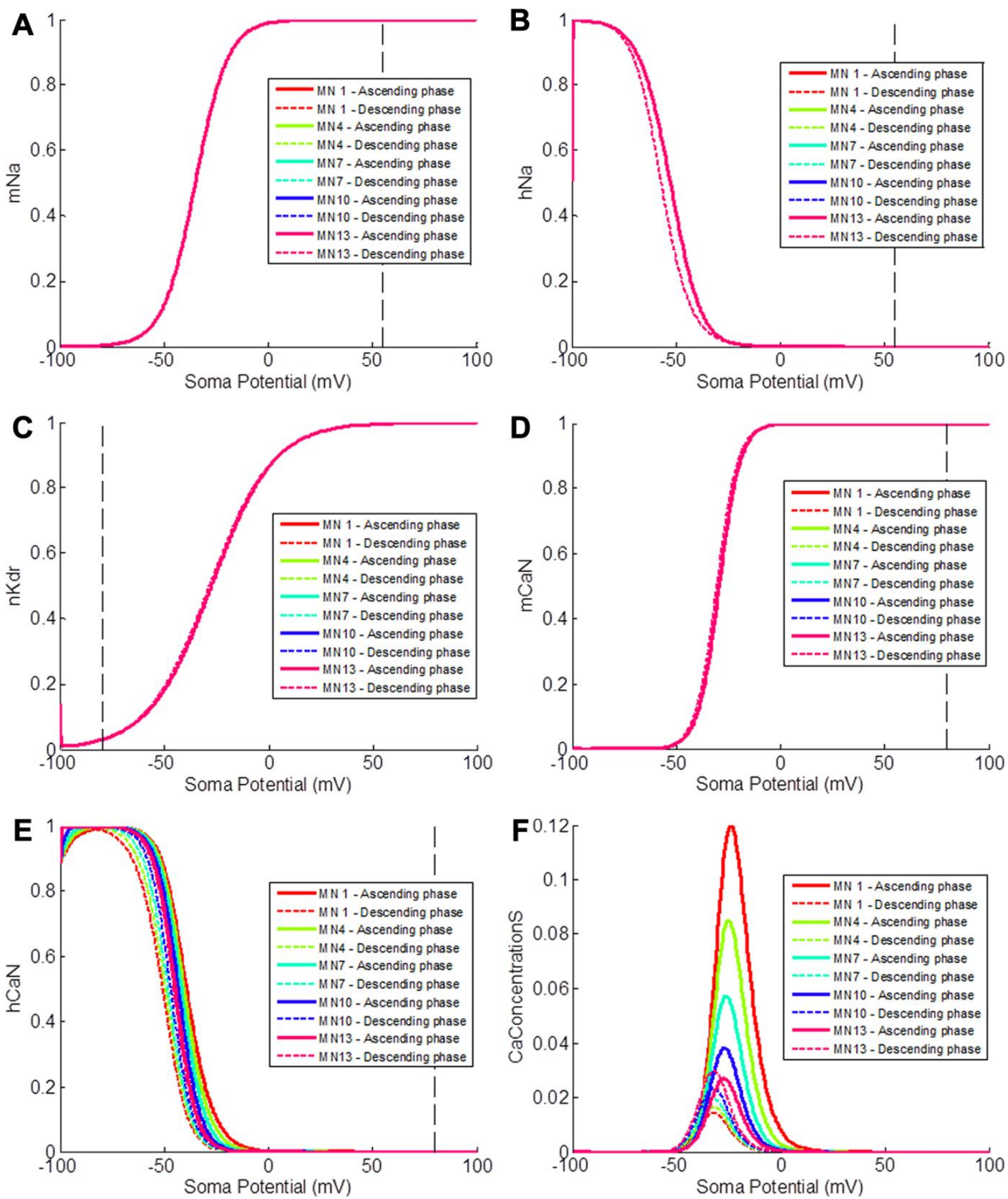

Figura 4-3 - Variáveis de estado (variáveis de ativação e de inativação; e concentração de cálcio) associadas ao compartimento somático com um voltage-clamp triangular lento sobre este compartimento. As linhas tracejadas indicam o valor do potencial de reversão para a corrente iônica associada a cada variável de ativação ou inativação. 
A fim de facilitar a visualização e as simulações o pool de MNs foi constituído por apenas $13 \mathrm{MNs}$, estes, porém, abrangendo toda faixa de parâmetros estabelecida. Estes MNs mostrados podem ser pensados como uma amostragem de um pool de MNs mais numeroso, sendo o MN 1 o menor e o MN 13 o maior.
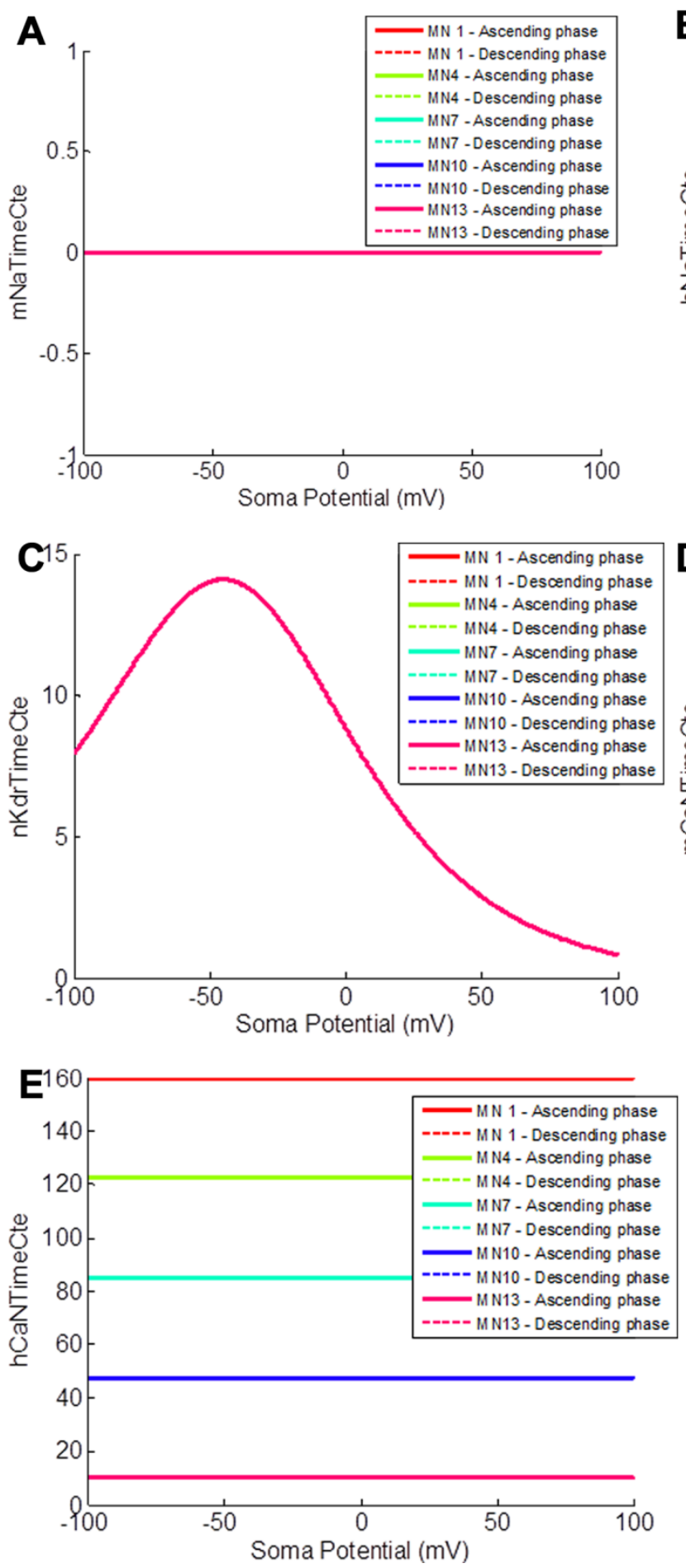
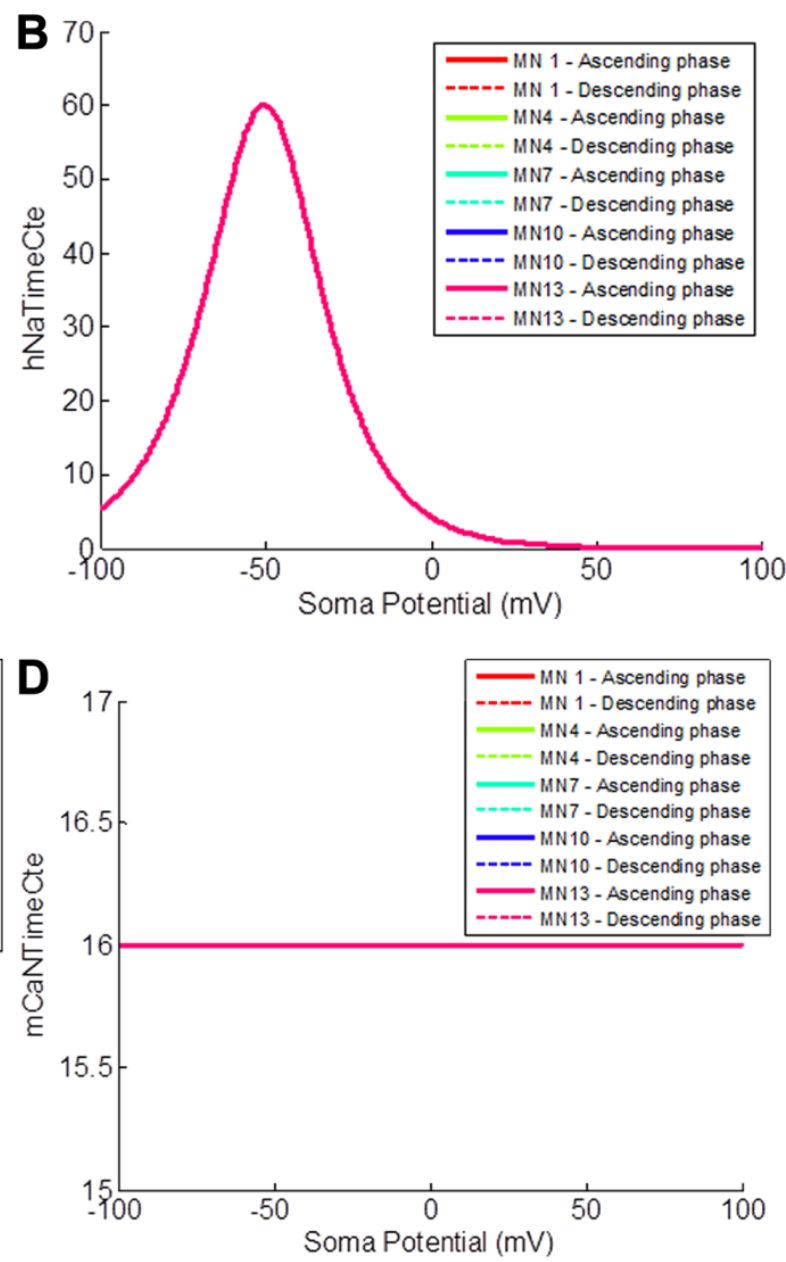

Figura 4-4 - Constantes de tempo associadas às condutâncias ativas no compartimento somático com um voltageclamp triangular lento sobre este compartimento. As linhas tracejadas indicam o valor do potencial de reversão para a corrente iônica associada a cada variável de ativação ou inativação. 
As relações mostradas na Figura 4-3 e na Figura 4-5 são resultantes da Equação (15) e da Equação (16), com a parametrização adotada, exceto as relações da Figura 4-3F e na Figura 4-5E (concentrações de cálcio), que obedecem à Equação (20) e são dependentes de outras variáveis de estado, as quais influenciam as correntes de cálcio.
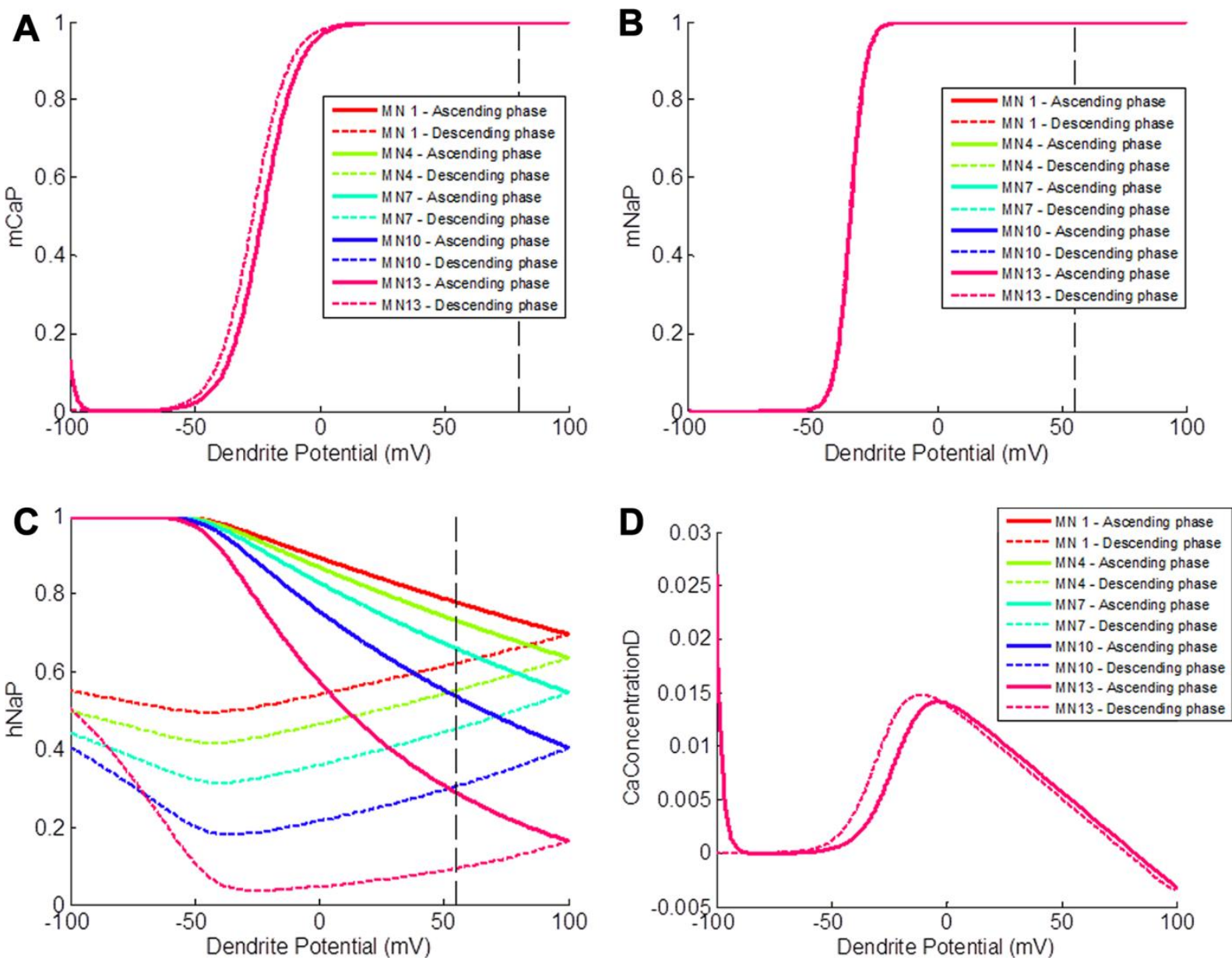

Figura 4-5 - Variáveis de estado (variáveis de ativação e de inativação; e concentração de cálcio) associadas ao compartimento dendrítico com um voltage-clamp triangular sobre o mesmo compartimento. As linhas tracejadas indicam o valor do potencial de reversão para a corrente iônica associada a cada variável de ativação ou inativação.

Dentre os MNs do pool, nota-se que os diferentes valores especificados para a constante de tempo associada à inativação da corrente CaN somática resultam em diferentes comportamentos para hCaN (Figura 4-3E) e para a concentração de cálcio neste compartimento (Figura 4-3F), durante o voltage-clamp. O mesmo vale para a constante de tempo associada à inativação da corrente NaP dendrítica (Figura 4-6B), influenciando hNaP (Figura 4-5C). 

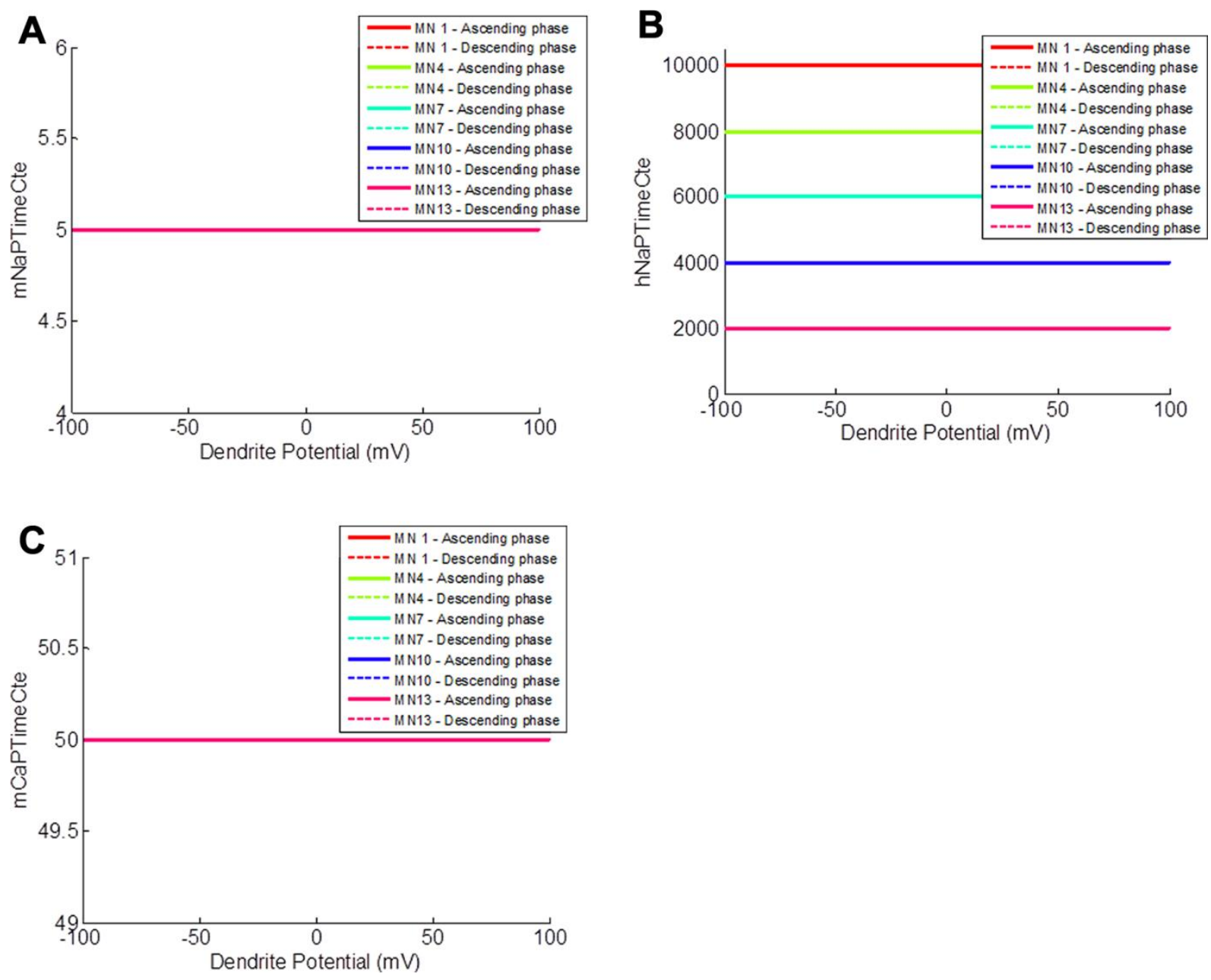

Figura 4-6 - Constantes de tempo associadas às condutâncias ativas no compartimento dendrítico com um voltageclamp triangular lento sobre o mesmo compartimento. As linhas tracejadas indicam o valor do potencial de reversão para a corrente iônica associada a cada variável de ativação ou inativação.

Além do cenário constituído pela parametrização mostrada e que resulta em um nível de excitabilidade chamado aqui de intermediário, outros dois cenários (conjunto de parâmetros) foram criados: o "cenário base", no qual as condutâncias $\mathrm{NaP}$ e CaP no compartimento dendrítico são desativadas; e o "cenário de alta excitabilidade", cuja única diferença com o cenário de excitabilidade intermediária é a alteração do parâmetro $\theta_{N a P_{m}}$ de $-35 \mathrm{mV}$ para $-55 \mathrm{mV}$.

Todas as simulações deste trabalho foram realizadas empregando o método de Euler para integração das equações diferenciais, com um passo de $0,01 \mathrm{~ms}$. 


\subsubsection{Protocolos de simulação}

Em uma primeira etapa, foram determinadas as propriedades passivas resultantes da parametrização adotada para o pool de MNs. A resistência específica é igual ao inverso da condutância específica (de fuga) (ver Tabela 4-2). A faixa de constantes de tempo de membrana do compartimento somático foi calculada desprezando-se a condutância de acoplamento entre os dois compartimentos, sendo que esta é mais de dez vezes menor que a condutância de fuga do compartimento somático. Portanto, a constante de tempo foi calculada como $\tau_{m s}=r_{m s} C_{m s}$.

A fim de avaliar as características dinâmicas da DDVA (KIM; JONES, 2012), foram simulados voltage-clamps senoidais (frequência de $250 \mathrm{~Hz}$ e $1 \mathrm{mV}$ de amplitude) no compartimento somático. Foi medida a amplitude do potencial elétrico no compartimento dendrítico e a defasagem entre o potencial somático e dendrítico. O módulo da DDVA dinâmica foi, então, calculado como a razão entre a amplitude do potencial do compartimento dendrito e do compartimento somático.

Foram realizadas simulações para determinar as correntes de reobase e os potenciais de limiar (thresholds) para os diferentes MNs do pool. Tais simulações mimetizaram os experimentos de (GUSTAFSSON; PINTER, 1984a; POWERS; BINDER, 1985a) e consistiam na injeção de degraus de correntes, com amplitude cada vez maior, no compartimento somático, no modelo de cada MN. O passo de corrente utilizado entre cada simulação foi de $1,0 \mathrm{uA} / \mathrm{cm}^{2}$. A corrente de reobase foi definida como a amplitude da corrente em degrau injetada para a qual o MN dispara APs de forma sustentada. Já o limiar foi definido como o valor que o potencial somático atinge (em regime) com a injeção de corrente com amplitude $1,0 \mathrm{uA} / \mathrm{cm}^{2}$ menor que a reobase.

Como já foi dito, a AHP é uma importante propriedade intrínseca dos MNs. A fim de validar a modelagem adotada foram simulados protocolos semelhantes aos empregados experimentalmente para medir a amplitude e o tempo de meio-decaimento da AHP (GUSTAFSSON; PINTER, 1984b; ZENGEL et al., 1985) A simulação consistiu em um pulso de corrente de amplitude $150 \mathrm{nA} / \mathrm{cm}^{2}$ e duração $1 \mathrm{~ms}$ injetada no compartimento somático, tanto para o cenário base quanto para o cenário de alta excitabilidade.

Por fim, foram realizadas simulações de current-clamp triangulares, a fim de verificar o comportamento dinâmico do pool de MNs para os cenários base, de excitabilidade média e de alta excitabilidade. O sinal de corrente injetada no compartimento somático é semelhante ao 
empregado experimentalmente (LEE; HECKMAN, 1998a) e está representado na Figura 4-10A. Todos os MNs do pool receberam a mesma densidade de corrente, a qual começou em $0 \mathrm{uA} / \mathrm{cm}^{2}$, aumentou linearmente por $5 \mathrm{~s}$ até $70 \mathrm{uA} / \mathrm{cm}^{2}$ e diminui por $6 \mathrm{~s}$ até $-14 \mathrm{uA} / \mathrm{cm}^{2}$. A frequência instantânea de disparos foi calculada pelo inverso dos intervalos entre disparos.

Todas as simulações deste trabalho foram realizadas empregando o método de Euler para integração das equações diferenciais, com um passo de $0,01 \mathrm{~ms}$. 


\subsection{Resultados}

\subsubsection{Propriedades passivas}

A Tabela 4-6 mostra os valores obtidos para estas grandezas, resultantes da parametrização adotada (ver Tabela 4-2).

Tabela 4-6. Valores calculados de grandezas associadas às características passivas do modelo de motoneurônio.

\begin{tabular}{|l|c|c|c|}
\hline \multicolumn{1}{|c|}{ Parâmetro } & $\begin{array}{c}\text { Símbolo } \\
\text { (unidade) }\end{array}$ & Menor MN & Maior MN \\
\hline $\begin{array}{l}\text { Resistência específica da membrana } \\
\text { para o compartimento somático }\end{array}$ & $r_{m s}\left(k \Omega . \mathrm{cm}^{2}\right)$ & 2,79 & 0,489 \\
\hline $\begin{array}{l}\text { Resistência específica da membrana } \\
\text { para o compartimento dendrítico }\end{array}$ & $r_{m d}\left(k \Omega \mathrm{cm}^{2}\right)$ & 322 & 55,6 \\
\hline $\begin{array}{l}\text { Constante de tempo de membrana do } \\
\text { compartimento somático }\end{array}$ & $\tau_{m s}(m s)$ & 14,0 & 2,45 \\
\hline
\end{tabular}

Os valores de resistência específica de membrana, para ambos os compartimentos, concordam com o que se espera, baseando-se em dados experimentais (CLEMENTS; REDMAN, 1989; FLESHMAN; SEGEV; BURKE, 1988). Mesmo levando em consideração uma possível diminuição da resistência de entrada do soma durante a realização de experimentos em que um eletrodo é empalado no soma ("somatic shunt"), espera-se que o soma possua uma menor resistência específica do que a árvore dendrítica (POWERS; BINDER, 2001). A resistência específica do soma é várias vezes menor do que a da árvore dendrítica e os valores calculados para o presente modelo são da mesma ordem de grandeza daqueles encontrados em (CLEMENTS; REDMAN, 1989; FLESHMAN; SEGEV; BURKE, 1988). Da mesma forma, a faixa de valores para as constantes de tempo é muito próxima daquela encontrada experimentalmente (ver Tabela 4-1). 


\section{Atenuação do potencial dependente da direção}

A Figura 4-7 mostra o resultado do voltage-clamp senoidal $(250 \mathrm{~Hz})$ no compartimento somático, utilizando os valores de $C_{m d}$ e $C_{m s}$ apresentados na Tabela 4-2.

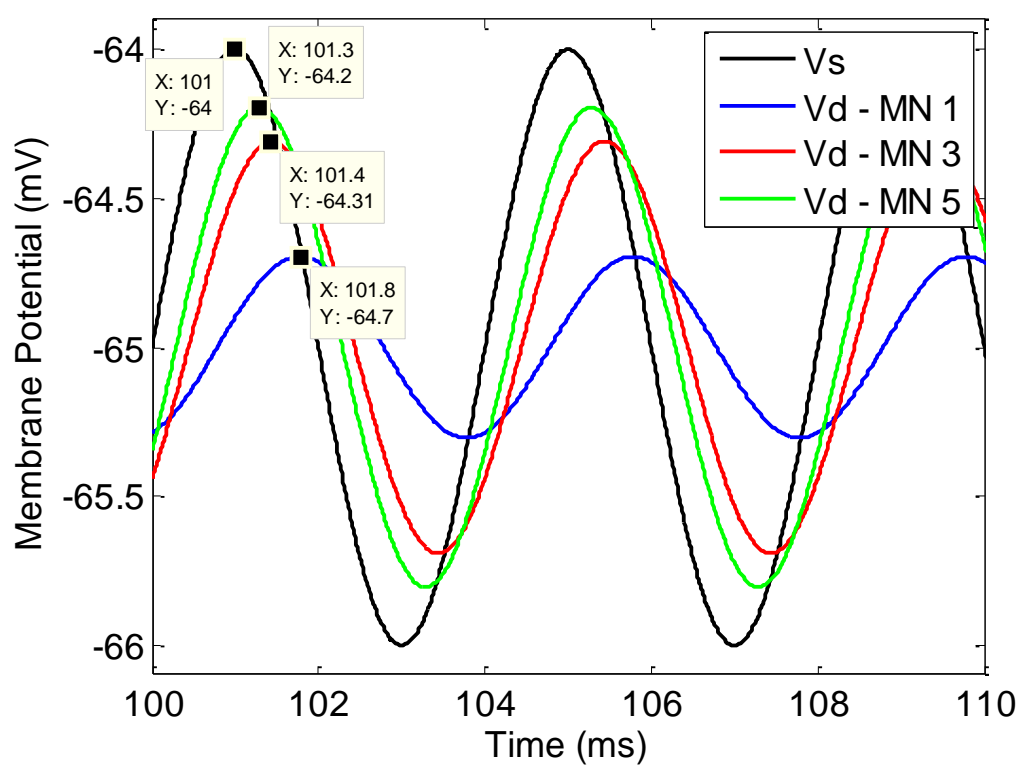

Figura 4-7 - Atenuação do potencial elétrico no compartimento dendrítico para um voltage-clamp senoidal no compartimento somático.

Os valores medidos a partir destas simulações encontram-se na Tabela 4-7. Mediu-se $\left|V A_{S D}^{A C}\right|$ variando entre 0,3 (menor $\mathrm{MN}$ ) e 0,8 (maior $\mathrm{MN}$ ). Esta faixa engloba o valor encontrado para um modelo morfologicamente realista (KIM; JONES, 2012) ( $\left|V A_{S D}^{A C}\right|$ médio de 0,49$)$. Medindo-se as defasagens entre o sinal aplicado ao soma e aquele medido no dendrito, a faixa de valores obtida foi de $-0,4 \pi$ (menor $\mathrm{MN}$ ) a $-0,15 \pi$ (maior $\mathrm{MN}$ ), ficando esta faixa também próxima do valor médio obtido para o modelo morfologicamente realista $(-0,30 \pi(\mathrm{KIM} ; \mathrm{JONES}, 2012))$.

Tabela 4-7. Valores de atenuação e defasagem do potencial elétrico medido no compartimento dendrítico para um voltage-clamp senoidal $(250 \mathrm{~Hz})$ no compartimento somático.

\begin{tabular}{|c|c|c|}
\hline & $\begin{array}{c}\text { DDVA AC (250 Hz) } \\
\text { (módulo) }\end{array}$ & DDVA AC (250 Hz) (defasagem) \\
\hline Menor MN & 0,3 & $0,4 \pi$ \\
\hline Médio MN & 0,69 & $0,2 \pi$ \\
\hline Maior MN & 0,8 & $0,15 \pi$ \\
\hline
\end{tabular}




\subsubsection{Propriedades ativas}

\section{Reobase e limiar}

A Figura 4-8 e a Tabela 4-8 mostram os resultados e as medidas de reobase e de potencial de limiar (threshold). Como houve passos de $1,0 \mathrm{uA} / \mathrm{cm}^{2}$ entre os valores de corrente injetada testados, as medidas de reobase e de limiar possuem uma incerteza, a qual é indicada pelas barras nos gráficos. Estas incertezas ( $\Delta i$ e $\Delta v)$ estão mostradas na Tabela 4-8 e foram medidas como a diferença entre os valores obtidos na última e na penúltima simulação (de injeção de corrente injetada) antes daquela que resultou na reobase. A incerteza para a reobase, porém, é bastante pequena, como pode ser observado na Figura 4-8A.

A

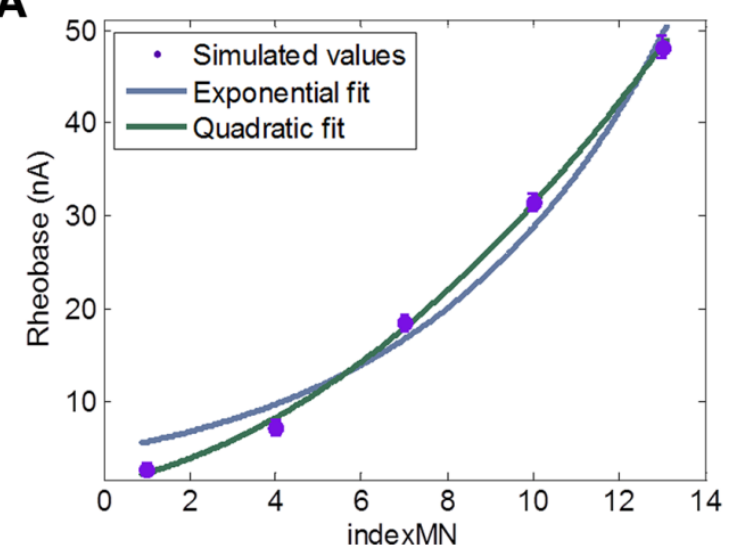

B

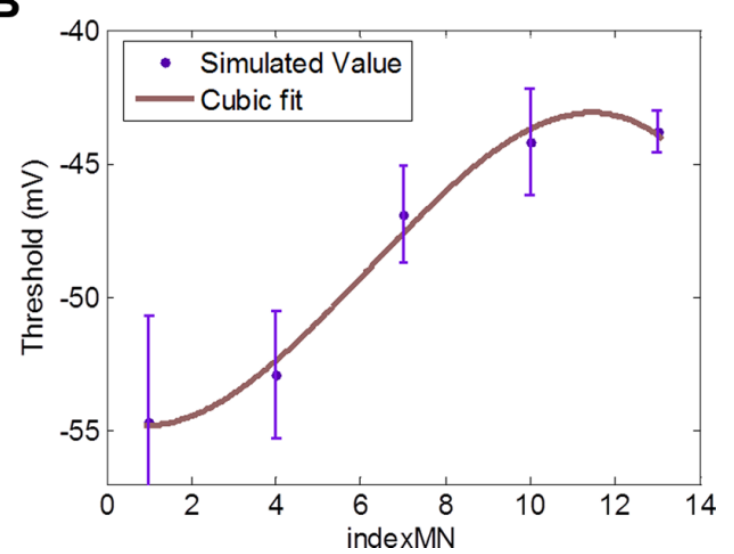

Figura 4-8. Simulações para determinar as correntes de reobase e os potenciais limiares (thresholds) para os MNs do pool.

Foram ainda feitos ajustes de curvas para os dados simulados, resultando em altos coeficientes de determinação (reobase: $\mathrm{R}^{2}=0,98$ para o ajuste exponencial, $\mathrm{R}^{2}=0,99$ para o ajuste quadrático; limiar: $\mathrm{R}^{2}=0,99$ para o ajuste cúbico).

Tabela 4-8. Medidas de corrente de reobase e de potencial limiar (threshold) para os MNs, assim como mostrado na Figura 4-8. $\Delta i$ é a incerteza na medida da reobase e $\Delta v$ é a incerteza na medida do limiar.

\begin{tabular}{|c|c|c|c|c|}
\hline & Reobase $(\mathbf{n A})$ & $\operatorname{Limiar}(\mathbf{m V})$ & $\Delta \boldsymbol{i}(\mathbf{n A})$ & $\Delta \boldsymbol{v}(\mathbf{m V})$ \\
\hline MN 1 & 2,69 & $-54,7$ & 0,67 & 4,0 \\
\hline MN 4 & 7,18 & $-52,9$ & 0,8 & 2,4 \\
\hline MN 7 & 18,5 & $-46,9$ & 0,9 & 1,8 \\
\hline MN 10 & 31,5 & $-44,2$ & 1,0 & 2,0 \\
\hline MN 13 & 48,2 & $-43,8$ & 1,2 & 0,8 \\
\hline
\end{tabular}




\section{Período de hiperpolarização}

A Figura 4-9 mostra o decurso temporal do potencial somático em resposta ao degrau de corrente injetada, para alguns MNs do pool, a fim de avaliar a AHP. Como resposta, houve um potencial de ação em cada MN, porém o gráfico ressalta apenas a AHP.

A

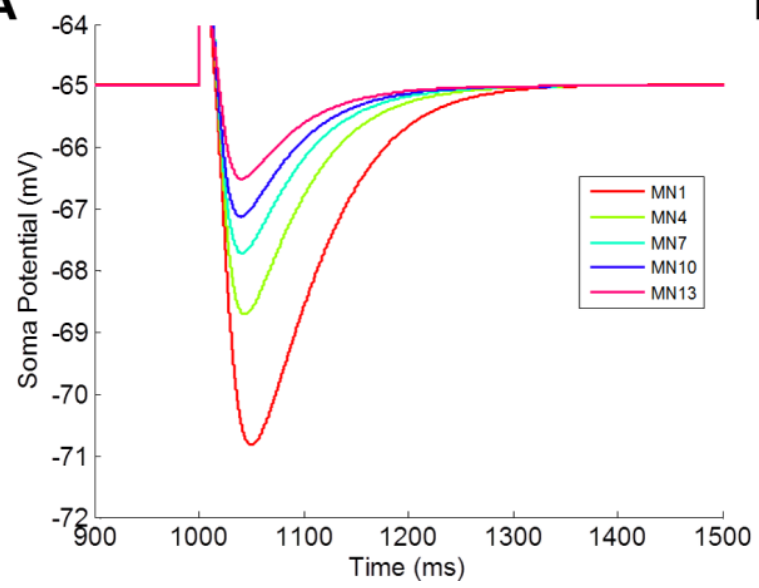

B

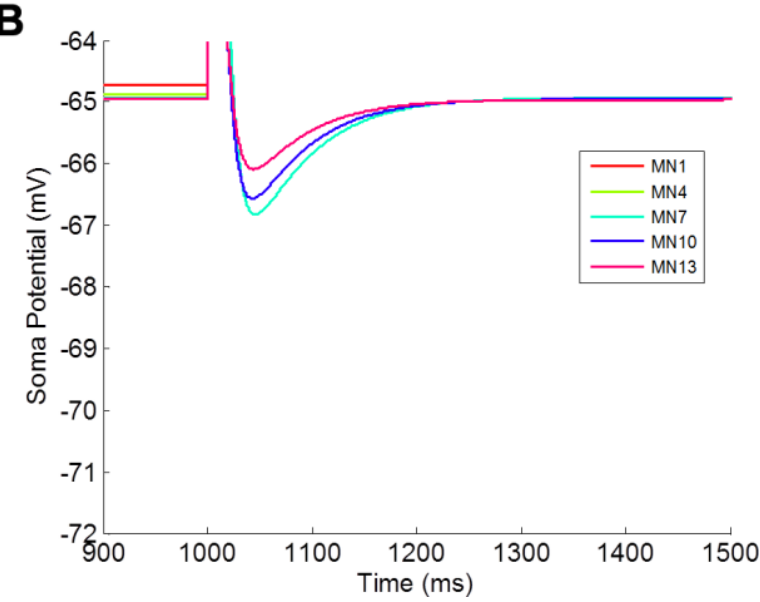

Figura 4-9. Decurso temporal da AHP em resposta a um pulso de corrente de duração $1 \mathrm{~ms}$ e amplitude de 150 $\mathbf{n A} / \mathbf{c m}^{2}$. A - Motoneurônio sem correntes persistentes dendríticas (cenário base). B - Motoneurônio com correntes persistentes dendríticas (cenário com nível intermediário de excitabilidade).

A Tabela 4-9 mostra as medidas das AHPs da Figura 4-9 para a simulação do cenário base e com um nível de excitabilidade intermediária. Comparando este dois cenários, é possível observar que, com o aumento do nível de excitabilidade dos MNs, houve uma redução da amplitude da AHP, embora o tempo de meio-decaimento não tenha se alterado substancialmente.

Tabela 4-9. Métricas resultantes para a AHP para as condições de dendritos passivos e ativos

\begin{tabular}{|c|c|c|c|c|}
\hline & $\begin{array}{c}\text { Amplitude (sem } \\
\text { PCs) (mV) }\end{array}$ & $\begin{array}{c}\text { Tempo de meio } \\
\text { decaimento (sem } \\
\text { PCs) (ms) }\end{array}$ & $\begin{array}{c}\text { Amplitude (com } \\
\text { PCs) (mV) }\end{array}$ & $\begin{array}{c}\text { Tempo de meio } \\
\text { decaimento (com } \\
\text { PCs) (ms) }\end{array}$ \\
\hline MN 1 & 5,82 & 64 & --- & --- \\
\hline MN 4 & 3,70 & 55 & --- & --- \\
\hline MN 7 & 2,71 & 50 & 1.82 & 51 \\
\hline MN 10 & 2,12 & 48 & 1,56 & 48 \\
\hline MN 13 & 1,51 & 48 & 1,09 & 46 \\
\hline
\end{tabular}




\section{Características de disparos}

A Figura 4-10 mostra o resultado da simulação de injeção de corrente (current-clamp) para os diferentes MNs do pool.

A

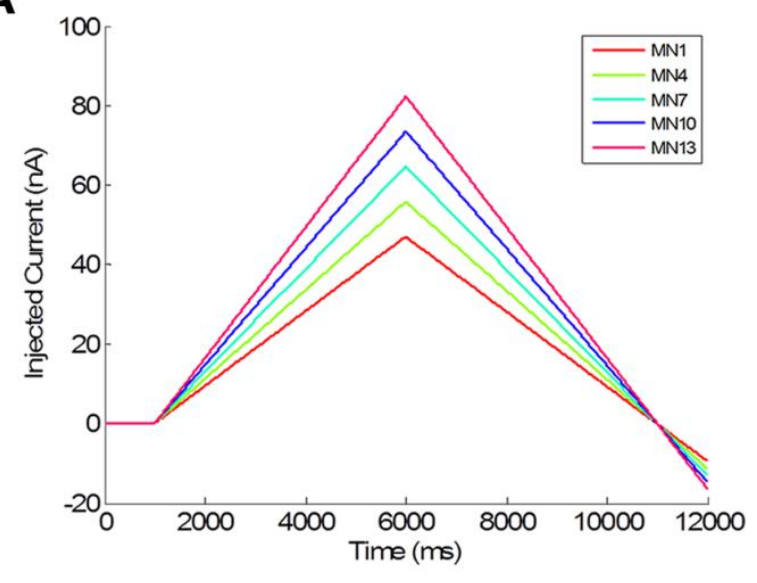

C

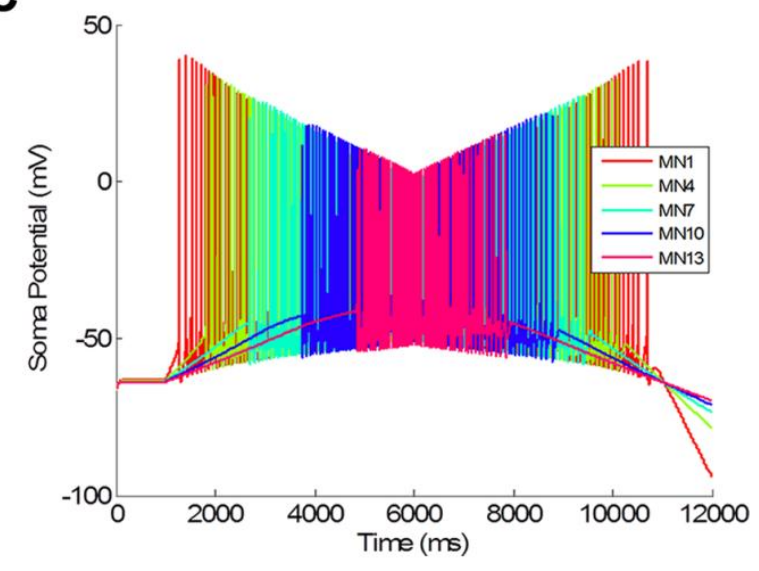

$\mathbf{E}$

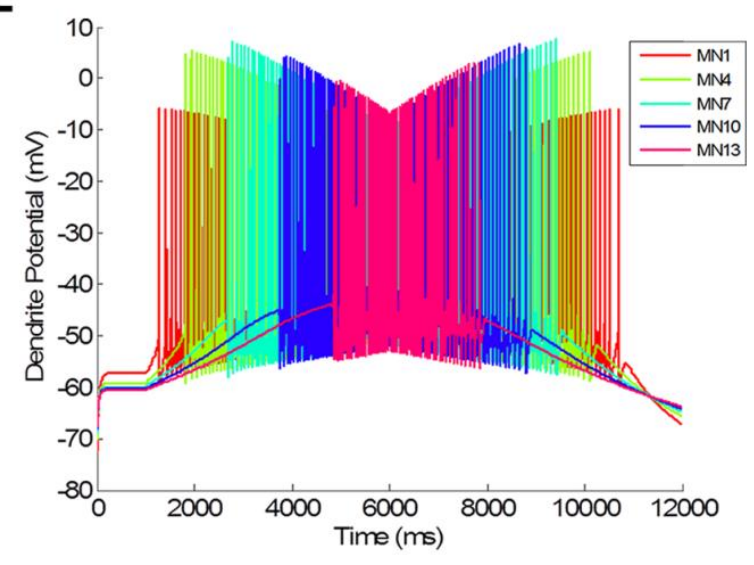

B

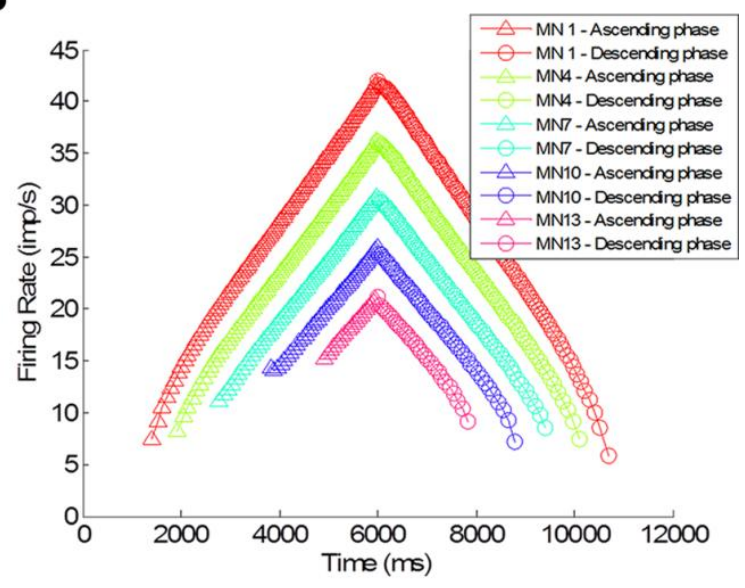

D

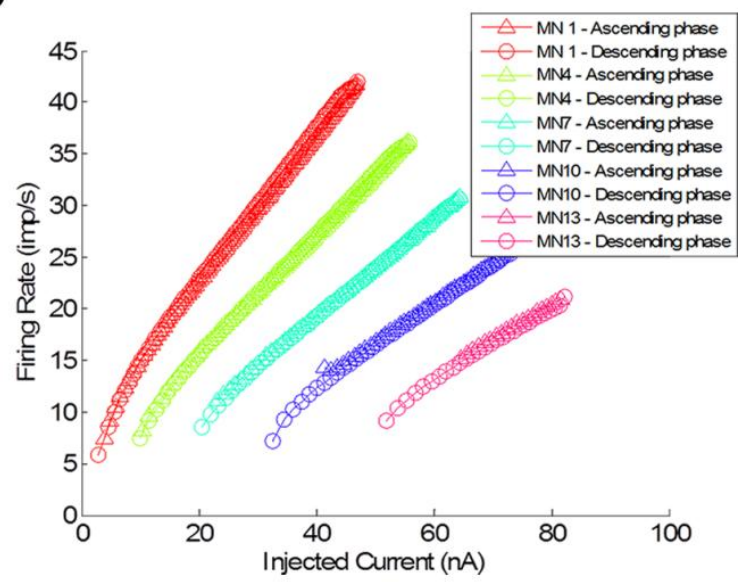

$\mathbf{F}$

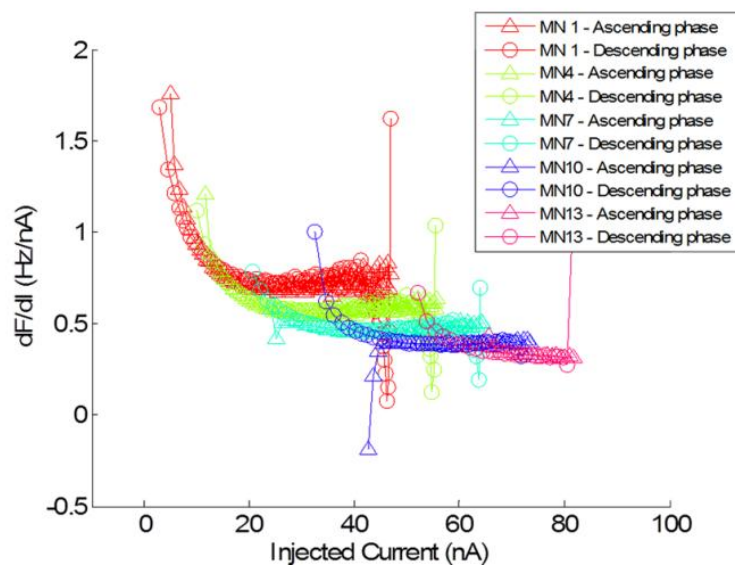

Figura 4-10. Características de disparo do pool de motoneurônios, no cenário base, em resposta a current-clamps triangulares. A: Correntes injetadas no compartimento somático. B: Taxas de disparos. C: Potencial somático. D: Curvas FI (corrente injetada versus taxa de disparos). E: Potencial dendrítico. F: Derivada da taxa de disparos com relação à corrente injetada (ganhos das curvas FI). Nas figuras da coluna da direita, marcadores com forma triangular representam a fase ascendente da corrente injetada, enquanto que marcadores com forma circular representam a fase descendente. 
A amplitude da corrente injetada dividida pela área do compartimento somático foi a mesma para todos MNs, resultando, porém, em diferentes valores absolutos de correntes (Figura 4-10A). A Figura 4-10B mostra a variação da taxa de disparos dos MNs conforme varia o nível de correntes injetadas. Várias das características encontradas experimentalmente podem ser visualizadas nesta figura. Por exemplo, o perfil de recrutamento dos MNs obedece ao princípio do tamanho (HENNEMAN, 1957), em que os MNs menores são recrutados antes dos MNs maiores, conforme aumenta o nível de excitação do pool de MNs. Outra característica presente é o onion skin (DE LUCA; HOSTAGE, 2010), em que os MNs recrutados primeiramente possuem frequências de disparos maiores que os MNs recrutados subsequentemente, para os diversos níveis de excitação (embora este termo seja geralmente empregado em experimentos com geração de força voluntária em humanos).

A Figura 4-10C e Figura 4-10E mostram o decurso temporal do potencial somático e do potencial dendrítico, respectivamente. Já a Figura 4-10D mostra a taxa de disparos dos MNs em função da corrente injetada (curva FI), enquanto que a Figura 4-10F mostra a derivada da taxa de disparos com relação à corrente injetada. Pode-se observar que não há histereses aparentes nas curvas FI, exceto pelas diferentes frequências de recrutamento e derrecrutamento. Isto é consistente com o cenário base (dendritos sem canais ativos). Os valores de ganhos das curvas FI ficam na faixa $-0,2$ a $1,8 \mathrm{~Hz} / \mathrm{nA}$.

A Figura 4-11 mostra o mesmo do que a Figura 4-10, porém para o cenário de excitação intermediária. Uma importante diferença nos resultados obtidos foi que os MNs passaram a se diferenciar dentro do pool, no que diz respeito à excitabilidade. Isto pode ser observado pelos altos potenciais dendríticos dos MNs menores na Figura 4-11E (comparar com a Figura 4-10E). Os MNs menores ficaram mais excitados do que os maiores, caracterizando os $\mathrm{MN}$ totalmente biestáveis observados experimentalmente (LEE; HECKMAN, 1998a, 1998b). Para MNs intermediários, é possível observar o fenômeno conhecido como aceleração da frequência de disparos e sua subsequente saturação (MN 10 (azul) da Figura 4-11B). É possível ainda observar pela Figura 4-11D a presença de histereses nas curvas FI e que o ganho da curva FI durante a aceleração (MN 10 Figura 4-11F) é bem maior que o ganho da fase primária (cerca de $8 \mathrm{~Hz} / \mathrm{nA} \mathrm{e} 0,6 \mathrm{~Hz} / \mathrm{nA}$, respectivamente).

Por fim, a Figura 4-12 mostra as características de disparos resultantes da simulação do pool de MNs no cenário de alta excitabilidade. Destacam-se os disparos auto-sustentado (i.e., na ausência de corrente injetada) dos MNs menores (Figura 4-12B, C) e a ausência de uma aceleração da frequência de disparos. Os ganhos das curvas FI são próximos àquelas 
observadas para o cenário base (Figura 4-10D, F) e são maiores para os MNs maiores. O perfil das frequências de disparos é semelhante ao do cenário base, porém com um aumento basal de aproximadamente $5 \mathrm{~Hz}$.

A

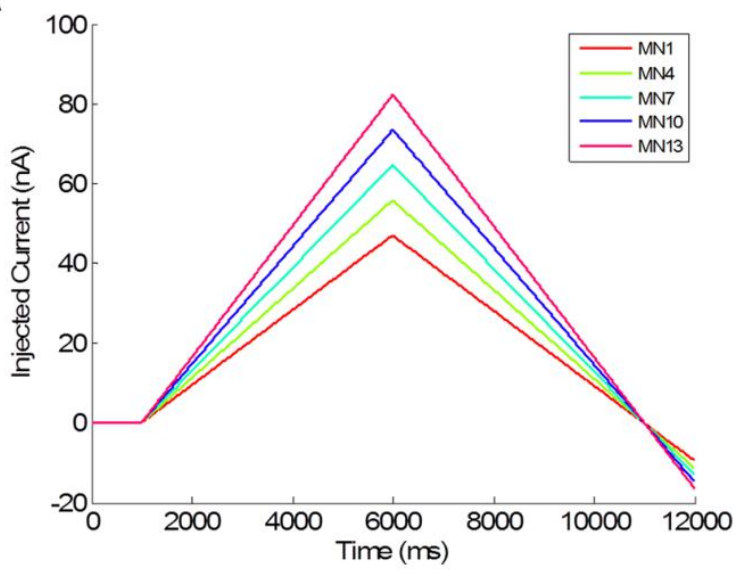

C

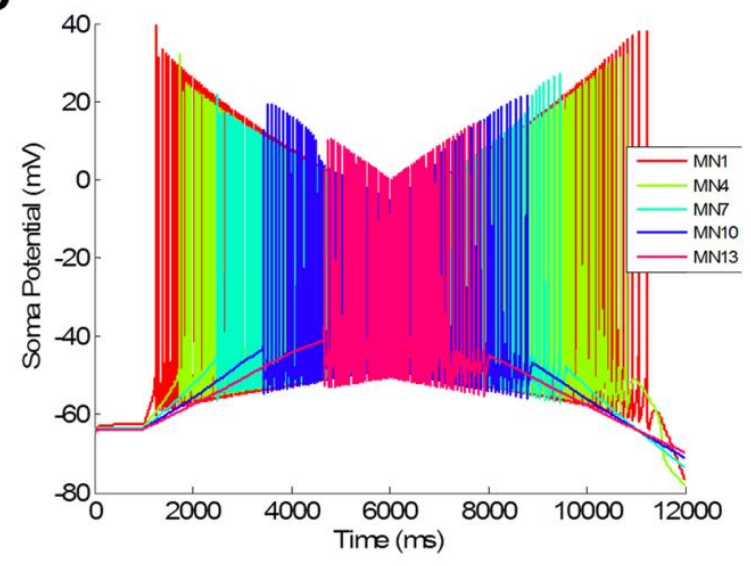

$\mathbf{E}$

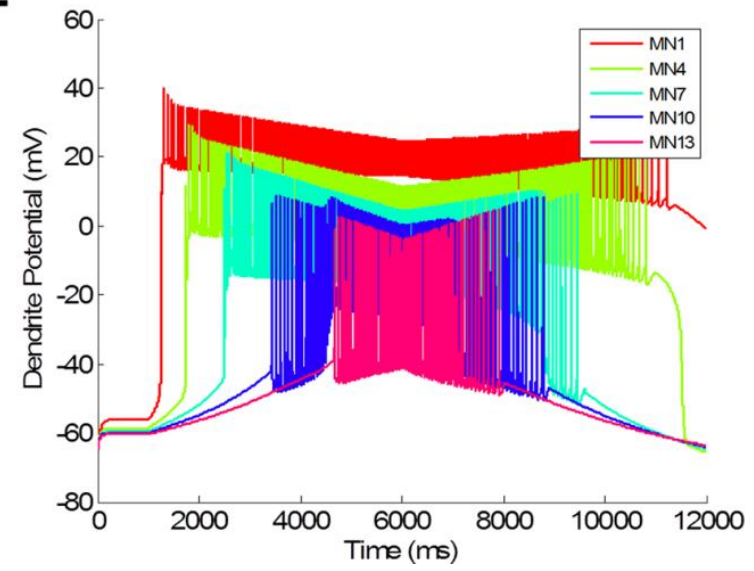

B

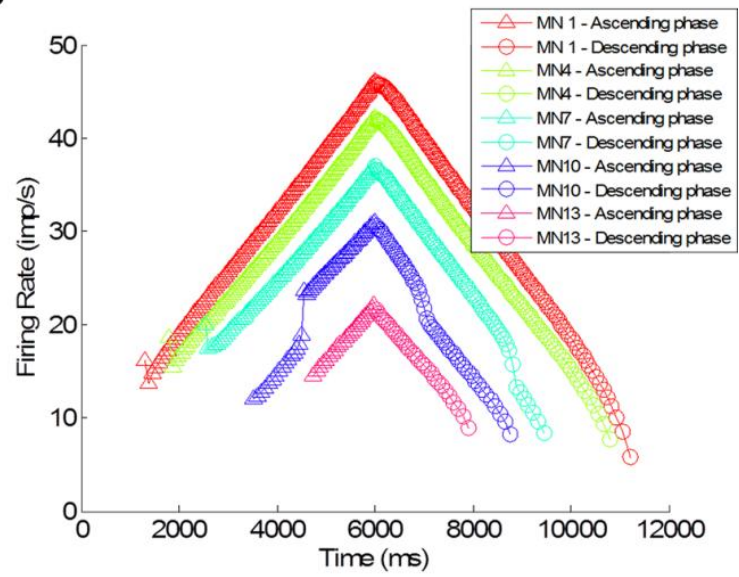

D

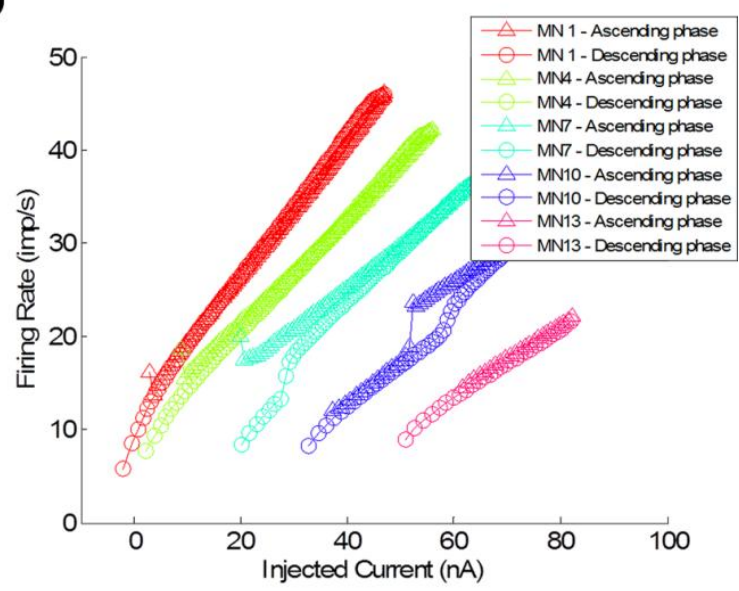

$\mathbf{F}$

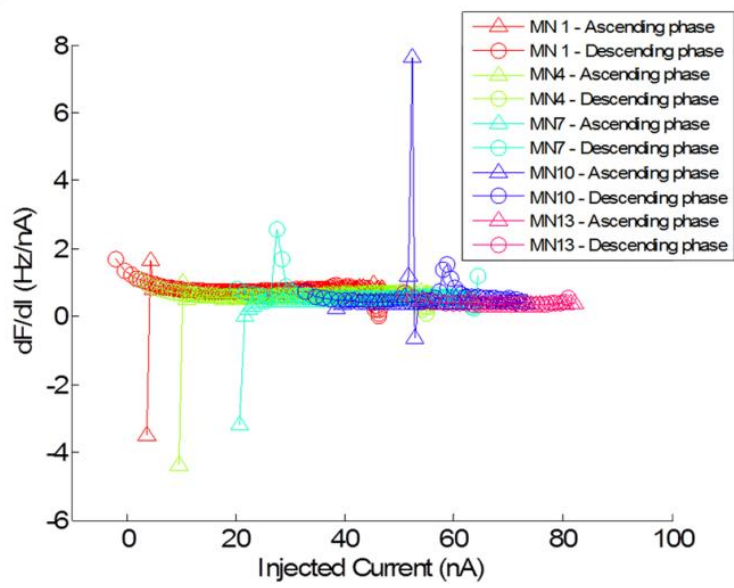

Figura 4-11. Características de disparo do pool de motoneurônios, no cenário de excitabilidade intermediária, em resposta a current-clamps triangulares. A: Correntes injetadas no compartimento somático. B: Taxas de disparos. C: Potencial somático. D: Curvas FI (corrente injetada versus taxa de disparos). E: Potencial dendrítico. F: Derivada da taxa de disparos com relação à corrente injetada (ganhos das curvas FI). Nas figuras da coluna da direita, marcadores com forma triangular representam a fase ascendente da corrente injetada, enquanto que marcadores com forma circular representam a fase descendente. 
A

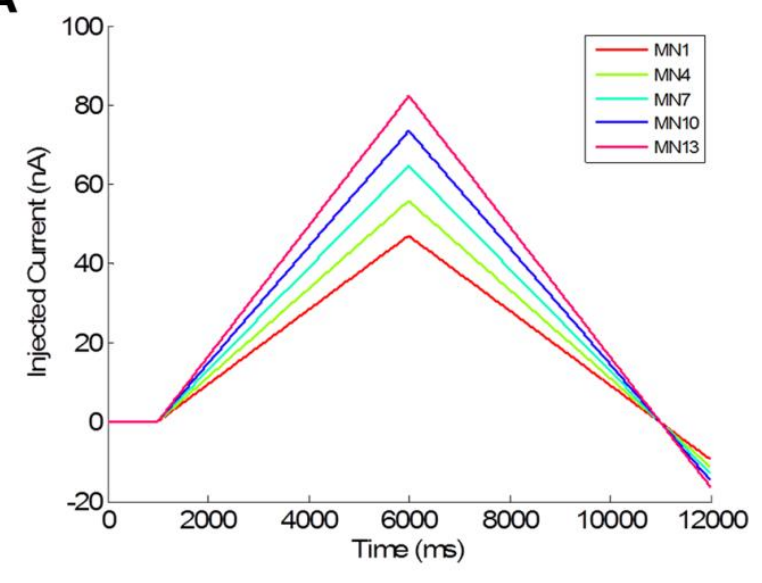

C

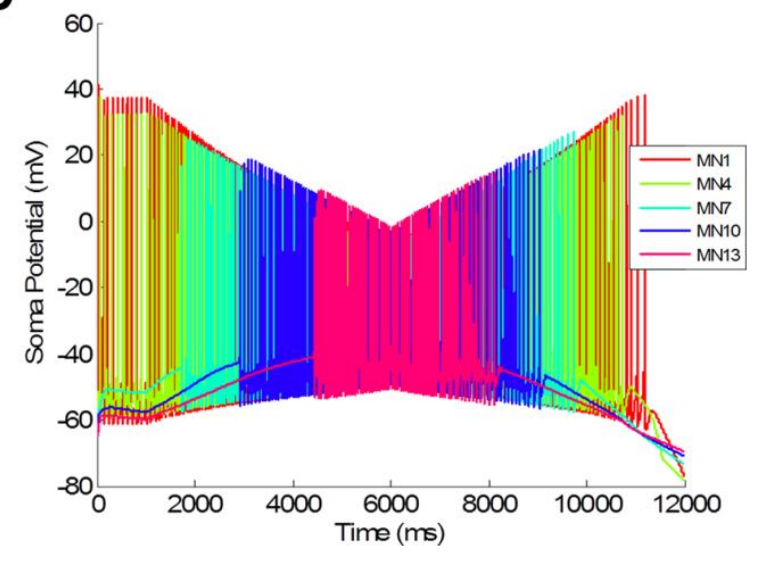

E

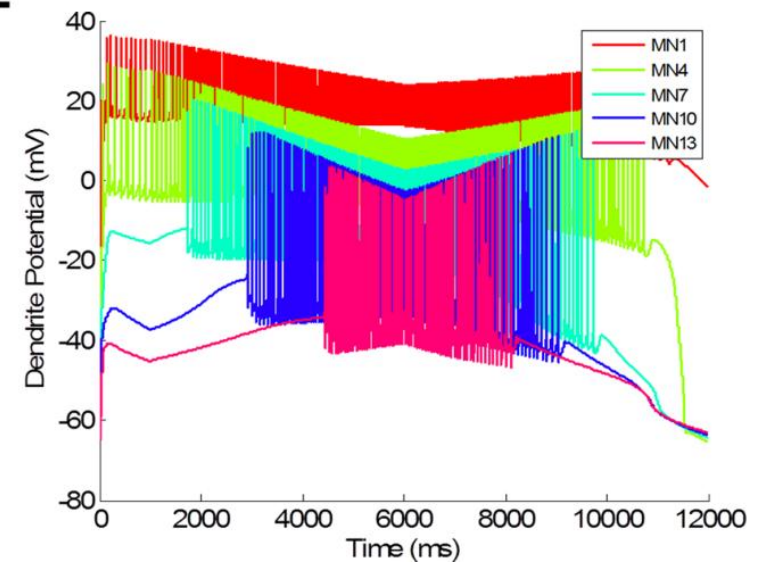

B

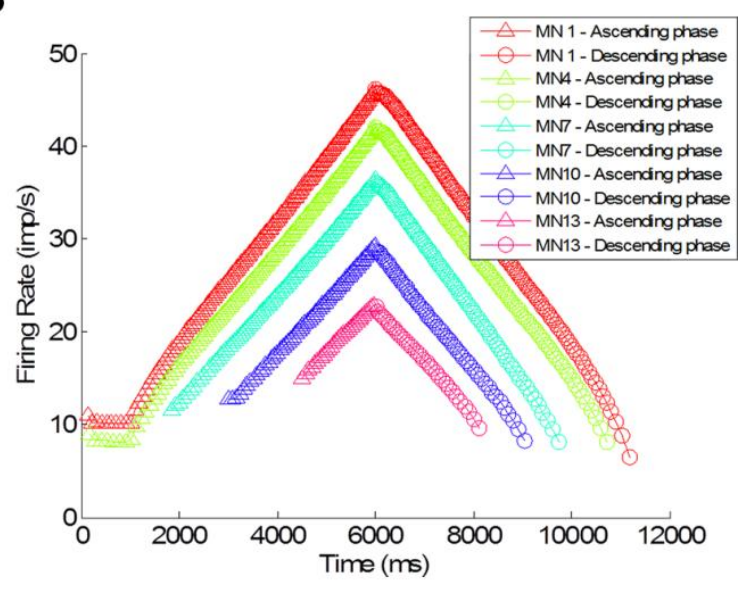

D

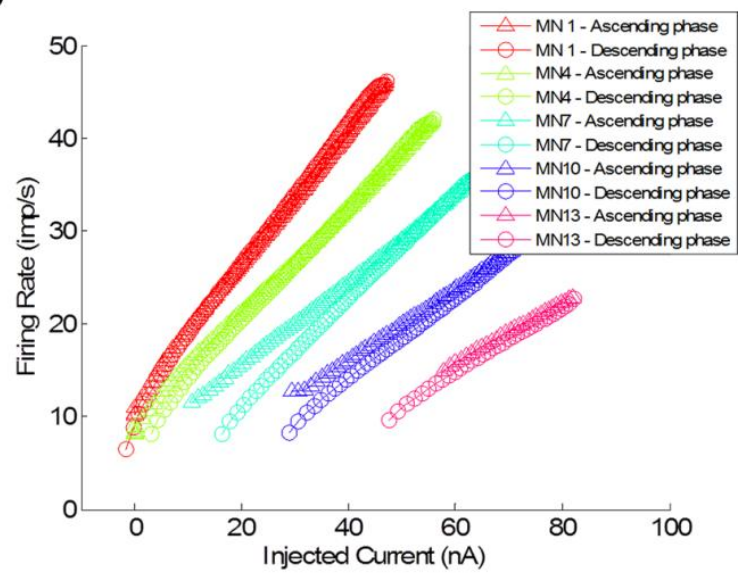

$\mathbf{F}$

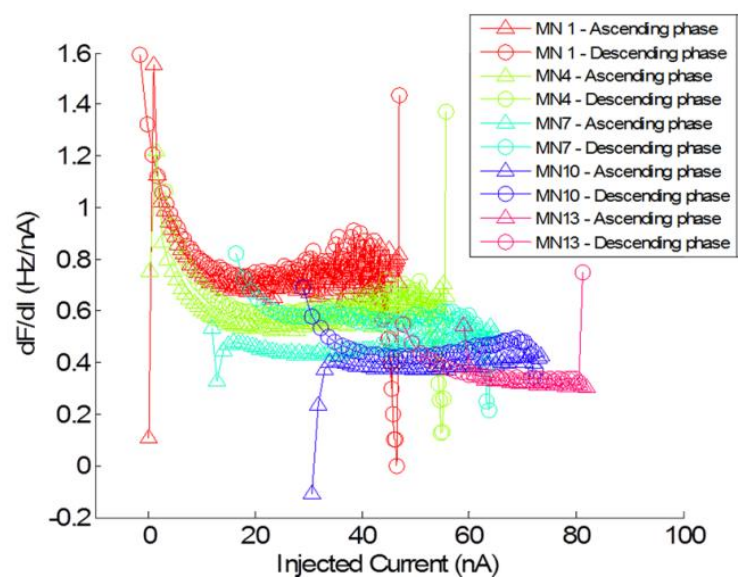

Figura 4-12. Características de disparo do pool de motoneurônios, no cenário alta excitabilidade, em resposta a current-clamps triangulares. A: Correntes injetadas no compartimento somático. B: Taxas de disparos. C: Potencial somático. D: Curvas FI (corrente injetada versus taxa de disparos). E: Potencial dendrítico. F: Derivada da taxa de disparos com relação à corrente injetada (ganhos das curvas FI). Nas figuras da coluna da direita, marcadores com forma triangular representam a fase ascendente da corrente injetada, enquanto que marcadores com forma circular representam a fase descendente. 


\subsection{Discussão}

Neste capítulo foi mostrado o desenvolvimento e algumas simulações de um modelo de pool de MNs. O modelo individual de MN é uma extensão de modelos prévios (BOOTH; RINZEL; KIEHN, 1997; KURIAN; CROOK; JUNG, 2011) e foi empregado para compor a representação de um pool de MNs. Para isto foi elaborada uma dispersão de alguns parâmetros dentre os MNs do pool a fim de obter resultados coerentes com o que é observado experimentalmente, ou seja, diferentes características fisiológicas entre MNs menores e maiores.

\subsubsection{Propriedades passivas}

Os valores de resistência específica de membrana, para ambos os compartimentos, concordam com o que se espera, baseando-se em dados experimentais (CLEMENTS; REDMAN, 1989; FLESHMAN; SEGEV; BURKE, 1988). Mesmo levando em consideração uma possível diminuição da resistência de entrada do soma durante a realização de experimentos em que um eletrodo é empalado no soma ("somatic shunt"), espera-se que o soma possua uma menor resistência específica do que a árvore dendrítica (POWERS; BINDER, 2001). A resistência específica do soma é várias vezes menor do que a da árvore dendrítica e os valores calculados para o presente modelo são da mesma ordem de grandeza daqueles encontrados em (CLEMENTS; REDMAN, 1989; FLESHMAN; SEGEV; BURKE, 1988). Da mesma forma, a faixa de valores para as constantes de tempo é muito próxima daquela encontrada experimentalmente (ver Tabela 4-1). Portanto, os resultados obtidos para as características passivas dos MNs confirmam a validade do modelo e da parametrização utilizada para os elementos passivos.

\subsubsection{Atenuação do potencial dependente da direção}

A concordância entre valores obtidos para resistência específica e constante de tempo de membrana com os dados disponíveis (Tabela 4-1) indica a consistência dos parâmetros passivos adotados, como DDVA, área do MN e resistência de entrada, dado que estes 
parâmetros foram retirados de diferentes fontes (FLESHMAN; SEGEV; BURKE, 1988; KIM; MAJOR; JONES, 2009; SEGEV; FLESHMAN; BURKE, 1990; ZENGEL et al., 1985).

Vale ressaltar que estas características de DDVA, até a publicação dos trabalhos de Kim e Jones (2009), não tinham sido incorporadas aos modelos reduzidos de MNs. Além disto, é a primeira vez que esta metodologia de parametrização é aplicada para representar a dispersão de características passivas em um conjunto (pool) de MNs. Kim e Jones, até o presente momento, aplicaram tal metodologia apenas para um modelo de MN específico (apenas um conjunto de parâmetros). A faixa de valores de DDVA encontrada em MN reais é desconhecida, sendo que os valores disponíveis foram obtidos a partir da reconstrução morfológica de uma pequena amostra de MNs (FLESHMAN; SEGEV; BURKE, 1988). Portanto, os valores obtidos para amplitude e fase do DDVA podem ser considerados, em vista dos dados disponíveis, adequados para representar tal característica. Outros modelos de dois compartimentos, como os apresentados em (BOOTH; RINZEL; KIEHN, 1997; CISI; KOHN, 2008; KURIAN; CROOK; JUNG, 2011) não representam adequadamente o DDVA, sendo que estes modelos (dadas suas parametrizações) possuem assimetria contrária àquela encontrada em modelos morfologicamente realistas (KIM; MAJOR; JONES, 2009).

\subsubsection{Efeitos de ressonância e de amplificação}

Embora não tenha sido feita uma análise explícita destas características, o modelo de MN desenvolvido possui tanto características ressonantes quanto características amplificadoras. Entretanto a manifestação ou não de ressonância dependente de uma complexa interação entre fatores passivos e ativos. As faixas de frequências em que se encontram as frequências de ressonância associadas às correntes iônicas ressonantes residem entre $1 /\left(2 \pi \cdot \tau_{w}\right)$ e $1 /\left(2 \pi \cdot \tau_{m}\right)$, sendo $\tau_{w}$ a constante de tempo da ativação ou inativação da corrente ressonante e $\tau_{m}$ a constante de tempo da membrana (HUTCHEON; YAROM, 2000). Assim, com a parametrização adotada para os elementos passivos da membrana, as frequências de ressonância são limitadas superiormente em $11 \mathrm{~Hz}\left(\tau_{m}=14,0 \mathrm{~ms}\right)$ para o MN menor e $65 \mathrm{~Hz} \tau_{m}=2,45 \mathrm{~ms}$ para o MN maior (vide Figura 2 de (HUTCHEON; YAROM, 2000)). A frequência de ressonância associada a uma corrente pode ser ainda dependente do potencial de membrana, caso a constante de tempo $\tau_{w}$ o seja. 
No compartimento somático, como pode ser observado pelas funções de ativação e inativação (Figura 4-3), as correntes $\mathrm{Na}$ e $\mathrm{CaN}$ possuem características, ao mesmo tempo, ressonantes e amplificadoras, enquanto que a corrente $\mathrm{Kdr}$ possui característica ressonante apenas. $\mathrm{O}$ modo de ressonância associado à corrente $\mathrm{Na}$ tende a ocorrer na faixa de -50 a -40 $\mathrm{mV}$ (região de sobreposição entre as curvas de ativação e inativação) e numa faixa frequências de 3,18-11 Hz (menor MN) a 3,18-65 Hz (maior MN). Já a ressonância associada à corrente $\mathrm{CaN}$ tende a ser mais acentuada que a de $\mathrm{Na}$, pois suas curvas de ativação e inativação possuem maior inclinação, e a ocorrer entre -45 e $-30 \mathrm{mV}$. Como a constante de tempo da inativação desta corrente possui diferentes valores dentre os MNs do pool (de $16 \mathrm{~ms}$ a $160 \mathrm{~ms}$ ) (Figura 4-4E), a frequência de ressonância desta corrente engloba as faixas de 1-11 $\mathrm{Hz}($ menor $\mathrm{MN})$ a $10-65 \mathrm{~Hz}$ (maior $\mathrm{MN})$. Por fim, a ressonância associada à corrente $\mathrm{Kdr}$ tende a ocorrer em uma faixa de frequências de "11-11" Hz (menor MN) a 11-65 Hz (maior $\mathrm{MN})$. Neste caso as faixas são muito restritas para os MNs menores e não deve haver ressonância.

No compartimento dendrítico, tanto a corrente $\mathrm{CaP}$ quanto a $\mathrm{NaP}$ possuem características amplificadoras. Além disto, ambos os compartimentos possuem ressonâncias associadas à dinâmica de cálcio. Com a parametrização empregada, a constante de tempo associada à Equação (20) é de $50 \mathrm{~ms}$. Esta dinâmica, em conjunto com a dinâmica da corrente de cálcio em cada compartimento e com as correntes de potássio, resulta em um efeito final ressonância, pois, enquanto a corrente de cálcio tende a despolarizar o potencial de membrana, a corrente de potássio tende a polarizá-la. No compartimento somático, a frequência associada a esta ressonância deve variar entre cerca de 3,18-11 Hz (menor MN) a 10-65 Hz (maior $\mathrm{MN}$ ), enquanto que no compartimento dendrítico a frequência de ressonância associada à concentração de cálcio deve estar em torno de 3.18-11 Hz (menor $\mathrm{MN})$ a $3.18-65 \mathrm{~Hz}($ maior MN).

A complexa integração de todos estes modos de ressonância do modelo pode ou não levar à manifestação de características ressonantes no modelo completo. Simulações para avaliar a resposta do modelo no domínio da frequência precisam ser realizadas para esclarecer estas questões. As possíveis diferenças na manifestação de modos ressonantes ou amplificatórios dentre os $\mathrm{MNs}$ do pool podem resultar em características fisiológicas importantes. Especula-se, por exemplo, que MNs maiores exibam característica ressonante devida a correntes de cátions ativadas em hiperpolarização, enquanto MNs menores não. Sob a presença de corretes amplificadoras rápidas (como a $\mathrm{NaP}$ ) esta característica levaria a uma 
facilitação do recrutamento de MNs maiores para entradas sinápticas fásicas (de alta frequência) e à amplificação de componentes de baixa frequência nas entradas de MNs menores (característica de potenciais-platô) (MANUEL et al., 2007).

\subsubsection{Reobase, limiar e AHP}

As faixas de valores de reobase e de limiar mostradas na Figura 4-8 concordam com aquelas observadas experimentalmente. Para a reobase, é observada uma faixa de aproximadamente 40 nA (POWERS; BINDER, 1985b; ZENGEL et al., 1985), enquanto que para o limiar a faixa observada é de aproximadamente $10 \mathrm{mV}$ (GUSTAFSSON; PINTER, 1984a). Ambos os dados são semelhantes aos resultantes das simulações, embora tenham sido obtidos valores um pouco maiores para as correntes de reobase. Isto é consequência da parametrização adotada neste trabalho, a qual foi realizada para englobar uma ampla faixa de áreas de compartimento somático e de resistência de entrada, com o fim de aumentar a representatividade das diferentes características fisiológicas dentre os MNs do pool. Portanto, os resultados obtidos podem ser considerados amplamente concordantes com os experimentais, servindo como mais uma validação do modelo.

Apesar de os parâmetros do modelo terem sido distribuídos linearmente, os dados de reobase e de limiar foram muito bem ajustados por uma curva quadrática e por uma cúbica, respectivamente $\left(\mathrm{R}^{2}>0.99\right)$ (Figura 4-8). Fuglevand (1993) utilizou uma relação exponencial para representar a distribuição das reobases pelo pool de MNs. Como mostrado (Figura 4-8A), este tipo de curva também pode ser uma boa aproximação para esta relação (pelo menos para este modelo mais complexo). O perfil da relação entre reobase e tamanho do $\mathrm{MN}$ concorda com dados experimentais, os quais mostram que a maioria dos MNs possui reobases baixas e poucos MNs possuem reobases altas (POWERS; BINDER, 1985b). Estas relações, porém, podem ser bastante alteradas quando há ativação de PCs, às quais podem causar uma despolarização basal do potencial somático.

Como pode ser observado na Tabela 4-9 os dados de amplitude de AHP obtidos para a condição sem PCs encontram-se dentro da faixa obtida experimentalmente (1,0-10 mV em (ZENGEL et al., 1985) e 1,8-9,7 mV (MANUEL et al., 2009)), porém não englobam os valores mais altos. Já os dados de tempo de meio-decaimento da AHP também estão na faixa experimental (10-60 ms em (ZENGEL et al., 1985) e 11,3 a 42,4 (MANUEL et al., 2009)), mas não englobam os menores valores. Os parâmetros relacionados à corrente $\mathrm{KCa}$ poderiam 
ser ajustados para representar a faixa completa observada experimental. Porém, o principal objetivo durante o ajuste destes parâmetros foi obter frequências de disparos semelhantes àquelas observadas em humanos, mantendo as características de AHP dentro da faixa experimental. Além disto, a diminuição da amplitude da AHP com a presença de PCs concorda com alguns experimentais (POWERS; BINDER, 2001) e não houve alteração aparente dos tempos de meio-decaimento entre os casos com e sem PCs. Porém, não estão bem estabelecidas ainda as influências de PCs na AHP em animais adultos (HECKMAN; ENOKA, 2012)

\subsubsection{Características de disparos}

As características de disparos obtidas para os cenários base e de excitabilidades intermediária e alta concordam de forma geral com o que é observado experimentalmente (LEE; HECKMAN, 1998a; TURKIN et al., 2010).

Em todos os cenários simulados, incluindo o cenário base (Figura 4-10) (no qual não há PCs), a frequência de derrecrutamento das MUs é menor que a de recrutamento. Este resultado concorda com achados experimentais (BUTTON et al., 2006; LEE; HECKMAN, 1998a; TURKIN et al., 2010; WIENECKE; ZHANG; HULTBORN, 2009) e é mais acentuado nas MUs maiores do que nos MNs menores. $\mathrm{O}$ fato de ter havido este fenômeno mesmo no cenário base (sem PCs) implica na existência de outros mecanismos intrínsecos, além das PCs, que propiciam ao MN uma menor frequência de derrecrutamento. Assim como em outro estudo computacional (REVILL; FUGLEVAND, 2011), estes resultados sugerem cautela ao utilizar esta diferença entre frequências de derrecrutamento e recrutamento para inferir a presença ou não de PCs em MNs, conforme sugerido em (GORASSINI et al., 2002).

No modelo apresentado, a concentração de cálcio no compartimento somático é maior durante o derrecrutamento do que durante o recrutamento. Isto leva a maiores correntes $\mathrm{KCaS}$ durante o derrecrutamento e, consequentemente, maiores períodos de AHP (WIENECKE; ZHANG; HULTBORN, 2009), o que explica as menores frequências de disparos. A diferente manifestação deste fenômeno entre MNs maiores e menores não é devida à diferente parametrização adotada para a constante de tempo associada à corrente $\mathrm{CaN}$, único parâmetro de propriedade ativa diferente dentre os MNs do pool no cenário base (Figura 4-4E), mas sim consequência da parametrização das propriedades passivas (resultados não mostrados). 
Assim como ocorre com as frequências de disparos, as correntes injetadas de derrecrutamento são menores que aquelas durante o recrutamento dos MNs. Além disto, MN maiores tendem a exibir maiores frequências e correntes de recrutamento e de derrecrutamento que MN menores (LEE; HECKMAN, 1998a; TURKIN et al., 2010), exceto no caso de excitabilidade intermediária, em que ocorre uma divisão do pool de MNs em dois grupos: aqueles cujas PCs estão ativadas antes e levam ao recrutamento (MNs 1, 4 e 7 na Figura 4-11E) e aqueles cuja ativação das PCs ocorre após o recrutamento ou não ocorre (MNs 10 e 13 na Figura 4-11E). Como mostra a Figura 4-11B, dentro destes dois grupos, a distribuição de frequências e de correntes de recrutamento e de derrecrutamento ocorre da forma mencionada.

Fenômenos classicamente associados à presença de PCs nos MNs podem ser observados na Figura 4-11 e na Figura 4-12. É possível notar uma aceleração da frequência de disparos do MN 10 (azul) na Figura 4-11B. Esta aceleração está associada ao período em que ocorre a ativação das PCs despolarizantes no dendrito Figura 4-11E (MN 10). Outra característica é a ocorrência de disparos mesmo após a corrente injetada ter sido diminuída abaixo de zero, assim como ocorre com o MN 1 na Figura 4-11E. Além disto, houve um aumento basal, de aproximadamente $5 \mathrm{~Hz}$, enquanto as PCs estavam ativadas. Por fim, é possível observar a presença de disparos autossustentados (na ausência de corrente injetada) para os MNs 1 e 4 na Figura 4-12B.

Nos resultados mostrados, não é possível observar uma histerese da curva FI no sentindo anti-horário, o que é característico de MNs biestáveis (LEE; HECKMAN, 1998a). Os MNs que estariam aptos para exibir tal comportamento (MN menores) se encontraram em altos estados de excitação, mesmo no cenário chamado de excitabilidade intermediária, não tendo havido uma fase de aceleração de suas frequências de disparos. Como suas PCs ativaram durante o recrutamento, estes MNs, assim que recrutados, passaram a disparar na região de saturação das PCs (região terciária). Em simulações com níveis menores de excitabilidade, os MNs menores exibiram curvas FI com histereses no sentido anti-horário (resultado não mostrado).

Outra característica observada experimentalmente é a presença de histereses da curva FI no sentido horário, principalmente em MNs parcialmente biestáveis (MNs maiores) (LEE; HECKMAN, 1998a). A Figura 4-11D mostra a ocorrência deste tipo de histerese para o MN 10, a qual é devida a uma diminuição da frequência de disparos, associada à inativação da corrente $\mathrm{NaP}$. 
Os ganhos das curvas FI estão próximos aos dados experimentais (SCHWINDT; CRILL, 1984), inclusive durante a aceleração da frequência de disparos Figura 4-11F. Além disto, os MN menores, de forma geral, possuem maiores ganhos que MNs maiores (TURKIN et al., 2010).

Como mencionado, alguns resultados obtidos, apesar de interessantes, não foram incluídos neste capítulo, pois o principal objetivo era ter uma visão geral das características exibidas pelo modelo de MN e pelo modelo de pool de MN. Existe uma infinidade de estudos que poderiam ser conduzidos a partir de aspectos específicos presentes no modelo desenvolvido. Outros levantamentos deveriam ser feitos para um completo entendimento de certas características importantes para o comportamento dinâmico do $\mathrm{MN}$, como, por exemplo, a adaptação da frequência de disparos, as quais não foram ainda investigadas de forma sistemática com o modelo desenvolvido. Este modelo, porém, servirá como base para o desenvolvimento de novos trabalhos, assim como aquele descrito no capítulo seguinte. 


\section{Capítulo 5 Geração e variabilidade de forças isométricas em jovens e idosos}




\subsection{Introdução}

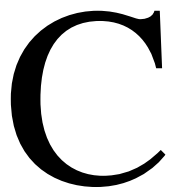

om o envelhecimento, há uma redução substancial da faixa funcional do sistema motor (PASCOE; ENOKA, 2010). A Tabela 5-1 resume as principais alterações observadas no sistema neuromuscular de idosos. Dentre as alterações anatômicas das MUs incluem-se: redução do número de MUs funcionais; aumento da taxa de inervação das MUs sobreviventes; e aumento da densidade e da área de MUs sofrendo reinervação. Já as alterações nas propriedades intrínsecas dos MNs podem incluir: aumento na resistência de entrada dos MNs; diminuição da corrente de reobase; aumento da duração do período póshiperpolarização (AHP). No que diz respeito aos disparos das MUs, as seguintes características são observadas: deslocamento do limiar de recrutamento das MUs para níveis menores de força; redução do máximo limiar de recrutamento; e redução da taxa máxima de disparos.

Estas alterações podem contribuir com os déficits motores associados ao envelhecimento, como a redução da força máxima, o aumento da variabilidade (GALGANSKI; FUGLEVAND; ENOKA, 1993) (ver Figura 5-1) e a redução da taxa de desenvolvimento de força (KLASS; BAUDRY; DUCHATEAU, 2008). Com base nos dados mostrados na Tabela 5-1, os parâmetros de um modelo do sistema neuromuscular podem ser ajustados para avaliar como cada propriedade (ou um conjunto delas) pode influenciar no controle e na geração de força. Estas características, porém, não são independentes, sendo que umas podem levar às outras. Por exemplo, a simples eliminação de algumas das MUs maiores, mantendo todos os outros parâmetros constantes, causaria um aumento da AHP média e dos tempos médios de contração das MUs.

A
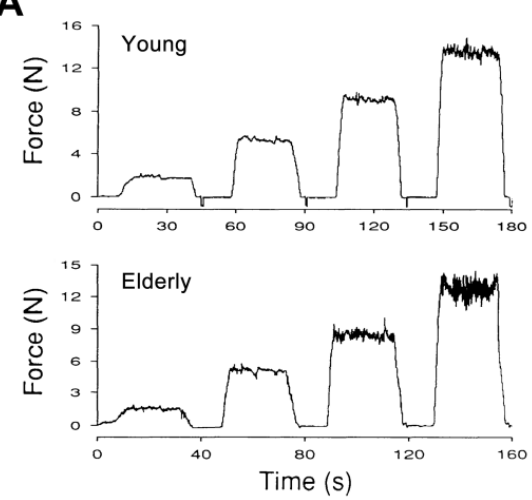

B

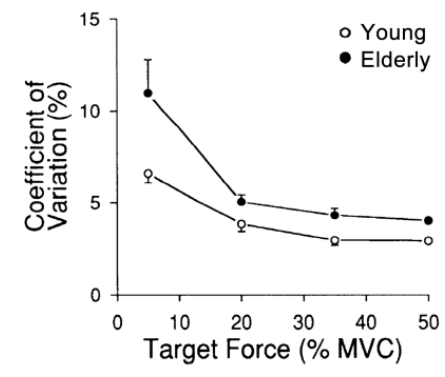

Figura 5-1. A) Exemplo representativo do desempenho de jovens e idosos na manutenção de forças a 5, 20, 35 e 50\% da MVC (GALGANSKI; FUGLEVAND; ENOKA, 1993). B) Variabilidade da força (medida pelo coeficiente de variação - CV) durante a tarefa ilustrada na figura A, para jovens e idosos (GALGANSKI; FUGLEVAND; ENOKA, 1993). 
Tabela 5-1. Alterações do sistema neuromuscular com envelhecimento

\begin{tabular}{|c|c|c|}
\hline Característica & Alteração sob envelhecimento & Referências \\
\hline Quantidade de MUs & Diminuição & $\begin{array}{l}\text { (DOHERTY; BROWN, 1993) } \\
\text { (SUZUKI et al., 2005) } \\
\text { (MCNEIL et al., 2005) }\end{array}$ \\
\hline $\begin{array}{l}\text { Proporção dos tipos } \\
\text { de fibras musculares }\end{array}$ & $\begin{array}{l}\text { Aumento da proporção de fibras } \\
\text { do tipo I (perda de fibras do tipo } \\
\text { II) }\end{array}$ & $\begin{array}{l}\text { (PETTIGREW; GARDINER, 1987) } \\
\text { (KANDA; HASHIZUME, 1989) } \\
\text { (MERLETTI et al., 1992) }\end{array}$ \\
\hline Número de inervação & Aumento & $\begin{array}{l}\text { (GALGANSKI; FUGLEVAND; ENOKA, } \\
\text { 1993) } \\
\text { (MASAKADO et al., 1994) }\end{array}$ \\
\hline $\begin{array}{l}\text { Arquitetura } \\
\text { muscular }\end{array}$ & $\begin{array}{l}\text { Diminuição do comprimento do } \\
\text { fascículo e do ângulo de } \\
\text { penação. Aumento da } \\
\text { complacência do músculo e do } \\
\text { tendão. }\end{array}$ & $\begin{array}{l}\text { (NARICI et al., 2003) } \\
\text { (NARICI; MAGANARIS, 2006) }\end{array}$ \\
\hline $\begin{array}{l}\text { Via monossináptica } \\
\text { Ia }\end{array}$ & Diminuição & $\begin{array}{l}\text { (MORITA et al., 1995) } \\
\text { (BAUDRY; MAERZ; ENOKA, 2010) } \\
\text { (KALLIO et al., 2010) }\end{array}$ \\
\hline $\begin{array}{l}\text { Inibição pré- } \\
\text { sináptica }\end{array}$ & Diminuição & (EARLES; VARDAXIS; KOCEJA, 2001) \\
\hline Inibição recíproca & Diminuição & (KIDO; TANAKA; STEIN, 2004) \\
\hline Inibição recorrente & Inalterado & $\begin{array}{l}\text { (ROSSI; MAZZOCCHIO; DECCHI, 2003) } \\
\text { (CHALMERS; KNUTZEN, 2004) } \\
\text { (HORTOBÁGYI; DEL OLMO; JOHN C. } \\
\text { ROTHWELL, 2006) }\end{array}$ \\
\hline Tratos descendentes & $\begin{array}{c}\text { Redução de } 35 \% \text { do trato CMN. } \\
\text { Redução de axônios } \\
\text { serotonérgicos }\end{array}$ & $\begin{array}{c}\text { (JOHNSON et al., 1993) } \\
\text { (EISEN; ENTEZARI-TAHER; STEWART, } \\
\text { 1996) } \\
\text { (OLIVIERO et al., 2006) }\end{array}$ \\
\hline Duração da AHP & Aumento & $\begin{array}{l}\text { (PIOTRKIEWICZ et al., 2007) } \\
\text { (KALMAR et al., 2009) } \\
\text { (CHRISTIE; KAMEN, 2010) }\end{array}$ \\
\hline $\begin{array}{l}\text { Resistência de } \\
\text { entrada }\end{array}$ & Aumento & $\begin{array}{l}\text { (CHASE, 1985) } \\
\text { (MORALES et al., 1987) } \\
\text { (KALMAR et al., 2009) }\end{array}$ \\
\hline Corrente de reobase & Diminuição & $\begin{array}{l}\text { (MORALES et al., 1987) } \\
\text { (KALMAR et al., 2009) }\end{array}$ \\
\hline $\begin{array}{c}\text { Faixa de } \\
\text { recrutamento }\end{array}$ & Diminuição & $\begin{array}{c}\text { (ERIM et al., 1999) } \\
\text { (KLASS; BAUDRY; DUCHATEAU, 2008) }\end{array}$ \\
\hline $\begin{array}{l}\text { Taxa mínima de } \\
\text { disparos }\end{array}$ & Inalterado & (BARRY et al., 2007) \\
\hline $\begin{array}{l}\text { Taxa máxima de } \\
\text { disparos }\end{array}$ & Diminuição & $\begin{array}{l}\text { (KAMEN et al., 1995) } \\
\text { (BARRY et al., 2007) }\end{array}$ \\
\hline $\begin{array}{c}\text { Variabilidade da taxa } \\
\text { de disparos }\end{array}$ & $\begin{array}{l}\text { Inalterado para a maior parte da } \\
\text { faixa de recrutamento }\end{array}$ & (BARRY et al., 2007) \\
\hline
\end{tabular}


No trabalho (BARRY et al., 2007) utilizou-se modelagem matemática para investigar alterações, na geração de força, associadas ao envelhecimento. Foi empregado um modelo de recrutamento de MUs, baseado no modelo de (FUGLEVAND; WINTER A.; PATLA, 1993), em que as propriedades biofísicas dos MNs não são representadas. Apesar de terem obtido resultados semelhantes àqueles encontrados em seus experimentos, tais resultados são limitados ao procedimento e às suposições por eles adotados. Não representaram, por exemplo, um recrutamento do tipo onion skin (DE LUCA; CONTESSA, 2012) e supuseram que a faixa de recrutamento de MUs é a mesma para jovens e idosos, o que não está de acordo com os resultados de outros trabalhos (PASCOE; ENOKA, 2010). Assim sendo, muitas das alterações associadas ao envelhecimento (e.g. diminuição ou não da ativação voluntária e manutenção ou não de um padrão de recrutamento das MUs similar ao dos jovens) são ainda tema de debate (KLASS; BAUDRY; DUCHATEAU, 2007) e o estudo aqui proposto, pode auxiliar na compreensão de tais disparidades.

Este capítulo descreve a criação de um modelo do sistema neuromuscular do FDI utilizando o modelo de pool de MNs descrito no capítulo anterior e a parametrização para representar as características associadas ao envelhecimento. São, por fim, realizadas simulações para comparar a variabilidade da força entre jovens e idosos. 


\subsection{Metodologia}

A Figura 5-2 ilustra a arquitetura do modelo desenvolvido. Neste modelo há duas categorias de neurônios: aqueles realizando conexões sobre os MNs, pré-motoneuronais (PMN i), e aqueles que representam os MNs alfa ( $\mathrm{MN}$ j), responsáveis pela ativação muscular. O modelo de MN utilizado é aquele apresentado no Capítulo 4. A atividade dos PMNs é modelada por processos estocásticos pontuais (JOHNSON, 2000). Apesar de ser ilustrada a geração de EMG, neste trabalho não foram realizados estudos baseados no EMG.

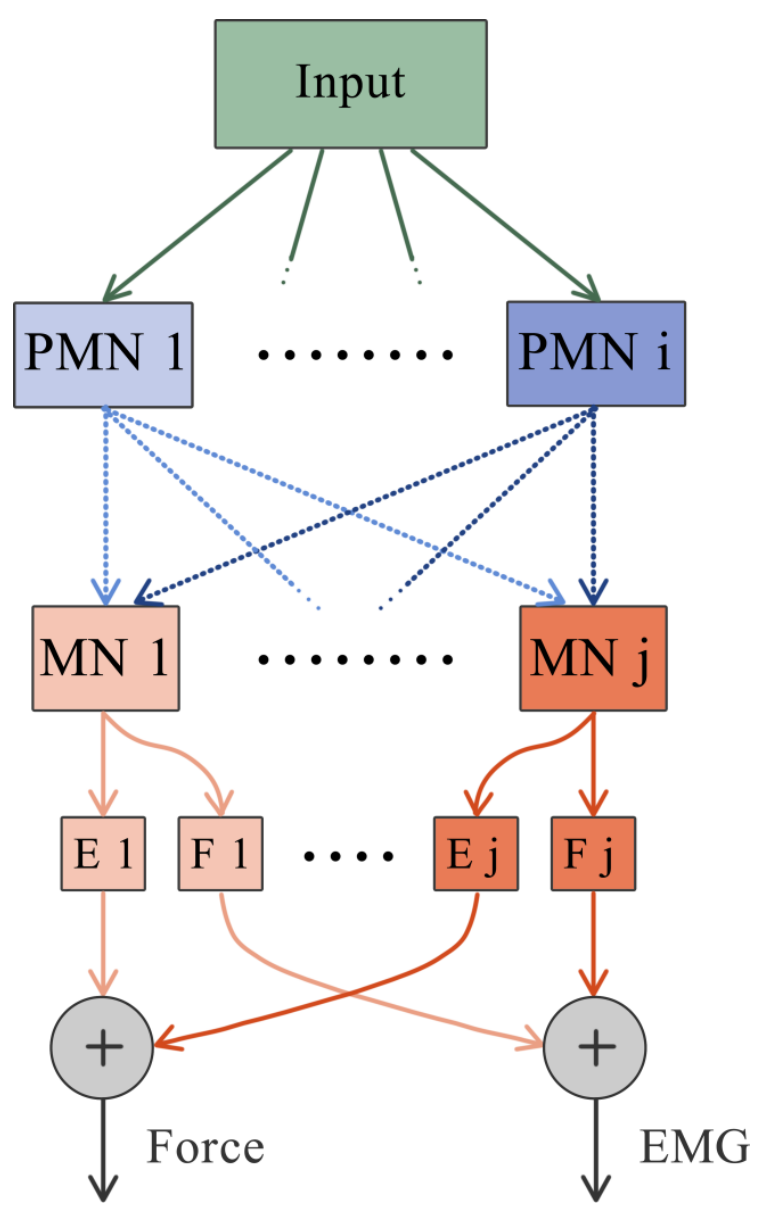

Figura 5-2. Esquema do modelo sistema neuromuscular. A atividade do neurônio pré-motoneuronal (PMN i) é modulada pelo sinal de entrada. Tais neurônios fazem sinapses excitatórias com os MNs, dependendo do grau de conectividade estipulado. $O$ trem de disparos de um $M N$ j é entrada para um gerador de força ( $F$ j) e um gerador de MUAPs (E j). A soma das saídas dos geradores de força resulta na força total do músculo, enquanto que a soma das saídas dos gerados de MUAPs resulta no EMG do músculo. 


\subsubsection{Modelo das vias pré-motoneuronais}

Os instantes de disparos de APs dos neurônios pré-motoneuronais (PMNs) são modelados por processos estocásticos pontuais. Um processo pontual regular (ou ordenado) pode ser definido de tal forma que a probabilidade de um evento (potencial de ação, neste caso) ocorrer no intervalo de tempo $[\mathrm{t}, \mathrm{t}+\Delta \mathrm{t})$ é dada por

$$
\begin{gathered}
\operatorname{Pr}\left[\text { um evento em }[\mathrm{t}, \mathrm{t}+\Delta \mathrm{t}) \mid \mathrm{N}_{\mathrm{t}}, \mathbf{w}_{\mathrm{t}}\right]=\mu\left(\mathrm{t} ; \mathrm{H}_{\mathrm{t}}, \mathbf{w}_{\mathrm{t}}\right) \Delta \mathrm{t} \\
\operatorname{Pr}\left[\text { mais de um evento em }[\mathrm{t}, \mathrm{t}+\Delta \mathrm{t}) \mid \mathrm{N}_{\mathrm{t}}, \mathbf{w}_{\mathrm{t}}\right]=o(\mathrm{t}, \Delta \mathrm{t})
\end{gathered}
$$

em que

$\mathrm{N}_{\mathrm{t}}$ é o número de eventos ocorridos do instante $\mathrm{t}=0$ ao instante $\mathrm{t}$.

$\mathbf{w}_{\mathrm{t}}$ é um vetor dos tempos de ocorrência dos $\mathrm{N}_{\mathrm{t}}$ eventos.

$\mu\left(\mathrm{t} ; \mathrm{N}_{\mathrm{t}}, \mathbf{w}_{\mathrm{t}}\right)$ é a função intensidade condicional.

$o(\mathrm{t}, \Delta \mathrm{t})$ tende a zero quando $\Delta \mathrm{t} \rightarrow 0$ de forma mais rápida que a linear, ou seja $\lim _{\Delta t \rightarrow 0}\left[\frac{o(t, \Delta t)}{\Delta t}\right]=0$

Com base nesta definição (JOHNSON, 2000), pode-se afirmar que não mais que um evento pode ocorrer em um intervalo de tempo suficientemente pequeno e que a probabilidade de um evento ocorrer num pequeno intervalo é proporcional a este intervalo. A probabilidade condicional de um evento ocorrer num pequeno intervalo de tempo depende diretamente de $\mu\left(t ; N_{t}, \mathbf{w}_{t}\right)$, a qual incorpora a dependência histórica de eventos do processo (representada por $\mathrm{N}_{\mathrm{t}}$ e $\mathbf{w}_{\mathrm{t}}$ ) e possui unidade de eventos/segundo, podendo ser considerada como uma taxa instantânea de eventos.

$\mathrm{O}$ tipo de dependência temporal de $\mu\left(\mathrm{t} ; \mathrm{N}_{\mathrm{t}}, \mathbf{w}_{\mathrm{t}}\right)$ leva a diferentes nomenclaturas $\mathrm{e}$ propriedades do processo pontual. Se $\mu$ não depende do tempo, o processo é chamado de homogêneo ou estacionário. Caso contrário, o processo é dito não-homogêneo ou nãoestacionário. Caso $\mu$ não dependa do historio de eventos, ou seja, $\mu\left(t ; N_{t}, \mathbf{w}_{t}\right)=\mu(t)$, o processo é chamado de processo de Poisson. Caso $\mu$ possa depender apenas do instante do último evento, ou seja, $\mu\left(\mathrm{t} ; \mathrm{N}_{\mathrm{t}}, \mathbf{w}_{\mathrm{t}}\right)=\mu\left(\mathrm{t}, \mathrm{w}_{\mathrm{N}_{\mathrm{t}}}\right)$, o processo é chamado de processo de renovação. O processo de Poisson é, então, um caso especial de processos de renovação. 
Uma importante característica dos processos de renovação é que estes possuem intervalos entre eventos (ISIs) independentes e identicamente distribuídos (i.i.d.).

Neste trabalho, os instantes de disparos dos neurônios PMNs foram modelados por processos de renovação Gama homogêneos. Tendo em vista a quantidade de PMNs adotada, o parâmetro de forma $n$ da distribuição Gama foi escolhido tal que a faixa de frequência de disparos dos PMNs permanecesse dentro do que é observado experimentalmente nas vias prémotoneuronais e que fosse suficiente para recrutar todo pool de MNs, os modulando até suas máximas taxas de disparos. Assim, foi adotado $n=2$.

Estes processos possuem como característica a função densidade de probabilidade dos ISIs obedecendo a uma distribuição Gama (Equação (34)).

$$
p_{n}(I S I)=\frac{q(q \cdot I S I)^{n-1}}{(n-1) !} e^{(-q . I S I)}
$$

em que

$n$ é o parâmetro de forma (ordem).

$q$ é o parâmetro de taxa de eventos.

Para gerar cada ISI seguindo uma distribuição gama com parâmetros $n$ e $q$, foi adotado o seguinte procedimento:

- Gera-se $n$ números aleatórios com distribuição exponencial e média 1.

- Em seguida, estes números são somados e divididos por $n$, o que resulta num número aleatório com distribuição gama e média também igual a 1.

- Uma variável auxiliar é criada sendo igual à integral de $q$ a partir do último instante de disparo até o instante atual da simulação.

- Assim que o valor desta variável auxiliar se iguala ao número aleatório com distribuição gama gerado, este instante da simulação representa a ocorrência de um evento. 


\subsubsection{Modelo de sinapses}

O modelo de sinapse representa a geração de EPSPs no neurônio pós-sináptico quando há potenciais de ação no neurônio pré-sináptico. No caso deste trabalho, haverá somente sinapses entre PMNs e MNs, e o modelo será baseado em (DESTEXHE; MAINEN; SEJNOWSKI, 1994). Geralmente, são empregadas funções alfa para descrever a variação da condutância sináptica em resposta a eventos pré-sinápticos (RALL, 1967) (WILLIAMS; BAKER, 2009a, 2009b). Porém, este tipo de modelagem carece de uma fundamentação biofísica e não possui um mecanismo de saturação (DESTEXHE; MAINEN; SEJNOWSKI, 1994). Uma alternativa às funções alfa é o uso de modelos cinéticos que, além de possuírem o mesmo tipo de representação biofísica dos outros tipos de condutâncias iônicas, possibilita uma forma natural de saturação e uma simplificação que leva a soluções analíticas (DESTEXHE; MAINEN; SEJNOWSKI, 1994).

$$
R+T \underset{\leftarrow}{\stackrel{\alpha}{\rightarrow}} T R
$$

$R$ é a forma não ligada do receptor pós - sináptico

$T R$ é a forma ligada do receptor pós - sináptico

$\alpha$ é a taxa no sentido de ligação de neurotransmissor

$\beta$ é a taxa no sentido oposto à de ligação de neurotransmissor

Sendo $r(t)$ a fração de receptores ligados e [T] a concentração de neurotransmissor, a cinética modelada é representada pela Equação (36).

$$
\frac{d r(t)}{d t}=\alpha[T](1-r(t))-\beta r(t)
$$

Se for feita a suposição que a variação de [T] é muito rápida, comparando com as outras dinâmicas existentes, a variável [T] pode ser representada por pulsos, de amplitude $C_{\text {max }} \mathrm{e}$ duração $\left(t_{1}-t_{0}\right)$, decorrentes de eventos pré-sinápticos. 
Assim, a Equação (36) pode ser resolvida analiticamente (DESTEXHE; MAINEN; SEJNOWSKI, 1994):

(i) Durante um pulso: $\quad t_{0}<t<t_{1} \quad e \quad[T]=C_{\max }$

$$
r\left(t-t_{0}\right)=r_{\infty}+\left[r\left(t_{0}\right)-r_{\infty}\right] e^{-\frac{\left(t-t_{0}\right)}{\tau_{r}}}
$$

em que $\quad r_{\infty}=\frac{\alpha C_{\max }}{\alpha C_{\max }+\beta} \quad e \quad \tau_{r}=\frac{1}{\alpha C_{\max }+\beta}$

(ii) Após um pulso: $t>t_{1} \quad e \quad[T]=0$

$$
r\left(t-t_{1}\right)=r\left(t_{1}\right) e^{-\beta\left(t-t_{1}\right)}
$$

Assim, para uma sinapse em que a ligação entre neurotransmissor e o receptor está diretamente associada à abertura de certo tipo de canal iônico, a corrente sináptica $I_{\text {syn }}(t)$ causada no neurônio pós-sináptico pode ser descrita por

$$
I_{\text {syn }}(t)=g_{\text {sin }} r(t)\left[V_{\text {syn }}(t)-E_{\text {syn }}\right]
$$

em que

$g_{\text {sin }}$ é a máxima condutância sináptica

$V_{\text {sin }}(t)$ é $o E P S P$

$E_{\text {sin }}$ é o potencial de reversão sináptico

Estas equações proporcionam um método fácil para computar as correntes sinápticas. Para simular a sinapse, é necessário somente monitorar duas variáveis de estado (ou $t_{0} \mathrm{e}$ $r\left(t_{0}\right)$, ou $t_{1}$ e $\left.r\left(t_{1}\right)\right)$ e empregar a Equação (37) ou a Equação (38) para calcular seu valor. 
A partir do modelo de (DESTEXHE; MAINEN; SEJNOWSKI, 1994), Lytton (1996) desenvolveu um método que permite a aglutinação dos cálculos dos efeitos de várias sinapses agindo sobre um compartimento em apenas duas variáveis de estado, diminuindo muito a carga computacional necessária para simulações com grande quantidade de sinapses, como é o caso do presente trabalho. Reescrevendo a cinética de ligação de neurotransmissor ao receptor seguindo a notação de Hodgkin-Huxley (LYTTON, 1996), temos

$$
\begin{gathered}
\tau_{R} \dot{r}=r_{\infty}-r \\
r_{\infty}=\frac{\alpha}{\alpha+\beta} \\
\tau_{R}=\frac{1}{\alpha+\beta}
\end{gathered}
$$

A regra de atualização da variável de estado $r$, obtida da solução analítica (Equação (37) e Equação (38)), para um passo de integração $\Delta t$ é

$$
r_{k}=r_{\infty}\left(1-e^{-\frac{\Delta t}{\tau_{r}}}\right)+r_{k-1} e^{-\frac{\Delta t}{\tau_{r}}}
$$

em que o índice $k$ indica o passo em que a variável se encontra.

A Equação (43) pode ser desmembrada em duas regras de atualização dependendo da presença ou ausência de neurotransmissor, sendo

$$
\begin{gathered}
r_{o n_{k}}=r_{\infty}\left(1-e^{-\frac{\Delta t}{\tau_{r}}}\right)+r_{o n_{k-1}} e^{-\frac{\Delta t}{\tau_{r}}}, \quad \text { se } C>0 \\
r_{o f f_{k}}=r_{o f f_{k-1}} e^{-\beta \Delta t}, \quad \text { se } C=0
\end{gathered}
$$


Somando para os $r_{o n}$ das $N_{o n}$ sinapses no estado ativo sobre um neurônio e os $r_{o f f}$ das $N_{\text {off }}$ sinapses no estado inativo, temos

$$
\begin{gathered}
\sum_{i=1}^{N_{\text {on }}} r_{o i_{i}(k)}=\left(1-e^{-\frac{\Delta t}{\tau_{r}}}\right) \sum_{i=1}^{N_{\text {on }}} r_{\infty}+e^{-\frac{\Delta t}{\tau_{r}}} \sum_{i=1}^{N_{\text {on }}} r_{o n_{i}(k-1)}, \quad \text { se } C>0 \\
\sum_{i=1}^{N_{\text {off }}} r_{\text {off }}=e^{-\beta \Delta t} \sum_{i=1}^{N_{\text {off }}} r_{\text {off }} f_{i_{(k-1)}}, \quad \text { se } C=0
\end{gathered}
$$

Usando $R_{o n_{(k)}}=\sum_{i=1}^{N_{o n}} r_{o n_{i}(k)} ; R_{o f f}=\sum_{i=1}^{N_{o f f}} r_{o f f_{i(k)}}$ e $\sum_{i=1}^{N_{o n}} r_{\infty}=N_{o n} r_{\infty}$, temos

$$
\begin{gathered}
R_{o n_{(k)}}=N_{o n} r_{\infty}\left(1-e^{-\frac{\Delta t}{\tau_{r}}}\right)+R_{o n_{(k-1)}} e^{-\frac{\Delta t}{\tau_{r}}} \\
R_{o f f_{(k)}}=R_{o f f_{(k-1)}} e^{-\beta \Delta t}
\end{gathered}
$$

A Equação (48) e a Equação (49) são computadas a cada passo de integração para atualizar a variável de estado $R=R_{\text {on }}+R_{\text {off }}$ associada à sinapse complexa (termo utilizado para a somatória do conjunto de sinapses sobre um neurônio). Além disto, os valores de $R_{\text {on }}$, $R_{\text {off }}$ e de $N_{\text {on }}$ devem ser atualizados conforme as sinapses individuais mudem de estado. Assim, se a sinapse $i$ muda seu estado de ativação, as seguintes atualizações são realizadas.

$$
\begin{gathered}
r_{i_{\text {on } \rightarrow \text { off }}=} r_{\infty}\left(1-e^{-\frac{C_{d u r}}{\tau_{r}}}\right)+r_{i_{o f f \rightarrow o n}} e^{-\frac{C_{d u r}}{\tau_{r}}} \\
R_{\text {on }}=R_{\text {on }}-r_{i_{\text {on } \rightarrow \text { off }}}, \quad \text { se } i: \text { on } \rightarrow \text { off } \\
R_{\text {off }}=R_{\text {off }}+r_{i_{\text {on } \rightarrow \text { off }}} \\
N_{\text {on }}=N_{\text {on }}-1
\end{gathered}
$$




$$
\begin{gathered}
r_{i_{o f f} \rightarrow \text { on }}=r_{i_{\text {on } \rightarrow \text { off }}} e^{-\beta I S I} \\
R_{\text {on }}=R_{\text {on }}+r_{i_{\text {of } f \rightarrow o n}}, \quad \text { se } i: \text { off } \rightarrow \text { on } \\
R_{\text {off }}=R_{\text {off }}-r_{i_{\text {off } \rightarrow \text { on }}} \\
N_{\text {on }}=N_{\text {on }}+1
\end{gathered}
$$

em que

$C_{d u r}$ é o tempo que a sinapse i permanece no estado ativo.

ISI é o tempo que a sinapse i permanece no estado inativo.

Torna-se necessário, então, o armazenamento dos valores de $r_{i}$ a cada mudança de estado de cada sinapse $i$. Apenas o último valor, porém, é necessário para cada atualização.

Com o valor calculado da variável de estado $R$, associada à sinapse complexa, é possível computar o valor da corrente sináptica, como na equação (39). Porém, toda esta dedução supõe que o valor da condutância máxima $\bar{g}_{i}$ é o mesmo para toda sinapse. Se este não for o caso, a condutância global (complexa) passa a ser calculada por

$$
G=G_{o n}+G_{o f f}
$$

em que

$$
\begin{aligned}
& G_{\text {on }}=\bar{G} R_{\text {on }} \\
& G_{\text {off }}=\bar{G} R_{\text {off }}
\end{aligned}
$$

Além disto, substituímos $r_{o n_{i}}$ por $r_{o n_{i}}^{\prime}=\left(\overline{g_{l}} / \bar{G}\right) r_{o n_{i}}$ na Equação (46) e $r_{o f f_{i}}$ por $r_{o f f_{i}}^{\prime}=\left(\bar{g}_{l} / \bar{G}\right) r_{o f f_{i}}$ na Equação (47), redefinimos $R_{o n_{(k)}}=\sum_{i=1}^{N_{o n}} r_{o n_{i}}^{\prime} ; \quad R_{o f f}(k)=$ $\sum_{i=1}^{N_{o f f}} r_{o f f_{i}(k)}$ e substituímos $N_{o n}$ por $\tilde{G}_{o n}=\sum_{i=1}^{N_{o n}}\left(\overline{g_{l}} / \bar{G}\right)$.

Assim, ao invés de atualizar $N_{\text {on }}$ como na Equação (50) e na Equação (51), atualizamos $\tilde{G}_{\text {on }}$, incrementando ou decrementando $\left(\bar{g}_{l} / \bar{G}\right)$, para a mudança de estado da sinapse $i$.

Da mesma forma que em (POWERS et al., 2012), as correntes sinápticas foram distribuídas uniformemente entre os compartimentos somático e dendrítico. Para isto, as condutâncias sinápticas máximas foram ponderadas de acordo com a área de superfície do $\mathrm{MN}$ para que, quando expressas em $m S$, resultem no mesmo valor para todos MNs do pool. 


\subsubsection{Modelo de abalo da unidade motora}

O abalo das MUs é modelado pela resposta impulsiva de um sistema de segunda ordem criticamente amortecido (Equação (53)), assim como em (CISI; KOHN, 2008; FUGLEVAND; WINTER A.; PATLA, 1993).

$$
\begin{gathered}
f_{i}(t)=\frac{P_{i} t}{T_{i}} e^{1-\frac{t}{T_{i}}}, \quad t \geq 0 \\
P_{i}=e^{\ln (R P) \frac{i-1}{n-1}}
\end{gathered}
$$

em que

$P_{i}$ é a amplitude do abalo da unidade motora $i$.

$T_{i}$ é o tempo de contração da unidade motora $i$.

$R P$ é a faixa de amplitudes de abalos.

$n$ é o número de unidades motoras.

A amplitude de abalo $P_{i}$ é expressa em unidades arbitrárias (a. u.), sendo a amplitude de abalo da menor MU (de índice 1) igual a 1 e da maior MU igual a $R P$.

A fim de representar o efeito da saturação da força gerada por uma MU (BAWA; STEIN, 1976), da mesma forma que em (FUGLEVAND; WINTER A.; PATLA, 1993; WILLIAMS; BAKER, 2009a), a força gerada pela MU i é multiplicada por um ganho $g_{i, j}$ dependente da frequência instantânea de disparos $\left(1 / I S I_{j}\right)$ e do tempo de contração $T_{i}$ (Equação (55)).

$$
g_{i, j}= \begin{cases}\frac{1-e^{-2\left(\frac{T_{i}}{I S I_{j}}\right)^{3}},}{0.3004\left(\frac{T_{i}}{I S I_{j}}\right)^{2}}, & \text { se } \frac{T_{i}}{I S I_{j}} \geq 0,4 \\ 1 & \text { se } \frac{T_{i}}{I S I_{j}}<0,4\end{cases}
$$


Assim, a força em cada MU passa a ser descrita por

$$
F_{i}(t)=\sum_{j=1}^{k} g_{i, j} f_{i}\left(t-t_{i, j}\right)
$$

em que

$t_{i, j}$ representa o instante em que ocorre o $j$ - ésimo disparo na MU $i$.

Por fim, a força total do músculo é dada pela soma da força de cada MU que o constitui.

$$
F_{M}(t)=\sum_{i=1}^{n} F_{i}(t)
$$

Em (FUGLEVAND; WINTER A.; PATLA, 1993) é suposta uma relação exponencial entre a amplitude de abalo e o tempo de contração como mostra a Figura 5-3C, baseando em dados de gatos (Figura 5-3A). Porém, estudos em músculo da mão de ser humano (Figura 5-3B), não mostraram correlação entre estas duas grandezas (FUGLEVAND, 2011; THOMAS et al., 1990).

A

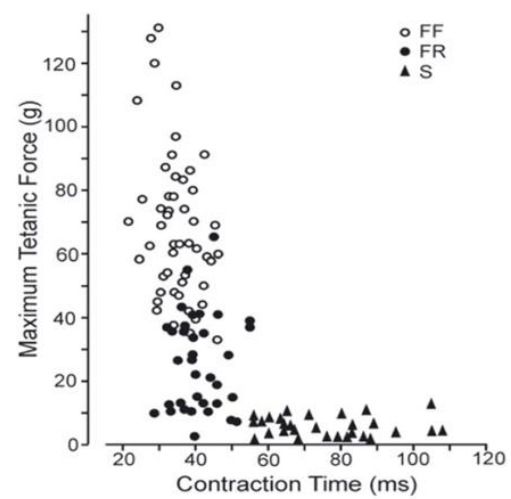

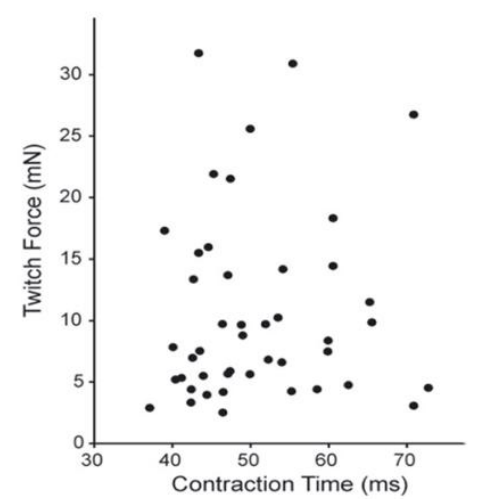

C

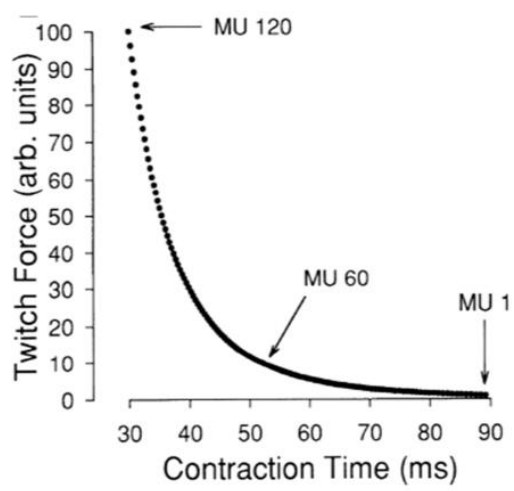

Figura 5-3 - Relação entre o tempo de contração e a amplitude de abalo de unidades motoras em: (A) gastrocnêmico de gato (BURKE; TSAIRIS, 1974); (B) músculo tenar da mão de humano (THOMAS et al., 1990); (C) modelo de (FUGLEVAND; WINTER A.; PATLA, 1993). 
A fim de aproximar melhor os dados experimentais, a amplitude dos abalos de cada MU foi determinada pela Equação (54), mas o tempo de contração atribuído obedecendo a uma distribuição estatística independente da amplitude de abalo. Como pode ser observado na Figura 5-4B a distribuição do tempo de contração de MUs do músculo tenar da mão de humanos pode ser razoavelmente aproximada por uma gaussiana. Assim, neste trabalho, foi adotada uma distribuição Gaussiana com média de $50 \mathrm{~ms}$ e desvio padrão de $10 \mathrm{~ms}$ para os tempos de contração.

A

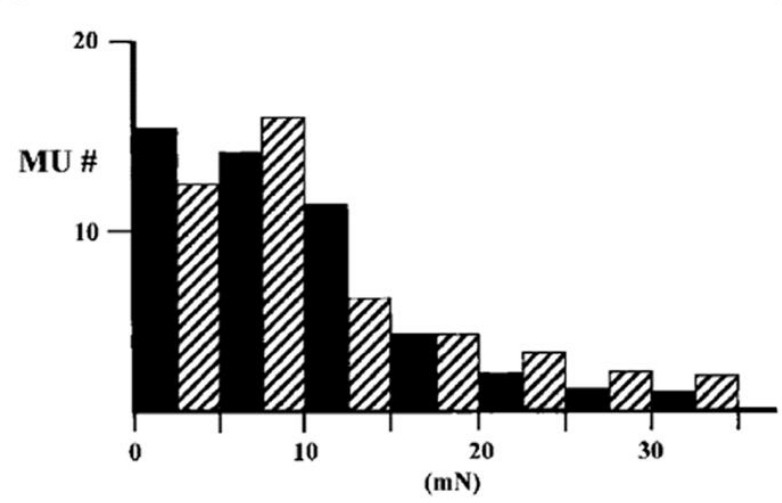

B

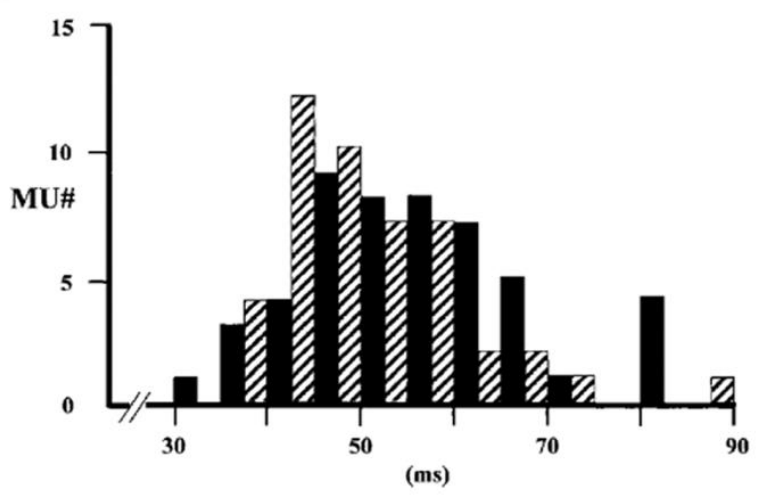

Figura 5-4 - A) Distribuição das amplitudes de abalos. B) Distribuição de tempos de contração no músculo tenar (na mão) de humano. Modificado de (Chan, Doherty et al. 2001).

O valor de máxima contração voluntária (MVC) foi definido como sendo aquele para o qual a maior frequência de disparos média dentre as MUs do pool fique próxima aos dados encontrados experimentalmente para o FDI. Estas frequências máximas são aproximadamente $30 \mathrm{~Hz}$ para jovens e $25 \mathrm{~Hz}$ para idosos (BARRY et al., 2007).

O modelo de pool de MNs descrito no capítulo anterior foi reparametrizado para que exibisse uma faixa de recrutamento curta, assim como se observa no FDI. O Apêndice 2 mostra os novos parâmetros adotados, enquanto que o Apêndice 3 mostra resultados de simulações para visualizar a faixa de recrutamento no modelo de jovens e de idosos. Além disto, as distribuições lineares dos parâmetros adotadas no capítulo anterior foram modificadas para distribuições exponenciais, com o intuito de melhor aproximar as dispersões observadas experimentalmente e adotada em outros trabalhos (TAYLOR; ENOKA, 2004).

Várias evidências levam a crer que muitas das características que resultam diferentes entre jovens e idosos (Tabela 5-1) são consequência da perda de MUs maiores por idosos. Desta forma, apenas duas alterações estruturais foram realizadas no modelo de pool de MNs 
apresentado no capítulo anterior, a fim de representar o envelhecimento neuromuscular. Tanto a quantidade de MNs quanto de PMNs foi reduzida de 1/3 (ver referências na Tabela 5-2). Concomitantemente, as faixas dos parâmetros do pool de MNs foram reajustadas para que a representação fosse de perda de MUs maiores. Por exemplo, o valor máximo da área do compartimento somático foi também reduzido de 1/3. A Tabela 5-2 resume os parâmetros adicionais àqueles descritos no capítulo anterior.

Os PMNs representam a atividade média dentre todos os tipos de neurônios prémotoneuronais, como vias descendentes, interneurônios e aferentes sensoriais. Como muitas destas vias pré-motoneuronais possuem alto grau de conectividade (PORTER; LEMON, 1993) o grau de conectividade entre PMNs e MNs adotado foi de $100 \%$.

Tabela 5-2. Parâmetros adotados para o modelo de sistema neuromuscular de jovens e de idosos.

\begin{tabular}{|l|c|c|c|}
\hline \multicolumn{1}{|c|}{ Parâmetro } & $\begin{array}{c}\text { Símbolo } \\
\text { (unidade) }\end{array}$ & Jovem & Idoso \\
\hline Quantidade de MNs & $N_{M N}$ & 181 & 129 \\
\hline Quantidade de PMNs & $N_{P M N}$ & 3000 & 2000 \\
\hline Máxima condutância sináptica & $\bar{g}_{i}\left(\mathrm{mS} / \mathrm{cm}^{2}\right)$ & 0,3 & 0,3 \\
\hline $\begin{array}{l}\text { Taxa de ligação de neurotransmissores } \\
\text { aos receptores }\end{array}$ & $\alpha_{0}(1 / \mathrm{ms})$ & 1,0 & 1,0 \\
\hline $\begin{array}{l}\text { Taxa de desligamento de } \\
\text { neurotransmissores aos receptores }\end{array}$ & $\beta(1 / \mathrm{ms})$ & 2,0 & 2,0 \\
\hline $\begin{array}{l}\text { Duração do “pulso" de transmissão } \\
\text { sináptica }\end{array}$ & $C_{d u r}(\mathrm{~ms})$ & 0,2 & 0,2 \\
\hline $\begin{array}{l}\text { Concentração máxima de } \\
\text { neurotransmissor na fenda sináptica }\end{array}$ & $C_{\max }(\mathrm{mM})$ & 1,0 & 1,0 \\
\hline Potencial de reversão sináptico & $E_{\sin }(\mathrm{mV})$ & 0,0 & 0,0 \\
\hline Grau de conectividade & --- & 100 & 100 \\
\hline $\begin{array}{l}\text { Relação entre a amplitude de abalo da } \\
\text { maior e da menor unidade motora }\end{array}$ & $R P$ & 100 & 66 \\
\hline
\end{tabular}




\subsubsection{Protocolos de simulação}

Para todas as simulações realizadas para o caso jovem a parametrização adotada para o pool de MNs foi aquela do cenário base, apresentada no capítulo anterior (exceto pelas modificações apresentadas no Apêndice 2). Para a realização das simulações, visando a estudar a variabilidade da força, sete níveis de frequência média de disparos dos PMNs foram adotados, iniciando em $10 \mathrm{~Hz}$ e chegando a $70 \mathrm{~Hz}$ (com intervalo de $10 \mathrm{~Hz}$ entre cada nível). A frequência de disparos média dos PMNs consistiu em um sinal em rampa, sendo zero entre os instantes 0 e $1 \mathrm{~s}$, aumentando linearmente de zero até seu valor máximo entre os instantes 1 $\mathrm{s}$ e $5 \mathrm{~s}$, e permanecendo constante até o instante $15 \mathrm{~s}$. Porém apenas os 6 últimos segundos simulados foram utilizados para os cálculos. Dez simulações foram realizadas para cada nível de força, a fim de melhor representar as características estatísticas de certos parâmetros e de obter melhores estimativas dos valores de força média, frequência média, etc. Não houve, porém, análises estatísticas dos resultados, tendo em vista que objetivo deste trabalho é fazer avaliações apenas qualitativas da variabilidade da força nos respectivos modelos para jovens e idosos, e das características de recrutamento e modulação do modelo de pool de MNs sob ativações sinápticas.

As frequência de disparos instantâneas (IFRs) dos MNs foram medidas como sendo o inverso dos ISIs. Todas as simulações deste trabalho foram realizadas empregando o método de Euler para integração das equações diferenciais, com um passo de 0,01 ms. 


\subsection{Resultados}

A Figura 5-5 ilustra a geração de EPSPs nos MNs (Figura 5-5B, C) a partir da atividade dos PMNs (Figura 5-5A).
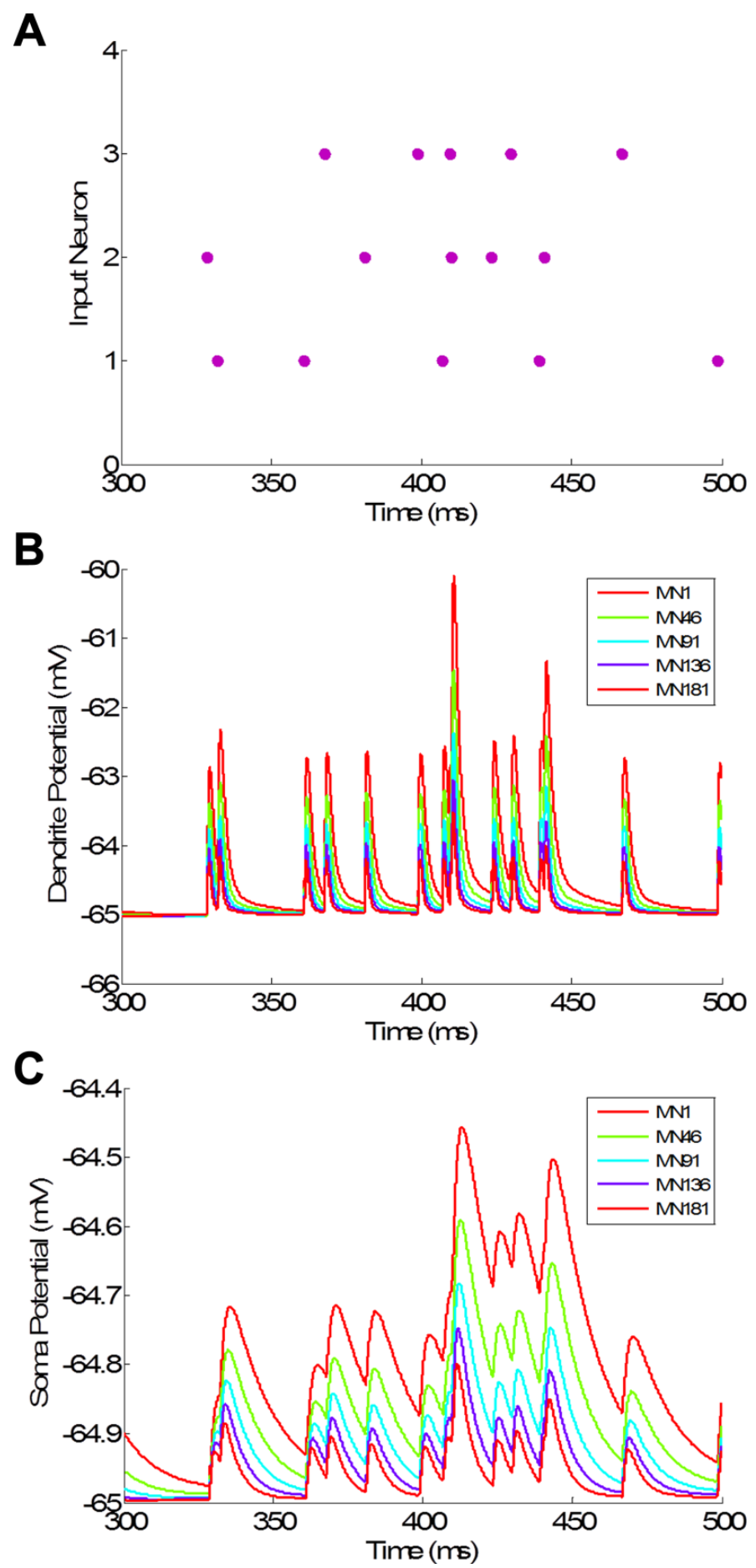

Figura 5-5 - Ilustração da geração de potenciais excitatórios pós-sinápticos no compartimento somático (C) e dendrítico (B) dos MNs, devidos à atividade dos neurônios PMNs (A). Nesta simulação foram utilizados apenas 3 PMNs para efeito ilustrativo. 
No exemplo de simulação da Figura 5-5, apenas três PMNs foram empregados para facilitar a visualização. Como o grau de conectividade adotado entre PMNs e MNs foi de $100 \%$, o disparo de AP em qualquer PMN gera EPSPs em todos MNs. Estes EPSPs se somam originando as flutuações do potencial de membrana. Esta somação, porém, ocorre de forma diferente dentre os MNs (Figura 5-5B, C), tendo em vista as diferentes características destes MNs. Os MNs menores, por possuírem maiores constantes de tempo para a dinâmica do potencial de membrana e por possuírem maiores resistências de entrada, geram uma maior somação dos EPSPs que os MNs maiores, para as mesmas correntes sinápticas.

A próxima seção descreve os resultados obtidos para a geração de força em jovens e para o estudo de variabilidade. Posteriormente, é feita a comparação entre o caso jovem e idoso.

\subsubsection{Geração de força em jovens}

A Figura 5-6A mostra exemplos de simulações de geração de força em jovens para os sete níveis de frequência média de disparos dos PMNs. Na Figura 5-6B é mostrada a força média gerada no músculo em função da frequência média dos PMNs. Os valores médios de força obtidos para cada nível de entrada foram: $2,5 \%, 10 \%, 30 \%, 60 \%, 80 \%, 90 \%$, e $100 \%$ da MVC. Estes dados foram bem ajustados por uma relação sigmoidal $\left(\mathrm{R}^{2}=0.999\right.$; equação na legenda da figura).
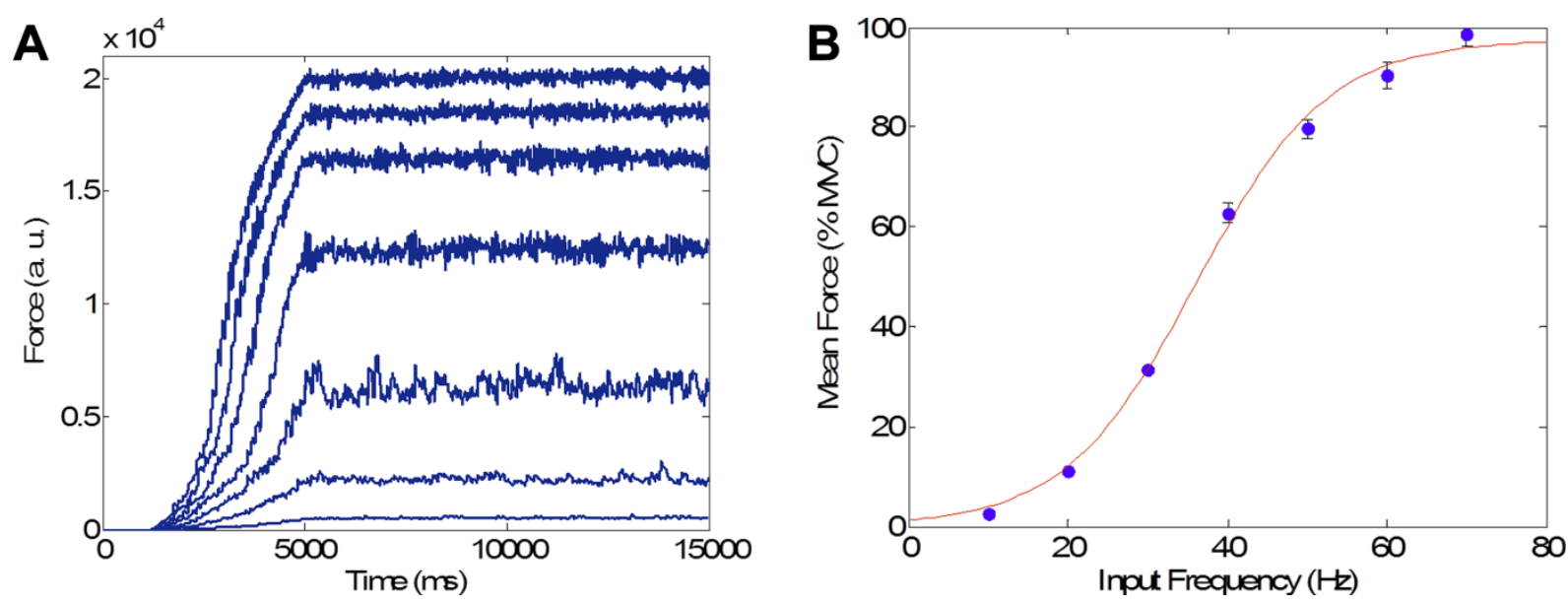

Figura 5-6 - A) Exemplo de simulações para geração de vários níveis de força em jovens. B) Força média gerada em função da frequência média de disparos dos neurônios PMNs. Os dados foram ajustados a uma sigmoide resultando em $R^{2}=0.999$. Sigmoide: Mean Force $=1.21 /(0.0124+\exp (-0.1217 *$ Input Frequency $))$. 
A Figura 5-7 mostra, para cada um dos sete níveis de força, o decurso temporal da frequência instantânea de disparos dos MNs.
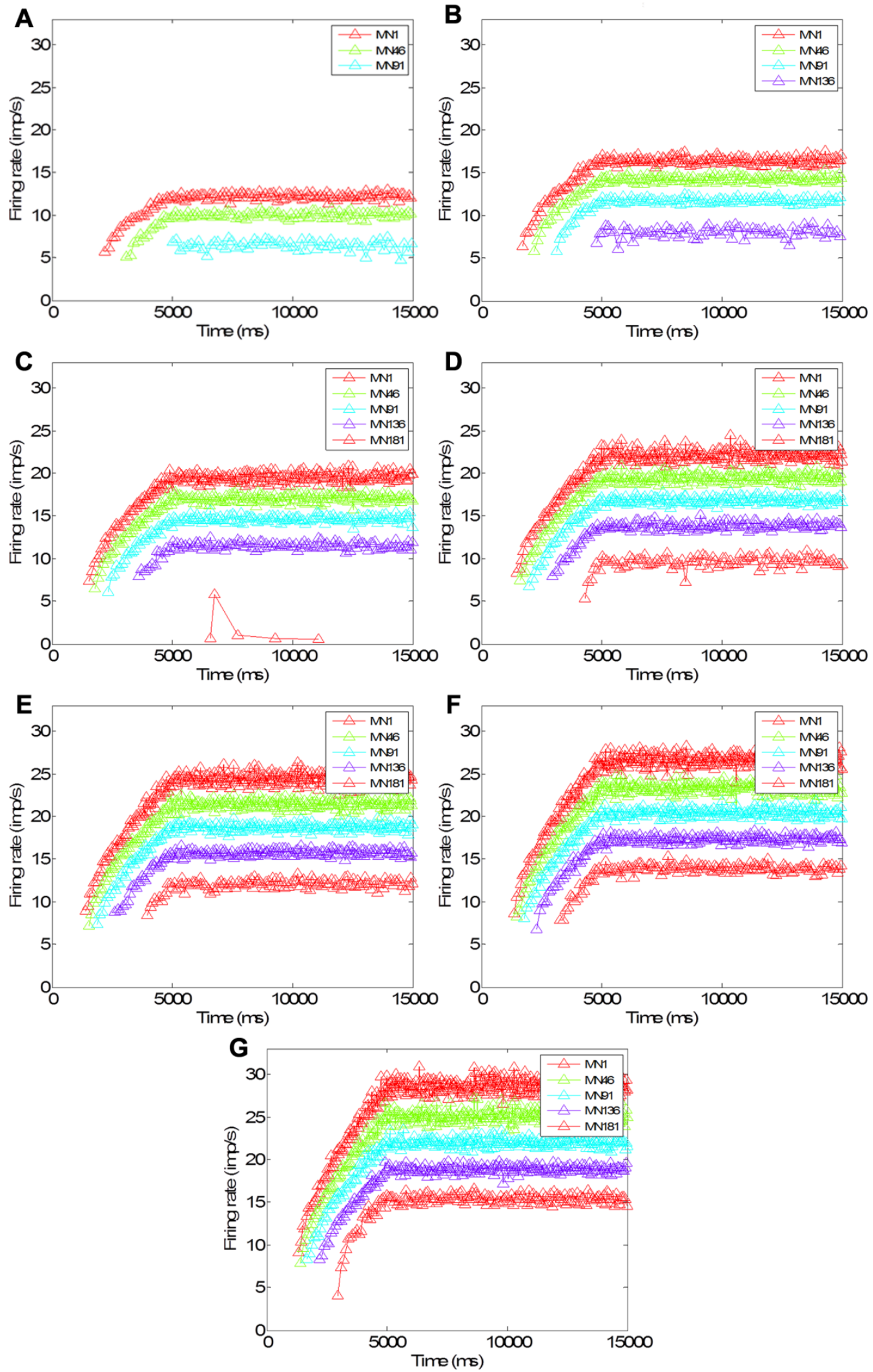

Figura 5-7 - Frequência instantânea de disparos dos MNs do pool (caso jovem) para diferentes níveis de força alvo: A) $2,5 \%$, B) $10 \%$, C) $30 \%$, D) $60 \%$, E) $80 \%$, F) $90 \%$, G) $100 \%$. 
Nota-se que, assim como no caso de corrente injetada no compartimento somático Figura 4-10, o onion skin continua ocorrendo para simulações com a distribuição sináptica adotada. Uma diferença, entretanto, entre os casos de correntes injetadas ou sinápticas foi que as MUs maiores passaram a ter frequências mínimas de disparos menores, quando excitadas por correntes sinápticas. A maior faixa de frequências máximas de disparos para as MUs (Figura 5-7G) foi de $\sim 15 \mathrm{~Hz}$ a $\sim 30 \mathrm{~Hz}$. O nível de força para o qual a última MU começa disparar tonicamente esteve entre 30 e $60 \%$ da MVC.

\subsubsection{Variabilidade da força em jovens}

A Figura 5-8 mostra os resultados das simulações para estudar a variabilidade da força em jovens. O desvio padrão, em função da média da força (Figura 5-8A), aumenta para os níveis mais baixos de força e depois diminui progressivamente. Já o coeficiente de variação (Figura 5-8B) possui uma tendência de queda com o aumento da força, exceto por um pico em $30 \%$ da MVC.
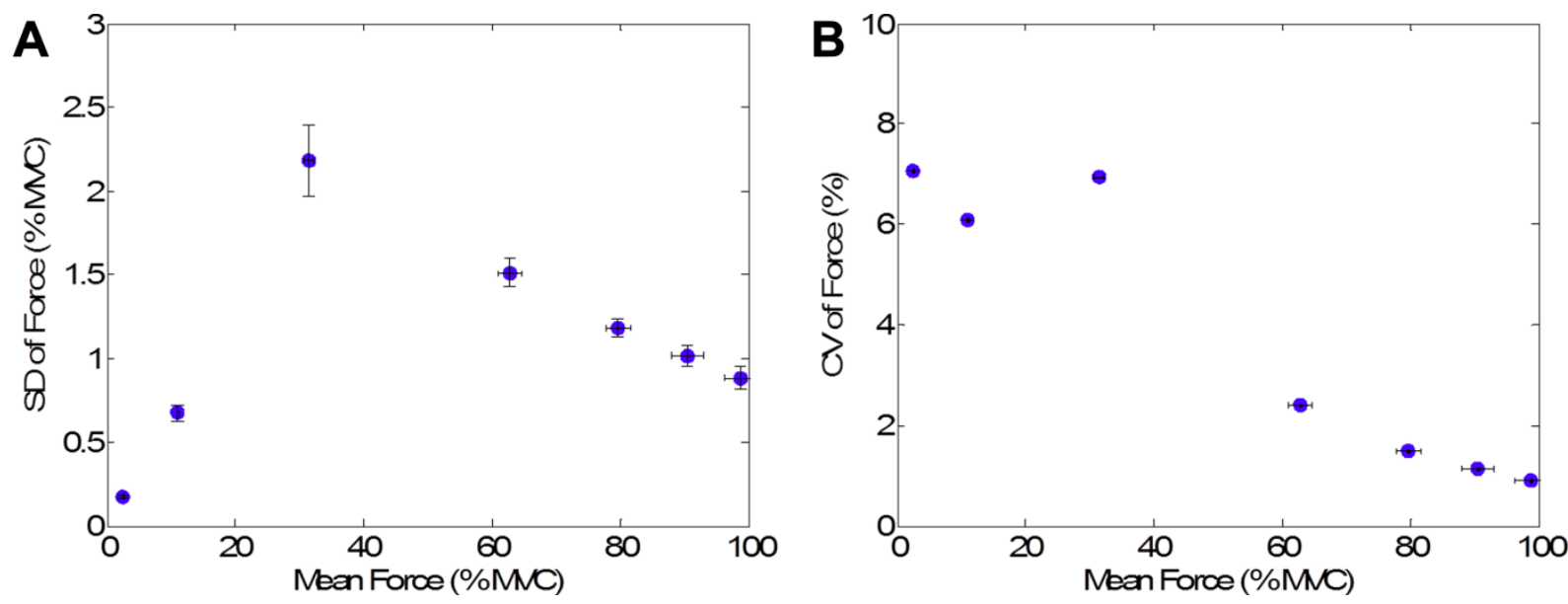

Figura 5-8 - Variabilidade da força gerada pelo modelo de jovem. A) Desvio padrão da força em função da força média. B) Coeficiente de variação da força em função da força média. As barras indicam desvio padrão dentre os valores obtidos das dez repetições para cada nível de força. 
A Figura 5-9 mostra as relações do desvio padrão do ISI com seu valor médio (Figura 5-9A) e do desvio padrão da frequência instantânea de disparos com seu valor médio (Figura 5-9B) para todos os MNs simultaneamente. Estas relações foram obtidas pela média das dez simulações realizadas para cada nível força. Como pode ser observado, tanto o desvio padrão dos ISIs quanto os das IFR possuem uma maior dispersão para menores níveis de força, tendo ainda o desvio padrão da IFR exibido uma região de diminuição, seguida de um aumento com seu valor médio.
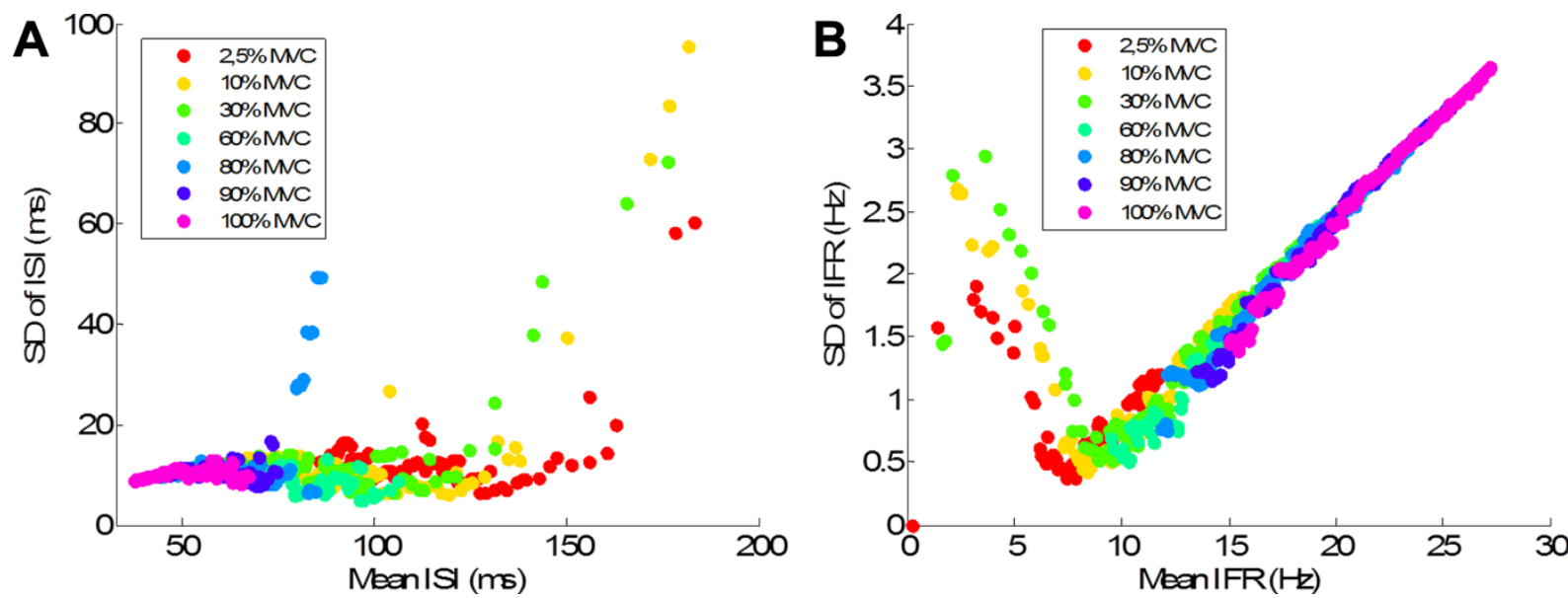

Figura 5-9 - A) Variabilidade dos instantes entre disparos e B) da frequência instantânea de disparos de todos os MNs do pool, para diferentes níveis de força.

A Figura 5-10 mostra a relação entre o desvio padrão da IFR com o valor médio da força gerada. Esta relação é monotonicamente crescente para todos os MNs visualizados, exceto para o MN 181, para o qual o desvio padrão da IFR apresenta um pico em $30 \%$ da MVC.

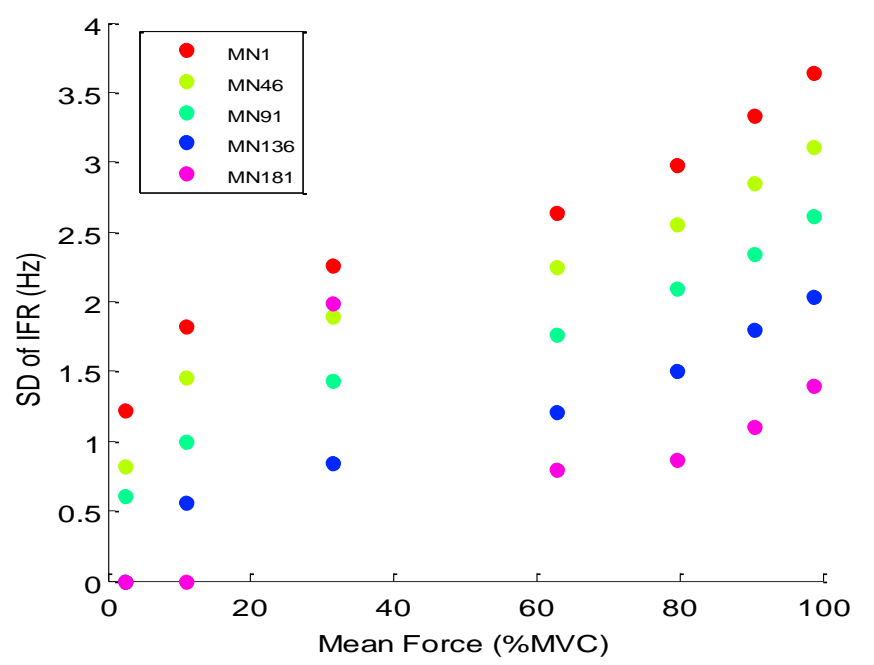

Figura 5-10 - Desvio padrão da frequência instantânea de disparos dos MNs em função do nível de força exercido. 
A Figura 5-11 mostra a participação da força gerada por cada uma das MNs visualizadas na força total. Cada ponto nos gráficos representa a média de 10 simulações.
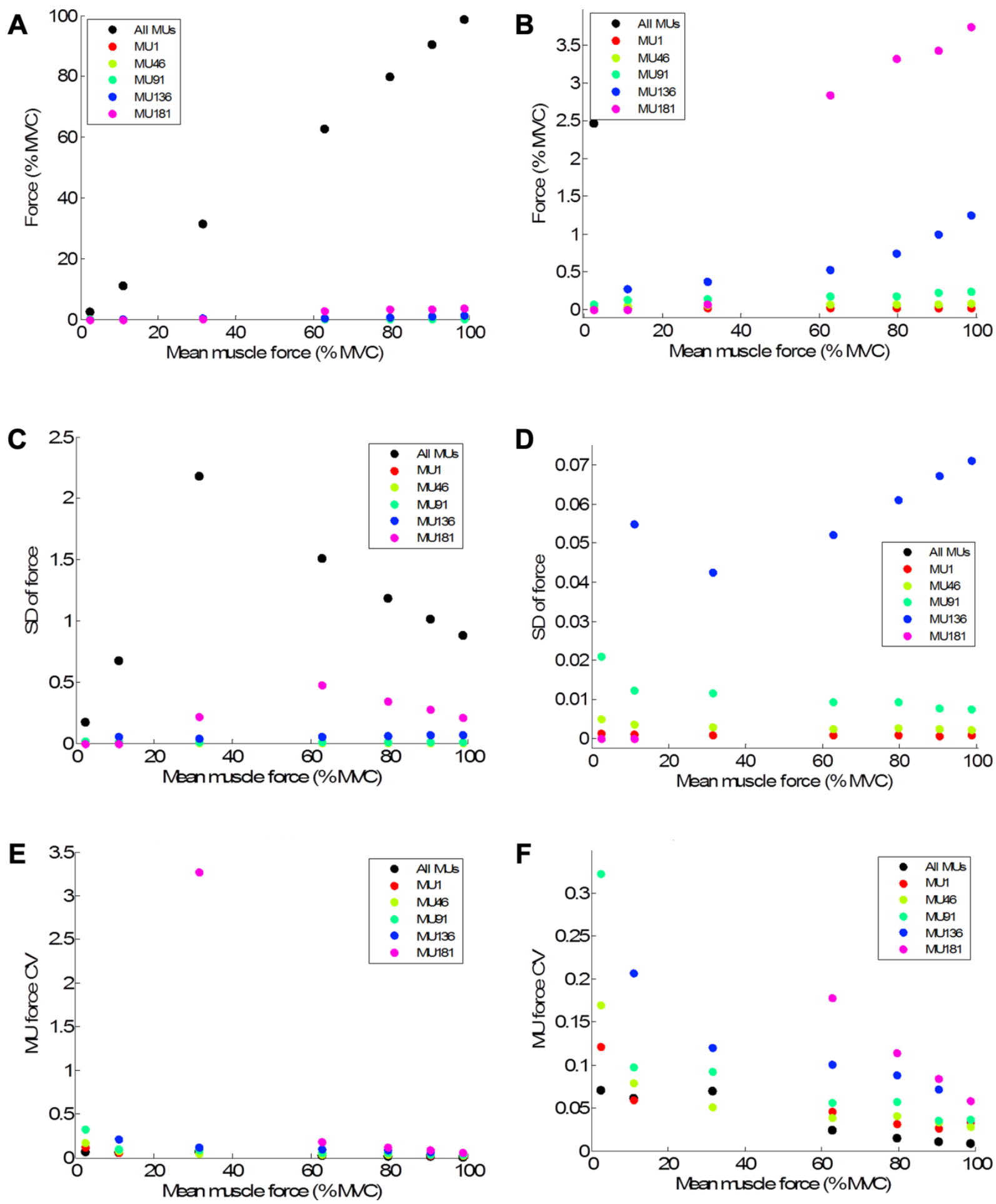

Figura 5-11 - Na coluna da esquerda são mostradas as forças médias exercidas por cada MU (A), os desvios-padrão (C) e os coeficientes de variação (E), para cada nível de força. Os gráficos da coluna da direita mostram uma ampliação da região de interesse dos gráficos à esquerda. A força média e seu desvio-padrão são dados em \% da MVC, enquanto que o CV é dado em \%. 
Na Figura 5-11B é possível observar a participação da força média gerada por cada MU na força total do músculo. Nota-se que, conforme aumenta o nível de força total, aumenta também a média da força gerada por cada MU. Além disto, para cada nível de força, as maiores forças médias de MUs geradas são as das MUs maiores. Na Figura 5-11C, D, nota-se que o comportamento do desvio-padrão da força gerada pelas MUs se diferencia dentro do pool e não estabelece uma relação simples com o desvio-padrão da IFR (Figura 5-10). As MUs maiores apresentam trechos de subida e de descida no desvio-padrão de suas forças, enquanto que as MUs menores apresentam uma tendência de queda, apenas. Por fim o CV da força de cada MU possui uma tendência geral de queda, conforme a força média muscular aumenta Figura 5-11E, F. É importante observar o alto valor de CV da força que as MUs apresentam assim que são recrutadas (vide, por exemplo, o CV da força do MN 181 na Figura 5-11E).

\subsubsection{Geração de força em idosos}

Assim como na Figura 5-6 para o caso de jovens, a Figura 5-12A mostra exemplos de simulações de geração de força em jovens para os sete níveis de frequência média de disparos dos PMNs. Na Figura 5-12B é mostrada a força média gerada no músculo em função da frequência média dos PMNs. Os valores médios de força obtidos para cada nível de entrada foram: $3 \%, 20 \%, 40 \%, 60 \%, 70 \%, 85 \%$, e $100 \%$ da MVC. Estes dados foram bem ajustados por uma relação sigmoidal $\left(\mathrm{R}^{2}=0.988\right.$; equação na legenda da figura).
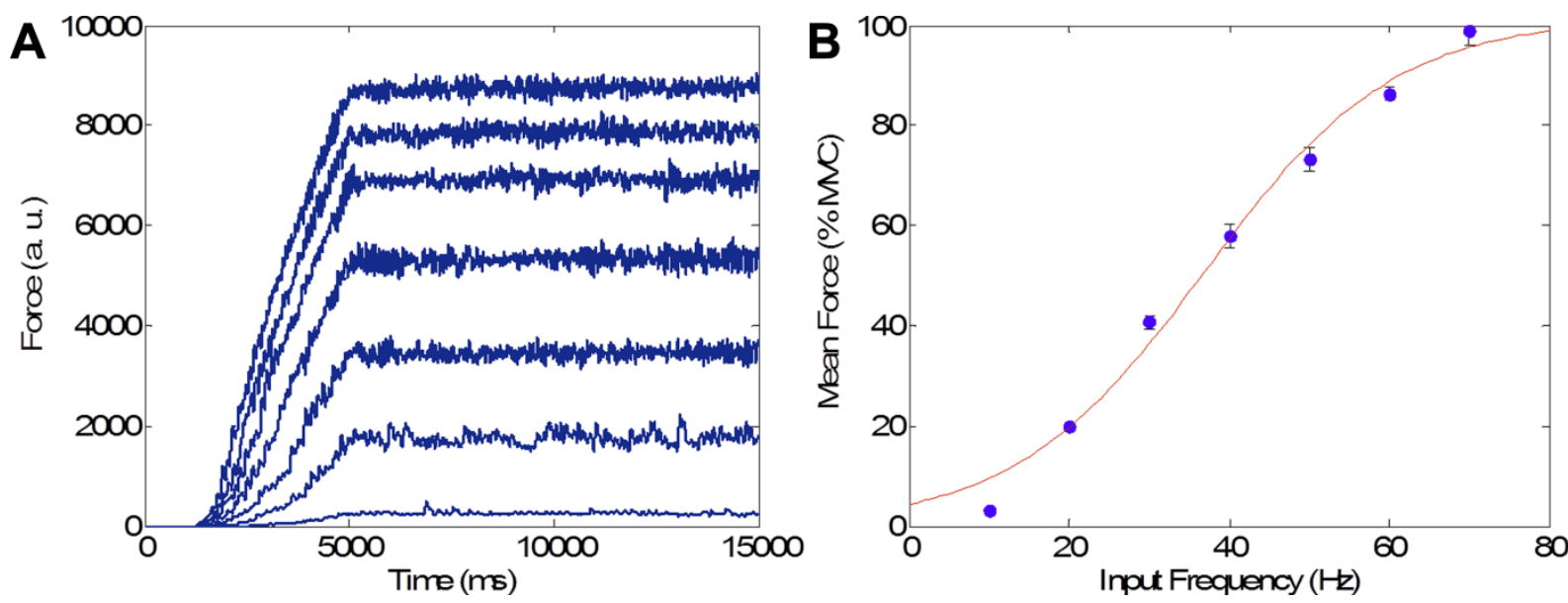

Figura 5-12 - A) Exemplo de simulações para geração de vários níveis de força em idosos. B) Força média gerada em função da frequência média de disparos dos neurônios PMNs. Os dados foram ajustados a uma sigmoide resultando em $R^{2}=0.988$. Sigmoide: Mean Force $=4.53 /(0.045+\exp (-0.084 *$ Input Frequency $))$. 
A Figura 5-13 mostra, para cada um dos sete níveis de força, o decurso temporal da frequência instantânea de disparos dos MNs.
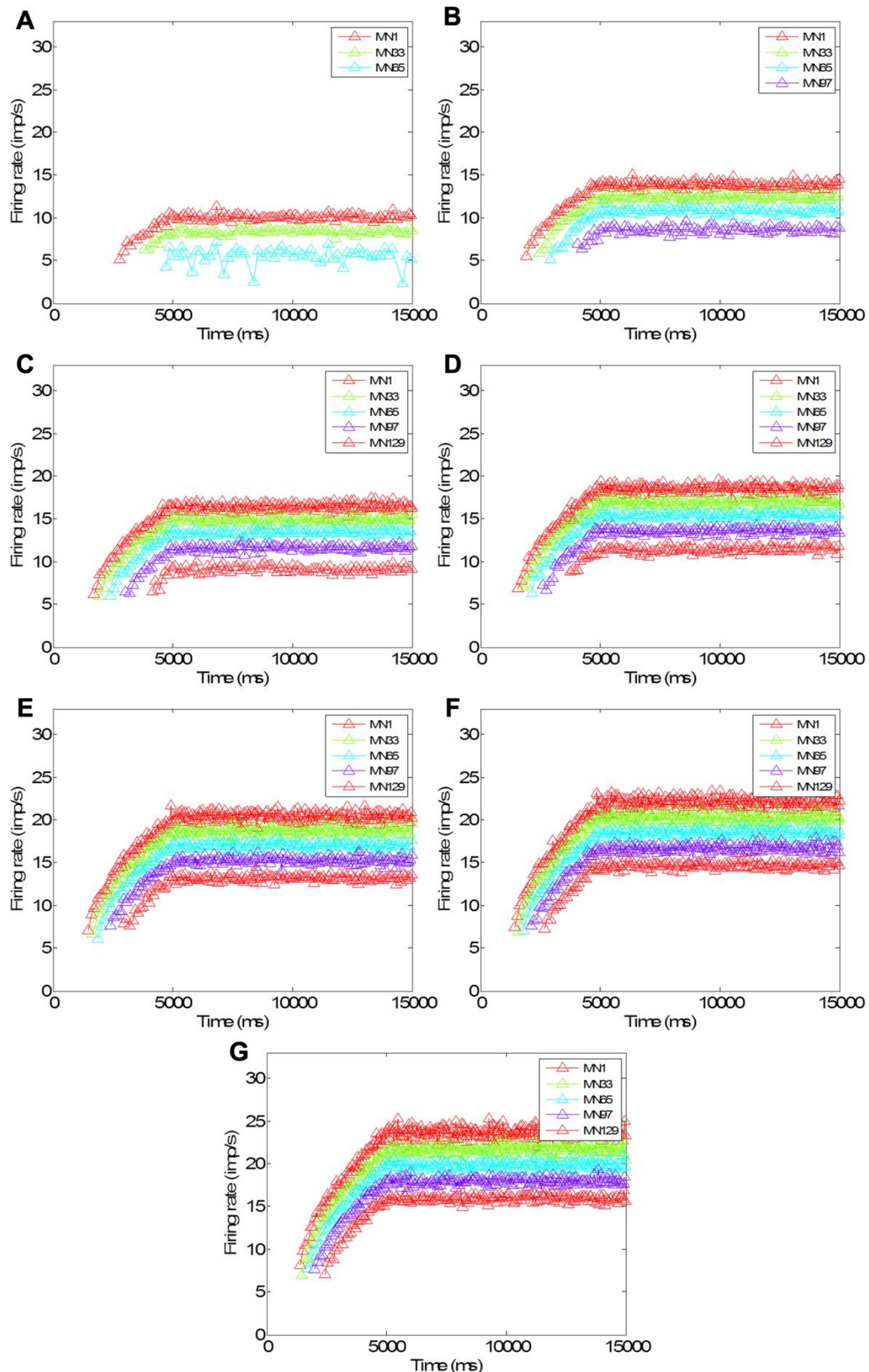

Figura 5-13 - Frequência instantânea de disparos dos MNs do pool (caso idoso) para diferentes níveis de força alvo: A) $3 \%$, B) $20 \%$, C) $40 \%$, D) $60 \%$, E) $70 \%$, F) $85 \%$, G) $100 \%$. 
Da mesma forma que para o modelo de jovem, para o caso de máxima excitação (Figura 5-13G) a faixa de frequências máximas de disparos para as MUs para o modelo de idosos foi muito próxima àquela encontrada experimentalmente $(\sim 14 \mathrm{~Hz}$ a $\sim 24 \mathrm{~Hz})$ (BARRY et al., 2007). Portanto, a diminuição da faixa de frequência de disparos observada experimentalmente em idosos foi também observada nas simulações.

\subsubsection{Variabilidade da força em idosos}

A Figura 5-14 mostra os resultados das simulações para estudar a variabilidade da força em idosos. O desvio padrão, em função da média da força (Figura 5-14A), possui uma tendência a aumentar para as forças menores e saturar para as maiores. Já o coeficiente de variação (Figura 5-14B) possui uma tendência de queda com o aumento da força.
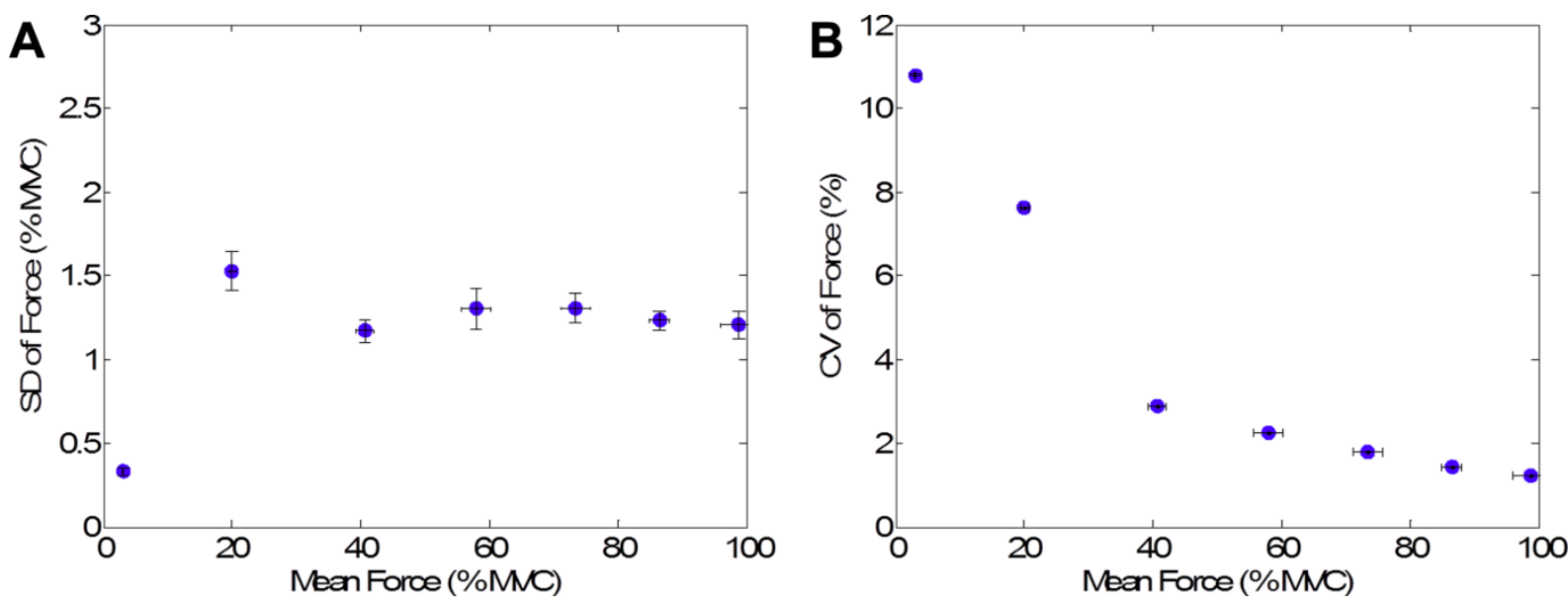

Figura 5-14 - Variabilidade da força gerada pelo modelo de idoso. A) Desvio padrão da força em função da força média. B) Coeficiente de variação da força em função da força média. As barras indicam desvio padrão dentre os valores obtidos das dez repetições para cada nível de força. 
Por fim, a Figura 5-15 mostra a comparação da variabilidade da força entre os modelos para jovens e idosos, sendo mostrado tanto um gráfico com a força média normalizada pela MVC (Figura 5-15A), quanto sem a normalização (Figura 5-15B). As barras ilustram os desvios-padrão dentre as 10 repetições realizadas, mas são quase imperceptíveis nas figuras. Nota-se uma maior variabilidade da força gerada pelos idosos nos níveis mais baixos. Porém, com o aumento da força média, o coeficiente de variação da força nos idosos apresenta uma queda maior que aquela dos jovens, mas ambos os CVs tendem para um valor de aproximadamente $1 \%$, assim como em (BARRY et al., 2007; JONES; HAMILTON; WOLPERT, 2002; MORITZ et al., 2005).
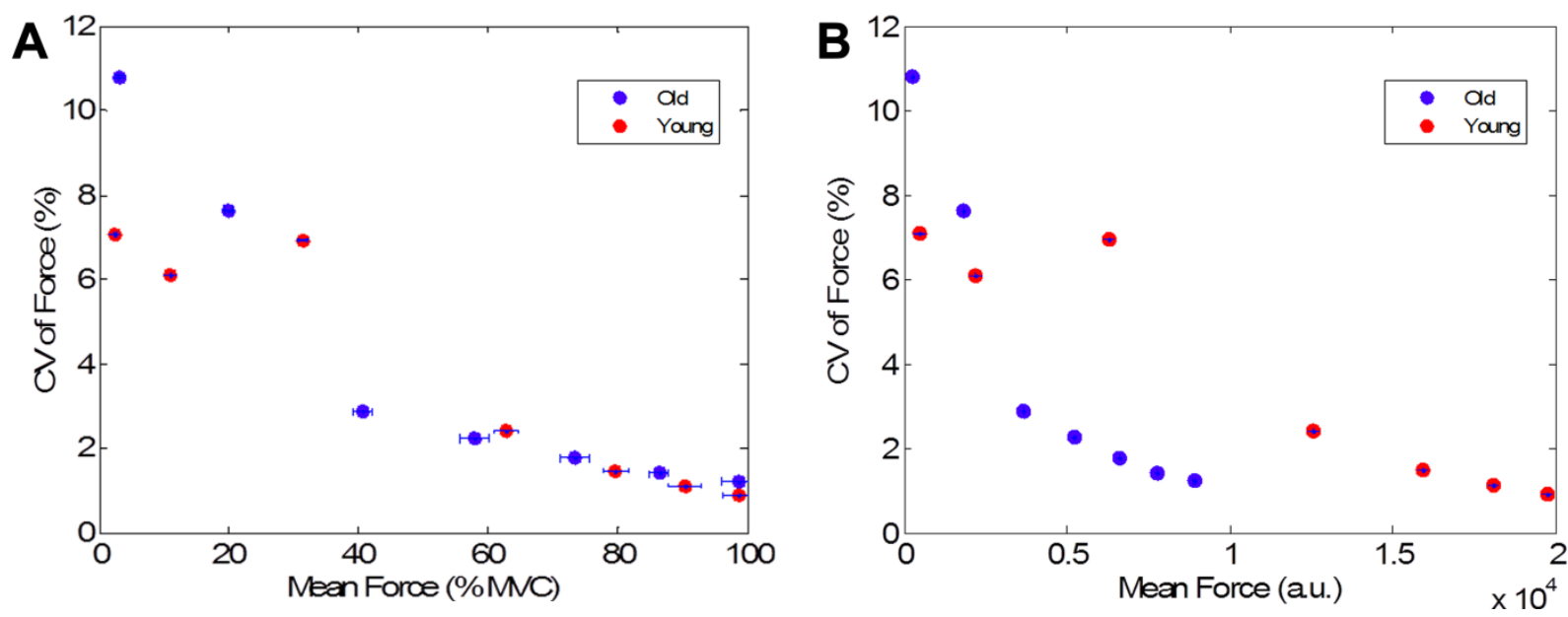

Figura 5-15 - Comparação da variabilidade da força em jovens (em vermelho) e idosos (em azul), com a força resultante normalizada (A) ou em valores absolutos (B). As barras indicam desvio padrão dentre os valores obtidos das dez repetições para cada nível de força. 


\subsection{Discussão}

Este trabalho constitui uma primeira etapa em uma série de estudos que se pretende fazer, empregando modelagem matemática e simulação computacional, para avaliar os efeitos do envelhecimento no sistema neuromuscular. Novas simulações e análises sistemáticas devem ser realizadas em estudos futuros, possibilitando a obtenção de resultados mais gerais e precisos.

\subsubsection{Geração de força em jovens}

Com a parametrização adotada, é possível observar (Figura 5-6B) que a relação entrada/saída do sistema neuromuscular de jovens modelado pode ser bem ajustada por uma função sigmoidal $\left(\mathrm{R}^{2}=0.999\right)$. Esta informação é bastante importante para o desenvolvimento de modelos mais simples, os quais podem ser empregados para outros tipos de análises, como, por exemplo, estudos de controle ótimo para o sistema motor. Além disto, a faixa de frequência de disparos escolhida para os PMNs $(0-70 \mathrm{~Hz})$ está dentro daquelas encontradas nas vias descendentes (BAKER et al., 2001; DAVIES; GERSTEIN; BAKER, 2006) e aferentes sensoriais (DIMITRIOU; EDIN, 2008; RIBOT-CISCAR et al., 2009).

\subsubsection{Características de disparos do pool de MNs em jovens}

Nota-se que, assim como no caso de corrente injetada no compartimento somático Figura 4-10E, o onion skin continua ocorrendo para simulações com a distribuição sináptica adotada. Tanto as características obtidas nas simulações de injeção triangular de correntes (Figura 4-10E) quanto aquelas obtidas nas simulações de entradas sinápticas moduladas (Figura 5-7) concordam com dados experimentais, empregando os respectivos paradigmas. Uma diferença, entretanto, entre os casos de correntes injetadas ou sinápticas foi que as MUs maiores passaram a ter frequências mínimas de disparos menores, quando excitadas por correntes sinápticas (DE LUCA; CONTESSA, 2012). Esta diminuição da frequência mínima de disparos para as MNs maiores indica que a distribuição dos pesos sinápticos adotados no modelo é adequada, tanto dentre os diferentes MNs do pool (distribuição uniforme da condutância sináptica em valores absolutos $(\mathrm{mS})$ ) quanto entre os dois compartimentos do 
modelo de MN (distribuição uniforme da condutância sináptica dividida pela área do compartimento, ou seja, o compartimento dendrítico, por ser 5 vezes maior, possui uma condutância sináptica 5 vezes maior que a do compartimento somático). É importante enfatizar, porém, que a modelagem dos PMNs não é biologicamente realista e visa a aglutinar o comportamento médio de vias descendentes, aferentes e interneuronais em uma única via. Cada uma das vias mencionadas possui uma diferente distribuição de pesos sinápticos sobre o pool de MNs. Aferentes Ia em gatos, por exemplo, levam a maiores correntes sinápticas efetivas em MNs menores do que em MNs maiores. Já os tratos piramidais possuem uma distribuição de correntes efetivas inversa a esta, ou seja, as correntes efetivas sinápticas são maiores nos MNs maiores (POWERS; BINDER, 2001).

A faixa de frequências de disparos (rate coding) para as MUs, durante a MVC (Figura 5-7G), foi de $\sim 15 \mathrm{~Hz}$ a $\sim 30 \mathrm{~Hz}$. O nível de força para o qual a última MU começa disparar tonicamente esteve entre 30 e $60 \%$ da MVC. Simulações posteriores indicaram que o recrutamento da última MU, no caso de jovens, ocorre em aproximadamente $43 \%$ da MVC (ver Apêndice 3). Este valor, embora um pouco abaixo dos valores frequentemente reportados para o FDI (DE LUCA; KLINE, 2012), possibilita uma razoável representação desta característica, que diferencia o FDI de outros músculos maiores, os quais possuem altas faixas de recrutamento.

Um resultado importante é que, no caso da MVC (Figura 5-7G) a faixa de frequências máximas de disparos para as MUs foi muito próxima àquela encontrada experimentalmente ( $16 \mathrm{~Hz}$ a $\sim 31 \mathrm{~Hz})$ (BARRY et al., 2007). Embora a taxa máxima do MN 1 tenha sido escolhida, a do MN 181 é uma consequência da organização do pool. 


\subsubsection{Variabilidade da força em jovens}

Vários estudos são realizados com o fim de avaliar a variabilidade da força, conforme se varia seu valor médio, tanto em jovens (DIDERIKSEN et al., 2012; JESUNATHADAS et al., 2012; JONES; HAMILTON; WOLPERT, 2002; KEENAN; VALERO-CUEVAS, 2007; MORITZ et al., 2005) quanto em idosos (BARRY et al., 2007; GALGANSKI; FUGLEVAND; ENOKA, 1993; LAIDLAW; BILODEAU; ENOKA, 2000; TRACY et al., 2005, 2007).

A variabilidade da força gerada por um músculo é consequência de uma série de fatores neurais e mecânicos, como: grau de rigidez da articulação, atividade proprioceptiva, grau de sincronismo das MUs, variabilidade das entradas comuns ao pool de MNs, forma do abalo das MUs e sua distribuição no pool e quantidade de MUs no músculo. Dentre estes fatores, o presente trabalho trata principalmente da reorganização do pool de MNs decorrente do envelhecimento. Embora outros fatores também estejam presentes, como, por exemplo, grau de sincronismo das unidades motoras, estes fatores não foram investigados sistematicamente. Porém, com a reparametrização realizada para representar o envelhecimento, vários destes fatores foram alterados, como, por exemplo, a distribuição das características mecânicas das MUs. Pela eliminação das MUs maiores, o valor médio das amplitudes de twitches diminuiu e o valor médio dos tempos de contração aumentou. Assim, não houve uma investigação sistemática do efeito de cada fator isoladamente, como em (KEENAN; VALERO-CUEVAS, 2007; TAYLOR; CHRISTOU; ENOKA, 2003), mas foram avaliados dois cenários representativos.

Tanto a faixa de valores absolutos encontrados para o desvio-padrão da força (Figura 5-8A) quanto a de CVs (Figura 5-8B) são próximas daqueles reportadas nos trabalho experimentais em que se estuda o FDI (BARRY et al., 2007; DIDERIKSEN et al., 2012; GALGANSKI; FUGLEVAND; ENOKA, 1993; MORITZ et al., 2005; TRACY et al., 2005). Porém, a variabilidade medida em $30 \%$ da MVC foge tanto da tendência de queda exibida pelo CV (Figura 5-8B) dos dados simulados, quanto dos dados experimentais. Conforme discutido mais adiante, esta alta variabilidade em $30 \%$ está associada ao recrutamento de MUs que possuem amplitudes de abalo altas e maior variabilidade de frequência de disparos.

Diferentemente do que ocorre no caso experimental, no modelo desenvolvido não há realimentações de informações correlacionadas com a força desenvolvida. Experimentalmente pode haver realimentação, por exemplo, por aferentes Ia, Ib ou cutâneos. Além disto, em parte 
dos trabalhos experimentais as análises de variabilidade são feitas num período em que o voluntário está com os olhos fechados e, em outra parte dos trabalhos, os voluntários permanecem com os olhos abertos e acompanham, em um osciloscópio, a força por eles gerada. Estas diferenças pode alterar significativamente a variabilidade da força e podem ter levado à disparidade da variabilidade em torno de $30 \%$ da MVC neste trabalho.

Quando todos os MNs são analisados simultaneamente, a variabilidade dos ISIs e das IFRs dos MNs concordam com o que se observa eu outros estudos (BARRY et al., 2007; JONES, 2005; STEIN; GOSSEN; JONES, 2005) (Figura 5-9). Assim como em (BARRY et al., 2007), houve uma faixa para a qual o desvio-padrão da frequência de disparos dos MNs diminui abruptamente com seu valor médio e outra faixa na qual o desvio padrão aumenta (Figura 5-9B). A faixa inicial de diminuição do desvio-padrão, porém, é aqui observada somente nas simulações de forças menores.

Apesar de a variabilidade da força em $30 \%$ estar acima do que é apresentado em outros estudos, este ocorrido serve de bom exemplo para ilustrar a influência das MUs recémrecrutadas sobre a variabilidade da força (GALGANSKI; FUGLEVAND; ENOKA, 1993). Na Figura 5-10 é possível observar uma forte tendência de o desvio-padrão da frequência de disparos aumentar, conforme se aumenta a força média. Porém, é nítida a alta variabilidade das MUs maiores, assim que são recrutadas.

Outro fator que influência na variabilidade da força é o ruído sináptico, o qual, associado à dinâmica dos MNs, vai determinar as variabilidade dos ISIs e das IFRs dos MN. Neste trabalho, foi feita a suposição de que a atividade das vias pré-motoneuronais pudesse ser representada por processos pontuais Gama com parâmetro de forma constante igual a dois e com a frequência variando conforme o nível desejado de força na saída do sistema. Porém, pode ser que uma modulação também do parâmetro de forma dos processos Gama levasse a resultados mais próximos dos experimentais, principalmente para os níveis mais baixos de força, os quais aqui apresentaram uma variabilidade maior do que o observado experimentalmente. 


\subsubsection{Geração de força em idosos}

Assim como no caso de jovens, é possível observar (Figura 5-16 B) que a relação entrada/saída do sistema neuromuscular de idosos modelado pode ser bem ajustado por uma função sigmoidal $\left(\mathrm{R}^{2}=0.988\right)$. Este ajuste, porém, é um pouco menos próximo dos dados do que no caso do modelo de jovens, embora ainda possua um alto coeficiente de determinação.

Em (LAIDLAW; BILODEAU; ENOKA, 2000) a MVC média para jovens foi de 32,9 $\mathrm{N}$, enquanto que para idosos foi de 22,7 N. Ou seja, os idosos tiveram, em média, uma MVC igual a $69 \%$ daquela apresentada pelos jovens. No presente trabalho a MVC definida para os jovens foi de 20.000 a. u., enquanto que para os idosos foi de 9,000 a. u.. Com isto, a MVC dos idosos é igual a $45 \%$ daquela dos jovens. Observa-se, então, que a redução da MVC, de jovens para idosos, foi mais acentua no modelo, comparando com os dados experimentais. Porém deve ser enfatizado que não houve na parametrização um reajuste nas amplitudes dos abalos a fim de representar a reinervação que ocorre com o envelhecimento. É possível que se o aumento devido à reinervação tivesse sido contemplado no modelo, os resultados para as MVCs ficariam mais próximos dos experimentais. Porém os resultados apresentados aqui são normalizados pela MVC e, supondo que a reinervação ocorra de forma uniforme dentre as MUs do pool, a diferença entre a razão $M V C_{\text {jovens }} / M V C_{\text {idosos }}$ no caso simulado e experimental não afeta as análises aqui realizadas. 


\subsubsection{Características de disparos do pool de MNs em idosos}

As características de disparos para o modelo de idosos mostradas na Figura 5-13 concordam com o que é reportado experimentalmente. O princípio do tamanho continua ocorrendo no modelo para idosos, assim como se mostra no caso experimental (FLING; KNIGHT; KAMEN, 2009). Como consequência da diminuição da quantidade de PMNs no modelo para idosos, houve uma diminuição da IFR dos MNs, durante a MVC (Figura 5-13F), de $\sim 30 \mathrm{~Hz}$ para $\sim 24 \mathrm{~Hz}$, concordando com os resultados mostrados em (BARRY et al., 2007; ERIM et al., 1999; KAMEN et al., 1995). Além disto, assim como reportado por Erim (1999), houve uma diminuição da diferença entre as IFRs de MUs recrutadas consecutivamente, resultando numa redução da faixa de codificação por frequência no pool de MUs (BARRY et al., 2007).

A simples eliminação das MUs maiores leva a uma série de características mostradas na Tabela 5-1, como um aumento da duração da amplitude média da AHP, um aumento do tempo de contração médio das MUs, uma diminuição da amplitude de twitch média e um aumento da IFR média, para um mesmo nível de excitação. Este aumento da IFR média é, porém, contrabalanceado pela redução no número de PMNs.

Pelos resultados mostrados na (Figura 5-7) e na Figura 5-13, não é conclusivo se a faixa de recrutamento das MUs reduziu nos idosos, pois as intensidades de força simuladas em jovens e idosos não coincidem. Porém, simulações posteriores indicaram que o recrutamento da última MU, no modelo para idosos, ocorre em aproximadamente $25 \%$ da MVC (ver Apêndice 3), 58 \% do valor encontrado no modelo para jovens. Este resultado vai contra a suposição de que jovens e idosos possuem uma mesma faixa de recrutamento, adotada no modelo de Barry (2007) e concorda com dados experimentais em humanos (KLASS; BAUDRY; DUCHATEAU, 2008). Além disto, o modelo de Barry (2007) não segue o onion skin, característica que vem se mostrando ocorrer em uma série de músculos dos seres humanos, incluindo o FDI (DE LUCA; CONTESSA, 2012; DE LUCA; HOSTAGE, 2010). 


\subsubsection{Variabilidade da força em idosos}

Na Figura 5-15 pode-se observar uma maior variabilidade da força no modelo para idosos, comparando com o modelo para jovens, principalmente nas forças menores, o que concorda com dados experimentais (BARRY et al., 2007; GALGANSKI; FUGLEVAND; ENOKA, 1993; LAIDLAW; BILODEAU; ENOKA, 2000). Além disto, nota-se que, com o aumento da força média, o coeficiente de variação da força nos idosos apresenta uma queda maior que aquela dos jovens, mas ambos os CVs tendem para um valor de aproximadamente $1 \%$, valor próximo aos reportados por (BARRY et al., 2007; JONES; HAMILTON; WOLPERT, 2002; MORITZ et al., 2005).

Como foi mostrado na Figura 5-11E, F, no modelo para jovens, a força gerada pelas MUs possui um alto $\mathrm{CV}$ quando a $\mathrm{MU}$ é recrutada e este $\mathrm{CV}$ tende a diminuir com o aumento da força gerada. Esta alta variabilidade das MUs recém-recrutadas é um fator importante na determinação da variabilidade da força total muscular, tanto em jovens quanto em idosos (GALGANSKI; FUGLEVAND; ENOKA, 1993). Este efeito, porém, só pode ocorrer dentro da faixa de recrutamento das MUs e, como foi mostrado neste modelo, a faixa de recrutamento é menor nos idosos. Além disto, a contribuição relativa da força e da variabilidade da força de uma MU na força total muscular é maior nos idosos do que nos jovens, tendo em vista a diminuição do número de MUs com o envelhecimento. Isto justifica um efeito mais pronunciado da variabilidade de MUs recém-recrutadas na variabilidade da força total, resultando na maior variabilidade da força em idosos do que em jovens, para as forças baixas. 


\section{Referências}

ALLUM, J. H.; MAURITZ, K. H. Compensation for intrinsic muscle stiffness by shortlatency reflexes in human triceps surae muscles. Journal of Neurophysiology, v. 52, n. 5, p. 797-818, 1984.

ARNOLD, E. et al. A Model of the Lower Limb for Analysis of Human Movement. Annals of Biomedical Engineering, v. 38, n. 2, p. 269-279, 2010.

BAKER, S. N. et al. Synchronization in monkey motor cortex during a precision grip task. I. Task-dependent modulation in single-unit synchrony. Journal of Neurophysiology, v. 85, p. 869-885, 2001.

BAKER, S. N. The primate reticulospinal tract, hand function and functional recovery. The Journal of Physiology, v. 589, n. 23, p. 5603-5612, 2011.

BARRY, B. K. et al. Rate coding is compressed but variability is unaltered for motor units in a hand muscle of old adults. J Neurophysiol, v. 97, n. 5, p. 3206-3218, 2007.

BAUDRY, S.; MAERZ, A. H.; ENOKA, R. M. Presynaptic Modulation of Ia Afferents in Young and Old Adults When Performing Force and Position Control. Journal of Neurophysiology , v. 103 , n. 2 , p. 623-631, fev. 2010.

BAWA, P.; STEIN, R. B. Frequency responses of human soleus muscle. Journal of Neurophysiology, v. 39, p. 788-793, 1976.

BEAR, M. F.; CONNORS, B. W.; PARADISO, M. A. Neuroscience, Exploring the Brain. Second Edi ed. Baltimore: Lippincott, Williams and Wilkins, 2001.

BERGQUIST, A. J.; CLAIR, J. M.; COLLINS, D. F. Motor unit recruitment when neuromuscular electrical stimulation is applied over a nerve trunk compared with a muscle belly: triceps surae. Journal of Applied Physiology, v. 110, n. 3, p. 627-637, 2011.

BOOTH, V.; RINZEL, J.; KIEHN, O. Compartmental model of vertebrate motoneurons for

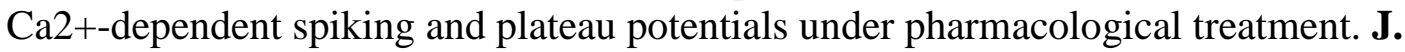
Neurophysiology, v. 78, p. 3371-3385, 1997.

BROWN, I. E.; SCOTT, S. H.; LOEB, G. E. Mechanics of feline soleus: II design and validation of a mathematical model. Journal of Muscle Research and Cell Motility, v. 17, n. 2, p. 221-233, 1996.

BUI, T. V et al. Computational estimation of the distribution of 1-type ca channels in motoneurons based on variable threshold of activation of persistent inward currents. Journal of Neurophysiology, v. 95, p. 225-241, 2006. 
BURKE, R. E. The spinal cord: ventral horn. In: SHEPHERD, G. M. (Ed.). Synaptic Organization of the Brain. 5th. ed. N.Y.: Oxford University Press, 2003. .

BURKE, R. E.; TSAIRIS, P. Correlation of Physiological Properties with Histochemical Characteristics in Single Muscle Units. Annals of the New York Academy of Sciences, v. 228, n. MAR 22, p. 145-159, 1974.

BUTLER, A. J.; YUE, G.; DARLING, W. G. Variations in soleus H-reflexes as a function of plantarflexion torque in man. Brain Research, v. 632, p. 95-104, 1993.

BUTTON, D. C. et al. Frequency-current relationships of rat hindlimb alpha-motoneurones. The Journal of physiology, v. 573, n. Pt 3, p. 663-77, 15 jun. 2006.

CAPADAY, C.; STEIN, R. B. A method for stimulation the reflex output of a motoneuron pool. Journal of Neuroscience Methods, v. 21, p. 91-104, 1987.

CHALMERS, G. R.; KNUTZEN, K. M. Recurrent inhibition in the soleus motor pool of elderly and young adults. Electromyography and clinical neurophysiology, v. 44, n. 7, p. 413-421, 2004.

CHASE, M. Aging of Motoneurons NOTE and Synaptic Processes in the Cat. Experimental Neurology, v. 90, p. 471-478, 1985.

CHRISTIE, A.; KAMEN, G. Short-term training adaptations in maximal motor unit firing rates and afterhyperpolarization duration. Muscle \& Nerve, v. 41, n. 5, p. 651-660, 2010.

CISI, R. R. L.; KOHN, A. F. Simulation system of spinal cord motor nuclei and associated nerves and muscles, in a Web-based architecture. J Comput Neurosci, v. 25, n. 3, p. 520$542,2008$.

CLEMENTS, J. D.; REDMAN, S. J. Cable properties of cat spinal motoneurons measured by combining voltage clamp, current clamp and intracellular staining. J. Physiol., v. 409, p. 6387, 1989.

COFER, D. et al. AnimatLab: A 3D graphics environment for neuromechanical simulations. Journal of Neuroscience Methods, v. 187, n. 2, p. 280-288, 2010.

CRONIN, N. J. et al. Effects of contraction intensity on muscle fascicle and stretch reflex behavior in the human triceps surae. Journal of Applied Physiology, v. 105, n. 1, p. 226-232, 2008.

CRONIN, N. J. et al. Mechanical and neural stretch responses of the human soleus muscle at different walking speeds. The Journal of Physiology, v. 587, n. 13, p. 3375-3382, 2009.

DAVIES, R. M.; GERSTEIN, G. L.; BAKER, S. N. Measurement of time-dependent changes in the irregularity of neural spiking. Journal of neurophysiology, v. 96, n. 2, p. 906-18, ago. 2006. 
DE LUCA, C. J.; CONTESSA, P. Hierarchical control of motor units in voluntary contractions. Journal of neurophysiology, v. 107, n. 1, p. 178-95, jan. 2012.

DE LUCA, C. J.; HOSTAGE, E. C. Relationship between firing rate and recruitment threshold of motoneurons in voluntary isometric contractions. Journal of neurophysiology, v. 104, n. 2, p. 1034-46, ago. 2010.

DE LUCA, C. J.; KLINE, J. C. Influence of proprioceptive feedback on the firing rate and recruitment of motoneurons. Journal of neural engineering, v. 9, n. 1, p. 016007, fev. 2012.

DE VLUGT, E. et al. Clonus is explained from increased reflex gain and enlarged tissue viscoelasticity. Journal of Biomechanics, v. 45, n. 1, p. 148-155, 2011.

DESTEXHE, A. Conductance-based integrate-and-fire models. Neural Comput, v. 9, n. 3, p. 503-514, 1997.

DESTEXHE, A.; MAINEN, Z. F.; SEJNOWSKI, T. J. An Efficient Method for Computing Synaptic Conductances Based on a Kinetic-Model of Receptor-Binding. Neural computation, v. 6, n. 1, p. 14-18, 1994.

DIDERIKSEN, J. L. et al. MOTOR UNIT RECRUITMENT STRATEGIES AND MUSCLE PROPERTIES DETERMINE THE INFLUENCE OF SYNAPTIC NOISE ON FORCE STEADINESS. Journal of Neurophysiology, 2012.

DIDERIKSEN, J. L.; ENOKA, R. M.; FARINA, D. A Model of the Surface Electromyogram in Pathological Tremor. Biomedical Engineering, IEEE Transactions on, v. 58, n. 8, p. 2178-2185, 2011.

DIMITRIOU, M.; EDIN, B. B. Discharges in human muscle spindle afferents during a keypressing task. The Journal of physiology, v. 586, n. Pt 22, p. 5455-70, 15 nov. 2008.

DOHERTY, T. J.; BROWN, W. F. The estimated numbers and relative sizes of thenar motor units as selected by multiple point stimulation in young and older adults. Muscle \& Nerve, v. 16, p. 355-366, 1993.

EARLES, D.; VARDAXIS, V.; KOCEJA, D. Regulation of motor output between young and elderly subjects. Clin Neurophysiol, v. 112, n. 7, p. 1273-9., 2001.

ECCLES, J. C.; SHERRINGTON, C. S. Numbers and Contraction-Values of Individual Motor-Units Examined in some Muscles of the Limb. Proceedings of the Royal Society of London. Series B, Containing Papers of a Biological Character, v. 106, n. 745, p. 326$357,1930$.

EISEN, A.; ENTEZARI-TAHER, M.; STEWART, H. Cortical projections to spinal motoneurons: changes with aging and amyotrophic lateral sclerosis. Neurology, v. 46, n. 5, p. 1396-1404, maio. 1996.

ELBASIOUNY, S. M. et al. Simulation of dendritic cav 1.3 channels in cat lumbar motoneurons: spatial distribution. J . Neurophysiol, v. 94, n. 6, p. 3961-3974, 2005. 
ELIAS, L. A. et al. Application of a web-based simulator to a study of neuromuscular training in humansBiomedical Engineering Society Annual Meeting. Anais...Hartford: 2011

ELIAS, L. A.; KOHN, A. F. Individual and collective properties of computationally efficient motoneuron models of types $S$ and $F$ with active dendrites. Neurocomputing, v. 99, n. 0, p. 521-533, 1 jan. 2013.

ENOKA, R. M. Neuromechanics of Human Movement. Champaign: Human Kinetics, 2008.

ENOKA, R. M. et al. Unraveling the neurophysiology of muscle fatigue. Journal of Electromyography and Kinesiology, v. 21, n. 2, p. 208-219, 2011.

ERIM, Z. et al. Effects of aging on motor-unit control properties. J. Neurophysiol., v. 82, p. 2081-2091, 1999.

FLESHMAN, J. W.; SEGEV, I.; BURKE, R. B. Electrotonic architecture of type-identified alpha-motoneurons in the cat spinal cord . Journal of Neurophysiology , v. 60 , n. 1 , p. 6085, 1 jul. 1988.

FLING, B.; KNIGHT, C.; KAMEN, G. Relationships between motor unit size and recruitment threshold in older adults: implications for size principle. Experimental Brain Research, v. 197, n. 2, p. 125-133, 1 ago. 2009.

FLOETER, M. K.; KOHN, A. F. H-Reflex of different sizes exhibit differential sensitivity to low frequency depression. Electroencephalography and Clinical Neurophysiology, v. 105, p. 470-475, 1997.

FUGLEVAND, A. J. Mechanical properties and neural control of human hand motor units. The Journal of Physiology, v. 589, n. 23, p. 5595-5602, 2011.

FUGLEVAND, A. J.; WINTER A., D.; PATLA, A. E. Models of recruitment and rate coding organization in motor-unit pools. Journal of Neurophysiology, v. 70, p. 2470-2488, 1993.

GALGANSKI, M. E.; FUGLEVAND, A. J.; ENOKA, R. M. Reduced control of motor output in a human hand muscle of elderly subjects during submaximal contractions. Journal of Neurophysiology , v. 69 , n. 6 , p. 2108-2115, 1 jun. 1993.

GORASSINI, M. et al. Intrinsic Activation of Human Motoneurons: Possible Contribution to Motor Unit Excitation. Journal of Neurophysiology , v. 87 , n. 4 , p. 1850-1858, 1 abr. 2002.

GOTTLIEB, G. L.; AGARWAL, G. C.; JAEGER, R. J. Response to sudden torques about ankle in man. IV. A functional role of alpha-gamma linkage. Journal of Neurophysiology, v. 46, n. 1, p. 179-190, 1981.

GRAY, H. Gray's anatomy. 37th. ed. Edinburgh: C. Livingstone: [s.n.].

GUSTAFSSON, B.; PINTER, M. J. An investigation of threshold properties among cat spinal alpha-motoneurons. Journal of Physiology, v. 357, p. 453-483, 1984a. 
GUSTAFSSON, B.; PINTER, M. J. Relations among passive electrical properties of lumbar alpha-motoneurones of the cat. Journal of Physiology, v. 356, p. 401-431, 1984b.

HECKMAN, C. J. et al. Persistent inward currents in spinal motoneurons and their influence on human motoneuron firing patterns. Neuroscientist, v. 14, n. 3, p. 264-275, 2008.

HECKMAN, C. J.; ENOKA, R. M. Physiology of the motor neuron and the motor unit. In: ANDREW, E. (Ed.). Handbook of Clinical Neurophysiology. [S.1.] Elsevier, 2004. v. Volume 4p. 119-147.

HECKMAN, C. J.; ENOKA, R. M. Motor Unit. In: Comprehensive Physiology. [S.1.] John Wiley \& Sons, Inc., 2012. .

HECKMAN, C. J.; GORASSINI, M. A.; BENNETT, D. J. Persistent inward currents in motoneuron dendrites: implications for motor output. Muscle and Nerve, v. 31, p. 135-156, 2005.

HENNEMAN, E. Relation between Size of Neurons and Their Susceptibility to Discharge. Science, v. 126, n. 3287, p. 1345-1347, 1957.

HIDLER, J. M.; RYMER, W. Z. A simulation study of reflex instability in spasticity: origins of clonus. Rehabilitation Engineering, IEEE Transactions on, v. 7, n. 3, p. 327-340, 1999.

HODGKIN, A. L.; HUXLEY, A. F. A Quantitative Description of Membrane Current and Its Application to Conduction and Excitation in Nerve. Journal of Physiology-London, v. 117, n. 4 , p. 500-544, 1952.

HORTOBÁGYI, T.; DEL OLMO, M.; JOHN C. ROTHWELL, J. C. R. Age reduces cortical reciprocal inhibition in humans. Experimental Brain Research, v. 171, n. 3, p. 322-329, maio. 2006.

HUDSON, A. L. et al. Coupling between mechanical and neural behaviour in the human first dorsal interosseous muscle. The Journal of Physiology , v. 587 , n. 4, p. 917-925, 15 fev. 2009.

HUTCHEON, B.; YAROM, Y. Resonance, oscillation and the intrinsic frequency preferences of neurons. Trends in Neurosciences, v. 23, n. 5, p. 216-222, 1 maio. 2000.

JESUNATHADAS, M. et al. Discharge properties of motor units during steady isometric contractions performed with the dorsiflexor muscles. Journal of Applied Physiology , v. 112 , n. 11 , p. 1897-1905, 1 jun. 2012.

JOHNSON, D. H. Point process models of single-neuron discharges. Journal of computational neuroscience, v. 3, n. 4, p. 275-99, dez. 2000.

JOHNSON, H. et al. The serotoninergic bulbospinal system and brainstern-spinal cord content of serotonin-, TRH-, and substance P-like immunoreactivity in the aged rat with special reference to the spinal cord motor nucleus. Synapse, v. 15, n. 1, p. 63-89, 1993. 
JONES, K. E. Motor unit firing statistics and the Fuglevand model. Journal of neurophysiology, v. 94, n. 3, p. 2255-6; author reply 2256-7, set. 2005.

JONES, K. E.; HAMILTON, A. F. C.; WOLPERT, D. M. Sources of signal-dependent noise during isometric force production. Journal of Neurophysiology, v. 88, p. 1533-1544, 2002.

KALLIO, J. et al. Effects of ageing on motor unit activation patterns and reflex sensitivity in dynamic movements. Journal of electromyography and kinesiology : official journal of the International Society of Electrophysiological Kinesiology, v. 20, n. 4, p. 590-8, ago. 2010.

KALMAR, J. M. et al. Caloric Restriction Does Not Offset Age-Associated Changes in the Biophysical Properties of Motoneurons. Journal of Neurophysiology, v. 101, n. 2, p. 548$557,2009$.

KAMEN, G. et al. Motor unit discharge behavior in older adults during maximal-effort contractions. Journal of Applied Physiology , v. 79 , n. 6 , p. 1908-1913, dez. 1995.

KANDA, K.; HASHIZUME, K. Changes in Properties of the Medial Gastrocnemius Motor Units in Aging Rats. Journal of Neurophysiology, v. 61, n. 4, p. 737-746, 1989.

KANDEL, E. et al. Principles of Neural Science. 5th. ed. [S.1.] McGraw-Hill, 2013. p. 1760

KANDEL, E. R.; SCHWARTZ, J. H.; JESSELL, T. M. Principles of Neural Science. 4th Editio ed. New York: McGraw-Hill, 2000.

KEENAN, K. G.; VALERO-CUEVAS, F. J. Experimentally valid predictions of muscle force and EMG in models of motor-unit function are most sensitive to neural properties. J

Neurophysiol, v. 98, n. 3, p. 1581-1590, 2007.

KERNELL, D. The limits of firing frequency in cat lumbosacral motoneurones possessing different time course of afterhyperpolarization. Acta Physiologica Scandinavica, v. 65, p. 87-100, 1965.

KIDO, A.; TANAKA, N.; STEIN, R. B. Spinal excitation and inhibition decrease as humans age. Canadian Journal of Physiology and Pharmacology, v. 82, n. 4, p. 238-248, abr. 2004.

KIM, H.; JONES, K. Asymmetric electrotonic coupling between the soma and dendrites alters the bistable firing behaviour of reduced models. Journal of Computational Neuroscience, v. 30, n. 3, p. 659-674, 2011.

KIM, H.; JONES, K. E. The Retrograde Frequency Response of Passive Dendritic Trees Constrains the Nonlinear Firing Behaviour of a Reduced Neuron Model. PLoS ONE, v. 7, n. 8, p. e43654, 2012.

KIM, H.; MAJOR, L.; JONES, K. Derivation of cable parameters for a reduced model that retains asymmetric voltage attenuation of reconstructed spinal motor neuron dendrites.

Journal of Computational Neuroscience, v. 27, n. 3, p. 321-336, 2009. 
KLASS, M.; BAUDRY, S.; DUCHATEAU, J. Voluntary activation during maximal contraction with advancing age: a brief review. European journal of applied physiology, v. 100, n. 5, p. 543-51, jul. 2007.

KLASS, M.; BAUDRY, S.; DUCHATEAU, J. Age-related decline in rate of torque development is accompanied by lower maximal motor unit discharge frequency during fast contractions. Journal of Applied Physiology, v. 104, n. 3, p. 739-746, 2008.

KNIKOU, M. The H-reflex as a probe: pathways and pitfalls. J Neurosci Methods, v. 171, n. 1, p. 1-12, 2008.

KURIAN, M.; CROOK, S.; JUNG, R. Motoneuron model of self-sustained firing after spinal cord injury. Journal of Computational Neuroscience, v. 31, n. 3, p. 625-645, 2011.

LAIDLAW, D. H.; BILODEAU, M.; ENOKA, R. M. Steadiness is reduced and motor unit discharge is more variable in old adults. Muscle \& nerve, v. 23, n. 4, p. 600-12, abr. 2000.

LEE, R. H.; HECKMAN, C. J. Bistability in spinal motoneurons in vivo: systematic variations in rhythmic firing patterns. Journal of Neurophysiology, v. 80, p. 572-582, 1998a.

LEE, R. H.; HECKMAN, C. J. Bistability in spinal motoneurons in vivo: systematic variations in persistent inward currents. Journal of Neurophysiology, v. 80, p. 583-593, 1998b.

LEMON, R. N. Descending pathways in motor control. In: Annual Review of Neuroscience. Palo Alto: Annual Reviews, 2008. v. 31p. 195-218.

LO CONTE, L. R.; MERLETTI, R.; SANDRI, G. V. Hermite expansions of compact support waveforms: applications to myoelectric signals. Ieee Transactions on Biomedical Engineering, v. 41, p. 1147-1159, 1994.

LYTTON, W. W. Optimizing synaptic conductance calculation for network simulations. Neural Comput, v. 8, n. 3, p. 501-509, 1996.

MAGANARIS, C. N. Force-length characteristics of in vivo human skeletal muscle. Acta Physiologica Scandinavica, v. 172, n. 4, p. 279-285, 2001.

MANUEL, M. et al. Resonant or not, two amplification modes of proprioceptive inputs by persistent inward currents in spinal motoneurons. J Neurosci, v. 27, n. 47, p. 12977-12988, 2007.

MANUEL, M. et al. Fast kinetics, high-frequency oscillations, and subprimary firing range in adult mouse spinal motoneurons. The Journal of neuroscience : the official journal of the Society for Neuroscience, v. 29, n. 36, p. 11246-56, 9 set. 2009.

MASAKADO, Y. et al. Macro-EMG and motor unit recruitment threshold: differences between the young and the aged. Neuroscience Letters, v. 179, p. 1-4, 1994. 
MCNEIL, C. J. et al. Motor unit number estimates in the tibialis anterior muscle of young, old, and very old men. Muscle \& Nerve, v. 31, n. 4, p. 461-467, 2005.

MERLETTI, R. et al. Age related changes in surface myoelectric signals. Scand J Rehabil Med, v. 24, n. 1, p. 25-36, 1992.

MILEUSNIC, M. P. et al. Mathematical models of proprioceptors. I. Control and transduction in the muscle spindle. J Neurophysiol, v. 96, n. 4, p. 1772-1788, 2006.

MORALES, F. R. et al. Basic electrophysiological properties of spinal cord motoneurons during old age in the cat. Journal of Neurophysiology , v. 58 , n. 1, p. 180-194, jul. 1987.

MORITA, H. et al. Progressive decrease in heteronymous monosynaptic Ia facilitation with human aging. Experimental Brain Research, v. 104, p. 167-170, 1995.

MORITZ, C. T. et al. Discharge rate variability influences the variation in force fluctuations across the working range of a hand muscle. Journal of Neurophysiology, v. 93, p. 24492459, 2005.

NARICI, M. V et al. Effect of aging on human muscle architecture. Journal of Applied Physiology , v. 95 , n. 6 , p. 2229-2234, 1 dez. 2003.

NARICI, M. V; MAGANARIS, C. N. Adaptability of elderly human muscles and tendons to increased loading. Journal of Anatomy, v. 208, n. 4, p. 433-443, 2006.

NEGRO, F.; FARINA, D. Decorrelation of cortical inputs and motoneuron output. Journal of Neurophysiology, v. 106, n. 5, p. 2688-2697, 2011.

OLIVIERO, A et al. Effects of aging on motor cortex excitability. Neuroscience research, v. 55 , n. 1 , p. $74-7$, maio. 2006.

OYA, T.; CRESSWELL, A. G. Evidence for reduced efficacy of the Ia-pathway during shortening plantar flexions with increasing effort. Experimental Brain Research, v. 185, n. 4, p. 699-707, 2008.

PASCOE, M. A.; ENOKA, R. M. Age-associated differences in discharge rate modulation of human motor units. [S.1.] University of Colorado, 2010.

PETTIGREW, F. P.; GARDINER, P. F. Changes in rat plantaris motor unit profiles with advanced age. Mechanisms of Ageing and Development, v. 40, n. 3, p. 243-259, 1987.

PIERROT-DESEILligNY, E.; BURKE, D. The Circuitry of the Human Spinal Cord. Cambridge: Cambridge University Press, 2005.

PINSKY, P. F.; RINZEL, J. Intrinsic and network rhythmogenesis in a reduced Traub model for CA3 neurons. Journal of Computational and Neuroscience, v. 1, n. 1-2, p. 39-60, 1994.

PIOTRKIEWICZ, M. et al. Age-related change in duration of afterhyperpolarization of human motoneurones. The Journal of Physiology , v. 585 , n. 2 , p. 483-490, dez. 2007. 
PORTER, R.; LEMON, R. Corticospinal Function \& Voluntary Movement. First ed. [S.1.] Oxford University Press, 1993. p. 428

POWERS, R. K. et al. Contribution of intrinsic properties and synaptic inputs to motoneuron discharge patterns: a simulation study. Journal of Neurophysiology, v. 107, n. 3, p. 808-823, 2012.

POWERS, R. K.; BINDER, M. D. Determination of afferent fibres mediating oligasynaptic group I input to cat medial gastrocnemius motoneurons. Journal of Neurophysiology, v. 53, n. 2, 1985a.

POWERS, R. K.; BINDER, M. D. Distribution of oligosynaptic group I input to the cat medial gastrocnemius motoneuron pool. Journal of Neurophysiology, v. 53, p. 497-517, 1985b.

POWERS, R. K.; BINDER, M. D. Input-output functions of mammalian motoneurons. Rev. Physiol. Bioch. P., v. 143, p. 137-263, 2001.

PROSKE, U.; MORGAN, D. L. Tendon stiffness: Methods of measurement and significance for the control of movement. A review. Journal of Biomechanics, v. 20, n. 1, p. 75-82, 1987.

RACK, P. M. et al. Reflex responses at the human ankle: the importance of tendon compliance. The Journal of Physiology, v. 344, n. 1, p. 503-524, 1983.

RALL, W. Distinguishing theoretical synaptic potentials computed for different somadendritic distributions of synaptic input. J. Neurophysiology, v. 30, p. 1138-1168, 1967.

REVILL, A. L.; FUGLEVAND, A. J. Effects of persistent inward currents, accommodation, and adaptation on motor unit behavior: a simulation study. Journal of neurophysiology, $\mathrm{v}$. 106, n. 3, p. 1467-79, set. 2011.

RIBOT-CISCAR, E. et al. Fusimotor drive may adjust muscle spindle feedback to task requirements in humans. Journal of neurophysiology, v. 101, n. 2, p. 633-40, fev. 2009.

ROSSI, A.; MAZZOCCHIO, R.; DECCHI, B. Effect of chemically activated fine muscle afferents on spinal recurrent inhibition in humans. v. 114, p. 279-287, 2003.

ROTHWELL, J. Control of Human Voluntary Movement. London: Chapman and Hall, 1994.

RUEGG, D. G.; KRAUER, R.; DREWS, H. Superposition of H reflexes on steady contractions in man. J Physiol, v. 427, p. 1-18., 1990.

SCHWINDT, P. C.; CRILL, W. E. Membrane properties of cat spinal motoneurons. In: DAVIDOFF, R. A. (Ed.). Handbook of the Spinal Cord. [S.l: s.n.]. v. 2/3p. 199-242.

SEGEV, I.; FLESHMAN, J. W.; BURKE, R. E. Computer-Simulation of Group Ia Epsps Using Morphologically Realistic Models of Cat Alpha-Motoneurons. Journal of Neurophysiology, v. 64, n. 2, p. 648-660, 1990. 
SHERRINGTON, C. S. Remarks on some Aspects of Reflex Inhibition. Proceedings of the Royal Society of London. Series B, Containing Papers of a Biological Character, v. 97, n. 686, p. 519-545, 1925.

STEIN, R. B.; GOSSEN, E. R.; JONES, K. E. Neutronal variability: noise or part of the signal? Nature Reviews/Neuroscience, v. 6, p. 389, 2005.

SUZUKI, J. et al. Morphometric Comparison of Human Spinal Cord Anterior Horn Cells between the Cervical and Lumbar Levels. Okajimas Folia Anatomica Japonica, v. 82, n. 2, p. 43-48, 2005.

TAYLOR, A. M.; CHRISTOU, E. A.; ENOKA, R. M. Multiple features of motor-unit activity influence force fluctuations during isometric contractions. J Neurophysiol, v. 90, n. 2, p. 1350-1361, 2003.

TAYLOR, A. M.; ENOKA, R. M. Quantification of the factors that influence discharge correlation in model motor neurons. Journal of Neurophysiology, v. 91, p. 796-814, 2004.

THELEN, D. G. Adjustment of Muscle Mechanics Model Parameters to Simulate Dynamic Contractions in Older Adults. Journal of Biomechanical Engineering, v. 125, n. 1, p. 70-77, 2003.

THOMAS, C. K. et al. Twitch properties of human thenar motor units measured in response to intraneural motor-axon simulation. Journal of Neurophysiology, v. 64, p. 1339-1346, 1990.

TOFT, E. et al. Mechanical and electromyographic responses to stretch of the human ankle extensors. Journal of Neurophysiology, v. 65, p. 1402-1410, 1991.

TRACY, B. L. et al. Variability of motor unit discharge and force fluctuations across a range of muscle forces in older adults. Muscle Nerve, v. 32, n. 4, p. 533-540, 2005.

TRACY, B. L. et al. Aging, visuomotor correction, and force fluctuations in large muscles. Med Sci Sports Exerc, v. 39, n. 3, p. 469-479, 2007.

TURKIN, V. V et al. Characteristics and organization of discharge properties in rat hindlimb motoneurons. Journal of neurophysiology, v. 104, n. 3, p. 1549-65, set. 2010.

WIENECKE, J.; ZHANG, M.; HULTBORN, H. A prolongation of the postspike afterhyperpolarization following spike trains can partly explain the lower firing rates at derecruitment than those at recruitment. Journal of neurophysiology, v. 102, n. 6, p. 3698710, dez. 2009.

WILLIAMS, E. R.; BAKER, S. N. Circuits Generating Corticomuscular Coherence Investigated Using a Biophysically Based Computational Model. I. Descending Systems. Journal of Neurophysiology, v. 101, n. 1, p. 31-41, 2009a. 
WILLIAMS, E. R.; BAKER, S. N. Renshaw cell recurrent inhibition improves physiological tremor by reducing corticomuscular coupling at 10 Hz. J Neurosci, v. 29, n. 20, p. 6616$6624,2009 b$.

WINDHORST, U. Muscle proprioceptive feedback and spinal networks. Brain Research Bulletin, v. 73, n. 4-6, p. 155-202, 2007.

ZAJAC, F. E. Muscle and tendon: properties, models, scaling an application to biomechanics and motor control. Critical Reviews in Biomedical Engineering, v. 17, p. 359-411, 1989.

ZENGEL, J. E. et al. Membrane Electrical-Properties and Prediction of Motor-Unit Type of Medial Gastrocnemius Motoneurons in the Cat. Journal of Neurophysiology, v. 53, n. 5, p. 1323-1344, 1985. 


\section{Apêndice 1 Cálculo dos parâmetros passivos}

As seguintes equações são baseadas em (KIM; JONES, 2011, 2012; KIM; MAJOR; JONES, 2009) e possibilitam o cálculo dos parâmetros passivos do modelo de MN a partir dos parâmetros eletrotônicos especificados (ver seção 4.2.2).

$$
\begin{gathered}
g_{L s}=\frac{1-V A_{D S}^{D C}}{r_{n}\left(1-V A_{S D}^{D C} \cdot V A_{D S}^{D C}\right)} \\
g_{L d}=\frac{p \cdot V A_{D S}^{D C}\left(1-V A_{S D}^{D C}\right)}{(1-p) \cdot r_{n} \cdot V A_{S D}^{D C}\left(1-V A_{S D}^{D C} \cdot V A_{D S}^{D C}\right)} \\
g_{c}=\frac{p \cdot V A_{D S}^{D C}}{r_{n}\left(1-V A_{S D}^{D C} \cdot V A_{D S}^{D C}\right)} \\
C_{m d}=\frac{1}{w(1-p)} \sqrt{\left(\frac{g_{c}}{V A_{S D}^{A C}}\right)^{2}-\left[g_{c}+g_{L d}(1-p)\right]^{2}} \\
p\left[(1-p)\left(\tau_{m} g_{L d}-C_{m d}\right)+\tau_{m} g_{c}\right]
\end{gathered}
$$




\section{Apêndice 2 Reparametrização das propriedades}

\section{passivas}

A Tabela A 1 e a Tabela A 2 mostram os dados referentes às propriedades passivas, reparametrizados no estudo descrito no Capítulo 5.

Tabela A 1 - Comparativo dos parâmetros associados às características passivas dos MNs. $R_{n}$ é a resistência de entrada no soma, $\tau_{m}$ é a constante de tempo da membrana, $p$ é a relação entre a área do compartimento somático $\left(A_{s}\right)$ e a área total, $D$ é a distância com relação ao centro do soma em que se divide o MN em dois compartimentos.

\begin{tabular}{|c|c|c|c|}
\hline $\begin{array}{c}\text { (ZENGEL et al., } \\
1985)\end{array}$ & $\begin{array}{c}\text { (FLESHMAN; SEGEV; } \\
\text { BURKE, 1988; SEGEV; } \\
\text { FLESHMAN; BURKE, } \\
\text { 1990) }\end{array}$ & $\begin{array}{c}\text { (KIM; JONES, } \\
\text { 2012) }\end{array}$ & Parâmetros adotados \\
\hline $\begin{array}{l}R_{n}=0,4 a 4,0 \mathrm{M} \Omega \\
\tau_{m}=4,0 \text { a } 14,0 \mathrm{~ms} \\
I_{r h}=2 \text { a } 38 \mathrm{nA}\end{array}$ & $\begin{array}{l}R_{n}=0,7 \text { a } 4,2 \mathrm{M} \Omega \\
\tau_{m}=7,1 \text { a } 13,0 \mathrm{~ms} \\
\text { Área total } \\
=414.900 \text { a } 726.600 \mathrm{\mu m}^{2}\end{array}$ & $\begin{array}{l}p=0,168 \\
D=300 \mu m\end{array}$ & $\begin{array}{l}p=0,168 \\
D=300 \mu \mathrm{m} \\
R_{n}=0,7 \mathrm{a} 4,0 \mathrm{M} \Omega \\
\text { Área total } \\
=400.000 \text { a } 750.000 \mathrm{\mu m}^{2} \\
A_{s}=p * \text { Área total } \\
=67.200 \text { a } 126.000 \mathrm{~mm}^{2}\end{array}$ \\
\hline
\end{tabular}

Tabela A 2 - Parâmetros associados às características passivas do modelo de MN. Notar que

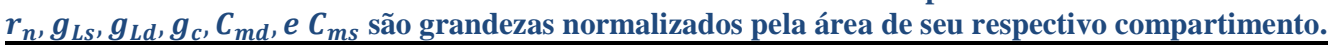

\begin{tabular}{lccc}
\multicolumn{1}{c}{ Parâmetro } & Símbolo (unidade) & Menor MN & Maior MN \\
\hline Área do compartimento somático & $A_{S}\left(\mathrm{~cm}^{2}\right)$ & $0,672.10^{-3}$ & $1,26.10^{-3}$ \\
\hline Área do compartimento dendrítico & $A_{d}\left(\mathrm{~cm}^{2}\right)$ & $3,3.10^{-3}$ & \\
\hline $\begin{array}{l}\text { Resistência de entrada do soma } \\
\text { Resistência de entrada do } \\
\text { compartimento somático }\end{array}$ & $R_{n}(\mathrm{M} \Omega)$ & 4,0 & 0,7 \\
$\begin{array}{l}\text { Condutância de fuga do } \\
\text { compartimento somático }\end{array}$ & $r_{n}\left(k \Omega \mathrm{cm}^{2}\right)$ & 2,69 & 0,882 \\
$\begin{array}{l}\text { Condutância de fuga do } \\
\text { compartimento dendrítico }\end{array}$ & $g_{L s}\left(\mathrm{mS} / \mathrm{cm}^{2}\right)$ & 0,358 & 1,09 \\
$\begin{array}{l}\text { Condutância de acoplamento entre os } \\
\text { compartimentos }\end{array}$ & $g_{L d}\left(\mathrm{mS} / \mathrm{cm}^{2}\right)$ & 0,0031 & 0,00957 \\
$\begin{array}{l}\text { Capacitância de membrana do } \\
\text { compartimento somático }\end{array}$ & $g_{c}\left(\mathrm{mS} / \mathrm{cm}^{2}\right)$ & 0,0211 & 0,0644 \\
$\begin{array}{l}\text { Capacitância de membrana do } \\
\text { compartimento dendrítico }\end{array}$ & $C_{m s}\left(\mu \mathrm{F} / \mathrm{cm}^{2}\right)$ & 5,0 & 5,0 \\
\hline
\end{tabular}




\section{Apêndice 3 Faixa de recrutamento em jovens e idosos}

A Figura A 1 mostra o resultado de simulações para visualizar a faixa de recrutamento no modelo de jovens e de idosos. A simulação consistiu em uma modulação triangular (simétrica) da frequência de disparos média dos PMNs. No caso jovem (Figura A 1A) o último MN é recrutado em cerca de $43 \%$ da MVC, enquanto que, no caso idoso (Figura $\mathrm{A}$ 1B), isto ocorre em aproximadamente $25 \%$ da MVC.
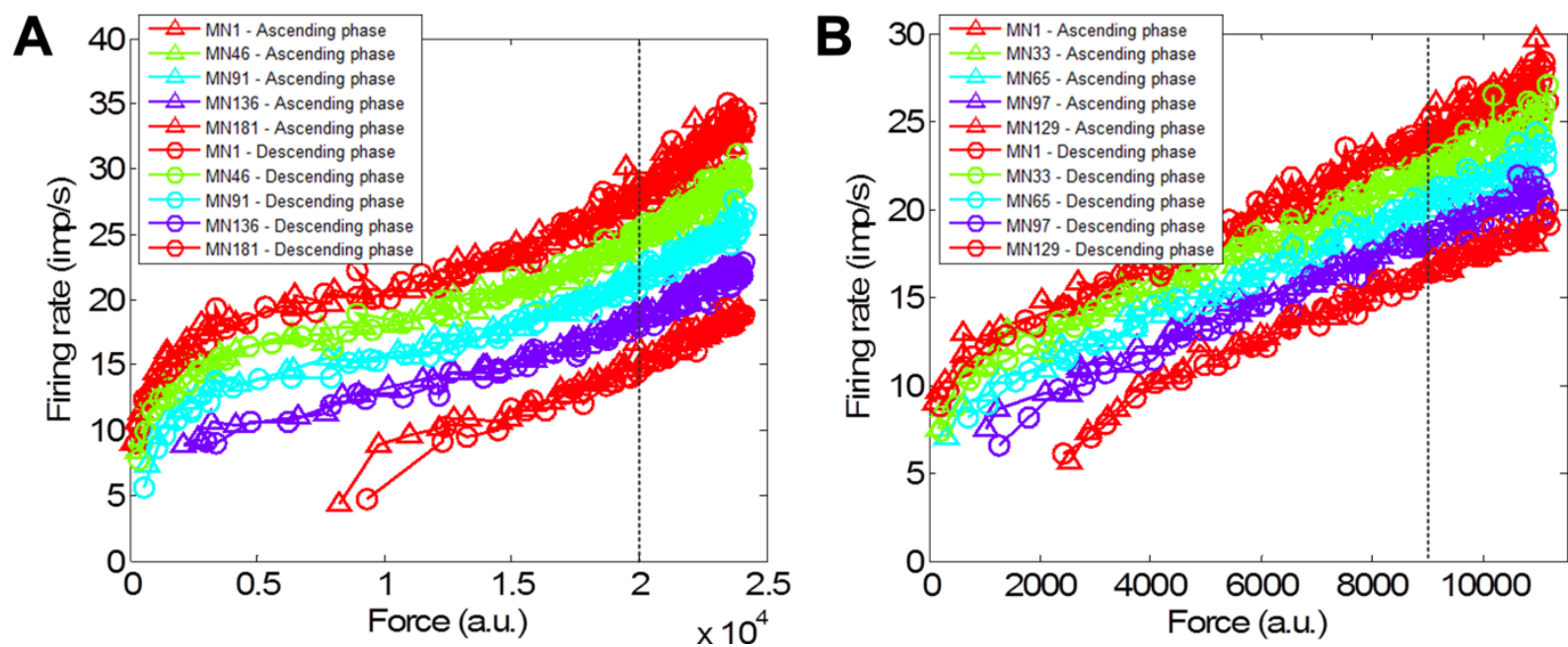

Figura A 1 - Frequência de disparos em função da força desenvolvida pelo músculo para o modelo de jovens (A) e de idosos (B). As linhas tracejas indicam a força que foi adotada como MVC. 